\title{
RELATIONSHIP BETWEEN $a$-AMYLASE DEGRADATION AND THE STRUCTURE AND PHYSICOCHEMICAL PROPERTIES OF LEGUME STARCHES
}

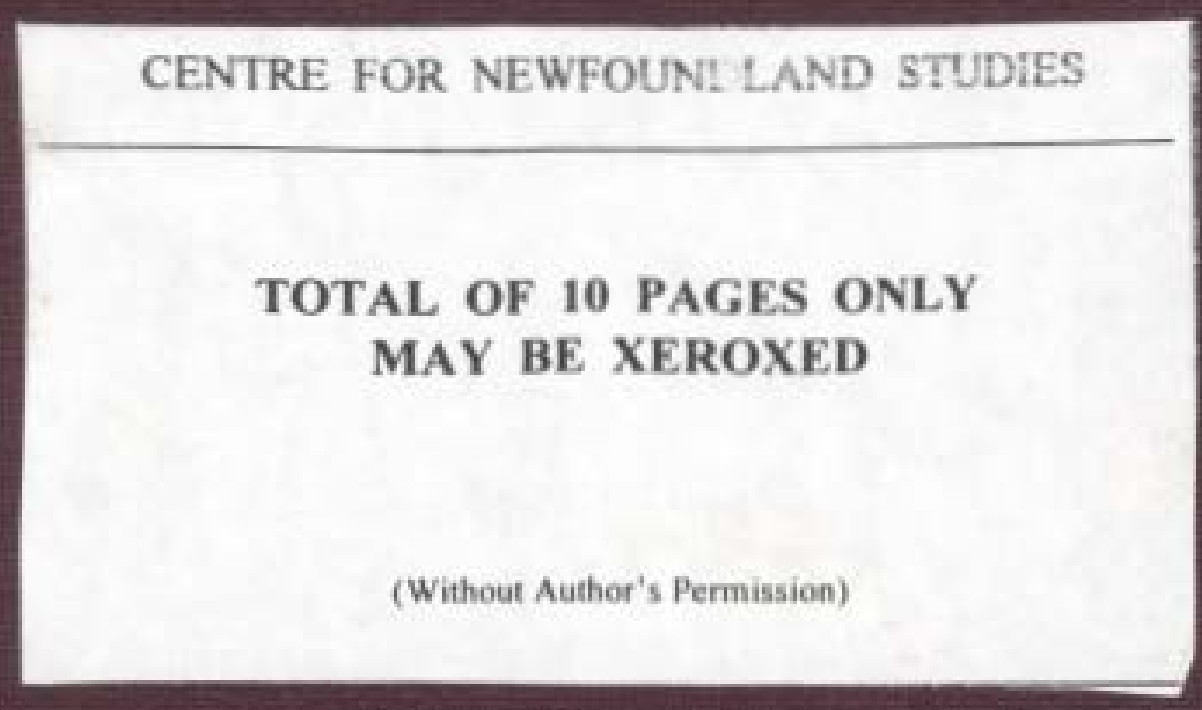

\section{YANG ZHOU}




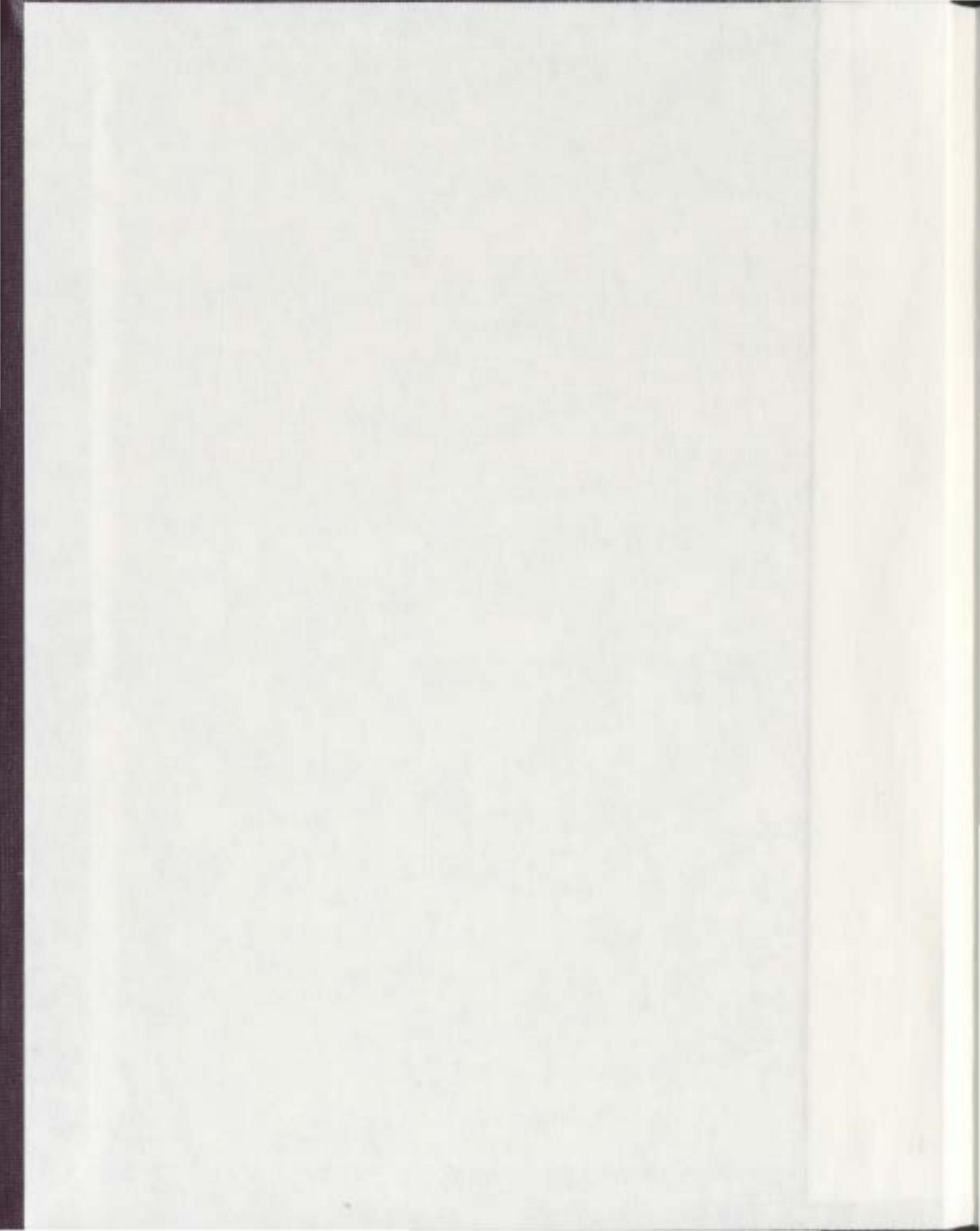






\section{NOTE TO USERS}

This reproduction is the best copy available.

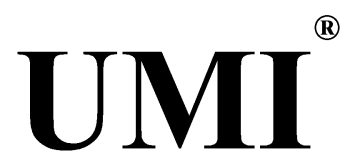





\title{
Relationship between $\alpha$-amylase degradation and the structure and physicochemical properties of legume starches
}

\author{
By
}

\section{Yang Zhou}

A thesis submitted to the School of Graduate Studies in partial fulfillment of the requirements for the degree of Master of Science

Department of Biochemistry

Memorial University of Newfoundland.

December 2003

St. John's

Newfoundland

Canada 


$\begin{array}{ll}\begin{array}{l}\text { Library and } \\ \text { Archives Canada }\end{array} & \begin{array}{l}\text { Bibliothèque et } \\ \text { Archives Canada }\end{array} \\ \begin{array}{l}\text { Published Heritage } \\ \text { Branch }\end{array} & \begin{array}{l}\text { Direction du } \\ \text { Patrimoine de l'édition }\end{array} \\ \begin{array}{l}\text { 395 Wellington Street } \\ \text { Ottawa ON K1A 0N4 }\end{array} & \begin{array}{l}\text { 395, rue Wellington } \\ \text { Ottawa ON K1A ON4 }\end{array} \\ \text { Canada } & \text { Canada }\end{array}$

Your file Votre référence

ISBN: 0-612-99132-6

Ourfile Notre référence

ISBN: 0-612-99132-6

NOTICE:

The author has granted a nonexclusive license allowing Library and Archives Canada to reproduce, publish, archive, preserve, conserve, communicate to the public by telecommunication or on the Internet, loan, distribute and sell theses worldwide, for commercial or noncommercial purposes, in microform, paper, electronic and/or any other formats.

The author retains copyright ownership and moral rights in this thesis. Neither the thesis nor substantial extracts from it may be printed or otherwise reproduced without the author's permission.
AVIS:

L'auteur a accordé une licence non exclusive permettant à la Bibliothèque et Archives Canada de reproduire, publier, archiver, sauvegarder, conserver, transmettre au public par télécommunication ou par l'Internet, prêter, distribuer et vendre des thèses partout dans le monde, à des fins commerciales ou autres, sur support microforme, papier, électronique et/ou autres formats.

L'auteur conserve la propriété du droit d'auteur et des droits moraux qui protège cette thèse. $\mathrm{Ni}$ la thèse ni des extraits substantiels de celle-ci ne doivent être imprimés ou autrement reproduits sans son autorisation.
In compliance with the Canadian

Privacy Act some supporting forms may have been removed from this thesis.

While these forms may be included in the document page count, their removal does not represent any loss of content from the thesis.
Conformément à la loi canadienne sur la protection de la vie privée, quelques formulaires secondaires ont été enlevés de cette thèse.

Bien que ces formulaires aient inclus dans la pagination, il n'y aura aucun contenu manquant. 


\section{TABLE OF CONTENTS}

Page No.

$\begin{array}{lll}\text { Acknowledgements } & \text { VI }\end{array}$

$\begin{array}{ll}\text { List of figures } \quad \text { VII } & \text { III }\end{array}$

List of tables IX IX

List of abbreviations XI

$\begin{array}{ll}\text { Abstract } & \text { XIII }\end{array}$

\section{Chapter 1: Introduction}

1.1 Legumes - General information 1

1.1.1 Classification and production $\quad 1$

1.1.2 Composition of legume seeds 3

1.1.3 Utilization and potential $\quad 5$

$\begin{array}{ll}1.2 \text { Objectives of this research } & 8\end{array}$

\section{Chapter 2: Literature review}

2.1 Starch - General information 9

$\begin{array}{ll}2.2 \text { Starch production and utilization } & 10\end{array}$

$\begin{array}{ll}2.3 \text { Starch composition and structure } & 14\end{array}$

2.3.1 Composition

2.3.1.1 Major components 14

2.3.1.2 Minor components 16

2.3.1.2.1 Lipids 16

2.3.1.2.2 Proteins 18

2.3.1.2.3 Minerals and phosphorous $\quad 18$ 
2.3.2 Ultrastructure

2.3.2.1 Overview of granule structure $\quad 18$

2.3.2.2 Amylose 19

2.3.2.2.1 Amylose inclusion complexes 23

2.3.2.2.1.1 Amylose-lipid complex 24

2.3.2.2.1.2 Amylose-iodine complex $\quad 24$

2.3.2.2.2 Location of amylose $\quad 28$

2.3.2.3 Amylopectin 29

2.3.2.3.1 Structural model $\quad 30$

2.3.2.3.2 Chain length distribution 33

2.3.2.4 Double helices, crystallites and crystallinity

2.3.2.4.1 Double helices 36

2.3.2.4.2 Crystallites and polymorphic patterns $\quad 40$

2.3.2.4.3 Crystallinity 42

2.4 Starch properties

2.4.1 Gelatinization $\quad 48$

2.4.1.1 Mechanism 51

2.4.1.2 Factors influencing gelatinization $\quad 55$

2.4.2 Retrogradation $\quad 55$

$2.5 \alpha$-Amylolysis

2.5.1 $\alpha$-Amylase $\quad 56$

2.5.2 Mechanism of $\alpha$-amylolysis

2.5.2.1 Cleavage of glucosidic bonds - double displacement

2.5.2.2 Cleavage of starch chains - multiple attack $\quad 60$

2.5.3 Factors influencing starch digestibility $\quad 61$

2.5.3.1 Particle size and porosity 64

2.5.3.2 Amylose/amylopectin ratio $\quad 66$

2.5.3.3 Starch interactions/physical structure $\quad 67$

2.5.4 Hydrolysis of legume starches 69 


\section{Chapter 3: Materials and methods}

$\begin{array}{ll}3.1 \text { Materials } & 72\end{array}$

3.2 Methods

3.2.1 Starch isolation $\quad 72$

3.2.2 Granule morphology 73

3.2.3 Compositional analyses

3.2.3.1 Moisture content $\quad 73$

3.2.3.2 Ash content 74

3.2.3.3 Nitrogen content 74

3.2.3.4 Lipid content

3.2.3.4.1 Surface lipids $\quad 75$

3.2.3.1.1 Blight and Dyer (1959) method of lipid purification $\quad 75$

3.2.3.4.2 Bound lipids $\quad 76$

3.2.3.4.3 Total lipids $\quad 76$

3.2.3.5 Amylose content

3.2.3.5.1 Apparent amylose $\quad 76$

3.2.3.5.2 Total amylose $\quad 77$

$\begin{array}{ll}\text { 3.2.4 Starch damage } & 77\end{array}$

3.2.4.1 Determination of reducing sugar content 78

3.2.5 Swelling factor $\quad 79$

3.2.6 Extent of amylose leaching $\quad 80$

3.2.7 Differential scanning calorimetry(DSC) 80

3.2.8X-ray diffraction $\quad 80$

3.2.8.1 Determination of relative crystallinity 81

3.2.8.2 Determination of B-polymorphic composition 81

3.2.9 Enzymatic hydrolysis by porcine pancreatic $\alpha$-amylase

3.2.9.1 Hydrolysis pattern $\quad 82$

3.2.9.2 Preparation of hydrolyzed residues 82

3.2.9.3 Calculation of initial velocity 83

3.2.10 Statistical analysis $\quad 83$ 


\section{Chapter 4: Results and discussion}

4.1 Chemical composition of the starches 84

4.2 X-ray diffraction of the native starches 86

4.3 Swelling factor (SF) and extent of amylose leaching (AML) at $80^{\circ} \mathrm{C} \quad 89$

4.4 Gelatinization parameters 92

4.5 Hydrolysis patterns 94

4.6 Morphology of native starch granules \& enzyme hydrolyzed starch $\quad 100$ residues

4.7 X-ray analysis of hydrolyzed starch residues 106

4.8 Apparent amylose content of hydrolyzed starch residues 109

4.9 Thermal properties of hydrolyzed starch residues 111

$\begin{array}{ll}\text { Summary and conclusion } & 114\end{array}$

$\begin{array}{ll}\text { Directions for future research } & 115\end{array}$

$\begin{array}{ll}\text { Publications } & 116\end{array}$

$\begin{array}{ll}\text { Presentation } & 116\end{array}$

Honors \& awards 116

$\begin{array}{ll}\text { References } & 117\end{array}$

$\begin{array}{ll}\text { Appendices } & 147\end{array}$ 


\section{Acknowledgements}

First of all, I would like to express my sincere appreciation to my supervisor Dr. Hoover for his guidance and advice throughout the course of this study.

I also want to thank my co-supervisors Dr. Martin and Dr. Shahidi for their advice, encouragement and generous help.

Thanks are also extended to Ms. Lisa Lee (Department of Biology), Ms. M. Piranian (Department of Earth Science) and Ms. L. Thompson (Department of Chemistry) for technical assistance (SEM, X-ray and DSC).

I also wish to thank the Department of Biochemistry and the School of Graduate Studies for financial support. Appreciation also goes to my colleagues (Luckshman and Renuka) who made my stay in the Department of Biochemistry a pleasure to remember.

Finally, I wish to express my special thanks to my dear wife Crystal for her understanding and support throughout the period of my study. 


\section{List of figures}

Figure $\quad$ Page

2 - 1 Products derived from starch 12

2 - 2 Internal structure of starch granules showing alternating 20 amorphous and semi-crystalline growth rings

2 - $3 \quad$ Blocklet model of starch granule structure 21

2 - 4 Representative partial structure of amylose (A) and 22

2 - $5 \quad$ Schematic illustration of amylose-lipid complex 27

2 - 6 One possible mechanism to explain the disruption of 31 amylopectin double helical packing by amylose

2 - $7 \quad$ Cluster structure of amylopectin showing growth rings and 32 areas for amorphous and crystalline lamellae formation

2 - $8 \quad$ Gel-permeation chromatograms of debranched amylopectins 34

2-9 Double helix model of starch chain 39

2-10 Packing arrangement of double helices of A and B type 43 crystallite unit cell

2 - $11 \quad$ X-ray diffraction patterns of A, B, and C type starches with 44 their characteristic $d$-spacing

2 - 12 Proposed models for branching patterns of A type (waxy maize) 45 and $B$ type (potato) amylopectin

2-13 Schematic representation of the possible interrelationships among the various parameters involved in phase transition phenomena of granular starch (solvation-assisted melting process)

2 - $14 \quad$ SCLCP model for starch gelatinization

2-15 Schematic representation of the polypeptide chain fold of human 58 pancreatic $\alpha$-amylase 
Figure Page

2-16 Double displacement mechanism of $\alpha$-amylase 62

2-17 Multiple attack of $\alpha$-amylase 63

$2-18 \quad$ Factors involved in the kinetics of starch hydrolysis by $\alpha$-amylase 65

4-1 X-ray diffraction patterns of native and hydrolyzed black bean 87 and wrinkled pea starch

4-2 Hydrolysis patterns $\left(37^{\circ} \mathrm{C}\right)$ by porcine pancreatic $\alpha$-amylase of 95 legume starches

4 - $3 \quad$ Scanning electron micrographs of native black bean granules and hydrolyzed granules

4- 4 Scanning electron micrographs of native pinto bean granules and hydrolyzed granules

4- 5 Scanning electron micrographs of native smooth pea granules and hydrolyzed granules

4 - $6 \quad$ Scanning electron micrographs of native lentil granules and hydrolyzed granules

4- 7 Scanning electron micrographs of native wrinkled pea granules and hydrolyzed granules

4- 8 Apparent amylose content of legume starches at different time periods of $\alpha$-amylase hydrolysis 


\section{List of tables}

Table

Page

1-1 Most common food legumes grown in the world 2

1-2 World pulse production 4

1 - 3 Canada pulse production 4

1-4 Proximate composition of legume seeds(\%) 6

2 - 1 Starch production by raw material in the EU, US and other 11 countries, year 2000

2 - 2 Application of starch and starch derivatives in food and non-food industries

2 - 3 Proximate composition of legume starches

2 - 4 General characteristics of amylose and amylopectin 25

2 - 5 Physicochemical characteristics of legume amyloses 26

2-6 Average chain length of isolated legume amylopectins 37

2 - $7 \quad$ Comparison of short-range order in starches with moderate and 38 low water contents

2 - $8 \quad$ Structures of A and B type crystalline unit cells 46

2 - 9 Crystallinity of A, B, and C starches 47

2-10 Thermal characteristics of legume starches (DSC parameters) 50

2-11 In vitro digestibility of native legume starches 71

4-1 Chemical composition(\%) and some properties of legume 85 starches

4-2 X-ray diffraction pattern, relative crystallinity and 'B' polymorphic content of legume starches 
4-3 Swelling factor(SF) and amylose leaching(AML) of native legume starches at $80^{\circ} \mathrm{C}$

4-4 Gelatinization characteristics of native legume starches

4-5 Initial velocity of $\alpha$-amylase hydrolysis of legume starches

96

4-6 X-ray diffraction parameters of $\alpha$-amylase hydrolyzed legume 107 starch residues

4 - 7 DSC parameters of $\alpha$-amylase hydrolyzed legume starch residues 


\section{List of abbreviations}

ALC

AFM

AM

AML

AMP

ANOVA

BV

CL

CP/MAS

$\mathrm{Da}$

DE

DMA

DMSO

DNS

DP

DSC

EC

FACE

FT/IR

GPC

$\Delta \mathrm{H}$

$\triangle H / A P$

IA

IBC

M
Amylose-lipid complex

Atomic force microscopy

Amylose

Amylose leaching

Amylopectin

Analysis of variance

Blue value

Chain length

Cross polarization/magic angle spinning

Dalton

Dextrose equivalent

Dynamic mechanical analysis

Dimethylsulfoxide

3,5 - dinitrosalicylic acid

Degree of polymerization

Differential scanning calorimetry

Enzyme code

Fluorophose-assisted charbohydrate electrophoresis

Fourier transform infrared (spectroscopy)

Gel permeation chromatography

Gelatinization enthalpy

Gelatinization enthalpy divided by amylopectin content

lodine affinity

lodine binding capacity

Molarity (Molar) 


\begin{tabular}{|c|c|}
\hline MALDI-MS & Matrix-assisted laser desorption/ionization mass spectrometry \\
\hline$M_{w}$ & Weight average molecular weight \\
\hline NMR & Nuclear magnetic resonance \\
\hline $\mathbf{N}$ & Normality \\
\hline $\mathrm{RC}$ & Relative crystallinity \\
\hline RDS & Rapid digestible starch \\
\hline RS & Resistant starch \\
\hline SAXS & Small angle $X$-ray scattering \\
\hline SCLCP & Side-chain liquid-crystalline polymer \\
\hline SD & Standard deviation \\
\hline SDS & Slowly digestible starch \\
\hline SDS-PAGE & Sodium dodecyl sulphate polyacrylamide gel electrophoresis \\
\hline SEC & Size exclusion chromatography \\
\hline SEM & Scanning electron microscopy \\
\hline SF & Swelling factor \\
\hline SGBSS & Starch granule-bound starch synthase \\
\hline$T_{c}$ & Conclusion temperature \\
\hline$T_{0}$ & Onset temperature \\
\hline$T_{p}$ & Peak temperature \\
\hline TEM & Transmission electron microscopy \\
\hline$v / v$ & Volume/volume \\
\hline$w / v$ & Weight/volume \\
\hline$w / w$ & Weight/weight \\
\hline
\end{tabular}




\begin{abstract}
Starches from different cultivars of black beans, pinto beans, smooth peas, lentils and wrinkled peas were isolated and their composition, physicochemical properties and susceptibility towards porcine pancreatic $\alpha$-amylase were determined.

The yield of starch ranged from 16.4 to $34.1 \%$ on a whole seed basis. The shape of the granules in black bean, pinto bean, smooth pea and lentil varied from round to oval to irregular, while compounds in rounded rosette were observed for wrinkled pea starch. Bound and total lipids ranged from 0.26 to $0.80 \%$ and 0.35 to $0.84 \%$, respectively. The total amylose content of black bean, pinto bean, smooth pea and lentil were in the range of $30.5-39.3 \%$, whereas that of wrinkled pea was much higher $(78.4 \%)$. The percentage of lipid-complexed amylose in native starches ranged from 10.3 to $12.2 \%$. The X-ray diffraction pattern was of the ' $\mathrm{B}$ ' type in wrinkled pea starch and of the ' $\mathrm{C}$ ' type in the other starches. The relative crystallinity and the ' $\mathrm{B}$ ' polymorphic content ranged from 17.7 to $33.4 \%$ and 27.1 to $92.2 \%$, respectively. Wrinkled pea starch exhibited the lowest relative crystallinity $(17.7 \%)$ and the highest ' $B$ ' polymorphic content $(92.2 \%)$.

The swelling factor (SF) and the extent of amylose leaching (AML) of native starches were in the range of $3.4-17.7$ and $11.0-17.8 \%$, respectively. The gelatinization temperatures $\left(T_{0}, T_{p}, T_{c}\right)$ and enthalpy $(\Delta H)$ of native starches (with the exception of wrinkled pea starch) were in the range of $60.0-65.7^{\circ} \mathrm{C}, 66.0-76.5^{\circ} \mathrm{C}, 76.4-88.8^{\circ} \mathrm{C}$, and 14.6-20.1mJ/mg, respectively. Differences in $\mathrm{SF}, \mathrm{AML}, \mathrm{T}_{0}, \mathrm{~T}_{\mathrm{p}}, \mathrm{T}_{\mathrm{c}}$, and $\Delta \mathrm{H}$ between cultivars of the same species were more pronounced in black bean and lentil starches. Wrinkled pea starch did not show an endothermic peak indicating that starch chain interactions within the amorphous domains were more extensive in wrinkled pea starch.
\end{abstract}


All starches exhibited a biphasic hydrolysis pattern, i.e a relatively rapid rate initially followed by a progressively decreasing rate thereafter. Wrinkled pea starch exhibited a much higher initial hydrolysis velocity than did the other starches. Cultivars of black bean and lentil showed significant differences in their initial velocities. However, differences in initial velocity between cultivars of smooth pea and pinto bean were not significant. Black bean, lentil and wrinkled pea starches showed a plateau at 93 , 85 and $65 \%$ hydrolysis, respectively. The time taken for the appearance of the plateau was identical for the black bean cultivars, but was different for the lentil cultivars. Pinto bean and smooth pea cultivars showed no plateau. At the end of the assay period (120h), cultivars of each legume species were hydrolyzed to the same extent, and the extent of hydrolysis among the legume species followed the order: black bean $>$ lentil $>$ smooth pea $>$ pinto bean $>$ wrinkled pea. Scanning electron micrographs showed that starches were slightly eroded during the initial hydrolysis stage $(<20 \%$ hydrolysis $)$, but the integrity of most of the granules was well maintained. However, roughened surfaces and disc like depressions were obvious for all starches, except for lentil starch. No morphological differences were observed between cultivars from the same species for both native and hydrolyzed starches. The X-ray diffraction pattern and the 'B' polymorphic content of all starches remained unchanged upon hydrolysis. However, the relative crystallinity increased in wrinkled pea, but remained unchanged in the other starches. On hydrolysis, the apparent amylose content decreased in all starches. The extent of this decrease was most pronounced in wrinkled pea. In all starches, the enthalpy of gelatinization decreased, and the gelatinization transition temperatures increased slightly, on hydrolysis. 
This study demonstrated that differences in the composition and physicochemical properties of starch between cultivars from the same species were marginal. The rate and extent of hydrolysis were influenced mainly by structural organization and interactions of the starch chains within the native granule, as well as by the extent of association between hydrolyzed amylose chains.

Keywords: Legume starches; physicochemical properties; $\alpha$-amylase hydrolysis. 


\section{Chapter 1 Introduction}

\subsection{Legumes - General information}

Legumes are dicotyledonous seeds of leguminous plants which belong to the Leguminosae family (Hoover and Sosulski, 1991). Leguminosae, containing about 650 genera and 18,000 species, is the third largest family of all flowering plants, after the Compositae and the Orchidaceae. Leguminosae comprises three sub-families: Caesalpinioideae, Mimosoideae and Papilionoideae. Papilionoideae is the largest and comprises 32 tribes compared with 5 in the Caesalpinioideae and 5 also in the Mimosoideae (Smartt, 1990; Sprent, 2001). Legumes are cultivated throughout the world and play an important role in the diets of many people.

\subsubsection{Classification and production}

In accordance with present Food and Agriculture Organization (FAO) practice, the word legume is used for all leguminous plants. For those containing only small amounts of fat, such as French beans, lima beans, etc., the term "pulse" is used and for those containing a high proportion of fat, such as soybeans and peanuts, the term "leguminous oilseed" is used. Although there are many legume species, only about 20 are commonly grown in different continents of the world and used for human consumption (Table 1-1). Of the various food legumes, soybean, peanut, dry bean, pea, broad bean, chickpea, and lentil are the major ones cultivated. Others are grown only in some countries, depending on the climatic conditions needed to support growth and the food habits of the consumers (Salunkhe and Kadam, 1989). 


\section{Table 1-1}

Most common food legumes grown in the world (Salunkhe and Kadam, 1989)

\begin{tabular}{|c|c|}
\hline Scientific name & Common name \\
\hline Arachis hypogaea L. & Groundnut, peanut \\
\hline Cajanus cajan (L.) Millsp. & Pigeonpea, red gram, Congo pea, Arhar, Tur, Gongo pea \\
\hline Cicer arietinum L. & Chickpea, Bengal gram, garbanzo gram \\
\hline Glycine max (L.) Merr. & Soybean, soya \\
\hline Lablab purpureus (L.) Sweet & Hyacinth bean, Egyptian bean, Val. \\
\hline Lathyrus sativus L. & Khesari, chickling vetch, grasspea \\
\hline Lens culinaris Medik. & Lentil, Masur \\
\hline Lupinus albus L. & White lupine \\
\hline Lupinus angustifolius L. & Blue lupine, New Zealand blue lupine \\
\hline Lupinus luteus L. & European yellow lupine \\
\hline Macrotyloma uniflorum (Lam.) Verdc. & Horse gram, Madras gram, Kulthi \\
\hline Phaseolus Iunatus L. & Lima bean, butter bean \\
\hline Phaseolus vulgaris $\mathrm{L}$. & $\begin{array}{l}\text { Bean, common bean, French bean, field bean, haricot bean, } \\
\text { pinto bean, navy bean, dry bean }\end{array}$ \\
\hline Pisum sativum L. & Common or garden pea, dry pea \\
\hline Psophocarpus tetragonolobus (L.) & $\begin{array}{l}\text { Winged bean, Goa bean, four-angled bean, Manila bean, } \\
\text { princess pea }\end{array}$ \\
\hline Vicia faba L. & Broad bean, faba bean, horse bean \\
\hline Vigna aconitifolia (Jacq.) Marechal & Moth bean, mat bean \\
\hline Vigna mungo (L.) Hopper & Urd, black gram \\
\hline Vigna radiata (L.) Wilczek & Green gram, golden gram, mung bean \\
\hline Vigna umbellata (Thumb.) & Rice bean, mambi bean \\
\hline Vigna unguiculta (L.) Walp. ssp. & Cowpea, black-eyed pea, crowder \\
\hline unguiculata & pea \\
\hline Voandzeia subterranea (L.) Thouars & Bambarra groundnut \\
\hline
\end{tabular}


The total pulse production of the world in 2002 was 55,164,796 tons (Table 1-2). Canada and the EU are the main pea-producing countries and the Indian subcontinent and South America are the main regions producing dry beans (Phaseolus ssp. and Vigna spp.). The main region consuming pulses is the Indian subcontinent. In 1999, the food supply of pulses in Asia and India represented 56 and $36 \%$ of the world food supply of pulses, respectively. Africa and the Americas used 18 and $20 \%$ of the world supply, respectively (Schneider, 2002).

In Canada, pulses are mainly cultivated in Saskatchewan, Manitoba and Ontario. There has been a tremendous increase in pulse production during the past decade (Table 1-3). Canada is the world's largest exporter of dry pea and lentils and in 2000-2001, Canada also became the largest exporter of chickpeas. It also holds a significant share of the world's export of dry bean (Agriculture and Agri-Food Canada, 2003b).

\subsubsection{Composition of legume seeds}

The composition of legumes is governed by the cultivar, geographic location and growth condition. Simplified compositions of some legumes are summarized in Table 1-4; protein, carbohydrate and lipid are the major components. Generally, the composition of legumes includes approximately $15-45 \%$ protein, $24-68 \%$ carbohydrate and $0.8-49.7 \%$ lipid. Starch is the most abundant carbohydrate in legume seeds $(22-45 \%)$. Some legumes such as peanuts, soy beans and chickpeas, are particularly high in their lipid and protein content, and contain about 45, 20 and 5\% lipid, respectively, whereas soy beans, in addition, contain the highest amount of crude protein $(\sim 45 \%)$. 
Table 1-2

World pulse production (Food and Agriculture Organization, 2003)

\begin{tabular}{lc}
\hline Continent & Production $(\mathrm{MT})^{1}$ \\
\hline Africa & $9,208,194$ \\
Asia & $25,624,163$ \\
Europe & $8,343,476$ \\
North \& Central America & $6,642,455$ \\
Oceania & $1,393,020$ \\
South America & $3,953,488$ \\
\hline World Total & $55,164,796$ \\
\hline 1. Million metric tons
\end{tabular}

Table 1 - 3

Canada pulse production (Agriculture and Agri-Food Canada, 2003a)

\begin{tabular}{lcc}
\hline Pulse & Year & Production $(\mathrm{KT})$ \\
\hline Dry Pea & $1991-1992$ & 410 \\
& $1996-1997$ & 1,169 \\
& $2003-2004 \mathrm{f}^{1}$ & 2,254 \\
Lentil & $1991-1992$ & 343 \\
& $1996-1997$ & 403 \\
Dry Beans & $2003-2004 \mathrm{f}^{1}$ & 550 \\
& $1991-1992$ & 136 \\
& $1996-1997$ & 133 \\
Chick pea & $2003-2004 \mathrm{f}^{1}$ & 270 \\
& $1991-1992$ & $\mathrm{NA}^{2}$ \\
& $1996-1997$ & 4 \\
\hline
\end{tabular}

1. Forecast

2. Not available 


\subsubsection{Utilization and potential}

Legumes are consumed as food in many parts of the world. Despite their relatively unfavorable protein quality (Gupta, 1983; Augustin and Klein, 1989; Friedman, 1996; Savage and Deo, 1989), they are regarded as an important source of protein in many developing countries. Extensive studies have been carried out to explore their functional properties and their uses as flours, protein isolates and concentrates (Sosulski et al., 1976; Sosulski and Youngs, 1979; Vose, 1980; Sumner et al., 1981; Sahasrabudhe et al., 1981).

Legumes are also used as feed for animals. Pea is used extensively as a feed ingredient for cattle, swine, poultry and fish in Canada and the EU (Agriculture and Agri-Food Canada, 2003b; Waldroup and Smith, 1989).

Although starch is the most abundant carbohydrate in legume seeds, unlike other starches, such as wheat, corn, potato, and rice whose structure and functional properties have been studied extensively and have wide applications in industry and food products, legume starches have not been subjected to intensive research and neither have they been used widely by the food industry. Some researchers (Hoover and Sosulski, 1985a; Tjahjadi and Breene, 1984) have ascribed this to their lack of availability and high retrogradation rates. It was recently reported that the high retrogradation rates of legume starches could be reduced by chemical modification (Hoover and Sosulski, 1985b; Hoover et al., 1988b) to levels that approach those of modified waxy maize starch. This, combined with their high thermal stability, should render legume starches advantageous for use in the food industry (Hoover and Sosulski, 1991).

Attention to legumes as a healthy food has been increasing recently. Firstly, legumes contain a relatively high fiber content (nondigestible food components) compared to other foods (Chen and Anderson, 1981), and this may be physiologically beneficial. Fermentation of the non-digestible food components (mainly dietary fiber and oligosaccharides) by anaerobic 
Table 1-4

Composition of legume seeds (\%)

\begin{tabular}{|c|c|c|c|c|c|c|c|}
\hline \multirow{2}{*}{$\begin{array}{l}\text { Legumes } \\
\text { Groundnuts, peanuts }\end{array}$} & \multicolumn{2}{|c|}{ Protein } & \multicolumn{2}{|c|}{ Fat } & \multicolumn{2}{|c|}{ Total Carbohydrate } & \multirow{2}{*}{ Starch } \\
\hline & 22.7 & $23.5-33.5$ & 44.5 & 49.7 & 25.5 & - & \\
\hline Pigeon peas, red gram & 19.8 & $18.8-28.5$ & 1.3 & 2.19 & 65.2 & $57.3-58.7$ & $40.4-48.2$ \\
\hline Chickpeas & 19.5 & $14.9-29.6$ & 5.7 & 4.99 & 61.7 & - & - \\
\hline Soybeans & 34.3 & $33.2-45.2$ & 18.7 & 21.3 & 31.6 & $25.4-33.5$ & $0.2-0.9$ \\
\hline Lentils & 24.7 & $20.4-30.5$ & 1.0 & 1.17 & 61.2 & 59.7 & $34.7-52.8$ \\
\hline Lima beans & 21.1 & - & 1.05 & 1.41 & 63.6 & - & - \\
\hline Black beans & 21.8 & $21.2-31.3$ & 1.4 & 1.64 & 63.5 & $56.5-63.7$ & $32.2-47.9$ \\
\hline Great Northern beans & 22.0 & - & 1.2 & 3.0 & 63.4 & $61.2-61.5$ & 44.0 \\
\hline Kidney beans & 21.5 & - & 1.3 & 1.9 & 62.7 & - & - \\
\hline Navy beans & 22.0 & - & 1.5 & - & 63.2 & 58.4 & $27.0-52.7$ \\
\hline Pink beans & 21.6 & - & 1.2 & - & 63.6 & - & 42.3 \\
\hline Pinto beans & 21.4 & - & 1.2 & 1.85 & 64.1 & 58.4 & $51.0-56.5$ \\
\hline Mung beans & 23.6 & - & 1.4 & - & 61.6 & $53.3-61.2$ & $37.0-53.6$ \\
\hline Cowpea, black-eyed peas & 22.0 & $20.9-34.6$ & 1.3 & $1.5-2.05$ & 63.4 & $56.0-68.0$ & $31.5-48.0$ \\
\hline References & a & $b$ & a & $b$ & a & $b$ & b \\
\hline
\end{tabular}

a. Augustin and Klein (1989)

b. Kadam et al. (1989) 
bacteria in the intestine gives rise to gas formation and to the formation of lactic acid and volatile fatty acids (VFA). These acids are reported to promote rapid intestinal transit of faeces and a more bulky, softer stool (Hellendoorn, 1978, 1979). Lack of fiber in the western diet is believed to result in constipation, and to be a main factor in the appearance of diverticular and colonrelated diseases. Hellendoorn $(1969,1973,1976,1978,1979)$ suggested that the ingestion of appreciable amounts of beans along with other foods eases or relieves constipation, and reduce the incidence of other colon related diseases.

Secondly, legumes are fairly resistant to attack by hydrolytic enzymes (Hoover and Sosulski, 1985a; Hoover and Sosulski, 1991; Hoover and Zhou, 2003; Dreher et al., 1984) and contain high amounts of resistant starch (RS) (Juliano, 1999). As a consequence, legumes exhibit a lower digestion rates and slower release of glucose into the blood stream, resulting in reduced glycemic and insulinemic postprandial responses compared with other common foods such as cereal grains or potatoes (Jenkins et al., 1982, 1988; Tovar et al., 1992b; Bornet et al., 1997). This is quite attractive to nutritionists, since it is helpful in the dietary control of diabetes as well as arterial disease. Several researchers have studied the digestibility and RS formation of raw and processed legumes (Hoover and Sosulski, 1985a; Björck et al., 1994; Jenkins et al.,1982; Tovar et al., 1992a; Tovar and Melito, 1996; Velasco et al., 1997; Bravo et al., 1998; Skrabanja et al., 1999; Mahadevamma et al., 2003).

In addition, legumes also show potential in the prevention of cardiovascular disease (Anderson and Major, 2002), cancers (Mathers, 2002), as well as lowering serum cholesterol concentrations (Geil and Anderson, 1994). Once known as poor man's meat, legumes are now facing a revival and are recommended for frequent consumption (Leterme, 2002). 


\subsection{Objectives of this research}

The literature is replete with information on the susceptibility of cereal starches (A type crystallinity) towards hydrolysis by $\alpha$-amylase. However, there is a dearth of information on the susceptibility of legume starches (C type crystallinity) towards hydrolysis by $\alpha$-amylase. Legume starches differ widely in their amylose content, crystallinity, B-polymorphic content and magnitude of starch chain associations within the granule interior. They make better substrates than cereal and tuber starches for gaining a deeper insight into the structural factors that influence $\alpha$-amylolysis due to the following reasons: 1) absence of pores on the granule surface (Hoover and Sosulski, 1985a); 2) absence of phosphate groups (Hoover and Sosulski, 1991); 3) presence of only trace quantities of bound lipids (Hoover and Sosulski, 1991); and 4) uniformity in granule size (Hoover and Sosulski, 1991). Thus, a comparative study of the susceptibility of legume starches (belonging to both the same and different biotypes) towards $\alpha$-amylase may lead to the identification of structural factors that limit $\alpha$-amylolysis.

Objectives of this research are:

1) To determine the composition and physicochemical properties of black bean (Black Jack, CDC Nighthawk), pinto bean (Othello, Sierra), smooth pea (CDC Sonata, CDC Mozart), lentil (CDC Redwing, $C D C$ Robin) and wrinkled pea starches;

2) To study the susceptibility of the above starches towards porcine pancreatic $\alpha$ amylase;

3) To determine changes in granular morphology, apparent amylose content, thermal properties, relative crystallinity and ' $\mathrm{B}$ ' polymorphic content of starches during the time course of hydrolysis. 


\section{Chapter 2 Literature Review}

\subsection{Starch - general information}

Starch is the second largest biomass, next to cellulose, produced on earth and is the major form of carbohydrate storage in green plants. Starch is abundant in many major agricultural crops and its content (dry basis) ranges from 40 to $90 \%, 65$ to $85 \%$, and 30 to $70 \%$ in cereals, roots and tubers, and pulses (legumes), respectively (Guilbot and Mercier, 1985). Most of the starches utilized world-wide come from a relatively small number of crops, the most important being maize, potato, wheat, and tapioca with smaller amounts from rice, sorghum, sweet potato, arrowroot, sago, and mung bean (Wang et al., 1998). Legume starches are not utilized widely in the food industry due to their poor functional properties (Sosulski et al., 1997; Ratnayake et al., 2002).

Chemically, starch consists of two types of macromolecule, amylose and amylopectin. Amylose is essentially a linear molecule (Buléon et al., 1998a) with a molecular weight of $5 \times$ $10^{5} \mathrm{Da}$ to $10^{6} \mathrm{Da}$ and is composed of anhydroglucose units connected through $\alpha-1,4$ linkages. Amylopectin has a molecular weight of several millions and is a much branched polymer formed by anhydroglucose units mainly linked by $\alpha-1,4$ bonds, but additionally with $2-6 \% \alpha-1,6$ linked branches (Hizukuri and Takagi, 1984; Takeda et al., 1984, 1986; Buléon et al., 1998a). "Normal" starches from most species contain about 25\% amylose and $75 \%$ amylopectin (Eliasson and Gudmundsson, 1996). However, some mutant genotypes of maize (Zea mays), barley (Hordeum vulgare), and rice (Oryza sativa) contain as much as $70 \%$ amylose whereas other genotypes, called waxy, contain less than $1 \%$ amylose (maize, barley, rice, sorghum) (Buléon et al., 1998a). 


\subsection{Starch production and utilization}

The most common sources of starch are corn, potato, wheat, tapioca and rice. Maize (corn) is dominant in nearly all regions of the world, and wheat features only in Western Europe, and marginally North America and in Australia, while potato plays a role mainly in Europe, and tapioca essentially in Asia (Gordon, 1999). Legume starches have not been widely used due to their lack of availability and high retrogradation rates.

The world starch production was about 48.5 million tons in 2000 (Table 2-1), including not only native and modified starches, but also the large volume of starch that is converted into syrups for direct use as glucose and isoglucose, and as substrates in the form of very high dextrose syrups (known as starch hydrolysates) for fermentation into organic chemicals, including ethanol. Maize is the main raw material in all three regions listed in the table, supplying over $80 \%$ of the global starch production, along with 8,5 and $5 \%$ from wheat, potato and other materials, respectively. Within the global industry, the US is the largest starch producer, with $51 \%$ of world production. The EU contributes more than $17 \%$ of world output, second only to the US.

Fig. 2-1 provides an overview of the wide range of products obtained from starch. LMC (2002) classified all starch products into four main categories: native and modified starches, ethanol, glucose and other syrup-based starch products. Products from these four categories accounted for 15, 40, 32 and 13\%, respectively of the entire US starch output in 2002.

Starch, as a renewable and biodegradable resource, is abundant, environmentally friendly, cost competitive, and versatile. The variations in starch source, composition and structure, and the diversities in properties, make starch suitable for various applications contributing to 
Table 2-1

Starch production by raw material in the EU, US and other countries, in 2000 (million metric tons)

\begin{tabular}{lccccc} 
& Maize & Potatoes & Wheat & Other & Total \\
\hline EU & 3.9 & 1.8 & 2.8 & 0 & $\mathbf{8 . 4}$ \\
US & 24.6 & 0.0 & 0.3 & 0 & $\mathbf{2 4 . 9}$ \\
Other countries & 10.9 & 0.8 & 1.1 & 2.5 & $\mathbf{1 5 . 2}$ \\
World & 39.4 & 2.6 & 4.1 & 2.5 & $\mathbf{4 8 . 5}$ \\
\hline
\end{tabular}

Source: LMC International Ltd, 2002 
Figure 2-1 Products derived from starch

Modified from Röper (2002) 


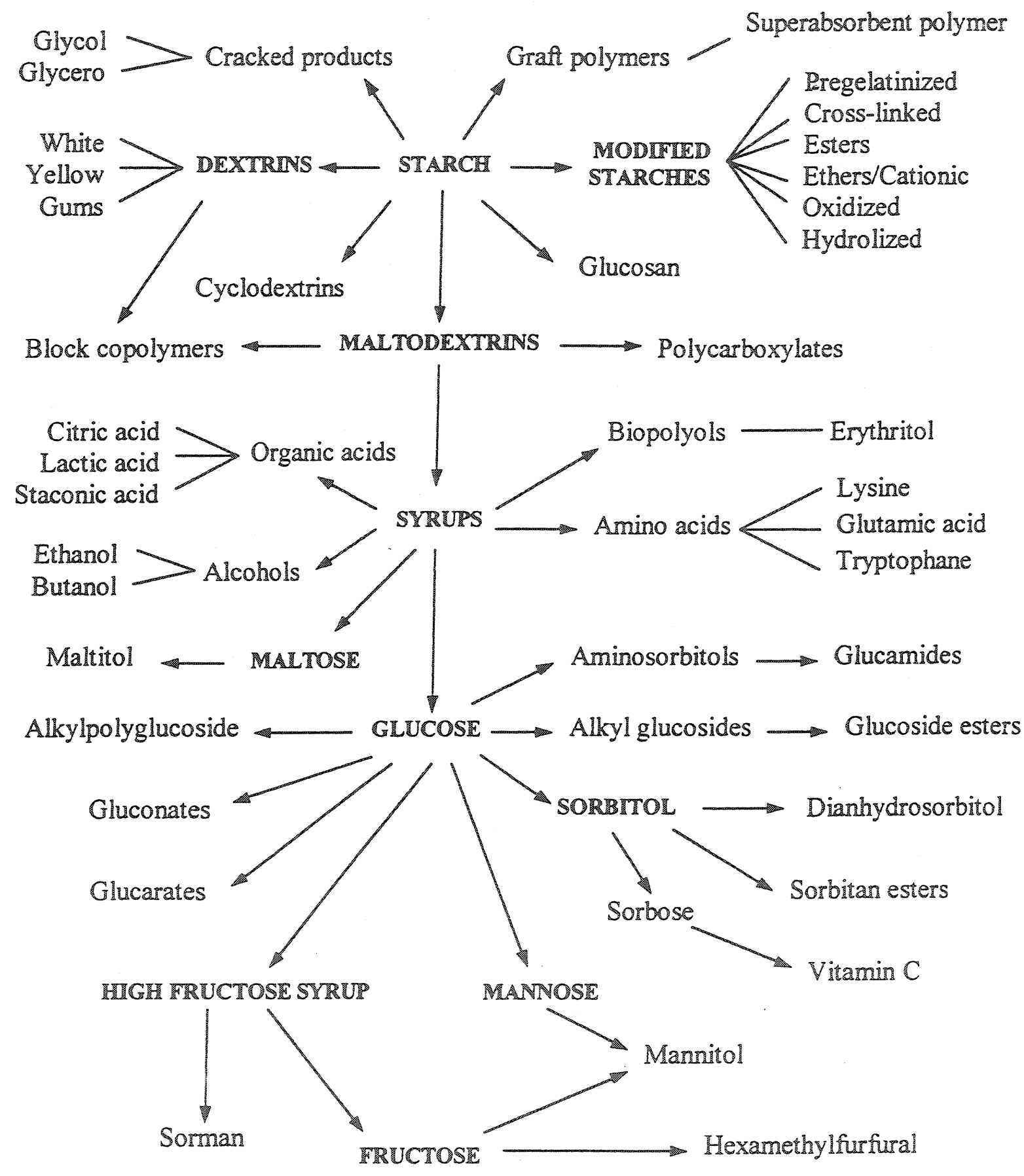


Table 2-2

Application of starch and starch derivatives in food and non-food industries.

\begin{tabular}{|c|c|c|}
\hline Industry & Uses & Type used \\
\hline Food & $\begin{array}{l}\text { Thickener for pie filling, puddings } \\
\text { stabilizer for salad dressings, frozen foods } \\
\text { binder for meat and pet foods } \\
\text { moisture retainer for bakery and meat } \\
\text { fat replacer for desserts, spreads, sauces } \\
\text { adhesive for food packing and meat gluing } \\
\text { glaze for cakes, donuts, fruits and nuts }\end{array}$ & $\begin{array}{l}\text { Native starches, modified starches, } \\
\text { maltodextrins, high fructose syrups }\end{array}$ \\
\hline Beverage & Soft drinks, beer, alcohol, instant coffee & Sweeteners \\
\hline Confectionery & $\begin{array}{l}\text { Ice cream, candy, gums, marshmallows, } \\
\text { canning, marmalade and jams }\end{array}$ & $\begin{array}{l}\text { Starch, maltodextrins, maltose } \\
\text { syrups }\end{array}$ \\
\hline Adhesive & $\begin{array}{l}\text { Case sealing, laminating, tube winding, } \\
\text { corrugated board }\end{array}$ & Starch and dextrins \\
\hline Paper \& Cardboard & $\begin{array}{l}\text { Wet end additives, spraying, surface sizing, } \\
\text { coating }\end{array}$ & $\begin{array}{l}\text { Native, cationic, and hydroxyethyl } \\
\text { starches }\end{array}$ \\
\hline Textile & Sizing, finishing, printing, fire resistances & Starch and modified \\
\hline Cosmetic & Emulsifiers, humectants, face powders & Starch, sorbitan esters \\
\hline Detergent & Surfactants, builders, bleach activators & Sucrose derivatives \\
\hline Pharmaceuticals & Diluents, binders, drug delivery, encapsulation & $\begin{array}{l}\text { Starch, malto- and cyclodextrins, } \\
\text { glucose syrups, polyols }\end{array}$ \\
\hline Plastics & Biodegradable filler & Starch \\
\hline Biochemistry & $\begin{array}{l}\text { Organic acids, amino acids, biopolymers, } \\
\text { polyols, enzymes, alcohols, antibiotics }\end{array}$ & Starch hydrolysates \\
\hline Other & $\begin{array}{l}\text { Ceramics, coal, water treatment, gypsum } \\
\text { and mineral fiber, oil drilling, concrete }\end{array}$ & Starch and modified starches \\
\hline
\end{tabular}

Source: Ellis et al. (1998); Guzmán-Maldonado and Paredes-López (1995); Lillford and Morrison (1997). 
different functions. Native starches have diverse properties, which meet different application requirements. However, physical and chemical modifications greatly improve the properties of native starches and extend the range of starch applications in food, paper and board, textiles, and pharmaceuticals. Also, numerous starch derivatives produced by enzymatic technology, including dextrins and various DE syrups, have been used for production of organic acids, solvents, alcohols, amino acids, biopolymers and other products. A wide range of applications for starch and starch derivatives in various industries are summarized in Table 2-2.

\subsection{Starch composition and structure}

\subsubsection{Composition}

Starch usually contains $10-15 \%$ moisture, $85-90 \%$ polysaccharides (amylose and amylopectin), and minor non-polysaccharide components (protein, lipid and minerals) (Tester, 1997). In legume starches (Table 2-3), protein, ash and lipid contents range from 0.10 to $1.12 \%$, 0.03 to $0.81 \%$, and 0.01 to $0.87 \%$, respectively.

\subsubsection{Major components}

Amylose and amylopectin are the principal components of starch and their content varies depending on starch source, species and cultivar (Galliard and Bowler, 1987). Normally, nonmutant starches from most species contain about 25\% amylose and 75\% amylopectin (Eliasson and Gudmundsson, 1996). The amylose content of legume starches (Table 2-3) ranges from 19.5 to $75.4 \%$. 
Table $2-3$

Composition of legume starches ${ }^{1,2,3}$

\begin{tabular}{|c|c|c|c|c|c|c|}
\hline Starch source & Yield of pure starch (\%) & Protein (\%) & Lipid (\%) & Ash (\%) & Amylose (\%) & lodine affinity (\%) \\
\hline Kidney bean & 25 & $0.13-0.30$ & 0.18 & 0.18 & $34.4-35.0$ & $7.02-8.04$ \\
\hline Northern bean & $18-31$ & $0.35-0.97$ & $0.20-0.46$ & - & 31.6 & - \\
\hline Navy bean & $21-40$ & $0.13-0.34$ & $0.09-0.60$ & $0.06-0.14$ & 36 & $6.58-7.20$ \\
\hline Black bean & 32 & $0.55-1.12$ & 0.15 & 0.11 & $35.1-37.3$ & $6.82-7.20$ \\
\hline Mung bean & $32-43$ & $0.12-0.28$ & $0.17-0.50$ & $0.18-0.27$ & $19.5-40$ & $5.95-6.98$ \\
\hline Pinto bean & $27-38$ & $0.37-0.52$ & $0.16-0.51$ & $0.05-0.09$ & $25.8-30.2$ & - \\
\hline Adzuki bean & 21.5 & $0.1-0.27$ & $0.03-0.06$ & $0.07-0.19$ & $21.2-34.9$ & 6.98 \\
\hline Moth bean & 33.5 & 0.58 & 0.87 & 0.62 & 26.4 & 5.81 \\
\hline Faba bean & 39.9 & $0.49-0.52$ & $0-0.08$ & 0.06 & $31.3-42.1$ & $6.03-5.61$ \\
\hline Horse bean & 37 & $0.16-0.90$ & 0.06 & 0.81 & $24-32$ & $4.50-6.28$ \\
\hline Lima bean & $23-30$ & $0.22-0.44$ & 0.1 & $0.07-0.13$ & - & $6.56-6.60$ \\
\hline Red bean & 46.3 & 0.13 & 0.01 & 0.05 & 35.7 & 4.83 \\
\hline Lablab bean & - & 0.21 & 0.2 & 0.03 & 30 & 6.05 \\
\hline Smooth pea & 40 & $0.52-0.70$ & $0.01-0.1$ & 0.07 & $32.5-33$ & 6.98 \\
\hline Wrinkled pea & $18-22$ & $0.34-0.46$ & $0.01-0.19$ & 0.08 & $62.8-75.4$ & $12.80-15.18$ \\
\hline Black gram & 45 & - & - & - & 26.65 & - \\
\hline Chick pea & 40 & $0.70-0.94$ & 0.06 & 0.07 & $30.4-32.2$ & 6.08 \\
\hline Cow pea & 37 & $0.12-0.50$ & $0.21-0.33$ & 0.06 & 33 & 6.6 \\
\hline Horse gram & 28 & 0.05 & - & 0.05 & 34.3 & - \\
\hline Lentil & $25-4 ?$ & $0.17-0.53$ & $0.05-0.23$ & 0.13 & $29-45.5$ & $6.97-9.09$ \\
\hline
\end{tabular}

1. Source: Hoover and Sosulski (1991)

2. For tuber and root starches, the nitrogen, lipid, phosphorous, and amylose content are in the range $0.006-0.49 \%, 0.006-3.96 \%$, $0.003-0.08 \%$ and $10-38 \%$, respectively (Hoover, 2001; Narayana Moorthy, 2002).

3. For barley starches, the protein, lipid, phosphorous, and amylose content are in the range $0.25-0.56 \%, 0.16-1.17 \%, 0.022-0.068 \%$, and 1.8 - 47.9\%, respectively (Morrison et al. , 1986; McDonald and Stark, 1988; Ellis et al., 1998; Kasemsuwan and Jane, 1996; Lim et al. , 1994; Song and Jane, 2000). 


\subsubsection{Minor components}

In addition to amylose and amylopectin, starch contains small amounts of proteins and lipids, as well as trace amounts of minerals. Lipid and protein may occur either on the surface of or inside, the starch granule (Lillfford and Morrison, 1997). Although these components occur in small amounts, their presence greatly influences the properties of starch granules such as digestibility, swelling ability, solubility, retrogradation, and granule integrity (Han and Hamaker, 2002; Appelqvisî and Debet, 1997; Galliard and Bowler, 1987).

\subsection{Lipids}

Lipids in cereal, tuber, root and legume starch granules have been found to occur both on the surface of and inside the granule (Morrison, 1981), The surface lipids are mainly triacylglycerides, followed by free fatty acids, glycolipids and phospholipids (Morrison, 1981; Galliard and Bowler, 1987; Vasanthan and Hoover, 1992). The internal lipids mostly are monoacylglycerides, with the major components being lysophospholipids and free fatty acids (Hargin and Morrison, 1980; Morrison, 1981; Vasanthan and Hoover, 1992). Total starch lipids (surface plus internal) have been found to be generally in the range of $0.7-1.2 \%$ in cereals (Morrison and Milligan, 1982; Takahashi and Seib, 1988; Vasanthan and Hoover, 1992), $0.01-0.87 \%$ in legumes (Table $2-3$ ) and $0.08-0.19 \%$ in tubers and roots (Emiola and Delarosa, 1981; Goshima et al., 1985; Vasanthan and Hoover, 1992).

Starch lipids may be present in a free state as well as bound to other starch components, linked via ionic or hydrogen bonding to hydroxyl groups of the starch components or in the form of an amylose-lipid complex in which the ligand resides within the central hydrophobic center of the helix (Morrison, 1981). Free lipids are easily extracted by using chloroform-methanol $(2: 1, \mathrm{v} / \mathrm{v})$ at ambient temperature, whereas bound lipids need many hours of extraction with hot aqueous solvent [n-propanol 
- water $(3: 1, \mathrm{v} / \mathrm{v})]$ or acid hydrolysis to completely disrupt the starch granule before the lipids are released (Morrison, 1981; Goshima et al., 1985; Hoover et al., 1988a; Vasanthan and Hoover, 1992).

\subsection{Proteins}

Proteins are also associated with starch granules and their amounts vary among and within species. Typical protein contents of wheat, maize and potato is $0.2-0.3,0.35$ and $0.06 \%$, respectively (Skerritt et al., 1990; Swinkels, 1985). In general, ten principal polypeptide bands are evident in sodium dodecyl sulfate polyacrylamide gel electrophoresis (SDS-PAGE) separations of starch granuleassociated protein extracts. These bands correspond to proteins with molecular weights ranging from $\sim 5$ to $149 \mathrm{kDa}$. As a function of their molecular weights, the proteins have been classified into two groups: surface proteins with low molecular weights $(\sim 5,8,15,19$ and $30 \mathrm{kDa})$ and internal proteins with higher molecular weights ( 60,77, 86, 95 and $149 \mathrm{kDa})$ (Baldwin, 2001).

\subsection{Minerals and phosphorous}

Starches contain trace amounts of minerals such as $\mathrm{Ca}^{2+}, \mathrm{K}^{+}, \mathrm{Mg}^{2+}$ and $\mathrm{Zn}^{2+}$ as well as bound

phosphorous. Most of the phosphorous in cereal starches is present in the form of lysophospholipid $(0.02-0.06 \%)$ (Morrison, 1995), whereas waxy starches have much less phosphorous $(<0.01 \%)$, mainly in the form of starch phosphate monoesters. High-amylose corn starch (70\% amylose) contains organic phosphorous $(0.02 \%)$ as starch phosphate monoesters and phospholipids in a 1:4 ratio. Root and tuber starches are phospholipid-free, the phosphorous is mainly in the form of phosphate monoesters. Legume starches contain $\sim 0.01 \%$ phosphorous, mainly in the form of phosphate monoesters which are exceptionally high in potato starch $(\sim 0.089 \%)$. Phosphate monoesters of all 
starches are located more on the primary carbon (C-6) than on the secondary carbon (C-3) of the anhydrous glucose unit of amylopectin (Lim et al., 1994; Kasemsuwan and Jane, 1996).

\subsubsection{Ultrastructure}

\subsubsection{Overview of granule structure}

The structural basis of starch granules is amylose and amylopectin. Amylose is essentially a linear molecule linked by $\alpha-(1,4)-D$-glycopyranosyl units. Amylopectin is highly branched, formed from chains of $\alpha$-D-glucopyranosyl residues linked together mainly by $(1 \rightarrow 4)$ linkages but with 5 $6 \%$ of $(1 \rightarrow 6)$ bonds at the branch points (Buléon et al., 1998a). Amylose and amylopectin chains further form crystalline and amorphous regions of the starch granule. Starch is biosynthesized as semicrystalline granules with varying polymorphic types and degrees of crystallinity. Granule crystallinity has been mainly attributed to the amylopectin fraction.

The inner architecture of the native starch granule is characterized by growth rings (Yamaguchi et al., 1979; Jenkins et al., 1993; Donald et al., 1997) that represent concentric crystalline shells or layers separated by amorphous regions. A model of the arrangement of the amorphous and crystalline regions is schematically shown in Fig. 2-2. Regions of amylopectin double helices fall within the crystalline lamellae, while the amylopectin branch points lie in the amorphous lamellae. The crystalline lamellae exist alternatively with the amorphous lamellae (Fig. 2-2B). The combined thickness of crystalline plus amorphous lamellae is 9 and $9.2 \mathrm{~nm}$ for A-type and B-type starches, respectively (Jenkins et al., 1993).

Gallant et al. (1997) recently revealed the different levels of structural organization within the starch granule. They proposed the presence of blocklets having dimensions of a few hundred nanometers within the growth rings. Helbert and Chanzy (1996) suggested that amylopectin is 
composed of "superclusters" having sizes similar to that of the blocklets. Oostergetel and Van Bruggen (1993) proposed a three-dimensional helical structure for the lamellae organization in lintnerized potato starch, suggesting the occurrence of a "superhelical" organization. Based on these results, the amylopectin side chain clusters have been suggested to form the submacroscopic structure of the blocklets. The blocklets range in diameter from approximately 20 to $500 \mathrm{~nm}$ depending on starch type (botanical source) and location in the granule. Starches resistant to enzymatic attack (potato and highamylose starches) have been shown to consist of larger blocklets than less resistant starches (Gallant et al., 1992). At the lowest level of granule organization, the starch granules contain alternating hard (crystalline) and soft (semicrystalline) shells of several hundred nanometer thickness. The hard shells are composed of larger blocklets (50 to $500 \mathrm{~nm}$ ) than the soft shells, where the blocklet size ranges between 20 and 50nm. The repeat of a hard and a soft shell has been regarded as a growth ring, which can be observed using light microscopy. The width of the shells becomes progressively thinner toward the exterior of the starch granules. A detailed schematic illustration of this blocklet structure is shown in Fig. 2-3.

\subsubsection{Amylose}

Amylose constitutes about $25 \%$ of the starch granule. Generally, it is a linear molecule linked by $\alpha$-(1,4)-D-glycopyranosyl units (Fig. 2-4). However, a slight degree of branching [ $9-20 \alpha(1 \rightarrow 6)$ branch points per molecule] has been reported in amylose from various starch sources. The side chains range in chain length from 4 to over 100 (Hizukuri et al., 1981; Takeda et al., 1987a). The extent of branching has been shown to increase with the molecular size of amylose (Greenwood and Thomson, 1959). Evidence of the occurrence of branch points in amylose is its incomplete conversion into 
Figure 2-2 Internal structure of a starch granule showing alternating amorphous and semi-crystalline growth rings
A) Stacks of semi-crystalline lamellae are separated by amorphous growth rings.
B) A magnified view of one such stack, showing that it is made up of alternating crystalline and amorphous lamellae.
C) The crystalline lamellae comprise regions of lined up double helices formed from amylopectin branches. The amorphous lamellae are where the amylopectin branch points sit.
Source: Donald et al. (1997), reproduced with permission. 


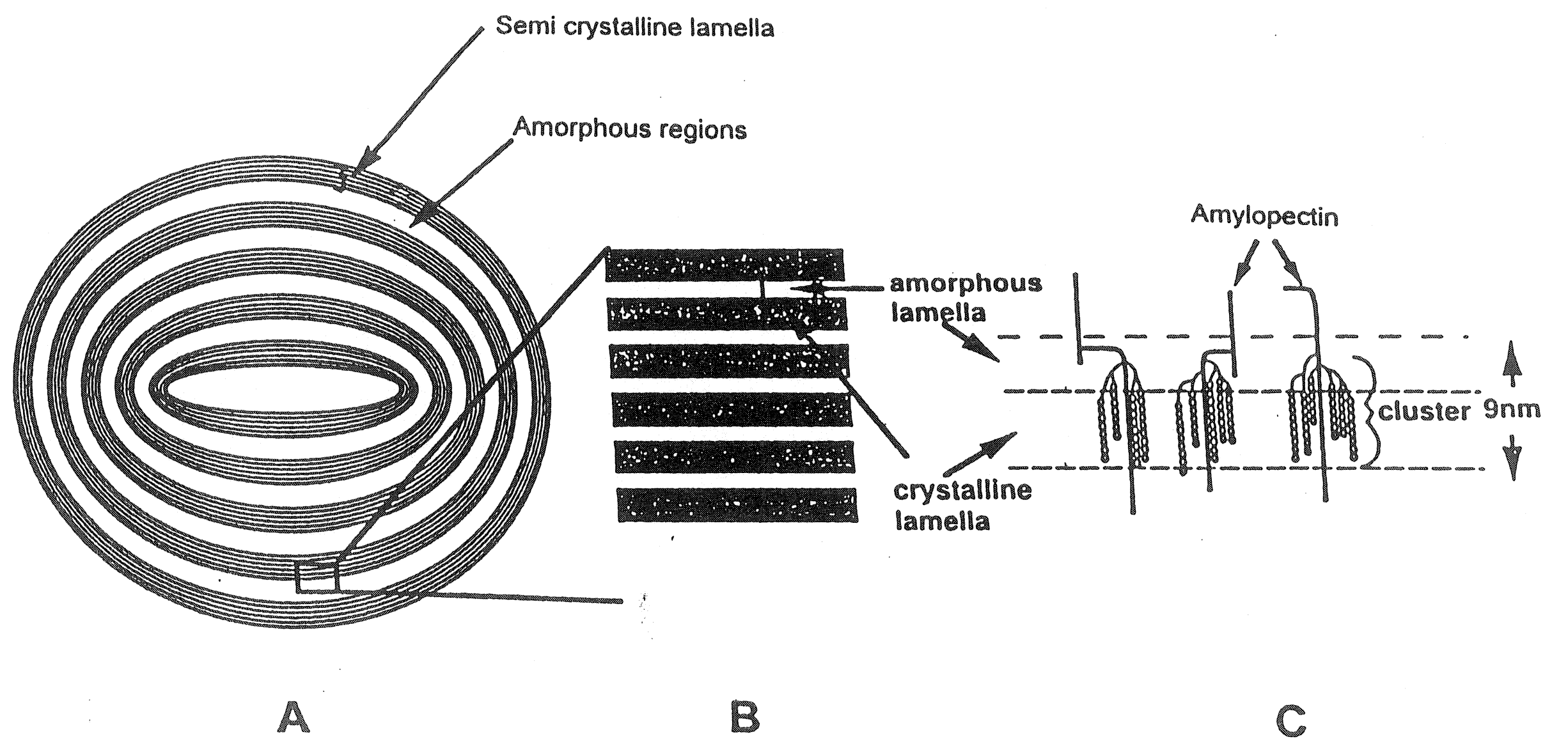




\section{Figure 2-3 Blocklet model of starch granule structure}

(a) The granule is composed of alternating crystalline (hard) and semi-crystalline (soft) shells (dark and light color, respectively). The shells are thinner towards the granule exterior (due to increasing surface area to be added to by constant growth rate) and the hilum is shown off centre.

(b) Blocklet structure is shown, in association with amorphous radial channels. Blocklet size is smaller in the semi-crystalline shells than in the crystalline shells.

(c) One blocklet is shown containing several amorphous and crystalline lamellae. The next diagram shows the magnified picture of amorphous and crystalline lamellae of amylopectin.

(d) Amylose-lipid (and protein) complexes feature in the organization of the amylopectin chains.

(e) The crystal structures of A and B type crystalline.

Source: Gallant et al. (1997), reproduced with permission. 
(a)

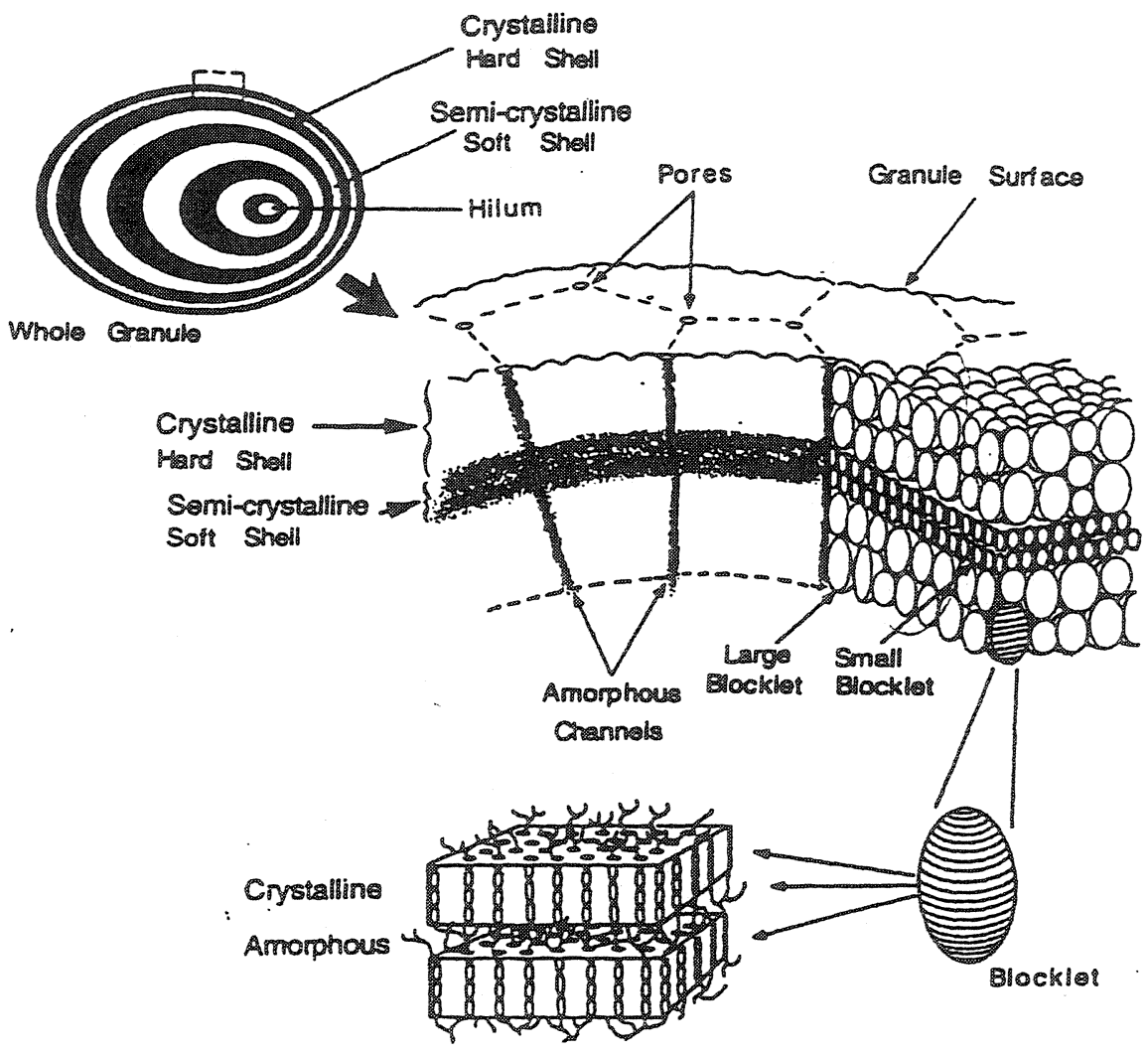

(c)

(b)

(d)

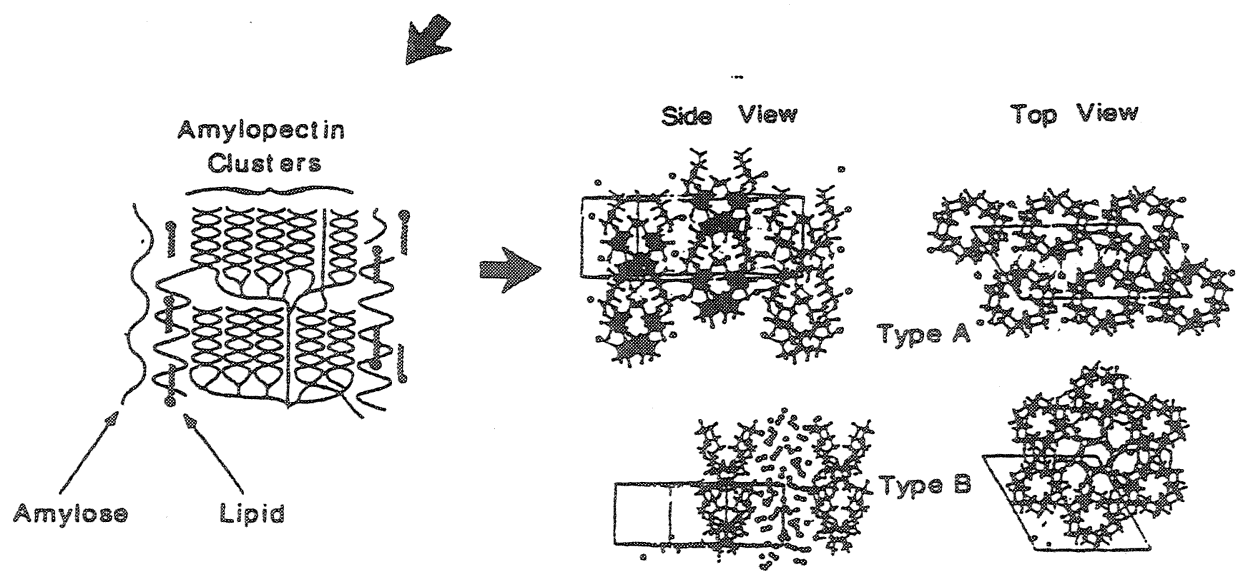


Figure 2-4 Representative partial structure of amylose (A) and amylopectin (B) Source: LSBU (London South Bank University) (2003) 
(A)

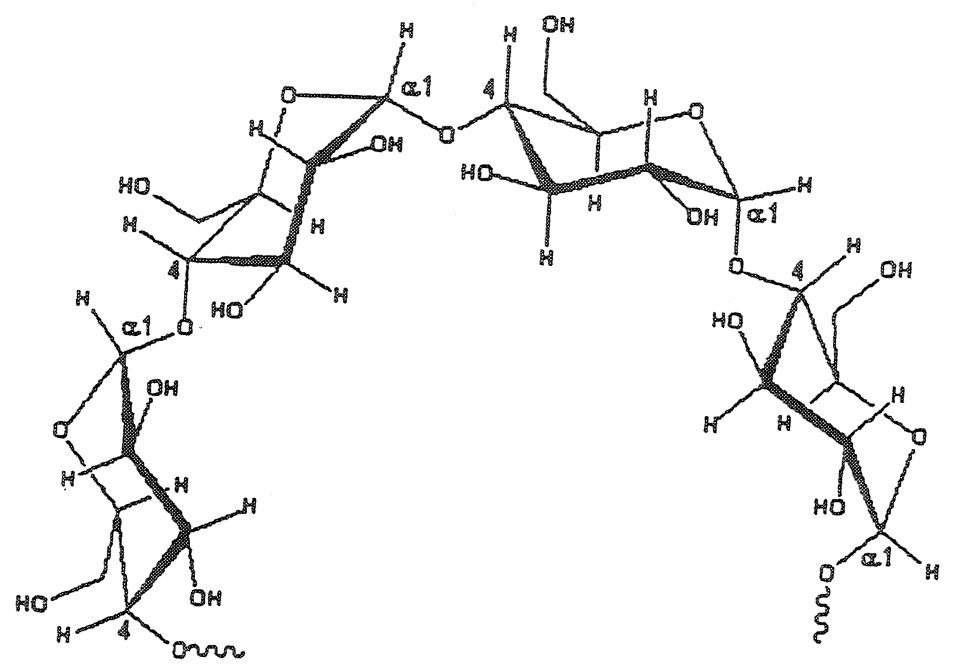

(B)

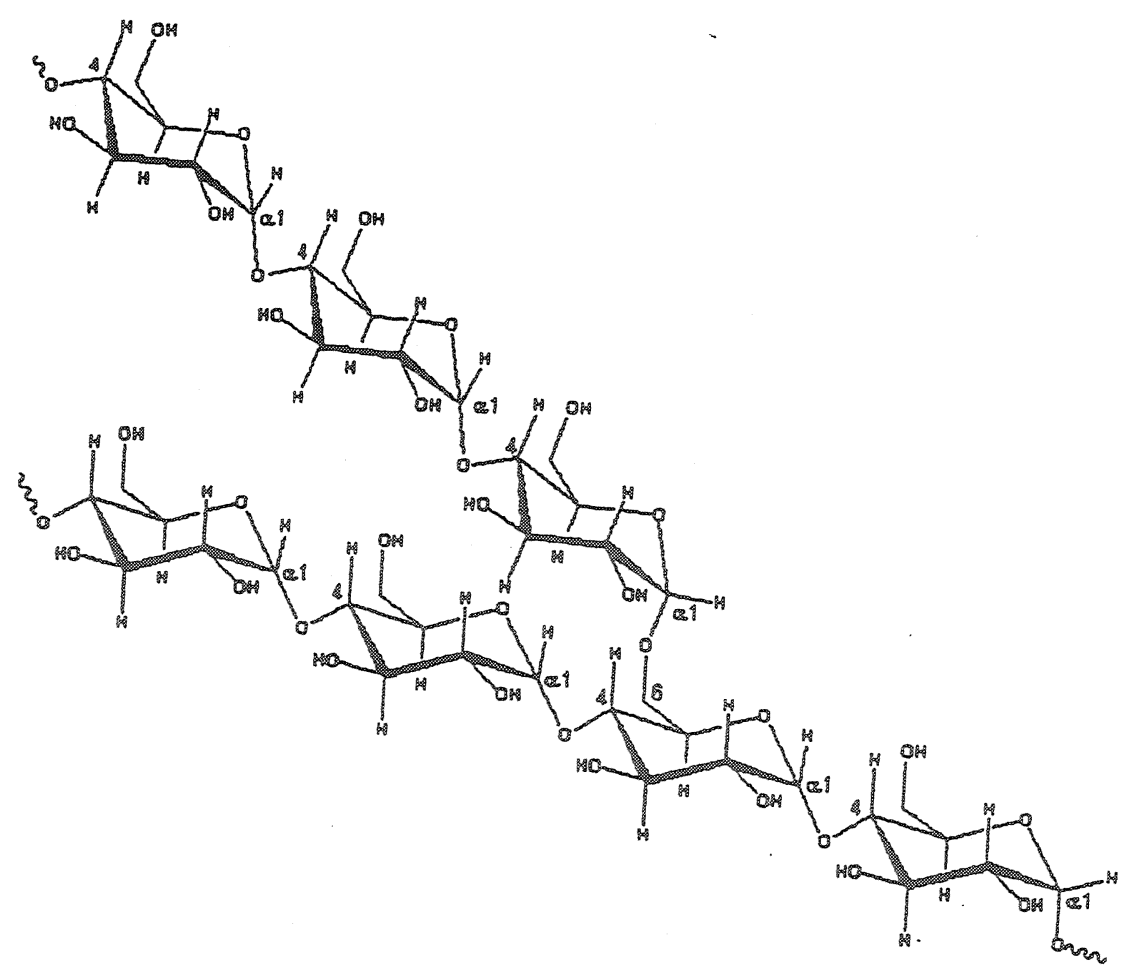


maltose by $\beta$-amylase; $\beta$-amylolysis has been shown to vary from 73 to $95 \%$ (Morrison and Karkalas, 1990). The molecular weight of amylose has been reported to vary between $10^{5}$ and $10^{6} \mathrm{Da}$ (Morrison and Karkalas, 1990; Hizukuri et al., 1989). Table 2-4 summarizes the general characteristics of amylose and amylopectin.

The physicochemical characteristics of some legume amyloses are presented in Table 25. The iodine binding capacity (IBC), limiting viscosity number $(\eta)$, degree of polymerization (DP) and $\beta$-amylolysis limit for amylose from legume starches are in the range of 16-22, 136280, 1000-1900, and 79-86.9\%, respectively. The molecular weights determined only on selected legume amyloses range from 165,000 to $312,000 \mathrm{Da}$. The DP values of legume amyloses are lower than those of tuber and root starches, which are 3400-4100, 2110-4920, 2660 for sweet potato, potato and tapioca, respectively (Hizukuri, 1996).

\subsection{Amylose inclusion complexes}

Despite its slightly branched nature, in neutral solutions and other solvents such as dimethylsulfoxide (DMSO), formamide and aqueous alkali, amylose behaves as a random coil, assuming a helical conformation in the presence of a complexing agent (Banks and Greenwood, 1971, 1975). It is well known that amylose can form inclusion complexes with guest molecules such as iodine, alcohols and certain lipids. The crystalline structure of the amylose-ligand complex is commonly referred to as V-polymorph. Amylose, in the single helical (V) conformation, has six glucosyl residues per turn (with bulky ligands there are seven or eight), stabilized by hydrogen bonds between the hydroxyl groups of adjacent glucosyl residues, 2-OH $-3^{\prime}-\mathrm{OH}$ and $2-\mathrm{OH}-6^{\prime}-\mathrm{OH}$ interturn hydrogen bonds, and numerous intra- and intermolecular van der Waals contacts located on the outer surface of the helix (Banks and Greenwood, 1975; Rappenecker and Zugenmaier, 1981; Blanshard, 1987; Biliaderis, 1998). The helix cavity is 
effectively a hydrophobic channel which provides a place to accommodate the guest molecules during complex formation.

\subsection{Amylose - lipid complex}

The formation of amylose-lipid complexes (ALC) can occur in situ with natural fatty acids and phospholipids during the biosynthesis of starch. Amylose-lipid complexes can also be formed during gelatinization of starch in the presence of naturally occurring lipids or added food emulsifiers such as monoacylglycerides, sodium or calcium stearoyl lactylate, and sorbitan monostearate. Fig. 2-5 is a schematic illustration of an ALC. The hydrophobic chain of the fatty acid or lipid lies inside the amylose helix and is stabilized by van der Waals contacts with the adjacent C (5) - hydrogen of amylose, but the polar ends of the lipids are not inside the helix cavity (Godet et al., 1993). The ' V' - X-ray pattern of ALC'S is found in high-amylose starches, and in starches containing genes such as amylose extender and in dull or sugary starches (Zobel, 1988a). Proof that ALC'S do exist in native starch granules and that they are not artifacts formed during starch isolation was obtained by ${ }^{13} \mathrm{C}$ CP/MAS-NMR spectroscopy (Morrison et al., 1993a, 1993b, 1993c).

\subsection{Amylose-iodine complex}

The reaction between amylose and iodine has been known for over a century. Rundle and Baldwin (1943) proposed that the iodine component of the complex is present in a unidimensional array within any amylose helix with six glucose residues per turn. Teitelbaum et al. $(1978,1980)$ studied the structure of the amylose-iodine complex using Raman and Mossbauer spectroscopy and postulated that the principal chromophore was pentaiodine anion $\left(\mathrm{I}^{5}\right)$. The blue color formed by amylose-iodine complex has served as the principle for 
Table $2-4$

General characteristics of amylose and amylopectin

\begin{tabular}{|c|c|c|}
\hline Property & Amylose & Amylopectin \\
\hline \multirow[t]{2}{*}{ Molecular structure } & Essentially linear, & Branched, \\
\hline & $\alpha-1,4$-glucosidic linkage & $\alpha-1,4$ and $\alpha-1,6$-glucosidic linkage \\
\hline Degree of branching (\%) & $0.2-0.7$ & $4.0-5.5$ \\
\hline Degree of polymerization (DP) & $700-5000$ & $10^{4}-10^{5}$ \\
\hline Molecular weight (Da) & $10^{5}-10^{6}$ & $10^{7}-10^{9}$ \\
\hline Average chain length & $100-550$ & $18-25$ \\
\hline Structural conformation & Partly complexed with lipid, amorphous & Double helix, partly crystalline \\
\hline \multicolumn{3}{|l|}{ lodine complex } \\
\hline lodine affinity $(g / 100 g)$ & $19-20.5$ & $0-1.2$ \\
\hline$\lambda_{\max }(\mathrm{nm})$ & $640-660$ & $530-570$ \\
\hline Blue value & $1.2-1.6$ & $0-0.2$ \\
\hline Color & Blue & Purple \\
\hline$\beta$-amylolysis limit (\%) & $70-95$ & $55-60$ \\
\hline Stability of dilute aqueous solutions & Unstable (retrogrades) & Stable \\
\hline Gel texture & Stiff, thermally irreversible $\left(<100^{\circ} \mathrm{C}\right)$ & Soft, thermally reversible $\left(<100^{\circ} \mathrm{C}\right)$ \\
\hline Film properties & Strong, coherent & Brittle \\
\hline Reference & \multicolumn{2}{|c|}{ Biliaderis, 1991; Hizukuri, 1996} \\
\hline
\end{tabular}


Table 2 - 5

Physicochemical characteristics of legume amyloses

\begin{tabular}{|c|c|c|c|c|c|}
\hline Starch source & lodine binding capacity & Limiting viscosity number $(\mathrm{mL} / \mathrm{g})$ & Degree of Polymerization & Molecular weight & $\beta$-Amylolysis \\
\hline Kidney bean ${ }^{a}$ & 20 & 180 & 1300 & - & 85.9 \\
\hline Navy bean ${ }^{a}$ & 18.48 & 174 & 1300 & 165000 & 86.2 \\
\hline Black bean $^{a}$ & 22.01 & - & - & - & \\
\hline Mung bean ${ }^{a}$ & 19.43 & 251 & 1900 & 245000 & 78.4 \\
\hline Pinto bean ${ }^{a}$ & - & - & - & 123000 & - \\
\hline Adzuki bean ${ }^{b}$ & 19.4 & - & 1350 & - & 83 \\
\hline Faba bean $^{\mathrm{a}}$ & 19.61 & 188 & 1400 & 191000 & 85.6 \\
\hline Horse bean ${ }^{a}$ & $17.1-19.2$ & $240-280$ & 1800 & - & 82 \\
\hline Smooth pea ${ }^{a}$ & $18.84-19.2$ & $136-150$ & $1000-1100$ & 125000 & $79-84.7$ \\
\hline $\mathrm{Pea}^{\mathrm{b}}$ & 19 & - & 820 & - & 90 \\
\hline
\end{tabular}
a. Hoover and Sosulski (1991)
b. Yoshimoto et al. (2001)
c. Ratnayake et al. (2001) 
Figure 2-5 Schematic illustration of amylose-lipid complex

Source: Carlson et al. (1979), reproduced with permission 


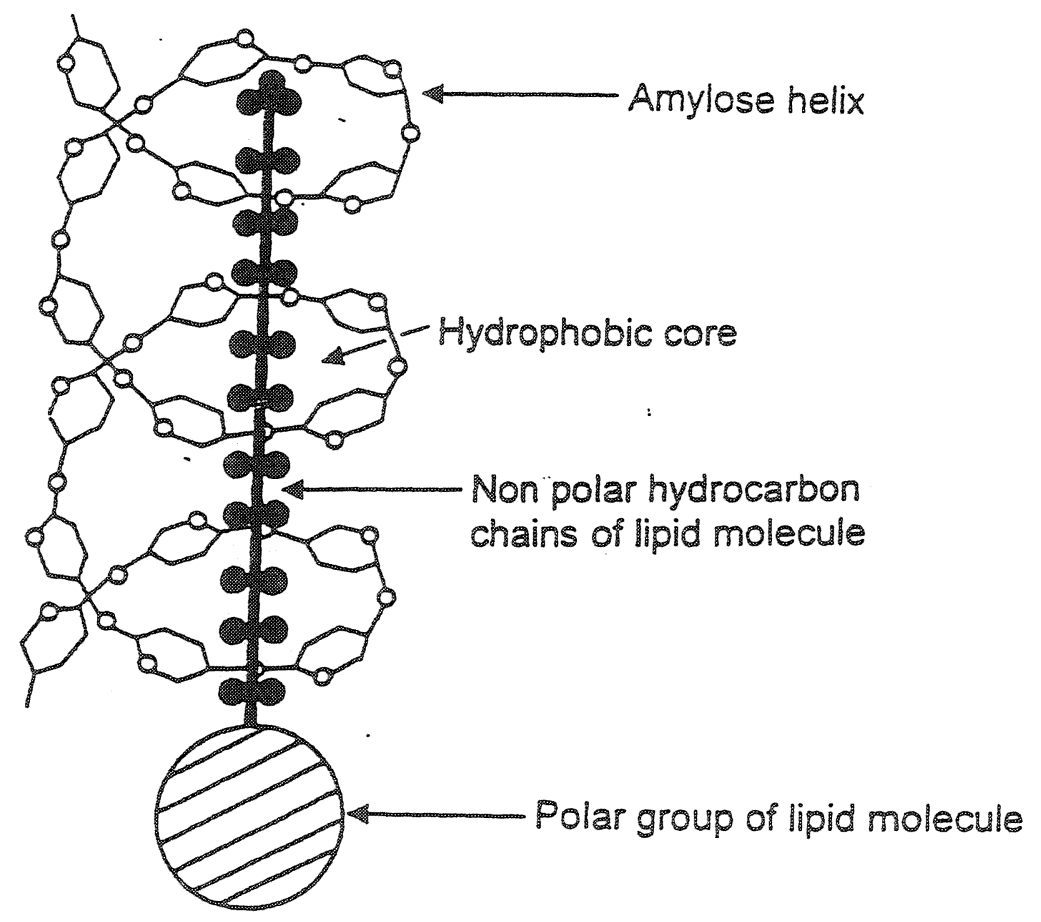


colorimetric methods to determine amylose content. Amylose can bind some $20 \%$ of its weight of iodine (Biliaderis, 1998). However, the color of the complex may vary as a result of the chain length (DP) of amylose, which influences its binding ability with iodide anions. John et al. (1983) reported that the color of the complexes changed from brown (DP $21-24$ ) to red (DP $25-29$ ), red-violet (DP $30-38$ ), blue-violet (DP $39-46$ ), and finally blue (DP $>47$ ). When DP is lower than 20 , no color was formed.

\subsection{Location of amylose}

The location of amylose in a starch granule is still in dispute. The possible locations are listed as follows: (1) amorphous growth ring; (2) amorphous lamellae of semi-crystalline growth ring (between crystalline lamellae); (3) interspersed or co-crystallized with amylopectin molecules (Jenkins and Donald, 1995; Jane et al., 1992; Kasemsuwan and Jane, 1994); (4) radial channels and central cavities (Gallant et al., 1997).

Amylose has been located in bundles between amylopectin clusters (Nikuni, 1978; Blanshard, 1986; Zobel, 1992). However, by using epichlorohydrin cross-linking, phosphorous-31nuclear magnetic resonance (NMR) spectroscopy and gel permeation chromatography, other researchers (Jane et al., 1992; Kasemsuwan and Jane, 1994) have shown that amylose molecules are randomly interspersed among amylopectin clusters in both the amorphous and crystalline regions instead of being in bundles. Reports about the distribution of amylose in starch granules are also contradictory. Increased values of blue value, iodine affinity, and amount of amylose fraction during granule development in maize (Inouchi et al., 1984), wheat (Morrison and Gadan, 1987), barley (McDonald et al., 1991), rice (Asaoka et al., 1985), pea (Biliaderis, 1982a), and potato (Jane and Shen, 1993) starches imply a richer amylose region in the periphery region than in the center of the granules. 
However, reverse amylose distribution in potato and maize hybrid ae/wx starch granules with reduced amylose content has also been reported (Schwatz, 1982; Yun and Matheson, 1992; Kuipers et al., 1994; Tatge et al., 1999). The independent localization of amylose and amylopectin in starch granules with varying amylose contents $(0-70 \%)$ by enzyme-gold labeling (Atkin et al., 1999) revealed that the location of amylose differed with different amylose contents. Amylose in low amylose content potato starch was mainly located in the amorphous growth rings alternating with semi-crystalline growth rings, whereas high amylose content (amylomaize) granules were shown to possess an amylopectin center surrounded by an amylose periphery encapsulated by an amylopectin surface.

Based on the fact that increasing amylose content has the effect of increasing the crystalline region size but reducing the electron density of small angle $\mathrm{x}$-ray scattering (SAXS), Jenkins and Donald (1995) suggested that increased amylose acts to disrupt the packing of the amylopectin double helices within the crystalline lamellae. Two mechanisms were provided. Mechanism 1 (Fig. 2-6) involves amylose co-crystallizing with amylopectin. Mechanism 2 involves amylose chains oriented

transverse to the lamella stack, penetrating the amorphous lamellae and introducing disorder. However, current evidence is insufficient to distinguish these two mechanisms.

\subsubsection{Amylopectin}

Amylopectin constitutes about $75 \%$ of most starches. It is a highly branched macromolecule formed through chains of $\alpha$-D-glucopyranosyl residues linked together mainly by $(1 \rightarrow 4)$ linkages but with $5 \sim 6 \%$ of $(1 \rightarrow 6)$ bonds at the branch points (Buléon et al., 1998a). Amylopectin is one of the largest polymers in the nature, with a $\mathrm{M}_{\mathrm{r}}$ (weight average molecular weight) of the order $10^{7} \sim 10^{9}$ (Aberle et al., 1994). Some general characteristics of amylopectin are listed in Table 2-4. The average size of the repeating unit chains of amylopectin is in the range of 20-25 (Hizukuri, 1985). 
Extensive studies have been carried out on amylopoectin structure in terms of molecular size, branch chain length (inner and outer) distribution, location of branch points, and crystallinity by various techniques, such as chemical and enzymatic analysis including chromatography, matrixassisted laser desorption/ionization mass spectrometry (MALDI-MS), fluorophore-assisted carbohydrate electrophoresis (FACE) (Broberg et al., 2000; Wang et al., 2000; Morell et al., 1998; Hizukuri, 1996; Morrison and Karkalas, 1990; Manners, 1989), optical and electron microscopy (Gallant et al., 1997; French, 1984), nuclear magnetic resonance (NMR) spectroscopy (Gidley, 2001; Morgan et al., 1995; Gidley and Bociek, 1985), and X-ray and neutron scattering (Donald et al., 1997, 2001). A number of reviews on amylopectin structure have been published (Gidley, 2001; Tester et al., 2001; Gallant, 1997; Oates, 1997; Hizukuri, 1996; Ball et al., 1996; Gidley and Cooke, 1991; Imberty et al., 1991; Manners, 1989; Zobel, 1988a, 1992; Sarko and Zugenmaier, 1980; Banks and Greenwood, 1975).

\subsection{Structural model}

It is now widely accepted that amylopectin is structured in a cluster model (Fig. 2-7). Three types of unit chains are present, referred to as A-, B-and C-chains. A-chains are unbranched and linked to B- chains through $\alpha-1,6$-bonds at their reducing end-group. B-chains are linked to other B-chains or $\mathrm{C}$ - chain in the same manner, carrying either A-chains or B-chains. C-chains is the only chain with a reducing end-group and carrying numerous B-chains. A- chains form crystalline lamellae and their $\alpha-(1,6)-$ branch points are located in amorphous lamellae. Some B-chains are long enough to traverse through both the semi-crystalline growth ring and the inter-crystalline amorphous growth ring.

The ratio of A-chains to B-chains, which is also referred to as the degree of multiple branching, is an important parameter. Manner and Matheson (1981) have shown the A:B ratio to be 0.8 
Figure 2- 6 One possible mechanism to explain the disruption of amylopectin double helical packing by amylose.
(A) Amylopectin structure with no amylose present. Small crystalline lamella size.
(B) Co-crystallizing between amylose and amylopectin pulls a number of the amylopectin chains out of register. The crystalline lamella size increases.
Source: Jenkins and Donald (1995), reproduced with permission. 


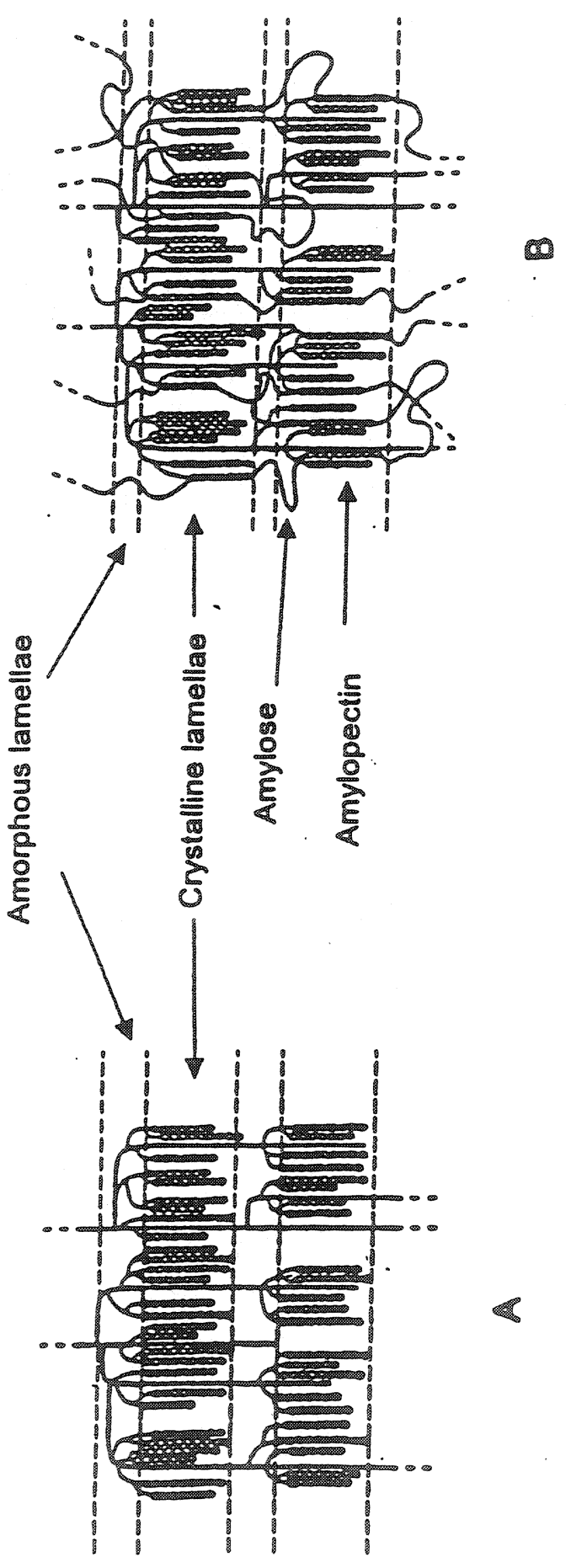


Figure $2-7$ Cluster structure of amylopectin showing growth rings and areas for amorphous and crystalline lamellae formation.

$\mathrm{AL}$, amorphous lamellae; CL, crystalline lamellae; SCGR, semi-crystalline growth ring; ICAGR, inter-crystalline amorphous growth ring. Source: French (1984), reproduced with permission. 


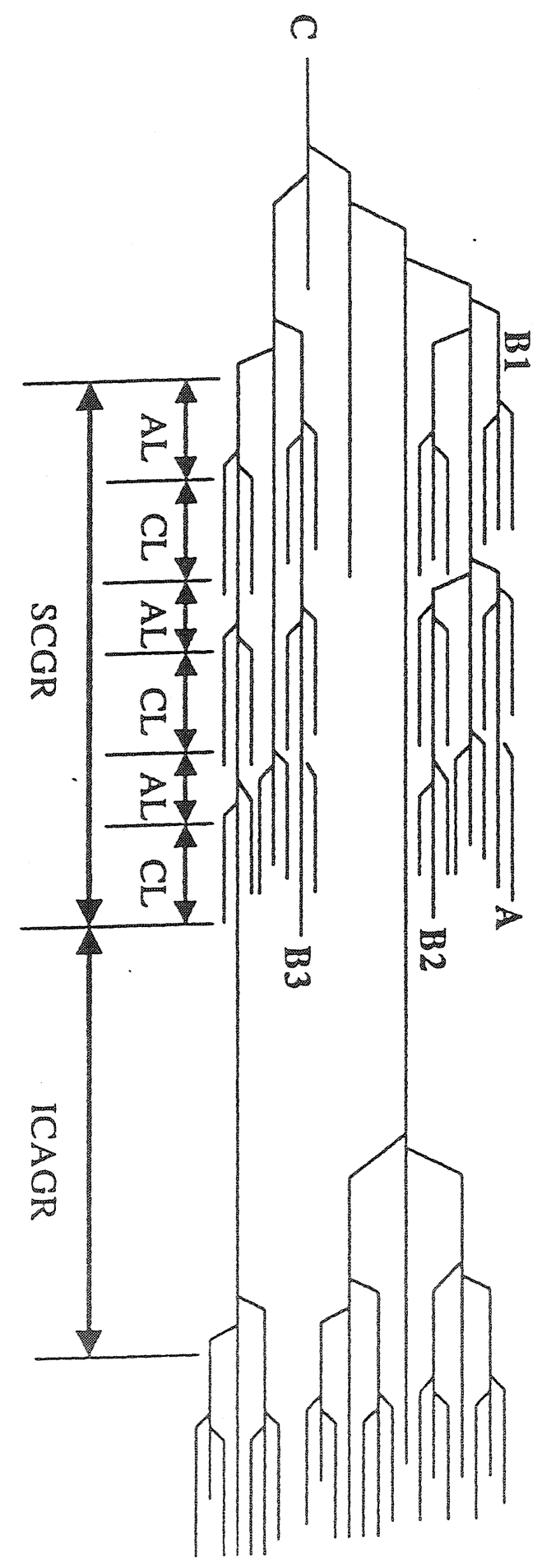


-2.2 on a mole basis and $0.4-1.0$ on a weight basis. Manners (1989) reported A:B ratios ranging from 1.1 to 1.5 , with potato amylopectin at 1.2 , whereas Hizukuri (1985) reported a $0.8 \mathrm{~A}: \mathrm{B}$ ratio on potato amylopectin. This discrepancy may be due to experimental errors or the different methods used. In general, amylopectins have rather more A-chains than B-chains, with ratios ranging from 1.1:1 to 1.5:1 (Manners, 1989).

\subsection{Chain length distribution}

To determine its chain length distribution, amylopectin is first subjected to the action of debranching enzymes (e.g. isoamylase and pullulanase, which specifically hydrolyze the branch linkages and produce short linear chains), followed by separation techniques to determine the molecular weight distribution. (size exclusion chromatography) SEC (Hizukuri, 1985, 1986) and highperformance anion-exchange chromatography with pulsed amperometric detection (APAE-PAD) (Hizukuri, 1986; Hanashiro et al., 1996; Wong and Jane, 1997) are the two basic techniques.

Extensive research has been done to study the chain length profile of amylopectin from different starch sources, such as maize (Takeda et al., 1988; Jane et al., 1999), barley (Tang et al., 2001a, b; Song and Jane, 2000; Jane et al., 1999; Yoshimoto et al., 2000, 2002; MacGregor and Morgan, 1984), rice (Jane et al., 1999; Hanashiro et al., 1996; Takeda et al., 1987b), wheat (Jane et al., 1999; Shibanuma et al., 1994; Franco et al., 2002; Hizukuri and Maehara, 1990), tapioca (Jane et al., 1999), sweet potato (Hanashito et al., 1996; McPherson and Jane, 1999) and legumes (Biliaderis, 1982b; Biliaderis et al., 1981; Ratnayake et al., 2001; Yoshimoto et al., 2001). The resulting chromatography showed that debranched amylopectin usually exhibits a trimodal or polymodal distribution pattern. 
Figure 2 -8 Gel-permeation chromatograms of debranched amylopectins.

Fractions of $A, B_{1}, B_{2}, B_{3}, B_{4}$ and ELC (extra-long chain) are different groups of branch chains. The peak DP (degree of polymerization) is labeled on the top of each fraction.

Source: Hizukuri (1996), reproduced with permission. 


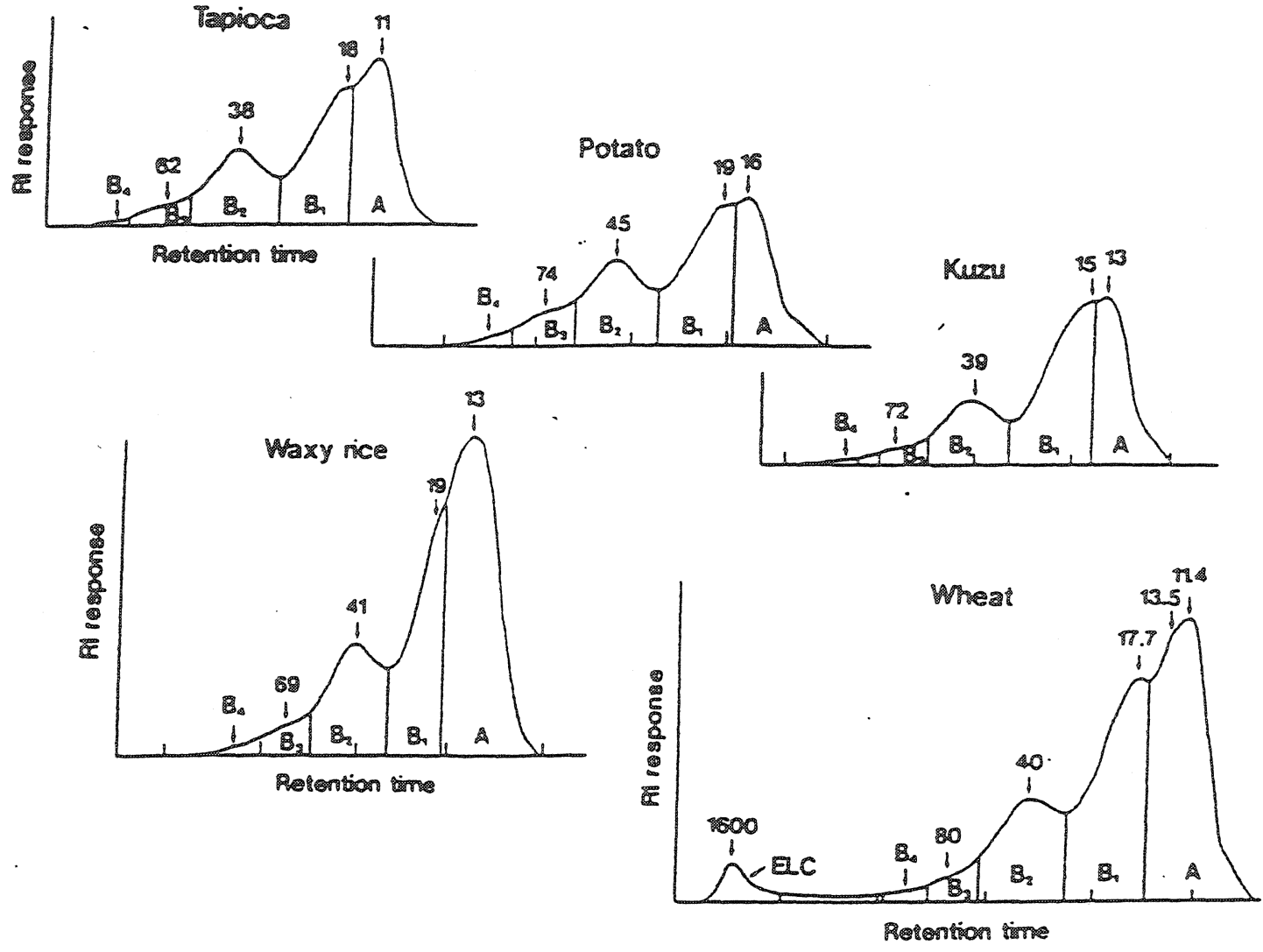


A polymodal distribution (Fig. 2-8) shows 5 fractions, $A, B_{1}, B_{2}, B_{3}$ and $B_{4}$, representing different chain groups of the amylopectin molecule with average chain lengths (CL) of 11-16, 20-24, 42-48, and $69-75$, respectively. The relative lengths among $B_{1}, B_{2}$ and $B_{3}$ are roughly $1: 2: 3$, implying that the $A$ and $B_{1}, B_{2}, B_{3}$ and $B_{4}$ chains may be involved in the formation of one, two, three, and more than four clusters (Hizukuri, 1996). The A- and $\mathrm{B}_{1}$ - chains account for $80-90 \%$ (mole basis) of total chains, which represent outer short chains in a single molecule, and $\mathrm{B}_{2}-$ chains $10 \%, \mathrm{~B}_{3}$-chains $1-3 \%$, and $\mathrm{B}_{4}-$ chains $0.1-0.6 \%$, which connect 2, 3 or more clusters (Hizukuri, 1986). Further analysis of the connection mode of branching (Hizukuri and Maehara, 1990; Hizukuri, 1996) indicated that the average span length (the number of glucose units linked through two adjacent branch points in a chain) is in the range of 3-12 and one B-chain carries 0-3 A- or other B-chains while $37 \%$ of B-chains have no A-chains and carry only B-chains. In general, the average $\mathrm{CL}$ for most amylopectins is in the range of 18-25, but its distribution is characteristic of starch sources. A-type starches have shorter peak DP and shorter average chain length than B- type starches. Also, A-type starches have relatively higher proportions of short chains (DP 6-12) than B-type starches and C-type starches have an intermediate amount. In addition, amylopectin from amylomaize starches have relatively longer average chain length and a higher proportion of long chains $(\mathrm{DP} \geq 37)$ compared to those from waxy and normal maize starches (Jane and Chen, 1992; Shi et al., 1998; Jane et al., 1999). Branch chain length distribution of amylopectin has been shown to influence starch physicochemical properties such as gelatinization temperature, pasting properties, retrogradation and acid hydrolysis (Franco et al., 2002; Jane et al., 1999; McPherson and Jane, 1999; Shi et al., 1998; Shi and Seib, 1992, 1995; Jane and Chen, 1992). Table 2-6 summarizes the average chain length of amylopectin from some legume starches. 


\subsubsection{Double helices, crystallites and crystallinity}

\subsection{Double helices}

Double helices are formed between the outer branch chains ( $A$ - and $B_{1}$ - chains) of amylopectin (French, 1972). This can occur either between adjacent branch chains in the same amylopectin branch cluster or between adjacent clusters in three dimensions (Oates, 1997). Two neighboring short chains fit together compactly with the hydrophobic parts of the opposed glucose units in close contact inside the structure, and the hydroxyl groups at the outside of the double helix, for strong interchain hydrogen bonding (helical order or short range order). French and Murphy (1977) proposed the first detailed computer model (Fig. 2-9) for a starch double helix with no intra-chain hydrogen bonds. The stability of the helix is attained by interchain hydrogen bonding between hydroxyl groups at positions $\mathrm{C} 2$ and C6 and from van der Waals forces. The helical core is highly hydrophobic and compact so that there is no room for water or any other molecule to reside within it. Within starch granules, about $40-50 \%$ of the weight of starch chains exists in the form of double helices, with approximately half of these helical chains present in crystallites large and perfect enough to diffract X-rays (Gidley, 2001; Gidley and Bociek, 1985). The water content of starch granules has been shown to influence the content of double helices (Paris et al., 1999; Bogracheva et al., 2001). Bogracheva et al.(2001) used ${ }^{13} \mathrm{C}$ crosspolarization magnetic angle spinning NMR to study the ordered and disordered structures of selected starches from different genotypes by measuring the content of double helices at different degrees of hydration (Table 2-7). They found water contents in the 10-50\% range did not influence the proportion of double helices in the starch. Decreasing the water content to $1-3 \%$ resulted in a significant decrease in the proportion of double helices, with the effect being greater in B- than in Atype starches. 
Table 2-6

Average chain length of isolated legume amylopectins

\begin{tabular}{|c|c|c|}
\hline Starch Source & Average Chain Length & Reference \\
\hline Adzuki bean & 21 & \multirow[t]{4}{*}{ Yoshimoto et al., 2001} \\
\hline Adzuki bean & $25-26$ & \\
\hline Garbanzo bean & 22 & \\
\hline Red kidney bean & 20 & \\
\hline Wrinkled pea & 34 & \multirow{5}{*}{ Biliaderis et al. , 1981} \\
\hline Lentil & 20 & \\
\hline Navy bean & 22 & \\
\hline Faba bean & 21 & \\
\hline Mung bean & 23 & \\
\hline \multirow[t]{2}{*}{ Smooth pea } & $22-22.4$ & Biliaderis et al., 1981; Ratnayake et al. , 2002 \\
\hline & & Yoshimoto et al., 2001 \\
\hline Pigeon pea & 27 & \\
\hline Bonavist bean & 28 & Tinay et al. , 1983 \\
\hline Chick pea & 29 & \\
\hline Chick pea (BG) & 26 & Madhusudhan and Tharanathan, 1996 \\
\hline
\end{tabular}


Table 2 - 7

Comparison of short-range order in starches with moderate and low water contents

\begin{tabular}{|c|c|c|c|c|}
\hline \multirow[t]{2}{*}{ Starch } & \multirow[t]{2}{*}{ Starch Type } & \multicolumn{2}{|c|}{$\begin{array}{l}\text { \% Proportion of Double Helices at Different Water } \\
\text { Content(\%) }\end{array}$} & \multirow{2}{*}{$\begin{array}{l}\text { Reduction in the Proportion of Double } \\
\text { Helices after Drying, \% }\end{array}$} \\
\hline & & Moderate & Low & \\
\hline Potato & $B$ & $48.3(15.2)^{a}$ & $23.4(2.6)$ & 51.6 \\
\hline Waxy potato & B & $50.9(13.5)$ & $24.5(2.0)$ & 51.9 \\
\hline Pea & $\mathrm{C}$ & $39.7(13.3)$ & $24.6(1.9)$ & 38.0 \\
\hline Low amylose pea & C & $48.6(12.7)$ & No data & No data \\
\hline Maize & $A$ & $37.7(12.3)$ & $29.9(0.5)$ & 20.7 \\
\hline Waxy maize & $\mathrm{A}$ & $46.1(12.2)$ & $34.3(0.5)$ & 25.6 \\
\hline Wheat & A & $31.5(11.4)$ & $23.7(2.8)$ & 24.8 \\
\hline
\end{tabular}

a. Moisture content(\%)

Adapted from Bogracheva et al. (2001) 
Figure 2-9 Double helix model of starch chain

Source: French and Murphy (1977), reproduced with permission. 


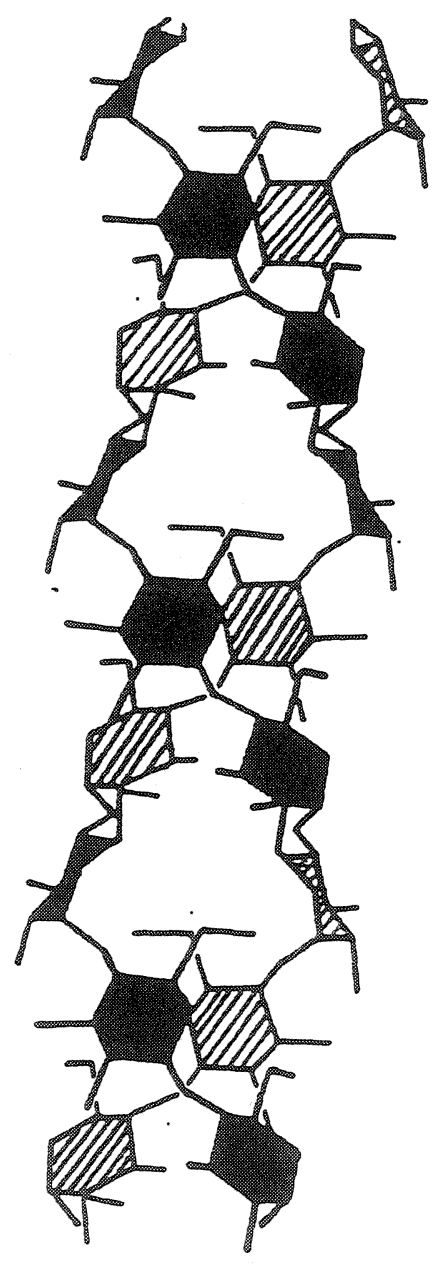




\subsection{Crystallites and polymorphic patterns}

Crystallites are formed by double helices which associate in pairs, nest together, and are stabilized by hydrogen and van der Waals forces (Oates, 1997). Three types of crystallite are known depending on the water content and the packing configuration of double helices, namely $\mathrm{A}, \mathrm{B}$, and $\mathrm{C}$ type. C type is a mixture of A and B type (Sarko and Wu, 1978; Blanshard, 1987; Gernat et al., 1990, 1993).

The structural models of A and B type crystallites have been developed and extensively reviewed (Wu and Sarko, 1978a, b; Imberty and Pérez, 1988; Imberty et al., 1988, 1991). One early model proposed by Wu and Sarko (1978a,b) is illustrated in Fig. 2-10. Both A and B type crystallite are based on parallel-stranded, right-handed double helices. The helices pack in antiparallel fashion into an orthorhombic unit cell in A type and a hexagonal unit cell in B type. Both unit cells contain twelve glucose residues. However, the B type crystallite has a more open packing structure than A type, and there are thirty six water molecules in its unit cell, whereas A type accommodates only eight water molecules. This model has been constantly reviewed and updated by other researchers. The most recent model described a face-centered monoclinic unit for the A-type crystallite instead of orthorhombic, and the helices are suggested to be left-handed instead of right-handed. Table 2-8 summarizes the structural features of A and B type crystallite unit cell.

The polymorphic patterns of starch granules can be distinguished by X-ray diffraction. Starches exhibit three types of diffraction patterns corresponding to their crystalline types (Fig. 2-11). A type appears in most cereal starches (normal maize, rice, wheat, barley, oats) and some root and tuber starches (taro, some sweet potatoes, tapioca, iris) (Zobel, 1988b; Cheetham and Tao, 1998; Hizukuri, 1996; Hoover, 2001). B type appears in tuber and root starches (potato, lily, cassava, tulip) as well as in high amylose $(>40 \%)$ cereal starches (amylomaize, high-amylose barley, high-amylose rice) 
(Zobel, 1988b; Hizukuri, 1996; Cheetham and Tao, 1998). The C-type, which is commonly observed in legume starches, is considered to be a mixture of A and B type in various proportions (Sarko and Wu, 1978; Blanshard, 1987; Gernat et al., 1990, 1993; Hoover and Sosulski, 1991). In addition to these three types of diffraction pattern, another pattern called ' $\mathrm{V}$ ' type was also reported, which is mainly exhibited by crystalline amylose helical inclusion compounds (Eliasson and Gudmundsson, 1996; Blanshard, 1987).

The main differences between the A and B type polymorphs are as follows: (1) packing arrangement of double helices and water content (Wu and Sarko, 1978a, b; Imberty and Pérez, 1988; Imberty et al., 1988, 1991); see Fig. 2-10 and Table 2-8; (2) Chain length of amylopectin (Hizukuri, 1985, 1996; Gidley and Bulpin, 1987; Gidley and Cooke, 1991; Pfannemüeller, 1987; Hanashiro et al., 1996). A type usually has a shorter average chain length, DP23 - 29; B type has a longer average chain length, DP30 - 44 (Gernat et al., 1993); C type displays intermediate chain length, DP26 - 36 (Hizukuri et al., 1983; Hizukuri, 1985). The difference in the average chain length between A type and B type starches can be as small as one glucose unit (Hanashiro et al., 1996). (3) Branching pattern (Jane et al., 1997). In A type amylopectin, the $\alpha-1,6$ branch linkages are more scattered and mainly located within the crystalline region (crystalline lamellae), whereas others are in the amorphous region (amorphous lamellae). In B type amylopectin, most of the $\alpha-1,6$ branch linkages are clustered in the amorphous region (Fig. 2-12). In A type amylopectin, due to the scattered branch points, there are likely more short A chains derived from branch linkages located inside the crystalline region, which produces an inferior crystalline structure containing $\alpha-1,6$ branch linkages and short double helices which is more susceptible to enzyme hydrolysis. Clustered branch points and relatively fewer short chains in B type amylopectin lead to the development of a superior crystalline structure, which is more resistant to enzyme attack. Additionally, other factors such as environmental temperature, the presence 
of certain solutes and solvents (anions and cations), and organic molecules (alcohol, lipid) were also reported to influence starch polymorphism, but play no decisive roles (Hizukuri, 1996; Gidley, 1987).

Unlike A and B type polymorphs, which are considered to be independent from each other, C type is a mixture of A and B type in various proportions. It is still not fully understood how C type starch granules are structured. For instance, are the A and B polymorphs distributed in different granules or do they coexist within the same granule? If the two types occur within the same granule, where are they located? From the results of X-ray wide-angle scattering patterns of legume starches, Gernat et al. (1990) suggested the legume starches consist of starch granules of pure A type as well as of pure B type in varying proportions. However, other researchers (Bogracheva et al., 1998; Buléon et al., 1998b) found that all C type starch granules contain both A and B type polymorphs, instead of a mixture of pure A and B type granules. The B polymorph is present in the center of the granule and is surrounded by the A polymorph.

\subsection{Crystallinity}

Starch granules exhibit an optical birefringence pattern known as a 'Maltese cross' when viewed under polarized light, which implies that there is a high degree of molecular order within the granule (Greenwood, 1979). In fact, starch is semi-crystalline with varying polymorphic types and degree of crystallinity. The crystallinity of native starch granules usually ranges from 15 to $45 \%$ (Zobel, 1988a) (Table 2-9).

The crystallinity is exclusively associated with the amylopectin component, as crystalline lamellae are formed by tightly packed double helices of amylopectin. Cheetham and Tao (1998) have shown that the degree of starch crystallinity decreased with an increase in amylose content and 
Figure 2-10 Packing arrangement of double helices of A and B type crystallite unit cell

Source: Wu and Sarko (1978a, b), reproduced with permission. 


\section{A-type}
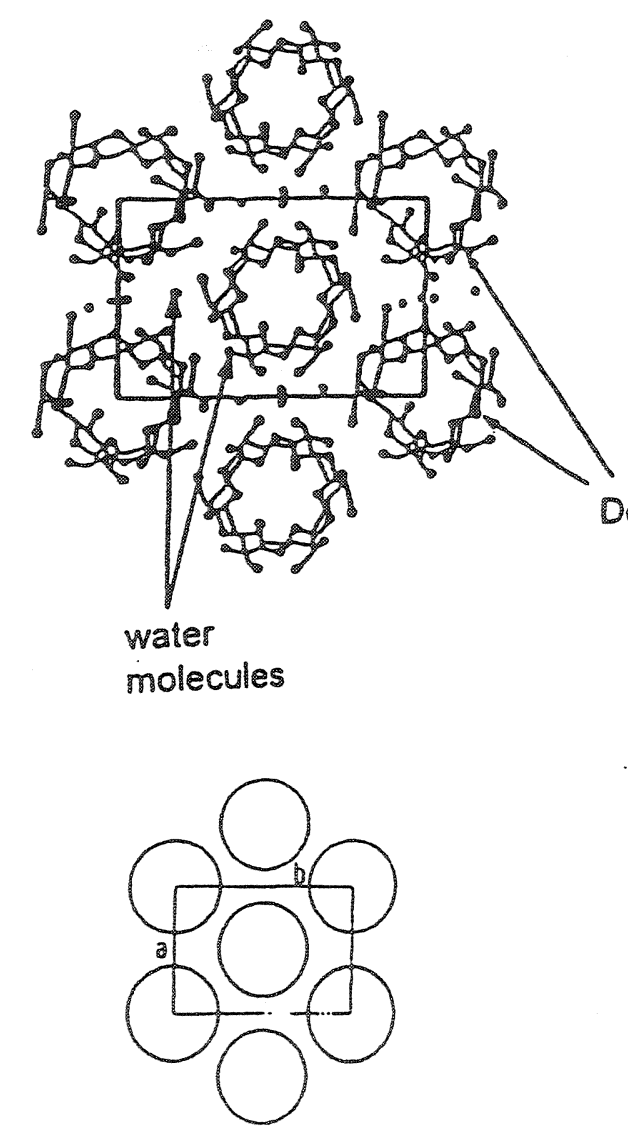

B-type

moler

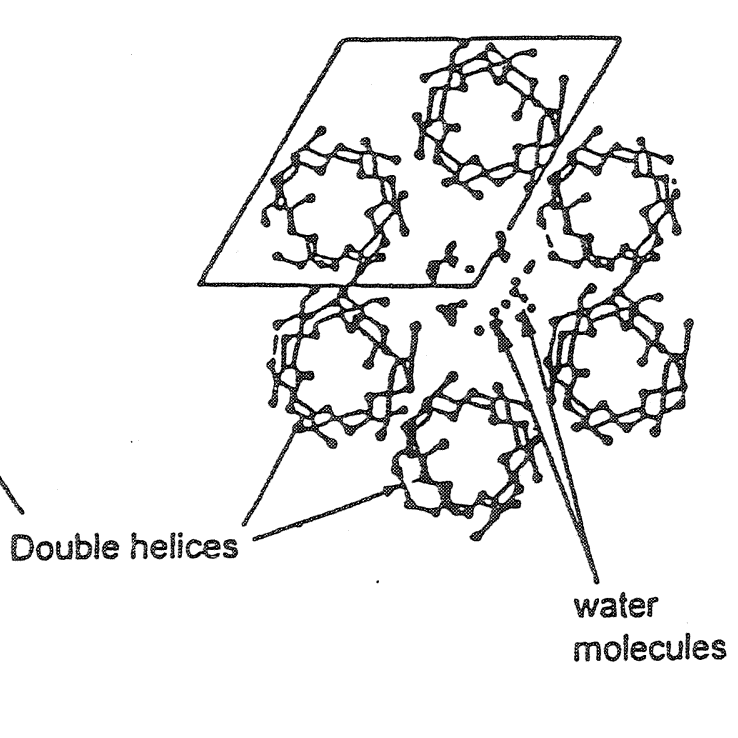

Double helices

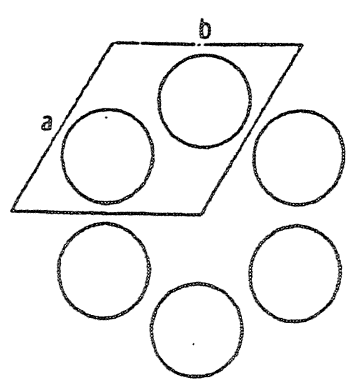


Figure 2-11 X-ray diffraction patterns of A, B, and C type starches with their characteristic d-spacing A type: shows strong peaks at $2 \theta 15.27^{\circ}$ or with a inter-crystalline spacing $d=5.8$ $\AA$ and $23.40^{\circ}(\mathrm{d}=3.8 \AA)$, and an incomplete doublet at $2017.05^{\circ}(\mathrm{d}=5.2 \AA)$ and $18.1^{\circ}(\mathrm{d}=4.9 \AA)$. The $\mathrm{d}$-spacing at $4.4 \AA$ is characteristic to amylose-lipid complex (Vasanthan and Bhatty, 1996).

B type: shows a peak at $2 \theta 5.52-5.6^{\circ}(\mathrm{d}=15.8-16.0 \AA)$, a broad medium intensity peak at $2 \theta 15.01^{\circ}(\mathrm{d}=5.9 \AA)$, the strongest peak at $2 \theta 17.05^{\circ}(\mathrm{d}=5.2 \AA)$ and medium intensity peaks at $19.72^{\circ}(\mathrm{d}=4.5 \AA), 22.22^{\circ}(\mathrm{d}=4.0 \AA)$ and $24.04^{\circ}(\mathrm{d}-$ 3.7 $\AA)$. There is a peak at $2 \theta 5^{\circ}(\mathrm{d}=17.70 \AA)$ which is characteristic to B pattern. C type: shows the same pattern as A type except the occurrence of the medium to strong peak at about $2 \theta 5.52^{\circ}(\mathrm{d}=16.0 \AA)$ Source: Zobel (1988b), reproduced with permission. 


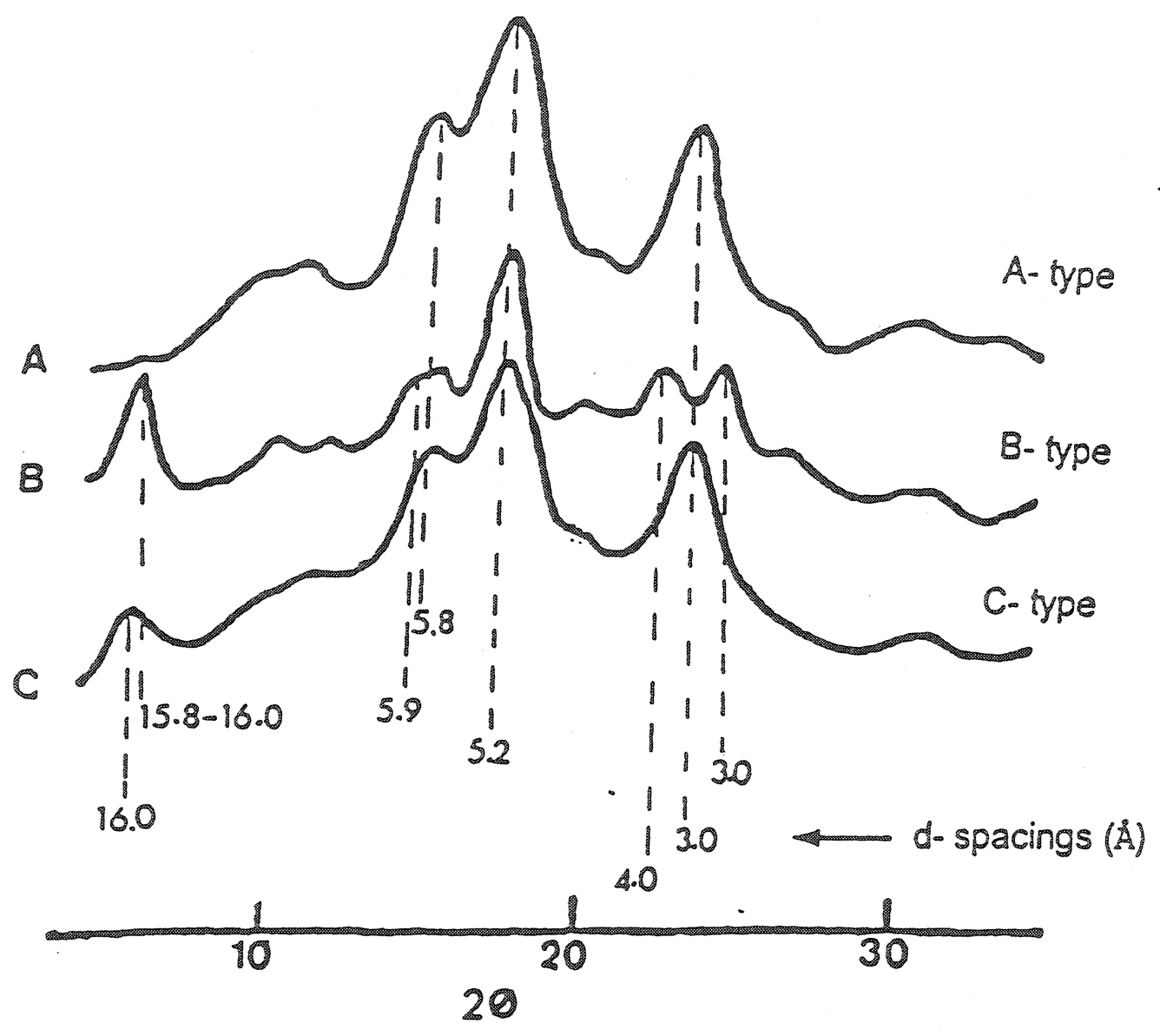


Figure 2-12 Proposed models for branching patterns of A type (waxy maize) and B type (potato) amylopectin.

$9.0 \mathrm{~nm}$ and $9.2 \mathrm{~nm}$ are the repeating distances of waxy maize and potato starches, respectively. The chain length between arrows stands for the length of internal long B- chains

Source: Jane et al. (1997), reproduced with permission. 
A - type amylopectin

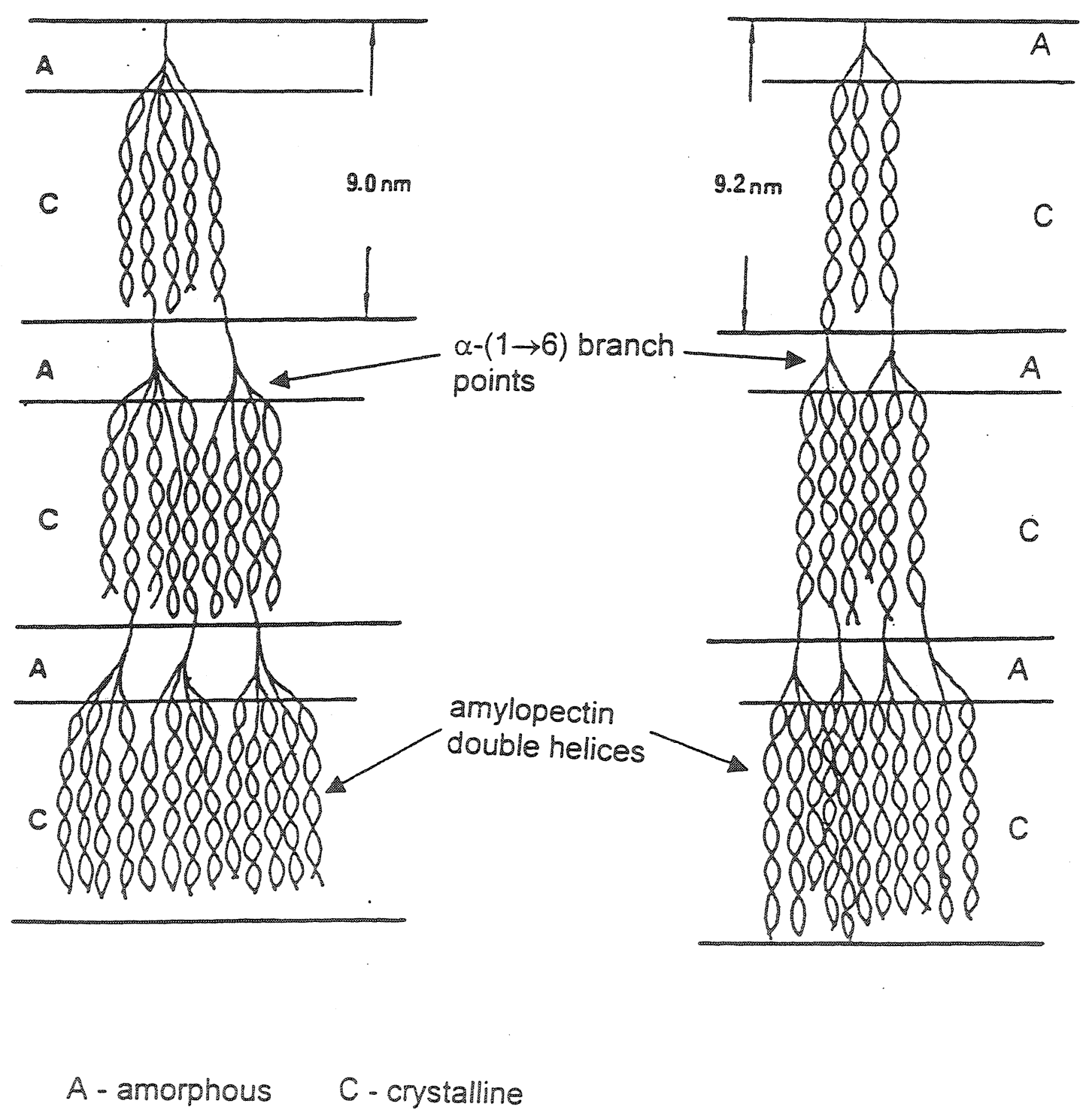

B - type amylopectin 
Table 2 - 8

Structures of 'A' and 'B' type crystalline unit cells

\begin{tabular}{lll}
\hline Parameter & A type & B type \\
\hline Dimension $(\mathrm{nm})$ & $a=2.124$ & $a=1.85$ \\
& $b=1.172$ & $b=1.85$ \\
& $c=1.069$ & $c=1.04$ \\
& $\gamma=123.5^{\circ}$ & \\
Density & $d=1.48$ & \\
Repeat unit & Maltotriose & Maltose \\
Space group & $\mathrm{B}_{2}$ & P6 \\
Geometry & Monoclinic & Hexagonal \\
Glucose residues & 12 & 12 \\
Water content & 4 & 36 \\
Conformation of double helices & Left-handed, double-stranded & Left-handed, double-stranded \\
\hline
\end{tabular}

Source: Imberty et al. (1991), Oates (1997) 
Table 2 - 9

Crystallinity of $A, B$, and $C$ starches

\begin{tabular}{|c|c|c|c|}
\hline Starch & Crystallinity (\%) & Amylose (\%) & Reference \\
\hline \multicolumn{4}{|c|}{ Starches with A structure } \\
\hline Oat & 33 & 23 & Zobel (1988a) \\
\hline Rye & 34 & 26 & $"$ \\
\hline Wheat & 36 & 23 & $"$ \\
\hline Waxy rice & 37 & - & $"$ \\
\hline Sorghum & 37 & 25 & $"$ \\
\hline Rice & 38 & 17 & $"$ \\
\hline Corn & 40 & 27 & $"$ \\
\hline Waxy maize & 40 & 0 & $"$ \\
\hline Dasheen & 45 & 16 & $"$ \\
\hline Nägeli amylodextrin & 48 & - & Zobel (1988a) \\
\hline \multicolumn{4}{|c|}{ Starches with B structure } \\
\hline Amylomaize & $15-22$ & $55-75$ & $"$ \\
\hline Edible canna & 26 & 28 & $"$ \\
\hline Potato & 28 & 22 & $"$ \\
\hline \multicolumn{4}{|c|}{ Starches with $\mathrm{C}$ structure } \\
\hline Sweet potato & 38 & 20 & $"$ \\
\hline Horse chestnut & 37 & 25 & $"$ \\
\hline Tapioca & 38 & 18 & Zobel (1988a) \\
\hline Smooth pea & $26-32$ & $30-43$ & Davydova et al. (1995) \\
\hline Field pea & $20-25$ & $42-44$ & Ratnayake et al. (2001) \\
\hline
\end{tabular}


amylopectin chain length, and it appeared to be directly proportional to the mole percent of the short chain amylopectin fraction with DP10 - 13.

Granule moisture content is another aspect related to crystallinity, but it does not affect crystal type (Cheetham and Tao, 1998). It has been reported that hydrated starches exhibited a significant increase in peak resolution and intensity of the X-ray diffractogram (Hizukuri et al., 1964; Nara et al., 1978; Buléon et al., 1982, 1987; Veregin et al., 1986; Hibi et al., 1993). Peak areas at 5.5 and $25.5^{\circ}$ in X-ray diffractograms were reported to be quite sensitive to variations in moisture content (Blanshard, 1987).

The crystallinity of starch granules can be destroyed by mechanical disruptions such as ball milling or by subjecting to high pressure at room temperature which will eventually completely destroy both the optical birefringence and the X-ray patterns (Lineback, 1984; Baldwin et al., 1994).

\subsection{Starch properties}

\subsubsection{Gelatinization}

Gelatinization is the collapse (disruption) of molecular orders within the starch granule manifested in irreversible changes in properties such as granular swelling, native crystallite melting, loss of birefringence, and starch solubilization. The point of initial gelatinization and the range over

which it occurs is governed by starch concentration, method of observation, granule type, and heterogenities within the granule population under observation (Atwell et al., 1988).

Granular starch is essentially insoluble in cold water, and even when it is added to water at room temperature, little happens until heat is applied. A combination of heat and water, however, causes uncooked granules to undergo unique and irreversible changes as mentioned above, the most dramatic of which are (1) the disruption of the semi-crystalline structure, as evidenced by a loss of 
birefringence; and (2) an increase in granule size, although not all granules within a given population swell at the same rate or to the same extent. As these changes are taking place, there is an attendant increase in the viscosity of the medium in which the starch is heated. When a majority of the granules have undergone this process, the starch is considered to be "pasted" or "cooked-out". In most cases, it is this pasting (i.e., viscosity-forming) ability that makes starch so functional as a food ingredient.

Various methods have been used to characterize starch gelatinization, such as polarized light microscope, Kofler hot stage microscopy, X-ray diffraction, differential scanning calorimetry (DSC), viscoamylography, NMR spectroscopy, enzymatic digestibility, and small-angle light scattering. Because not all the granules of a given starch, when subjected to water and heat, begin to gelatinize at exact by the same temperature, the gelatinization temperature is more approximately defined as a relatively narrow temperature range rather than one specific temperature. Gelatinization temperatures also vary depending on the source of the starch. In general, the gelatinization temperature of tuber and root starches such as potato and tapioca is slightly lower than that of cereal starches such as corn and wheat. The gelatinization parameters of legume starches are summarized in Table 2-10. DSC is widely used to estimate the gelatinization parameters (onset temperature $T_{0}$, peak temperature $T_{p}$, conclusion temperature $T_{c}$, gelatinization temperature range $T_{c}-T_{0}$, and gelatinization enthalpy $\left.\Delta H\right)$. Noda et al. (1996) have postulated that DSC parameters are influenced by the molecular architecture of the crystalline region, which corresponds to the distribution of amylopectin short chains (DP6 - 11), and not by the proportion of crystalline region which corresponds to the amylose to amylopectin ratio. The above authors have shown by studies on sweet potato and wheat starches, that a low $T_{0}, T_{p}, T_{c}$ and $\Delta H$ reflects the presence of abundant short amylopectin chains. Cooke and Gidley (1992) have shown $\left({ }^{13} \mathrm{C}-\mathrm{CP}-\mathrm{MAS}-\mathrm{NMR}\right.$ and $\mathrm{X}$-ray diffraction) that the enthalpy of transition is primarily due to the loss 
Table $2-10$

Thermal characteristics of legume starches (DSC parameters)

\begin{tabular}{|c|c|c|c|c|c|}
\hline Starch Source & $\mathrm{T}_{0}\left({ }^{\circ} \mathrm{C}\right)$ & $T_{p}\left({ }^{\circ} \mathrm{C}\right)$ & $\mathrm{T}_{c}\left({ }^{\circ} \mathrm{C}\right)$ & Unspecified $\left({ }^{\circ} \mathrm{C}\right)$ & $\Delta H(J / g)$ \\
\hline Kidney bean ${ }^{a}$ & $62-67$ & $70-73$ & $76-79$ & - & 15.0 \\
\hline Northern bean ${ }^{a}$ & 63 & 66 & 70 & - & 12.5 \\
\hline Navy bean ${ }^{a}$ & 64 & 68 & 71 & - & 13.4 \\
\hline Navy bean ${ }^{c}$ & $65.6-66.0$ & $74.4-75.1$ & $84.8-85.0$ & - & $13.2-13.5$ \\
\hline Navy bean ${ }^{g}$ & $69.8-71.8$ & $76.1-77.5$ & $81.7-85.8$ & - & $16.3-19.9$ \\
\hline Black bean ${ }^{a}$ & 62 & 66 & 70 & - & 12.5 \\
\hline Black bean ${ }^{c}$ & $62.0-66.9$ & $69.9-76.5$ & $82.8-84.2$ & - & $12.1-12.9$ \\
\hline Pinto bean ${ }^{a}$ & 72 & 74 & 79 & - & 16.7 \\
\hline Pinto bean ${ }^{c}$ & $72.0-72.5$ & $75.0-75.5$ & $80.5-81.0$ & & $15.4-16.2$ \\
\hline Adzuki bean ${ }^{a}$ & 70 & 76 & 87 & - & - \\
\hline Smooth pea ${ }^{a}$ & $48-55$ & $61-64$ & 80 & - & 13.4 \\
\hline Smooth pea ${ }^{c}$ & $60.8-61.6$ & $66.9-67.4$ & $73.4-74.5$ & - & $10.8-13.8$ \\
\hline Wrinkle pea ${ }^{a}$ & - & - & - & $>99$ & - \\
\hline Wrinkle pea $^{d}$ & 117 & 133 & 138 & - & 12.1 \\
\hline Field pea ${ }^{b}$ & $61.0-61.4$ & $66.8-67.5$ & $75.0-76.0$ & - & $11.2-11.5$ \\
\hline Chick pea ${ }^{c}$ & $59.4-59.7$ & $64.7-67.7$ & $71.1-78.2$ & - & $9.7-12.4$ \\
\hline Cowpea $^{e}$ & 72.7 & - & - & - & 16.9 \\
\hline Lentil $^{a}$ & 47 & 57 & 77 & - & 14.2 \\
\hline Lentil $^{c}$ & $60.7-63.0$ & $66.1-69.6$ & $76.1-78.7$ & - & $12.6-13.3$ \\
\hline Lentil $^{f}$ & $52.2-56.0$ & $61.2-62.0$ & $69.0-73.0$ & - & $8.8-13.4$ \\
\hline
\end{tabular}

a. Hoover and Sosulski (1991), starch: water $=1: 2$.

b. Ratnayake et al. (2001), starch: water $=1: 3$.

c. Hoover and Ratnayake (2002), starch : water $=1: 3$.

d. Colonna et al. (1982)

e. Chung et al. (1998)

f. Hoover and Manuel (1995)

g Srisuma et al. (1994) 
of double helical order rather than the loss of crystallinity. However, Tester and Morrison (1990) have postulated that $\Delta \mathrm{H}$ reflects the overall crystallinity (quality and amount of starch crystallites) of amylopectin. Gernat et al. (1993) have stated that the amount of double-helical order in native starches is strongly correlated to the amylopectin content, and that granule crystallinity increases with amylopectin content. This suggests that $\Delta \mathrm{H}$ values should preferably be calculated on an amylopectin basis.

\subsubsection{Mechanism of gelatinization}

According to Donovan (1979) and Jenkins and Donald (1997, 1998), gelatinization in excess water is primarily a swelling driven process. In the presence of excess water, extensive hydration and swelling of the amorphous regions are considered to "strip" starch chains from the surface of crystallites, thereby disrupting crystalline order. This swelling driven process generates the DSC endotherm (referred to as $\mathrm{G}$ ). It occurs rapidly for an individual crystallite, but over a limited temperature range for a single granule $\left(1-2^{\circ} \mathrm{C}\right)$ and a wider range $\left(10-15^{\circ} \mathrm{C}\right)$ for whole population of granules with endothermic enthalpy values in the range of $10-20 \mathrm{~J} / \mathrm{g}$ (French, 1984; Liu and Lelievre, 1993; Eliasson and Gudmundsson, 1996). When there is insufficient water present for all crystallites to be disrupted in this manner (usually defined as conditions in which a second endotherm is seen in DSC measurements) crystallites located in areas of locally high concentrations of water undergo "stripping", giving rise to the $\mathrm{G}$ endotherm; those remaining after the conclusion of this process undergo "melting" at higher temperatures, giving rise to the M1 endotherm. If the water content is reduced still further, none of the crystallites undergo the "stripping" process, and only the M1 melting endotherm is observed (Jenkins and Donald, 1998). Fig. 2-13 is an illustration of this solvation-assisted melting process. 
Based on a large amount of experimental data [DSC, SAXS, SANS, dynamic mechanical analyses (DMA), optical microscopy and NMR], Waigh et al. (2000b) established a side-chain liquidcrystalline polymer (SCLCP) model for the structure and physical properties of starch to explain the process of gelatinization. They postulated that gelatinization is due to the inter-play between selfassembly and the breakdown of structure during heating (Waigh et al., 2000a). The structural phase transitions (mesophases) can be neatly summarized by considering three order parameters: helical ordering $\left[P_{2}(\cos \theta)\right]$, the tendency of the helices to line up], lamellar ordering $(\psi$, the amplitude of a sinusoidal density modulation) and the number of helices ( $h$ ) (Landau and Lifshitz, 1958). At low water contents $(<5 \%, w / w)$ the amylopectin helices are in a glassy nematic state (Fig. 2-14a). Upon heating in a DSC a single endotherm is observed due to the helix $\rightarrow$ coil transition (Waigh et al., 2000a). Intermediate water contents $(>5 \%,<40 \%, w / w)$ have two steps in their breakdown and there are two corresponding DSC endotherms (Fig. 2-14b). The first is thought to be due to the rearrangement of dislocations between constituent amylopectin helices leading to a smectic $\rightarrow$ nematic (isotropic) transition. The second is the helix $\rightarrow$ coil transition as the amylopectin helices unwind in an irreversible manner. In excess water $(40 \%, w / w)$, lamellae break up and the helix-coil transition occurs at the same point, since free unassociated helices are unstable (Fig. 2-14c), Hydrated self-assembled starches are unable to experience swelling of the crystalline growth rings before a smectic $\rightarrow$ nematic or smectic $\rightarrow$ amorphous phase transition has taken place, because unless this self assembly has occurred it implies there is insufficient water entering the granule to provoke the swelling. The self-assembly can, therefore, be viewed as a signature of solvent ingress. 
Figure 2-13 Schematic representation of the possible interrelationships among the various parameters involved in phase transition phenomena of granular starch (solvation-assisted melting process).

Source: Biliaderis et al. (1980), reproduced with permission. 


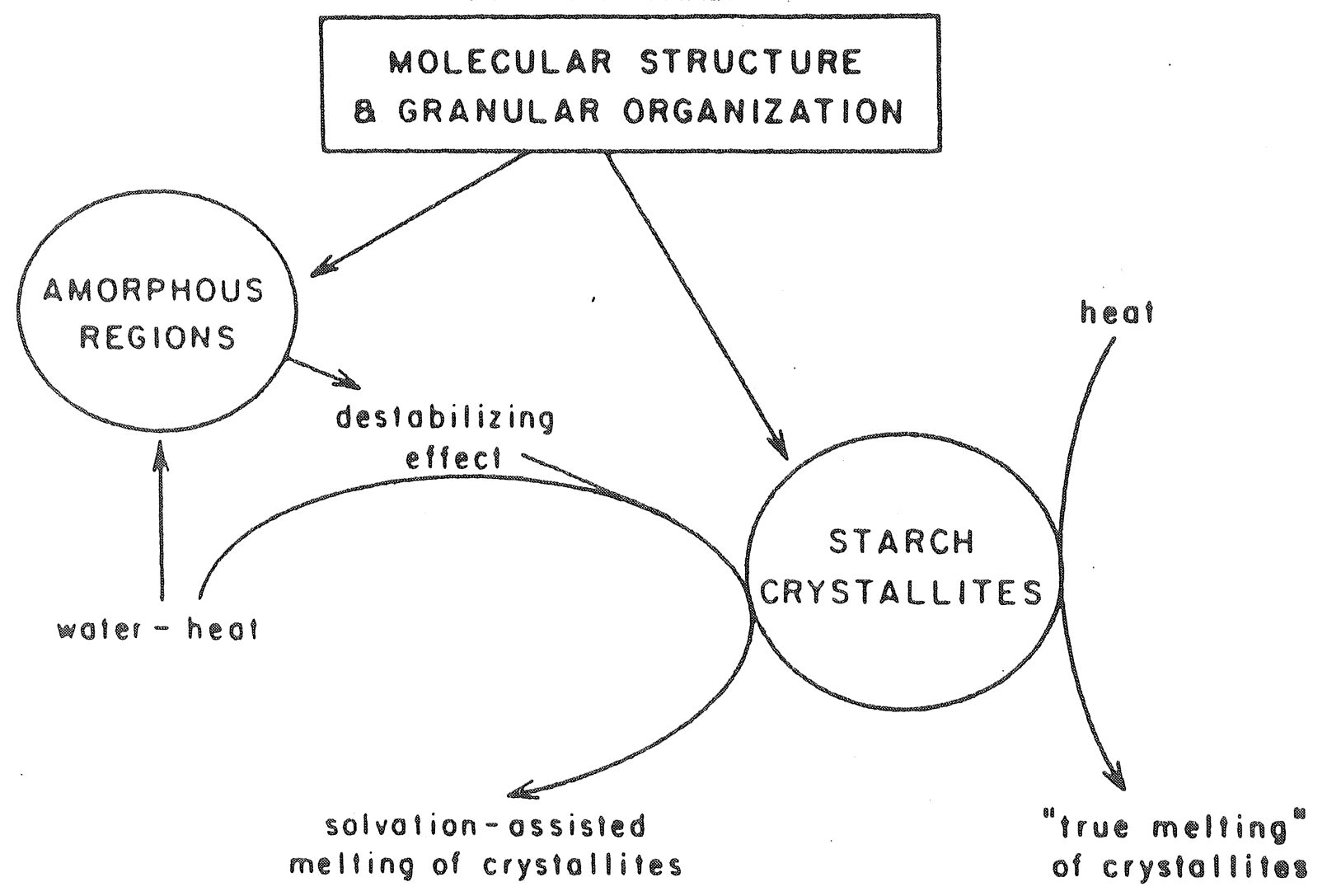


Figure 2-14 SCLCP model for starch gelatinization.

a) The single stage process in the gelatinization of starch at low water contents.

b) The two-stage process involved in the gelatinization of starch in limiting water. Two different processes are shown for $A$ and $B$ type starches: i) in B-type starch the intermediate phase is nematic in character; ii) and in A-type starch the intermediate phase is isotropic in character. It is proposed that the intermediate phase is determined by the length of the amylopectin helices.

c) The two-stage process involved in the gelatinization of starch in excess water $\left(\mathrm{T}_{\mathrm{hc}}<\mathrm{T}_{\mathrm{ss}}\right)$. The first stage involves a slow dissociation of the helices side-by-side. Immediately a helix-coil transition occurs as a secondary effect. Relative values of the orientational $(\phi)$, lamellar $(\psi)$ and helical order parameter $(\mathrm{h})$ are included. $\mathrm{T}_{\mathrm{hc}}$, temperature for the unassociated helix-coil transition of the amylopectin double helices; $\mathrm{T}_{\mathrm{sS}}$, temperature for the dissociation of helices side-by-side in their crystallites.

Source: Waigh et al. (2000a, b), reproduced with permission. 
a) Low Water Content Gelatinisation

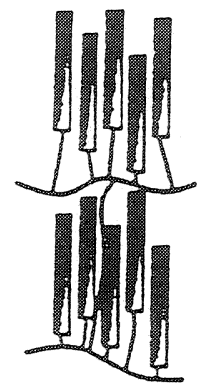

Glassy Nematic

$(b>0, w=0, h>0)$

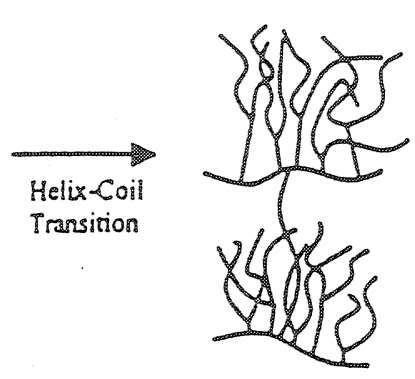

Amorphous $(\phi=0, \psi=0, h=0)$

b) Intermediate Water Content Gelatinisation.

(i)
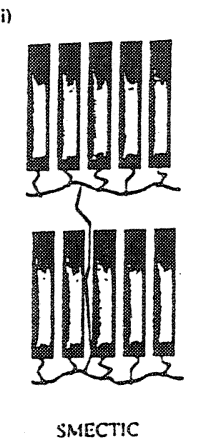

(0×). $(200 .(2>1))$

(ii)
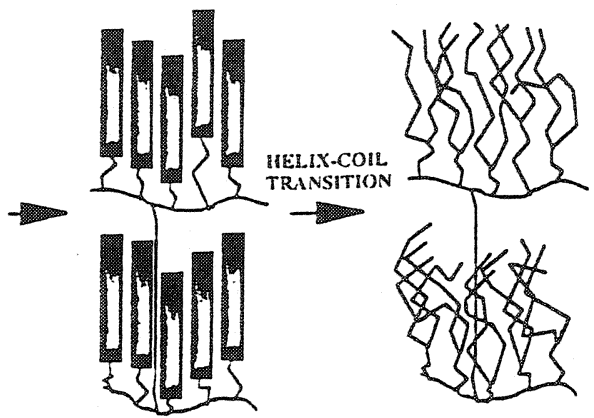

GEL $(0 \times 1), \psi=0 . h=0$ )

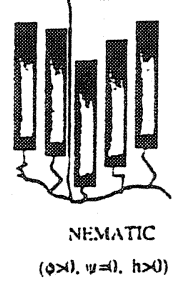

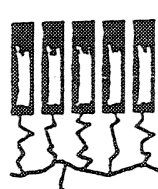

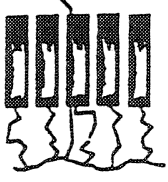

SMECTIC

$(\infty>0, \psi>0 ., 2>0)$

$>(4>x)$
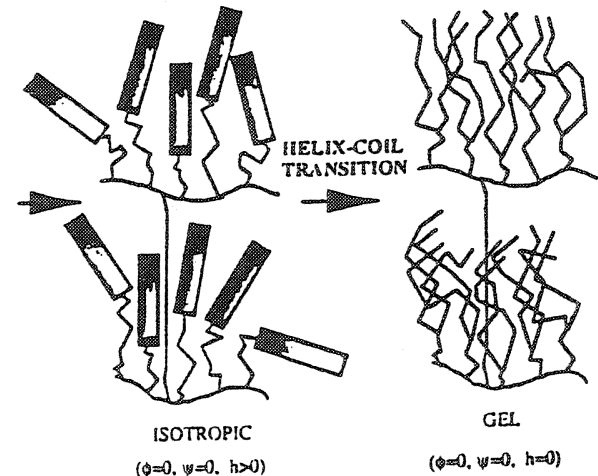

c) Excess Water Content Gelatinisation.

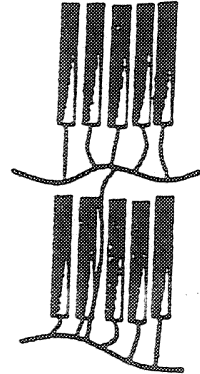

Smectic

$(\$>0, \psi>0, b>0)$

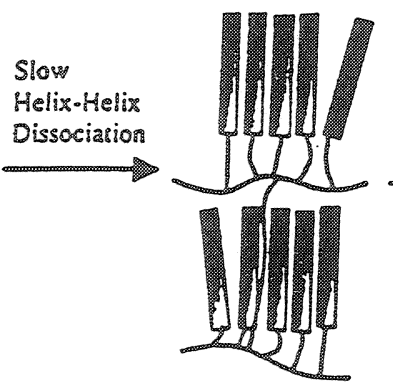

Unwisdin

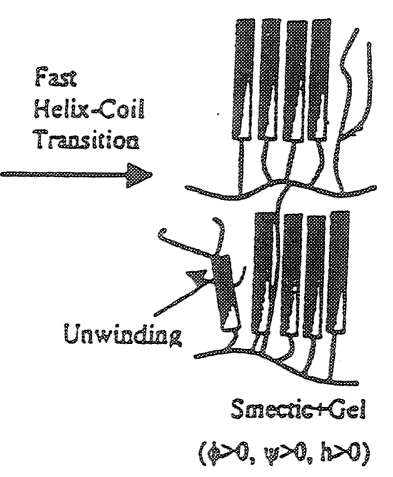




\subsubsection{Factors influencing gelatinization}

The gelatinization and swelling properties of starch are controlled in part by amylopectin structure (unit chain lengths, extent of branching, branching pattern, molecular weight, polydispersity and degree of phosphorylation), and starch composition (amylose/amylopectin ratio and lipid content) (Tester, 1997). However, besides these heritable traits, other factors can also influence starch gelatinization, e.g., solutes and solvents (sugars, salts, alcohols, lipids) (Evans and Haisman, 1982; Chiotelli et al., 2002), physical modification (annealing and heat-moisture treatment) (Hoover et al., 1993; Jacobs and Delcour, 1998; Tester and Debon, 2000), and defatting and chemical modification (acid hydrolysis, hydroxypropylation, acetylation) (Hoover et al., 1988b, 1993; Hoover, 2000; Kim and Eliasson, 1993; Atichokudomchai et al., 2002).

\subsubsection{Retrogradation}

Starch retrogradation is a process which occurs when the molecules comprising gelatinized starch begin to reassociate in an ordered structure. In its initial phase, two or more starch chains may form a simple juncture point which then may develop into more extensively ordered regions. Ultimately, under favorable conditions, a crystalline order appears (Atwell et al., 1988). The molecular interactions (mainly hydrogen bonding between starch chains) develop 'B' type crystallinity on storage (Miles et al., 1985a; Russell, 1987; Van Soest et al., 1995) regardless of the initial crystalline pattern of the native starch. This process exerts a major and usually unacceptable influence on the texture of foods rich in starch. Starch retrogradation is the main factor in the staling of bread and other baked products (Eliasson and Gudmundsson, 1996).

Common methods used to measure retrogradation include turbidity measurement (Miles et al., 1985b; Ring et al., 1987; Jacobson et al., 1997), DSC (Russell, 1987; Fredriksson et al., 1998; Hoover 
et al., 2003), rheology (I'Anson et al., 1988; Mita, 1992), X-ray diffraction (I'Anson et al., 1988), microscopy (Jacobson et al., 1997), FT/IR (Wilson et al., 1991; Van Soest et al., 1995) and NMR spectroscopy (Wu and Eads, 1993). These methods provide a variety of information about the process and products of retrogradation. X-ray diffraction gives a view of the crystalline structure of the retrograded gels, DSC is well suited to follow the rate and extent of the retrogradation, while rheological methods can be used to monitor gel firmness (rigidity) on aging.

Retrogradation proceeds in two stages (Miles et al., 1985a). In the first stage, the rigidity and crystallization of starch gels develop quickly as a result of amylose gelation and the increased mobility of the smaller size amylopectin fragments (Biliaderis, 1998; Zhang and Jackson, 1992). In the second stage, further crystallinity develops slowly in the amylopectin region (Biliaderis, 1998; Miles et al., 1985a).

Retrogradation is influenced by starch structure (Russell, 1987; Orford et al., 1987), storage temperature (Jankowski and Rha, 1986), moisture content (Longton and LeGrys, 1981; Zeleznak and Hoseney, 1986), lipids (Eliasson and Ljunger, 1988; Huang and White, 1993), sugars (Kohyama and Nishinari, 1991; Wang and Jane, 1994), salts (Ciacco and Fernandes, 1979; Bello-Perez and ParedesLopez, 1995), and physical and chemical modifications (Orford et al., 1993; Gunaratne and Hoover, 2002; Yook et al., 1993).

\section{$2.5 \alpha$-Amylolysis}

\subsection{1 $\alpha$-Amylase}

$\alpha$-amylase (E.C. 3.2.1.1) is representative of a large enzyme family (glycoside hydrolase clan GH-H) known as the $\alpha$-amylase family (Janeček 2000). It consists of twenty seven different enzyme specificities (Horváthová et al., 2000). The $\alpha$-amylase family has been defined (Takata et al. 1992) as 
a family of enzymes that: 1) catalyze hydrolysis and/or transglycosylation at the $\alpha-1,4-$ and $\alpha-1,6-$ glucosidic linkages; 2) act with the retaining mechanism with retention of the $\alpha$-anomeric configuration; 3) have four highly conserved sequence regions containing all the catalytic residues and most of the substrate binding sites; and 4) possess Asp, Glu and Asp residues as catalytic sites corresponding to Asp206, Glu230 and Asp297 of Taka-amylase A (Matsuura et al. 1984; Nakajima et al. 1986; Kuriki and Imanaka 1999).

Three-dimensional X-ray structures of some $\alpha$-amylases have been reported. These include: Aspergillus oryzae (Matsuura et al., 1984; Swift et al., 1991), A. niger (Boel et al., 1990; Brady et al., 1991), Bacillus licheniformis (Machius et al., 1995), Bacillus subtilis (Fujimoto et al., 1998), pig pancreas (Qian et al., 1993; Larson et al., 1994), human pancreas (Brayer et al., 1995), human salivary gland (Ramasubbu et al., 1996), and barley (Kadziola et al., 1994). These studies have provided the overall information about $\alpha$-amylase. Despite differences in their amino acid sequences, $\alpha$-amylases have generally similar three-dimensional structures with three domains: domain A consisting of a central $(\beta / \alpha)_{8}$-barrel flanking the active site, domain B overlaying the active site from one side, and domain $\mathrm{C}$ consisting of a $\beta$-structure with a Greek-key motif (Fig. 2-15).

One remarkable feature of $\alpha$-amylases isolated from different sources is the divergence observed in their primary sequences. For example, alignments of the sequences of animal and fungal $\alpha$-amylases has found homology on the order of only $\sim 10 \%$ between the residues present (Brayer et al., 1995). Overall, studies have found only four short segments of polypeptide chain that demonstrate reasonably good homology amongst the $\alpha$-amylases. The first of these segments is involved in binding a calcium ion, whereas the latter three each contain a putative active site residue (Boel et al., 1990; Larson et al., 1994; Qian et al., 1994). In total, these represent twenty seven amino acids out of the 
Figure 2-15 Schematic representation of the polypeptide chain fold of human pancreatic $\alpha$-amylase.

Also indicated are the relative positions of the three structural domains featured in all $\alpha$-amylases (Domain A, B, C), along with locations of the calcium and chloride binding sites. $\mathrm{N}$ and $\mathrm{C}$ indicate the terminal ends of the polypeptide chain. A central feature of this structure is the eight-stranded parallel $\beta$-barrel that forms the bulk of Domain A and is believed to contain the active site region. Source: Brayer et al. (1995), reproduced with permission. 

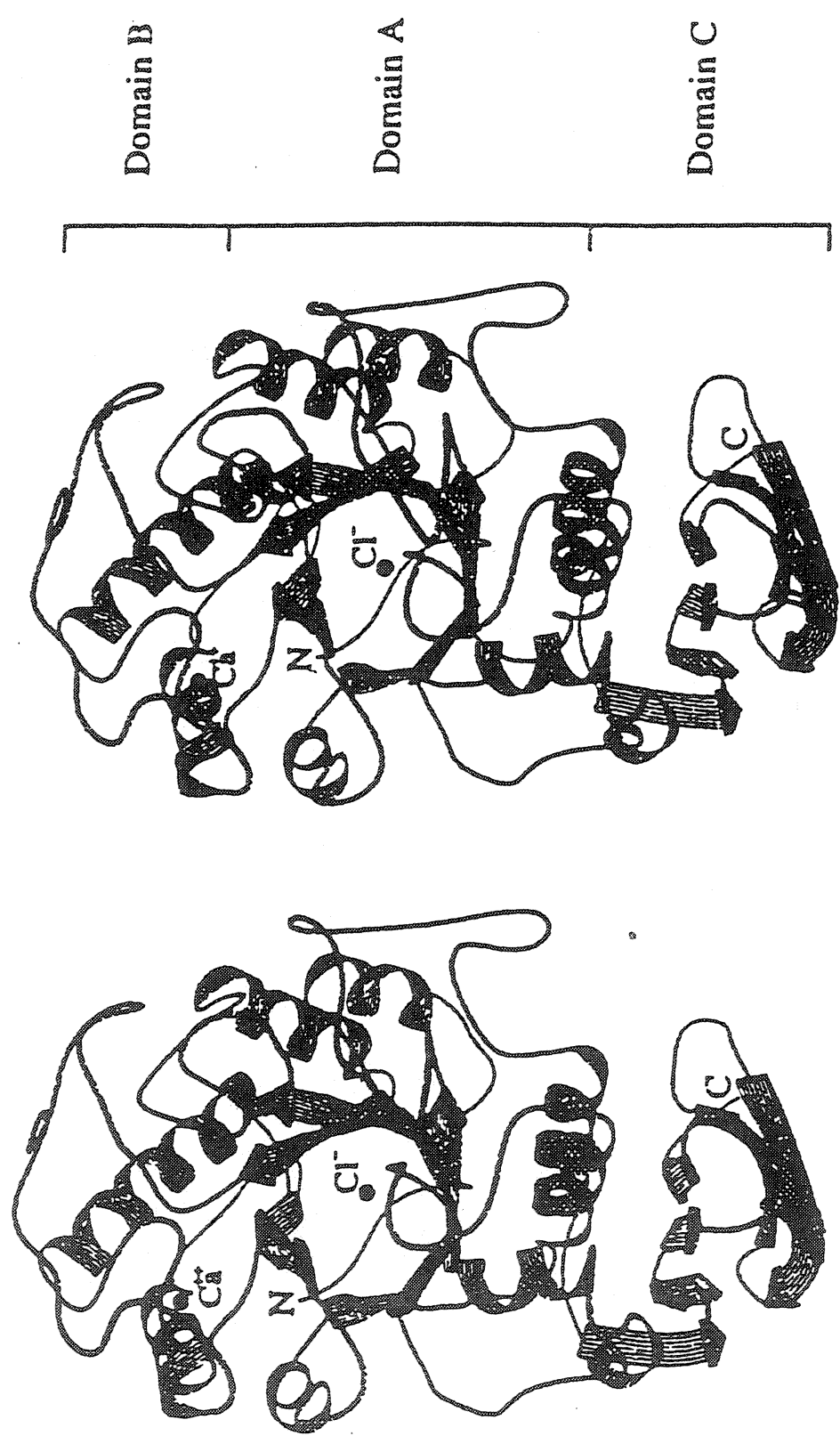
$\sim 500$ that make up the typical $\alpha$-amylase. All other regions of the polypeptide chain sequences of animal and fungal $\alpha$-amylases have essentially no homology when aligned using traditional methods based on matching schemes dependent solely on amino acid identity. Despite the results obtained from sequence alignments, recent structural studies have shown that $\alpha$-amylases do have considerable similarity with regard to polypeptide chain folding, even between distantly related $\alpha$-amylases. For example, Brayer et al.(1995) noted that overall there was $\sim 70 \%$ topological equivalence between the animal and fungal groups of $\alpha$-amylases. It seems that within the $\alpha$-amylase family of enzymes, that beyond the four short segments of polypeptide chain related to active site structure, considerable flexibility is available to alter the identities of other residues to optimize enzymatic activity under the particular conditions that each $\alpha$-amylase is required to function.

\subsubsection{Mechanism of $\alpha$-amylolysis}

\subsubsection{Cleavage of glucosidic bonds - double displacement mechanism}

Throughout the $\alpha$-amylase family, the enzymes are believed to have a similar mechanism of action, and so the catalytic amino residues are thought to be common to all enzymes (Svensson, 1994). Anomeric configuration is retained when the substrate is converted to product, i.e., the enzymes act on $\alpha$-linkages in glucans or glucosides and yield $\alpha$-linked products.

Three acidic amino acid residues (Asp, Glu, Asp) have been identified for the catalytic sites of $\alpha$-amylase family enzymes based on the results obtained by X-ray crystallographic analysis (Katsuya et al., 1998), chemical modification (Kuriki et al., 1996), and site-directed mutagenesis (Takata et al., 1994). Two distinct mechanisms have been proposed for the catalytic reaction of glycosylases: SN1 (Kaneko et al., 1998) and SN2 (Tao et al., 1989; Uitdehaag et al., 1999). However, the SN2 mechanism, also called the double displacement mechanism, is more accepted by researchers. 
The mechanism involves five steps (van der Maarel et al., 2002): (1) after the substrate has bound to the active site, the glutamic acid in the acid form donates a proton to the glycosidic bond oxygen, i.e. the oxygen between two glucose molecules at subsites -1 and +1 and the nucleophilic aspartate attacks the $\mathrm{C} 1$ of glucose at subsite $-1 ;(2)$ an oxocarbonium ion-like transition state is formed followed by the formation of a covalent intermediate; (3) the protonated glucose molecule at subsite +1 leaves the active site while a water molecule or a new glucose molecule moves into the active site and attacks the covalent bond between the glucose molecule at subsite -1 and the aspartate; (4) an oxocarbonium ion-like transition state is formed again; (5) the base catalyst glutamate accepts a hydrogen from an incoming water or the newly entered glucose molecule at subsite +1 , the oxygen of the incoming water or the newly entered glucose molecule at subsite +1 replaces the oxocarbonium bond between the glucose molecule at subsite -1 and the aspartate, forming a new hydroxyl group at the $\mathrm{C} 1$ position of the glucose at subsite -1 (hydrolysis) or a new glycosidic bond between the glucose at subsites -1 and +1 (transglycosylation). A schematic illustration of this process is shown in Fig. 216. The covalently bonded intermediate has been confirmed by many researchers (Tao et al., 1989; McCarter and Withers, 1996; Braun et al., 1996; Mosi et al., 1997; Mackenzie et al., 1997a, 1997b; Uitdehaag et al., 1999).

\subsubsection{Cleavage of starch chains - multiple attack}

It was proposed that $\alpha$-amylases have a multiple attack mechanism when acting on starch substrates (Robyt and French, 1967) (Fig. 2-17a). In the multiple-attack mechanism, once the enzyme forms a complex with the substrate and produces the first cleavage, the enzyme remains with one of the fragments of the original substrate and catalyzes the hydrolysis of several bonds before it dissociates and forms a new active complex with another substrate molecule. It was established that the 
direction of multiple attack is from the reducing end toward the nonreducing end: i.e., after the first cleavage, the fragment with the new nonreducing end dissociates from the active site, while the fragment with the newly formed hemiacetal reducing end remains associated with the active site and repositions itself to give another cleavage and the formation of maltose or maltotriose (Fig. 2-17b).

A chromatographic study of the types of low-molecular-weight products produced by porcine pancreatic and human salivary $\alpha$-amylases (Robyt and French, 1967) shows that the products are maltose, maltotriose, and maltotetraose. From the investigation, it was also postulated that porcine pancreatic $\alpha$-amylase has five $\mathrm{D}$-glucose subsites and that the catalytic groups are located between the second and third subsites from the reducing-end subsite. The action of porcine pancreatic $\alpha$-amylase on amylopectin or glycogen eventually gives a series of dextrins that contain $\alpha-D-(1 \rightarrow 6)$ linkages. The products include tetrasaccharide, pentasaccharide, and heptasaccharide in addition to D-glucose, maltose and maltotriose (Robyt, 1984).

\subsubsection{Factors influencing starch digestibility}

Differences in the in vitro digestibility of native starches, among and within species, have been attributed to the interplay of many factors such as starch source (Ring et al., 1988), granule size (Snow and O’Dea, 1981), extent of molecular association between starch components (Dreher et al., 1984), amylose/amylopectin ratio (Hoover and Sosulski, 1985a), degreee of crystallinity (Hoover and Sosulski, 1985a), type of crystalline polymorphic form (A, B or C) (Jane et al., 1997), distribution of B type crystallites in the granule (Gérard et al., 2001), amylose-lipid complexes (Guraya et al., 1997; Holm et al., 1983; Nebensy et al., 2002; Seneviratne and Biliaderis, 1991; Tufvesson et al., 2001), physical distribution of starch in relation to dietary fiber components (Dreher et al., 1984; Rao, 1969; 


\section{Figure 2-16 Double displacement mechanism of $\alpha$-amylase}

Source: Kuriki and Imanaka (1999), reproduced with permission. 


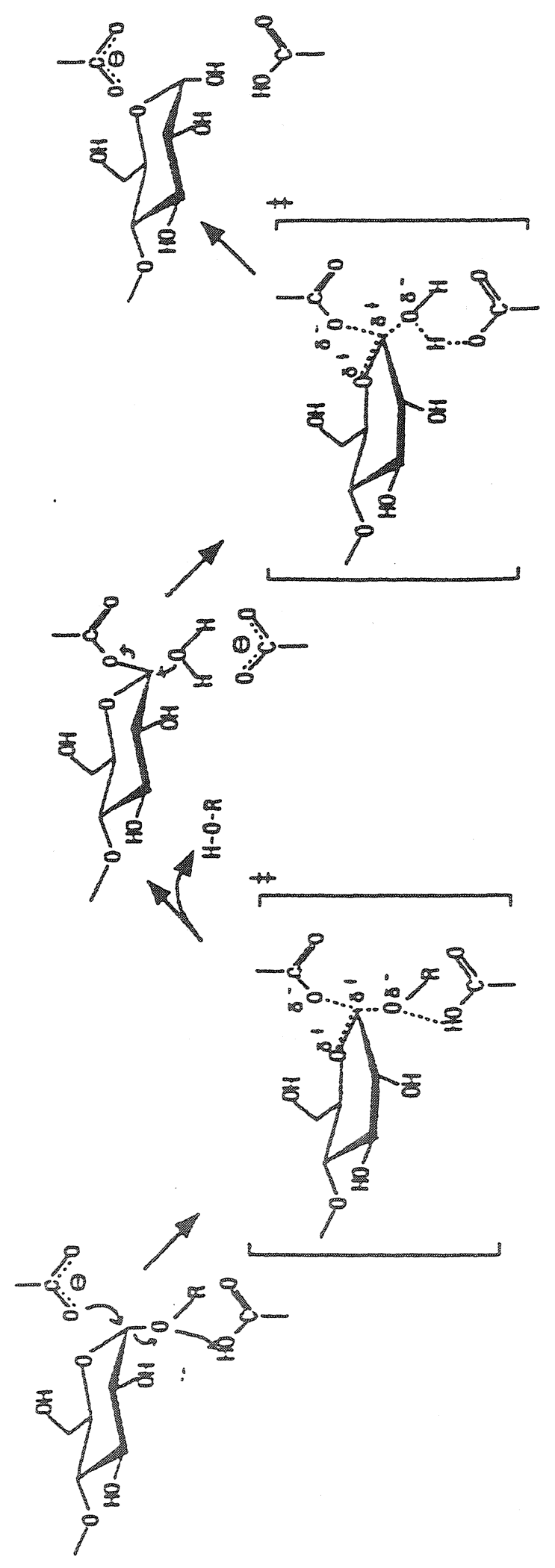


Figure 2-17 a) Multiple attack of $\alpha$-amylase.

The arrows represent the catalytic hydrolysis of a glycosidic bond; the numbers indicate the sequence of each catalytic event. The direction of multiple attack is toward the non-reducing end.

Source: Robyt and French (1970)

b) Sequence of events at the active site for multiple attack by an endoacting enzyme.

The active site is pictured here with five binding subsites and the catalytic groups located between the second and third subsites; $\boldsymbol{\Delta}$ and $\boldsymbol{\nabla}$ represent the catalytic groups; O represents a glucosyl unit; $\varnothing$, a reducing glucose unit; and -, an $\alpha-D-$ $(1 \rightarrow 4)$ glucosidic bond.

Source: Robyt (1984), reproduced with permission. 
a

Mulpiplo Alpock

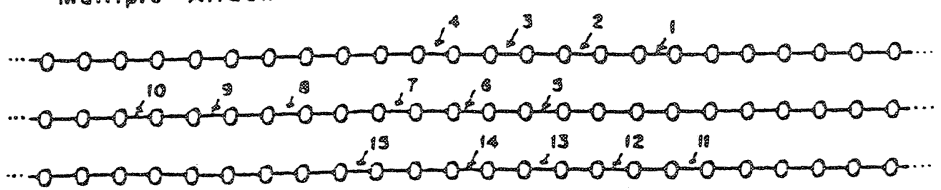

b

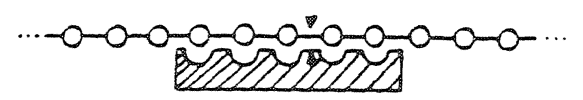

intial enżyma-subsiras complas

1

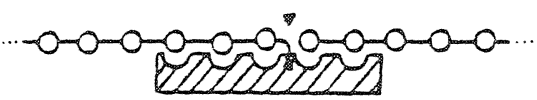

po polysecchoride frogmanis at sho active site

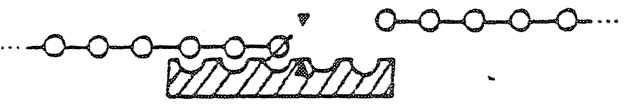

dis3ociation of ine frogment with the nonroducing / ond

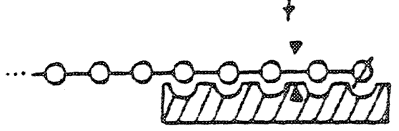

popositioning of

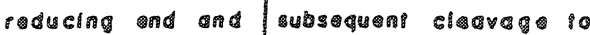
giv molros

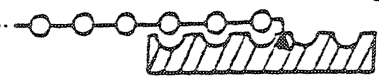

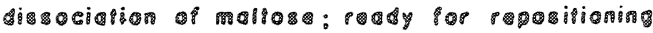

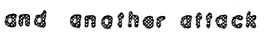


Snow and O'Dea, 1981), antinutrients (Thompson and Gabon, 1987), $\alpha$-amylase inhibitors (Lajolo et al., 1991; Puls and Keup, 1973), physical insulation of starch by thick walled cells (Wursch et al., 1986), porosity (Colonna et al., 1988), and the influence of drying and storage conditions (Kayisu and Hood, 1979).

Colonna et al. (1992) used a mechanistic approach to analyze the steps involved in an $\alpha$ amylolysis process. Four successive phases have been considered: the diffusion of the enzyme molecule towards its substrate, the porosity of starchy substrate, the adsorption of enzymes on the substrate, and finally the catalytic event. In addition, the overall hydrolysis rate was also thought to be influenced by the hydrolyzed products. Fig. 2-18 summarizes various factors involved in the kinetics of starch hydrolysis by $\alpha$-amylase.

\subsubsection{Particle size and porosity}

Particle size and surface area to starch ratio play an important role in influencing the enzymatic hydrolysis rate. A larger surface area available to enzymes leads to a higher initial rate of hydrolysis. Snow and O'Dea (1981) showed that starch in cereal flours was more rapidly hydrolyzed than starch in

rolled (flattened) cereals, when comparing both raw and cooked forms. Rolled cereals have a tightly packed physical form with a low surface area relative to flours. In a study on wheat (Holm et al., 1985), it was shown that wet-homogenization of steam-cooked grains resulted in a higher initial hydrolysis rate with $\alpha$-amylase compared with dry-milling. Microscopically, the wet-homogenized sample was more disintegrated, resulting in a greater surface area being available to the enzyme. Several researchers (Knutson et al., 1982; Guraya et al., 2001) have shown that the rate of $\alpha$-amylase hydrolysis of starches was directly proportional to the surface area of the granules. Kong et al. (2003) 
Figure 2-18 Factors involved in the kinetics of starch hydrolysis by $\alpha$-amylase Source: Colonna et al. (1992); Björck (1996); Hoover and Zhou (2003) 
1. Granule size

2. Surface porosity

3. Amylose/amylopectin ratio

4. Crystalline polymorphic forms $(A, B, C)$

5. Degree of crystallinity

6. Content and Distribution of 'B' polymorphs

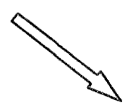

Starch isolation and Processing

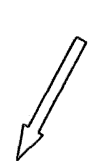

1. Starch damage during extraction

2. Gelatinization

3. Retrogradation (amylose and amylopectin gels)

4. Drying and storage conditions

Plant source

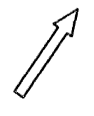

1. Starch chain interactions (AMAM, AM-AMP) within amorphous

or crystalline domains

2. Starch - lipid complexes

3. Starch - protein interaction

\section{Starch Digestibility}

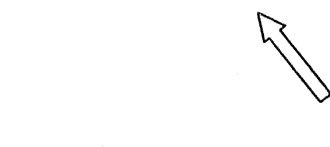

$\underline{\alpha-a m y l a s e ~ i n h i b i t o r s ~}$

Antinutrients

3. Viscous dietary fiber

4. Organic acids, phytic acids, tannins lectins. 
studied porcine pancreatic $\alpha$-amylase activity on native starch granules from potato, maize and rice, and they found that the reciprocal of initial velocity was a linear function of the reciprocal of surface area.

Specific area and porosity are considered as physicochemical factors responsible for differences in susceptibility of native starch granules (McGregor and McGregor, 1985; Colonna et al., 1988). It has been speculated (Leach and Schoch, 1961; Gallant et al., 1972) that amylases hydrolyze native starch granules by entering the granule through pores or a loose sponge-like structure that permits the enzyme molecules to penetrate into the granule and hydrolyze the starch chains. These pores might be inherent properties of the various starches and the number may vary according to the type of starch. The presence of pores has been observed by Fannon et al. (1992) for maize, sorghum and millet starches and by Baldwin et al. (1998) for potato, rice and wheat starches. Fannon et al. (1993) further pointed out that the pores present on the external surface of sorghum starch granules are openings to serpentine channels that penetrate into the granule interior.

\subsubsection{Amylose/amylopectin ratio}

The amylose/amylopectin ratio is higher in legume starches than in "common" varieties of cereal or tuber starches (Eliasson, 1988). Due to the low glycaemic index (GI) reported for most legume products, this has focused interest on potential varietal differences in amylose content.

Among cereals (e.g., rice, corn, and barley) the amylose/amylopectin ratio may differ considerably among genotypes. In some studies on rice (Goddard et al., 1984; Juliano and Goddard, 1986; Miller et al., 1992), a higher amylose content was shown to lower metabolic response. In fact, according to Miller et al. (1992), only high-amylose varieties of rice are potentially useful in low-GI diets. By exchanging high-amylose corn flour for ordinary corn flour (70\%) in glucose and insulin 
responses were significantly reduced in healthy subjects (Granfeldt et al., 1995). Sticky rice, with a lower amylose content, was hydrolyzed very rapidly in vitro, producing a hydrolysis graph similar to that with white bread (Granfeldt et al., 1992). Also, the metabolic responses and in vitro rate of starch hydrolysis of gels made from wheat, manihot, and smooth pea starch were inversely related to the amylose content (17-35\%) (Bornet et al., 1989).

Inclusion of high-amylose corn starch ( $70 \%$ amylose) into products has been shown to lower metabolic responses compared with products based on low-amylose starch. As a consequence, Behall et al. (1988) reported reduced postprandial responses of glucose and insulin in healthy subjects following ingestion of crackers made from high-amylose corn starch compared with a corresponding product made from low-amylose starch. A beneficial effect of incorporating autoclaved, high-amylose corn starch into products was further reported by van Amelsvoort and Weststrate (1992) in healthy subjects. In both investigations, the effect on insulin was most pronounced, which is in accordance with data on high-amylose rice starch (Goddard et al., 1984).

\subsubsection{Starch interactions/physical structure}

Interactions between starch and protein can greatly influence the $\alpha$-amylolysis rate. It has been demonstrated that the protein matrix, in cereal (Holm and Björck, 1988; Holm et al., 1989; Jenkins et al., 1987a) as well as in legume products (Tovar et al., 1990), limits the accessibility of starch to amylase. By deproteinizing pasta, the rate of in vitro amylolysis increased (Colonna et al., 1990). Differences in the in vitro rate of amylolysis between processed wheat samples were evened out following preincubation with pepsin (Holm and Björck, 1988; Holm et al., 1989). The in vitro procedure, which included pepsin, allowed closer prediction of glycemic response in rats, suggesting 
that at least some protein-starch interactions are broken under physiological conditions (Holm et al., 1989).

In pasta products, gluten forms a viscoelastic network that surrounds the starch granules, thus restricting starch swelling and leaching of starch during boiling (Colonna et al., 1990; Pagani et al., 1986). As to the cause of the slow-release starch features of pasta, the limited swelling of starch granules may reduce the availability to amylases. However, as judged from the prominent increase in the rate of amylolysis even at pregelatinized stages of granule crystallinity (Holm et al., 1988), differences in the extent of swelling of gelatinized granules might not account for the lowered availability observed. The presence of a glutinous phase, although available to preteolytic enzymes, will possibly release the starch substrate more gradually to amylolytic attack. According to Jenkins $e t$ al. (1987a), protein-starch interaction also reduces the availability of the starch in bread products, and a bread made from gluten-free flour elicited a higher glucose response than an ordinary wheat bread.

Other forms of starch interactions involve formation of amylose-lipid complexes and interactions between starch molecules. Amylose-lipid complexation affected the enzyme susceptibility of sago starch by reducing starch granule swelling (thus providing less opportunity for enzyme access to the granule interior and less leaching of amylose from the granules) and by increasing resistance to digestive enzymes (Cui and Oates, 1999). Amylose complexed with lysolecithin was more slowly digested and absorbed from the rat small intestine, and produced less pronounced postprandial glycemia than "soluble" amylose (Holm et al., 1983). This reduction is noteworthy, since the soluble amylose reference also can be expected to be less readily available to amylases due to its disposition to retrograde. In products based on starches in which amylose is the minor starch component, amylose retrogradation and/or formation of amylose-lipid complexes is probably most efficient in reducing the enzymic availability if the amylose involved is enriched on surfaces, thus encapsulating the bulk of 
starch, rather than being evenly distributed. Such interactions may explain the improvement in product characteristics of rice seen in some studies as a result of parboiling. The low glycemic responses reported for products based on high-amylose starches might, however, be related to retrogradation of amylose. Although high-amylose starch granules do not swell under "ordinary conditions for food preparation", following the disappearance of the crystalline granule structure, amylose molecules could still interact, leading to a reduction in the overall enzymic availability of starch. As to the effect of retrogradation of amylopectin, even significant staling of starch in bread did not reduce the rate of in vitro amylolysis (Siljeström et al., 1988).

\subsubsection{Hydrolysis of legume starches}

Native legume starches have been found to be more digestible than native potato or high amylose maize starch, but less digestible than native cereal or cassava starch (Dreher et al., 1984; Frins et al., 1998; Hoover and Sosulski, 1985a; Ring et al., 1988; Socorro et al., 1989; Tovar et al., 1991). Hoover and Sosulski (1985a) have shown that during a $6 \mathrm{~h}$ digestion with porcine pancreatic $\alpha$ amylase, maize starch was hydrolyzed to the extent of $75 \%$, whereas, at the same enzyme concentration, the corresponding value for legume starches belonging to the biotype Phaseolus vulgaris ranged from 25 to $35 \%$.

The reduced bioavailability of legume starches has been attributed to the presence of intact tissue/cell structures enclosing starch granules, higher levels of amylose $(30-65 \%)$, high content of viscous soluble dietary fiber components, the presence of a large number of antinutrients, 'B' type crystallites and strong interactions between amylose chains (Deshpande and Cheryan, 1984; Hoover and Sosulski, 1985a; Siddhuraju and Becker, 2001; Tovar et al., 1991; Wursch et al., 1986). Table $2-$ 11 presents the in vitro amylolysis of legume starches by $\alpha$-amylase from different origins. It is 
difficult to rank the legume starches with regard to their susceptibility towards $\alpha$-amylase, due to differences in enzyme concentration, time of hydrolysis and source of $\alpha$-amylase. Furthermore, the data presented in Table 2-11 have been on a single cultivar. Therefore, it is difficult to ascertain whether the reported extent of starch hydrolysis is truly representative of the particular species.

There is growing interest in the application of legume starches as resistant starch. Resistant starch is defined as the sum of starch and starch degradation products not digested in the small intestine of healthy individuals. It is subdivided into four categories depending on the cause of resistance (Englyst et al., 1992; Eerlingen et al., 1993): $\mathrm{RS}_{1}$, physically inaccessible starch due to entrapment in a nondigestible matrix; $\mathrm{RS}_{2}$, raw starch granules with crystallinity; $\mathrm{RS}_{3}$, retrograded amylose; and $\mathrm{RS}_{4}$, chemically modified starch slowly digestible starch (SDS) and RS are of particular interest because of their potential health benefits to humans. A high proportion of SDS relative to rapidly digestible starch (RDS) in a starchy food indicates a food with a low glycemic index. Foods with a low glycemic load are thought to be beneficial for all individuals, especially for type II diabetics (Englyst et al., 1999; Björck et al., 2000; Roberts, 2000; Roberts et al., 2000; Jenkins et al., 2001).

Raw and processed legumes have been shown to contain significant amounts of RS in comparison to cereal and potatoes (Bednar et al., 2001; Björck et al., 1994; Bravo et al., 1998; Elmstahl, 2002; Garcia-Alonso et al., 1998; Lehmann et al., 2003; Lintas and Cappelloni, 1992; Marlett and Longacre, 1996; Osorio-Diaz et al., 2002; Periago et al., 1997; Rosin et al., 2002; Tovar and Melito, 1996; Tovar et al., 1992a, b; Truswell, 1992; Velasco et al., 1997). For this reason the ingestion of legumes results in reduced glycemic and insulinemic postprandial responses in comparison to cereals or potatoes (Jenkins et al., 1982, 1987b; Tovar et al., 1992b). 
Table $2-11$

In vitro digestibility of native legume starches

\begin{tabular}{|c|c|c|c|}
\hline Starch Source & Source of a-amylase & Reaction Time(h) & Degree of hydrolysis $(\%)$ \\
\hline \multirow[t]{4}{*}{ Smooth pea (Pisum Sativum L.) } & Porcine Pancreatic & 24 & $18.2-22.2$ \\
\hline & Porcine Pancreatic & 29 & 91 \\
\hline & Bacillus Sp. & 29 & 78 \\
\hline & Aspergillus Fumigatus & 29 & 100 \\
\hline \multirow[t]{3}{*}{ Wrinkled pea (Pisum Sativum L.) } & Porcine Pancreatic & 29 & 72 \\
\hline & Bacillus Species & 29 & 66 \\
\hline & Aspergillus Fumigatus & 29 & 77 \\
\hline Grass pea (Pisum sativum L.) & Porcine Pancreatic & 24 & 22 \\
\hline Green pea (Pisum sativum L.) & Porcine Pancreatic & 24 & 16 \\
\hline Beach pea (lathyrus maritimus L..) & Porcine Pancreatic & 24 & 35 \\
\hline Lentil (lens culinaus L.) & Porcine Pancreatic & 24 & $14.5-35.5$ \\
\hline Mung bean (Phaseolus aureus ) & Porcine Pancreatic & 24 & 71.1 \\
\hline Lima bean (Phaseolus lunatus ) & Porcine Pancreatic & 6 & 25 \\
\hline Lablab bean (Lablab purpureus ) & Bacillus Subtilis & 2 & 30 \\
\hline \multirow[t]{2}{*}{ Pinto bean (Phaseolus vulgaris ) } & Porcine Pancreatic & 1 & 62 \\
\hline & Porcine Pancreatic & 6 & 25.2 \\
\hline Navy bean (Phaseolus vulgaris ) & Porcine Pancreatic & 6 & 32 \\
\hline Northern bean (Phaseolus vulgaris) & Porcine Pancreatic & 6 & 29 \\
\hline \multirow[t]{2}{*}{ Black bean (Phaseolus vulgaris ) } & Porcine Pancreatic & 6 & 34.8 \\
\hline & Porcine Pancreatic & 3 & 49.5 \\
\hline Kidney bean (Phaseolus vulgaris ) & Porcine Pancreatic & 6 & 31.4 \\
\hline \multirow[t]{2}{*}{ Moth bean (Phaseolus acontifolius ) } & Porcine Pancreatic & NA & $25.4-28.2$ \\
\hline & Human Salivary & 1.6 & 30.2 \\
\hline Tepary bean (Phaseolus acutifolius ) & Porcine Pancreatic & 2 & 8 \\
\hline Yam bean (Sphenostylis stenocarpa ) & Saliva & 1 & 18 \\
\hline \multirow{2}{*}{ Chick pea (Cicer arientum ) } & Porcine Pancreatic & 24 & 60 \\
\hline & Human Salivary & 2 & 15 \\
\hline Horse gram (Dolichos biflorus) & Saliva & 2 & 10.2 \\
\hline Cow pea (Vigna Sinensis ) & Saliva & 2 & 10.8 \\
\hline
\end{tabular}

Source: Hoover and Zhou (2003) 


\section{Chapter 3 Materials and Methods}

\subsection{Materials}

Black bean (Phaseolus vulgaris L.) cultivars (CDC Nighthawk, Black Jack); pinto bean (Phaseolus vulgaris L.) cultivars (Othello, Sierra); lentil (Lens culinaris Mekik) cultivars (CDC Rrobin, CDC Redwing); smooth pea (Pisum sativum L.) cultivars (CDC Mozart, CDC Sonata) and wrinkled pea (Pisum sativum L.) were obtained from the Crop Development Center, University of Saskatchewan, Saskatoon, Canada. Crystalline porcine pancreatic $\alpha$-amylase (E.C. 3.2.2.1, type 1A) was purchased from Sigma Chemical Co., (St. Louis, MO, USA). Potato starch and waxy corn starch were gifts from National Starch and Chemical Co., Bridgewater, NJ, USA. All other chemicals and solvents were of ACS-certified grade.

\subsection{Methods}

\subsubsection{Starch isolation}

Starch was isolated from legume seeds by the procedure of Hoover and Sosulski (1985a). Seeds $(200 \mathrm{~g})$ were steeped in $300 \mathrm{~mL}$ of $0.01 \%$ (w/v) sodium metabisulfite for $24 \mathrm{~h}$ at ambient temperature $\left(20-25^{\circ} \mathrm{C}\right)$. The swollen seeds were thoroughly washed with water, peeled and homogenized in a Commercial Waring Blender (Dynamics Corporation of America, New Hartford, CT, USA) for $90 \mathrm{sec}$. The homogenate was then filtered (under vacuum) through a double-layer of cheesecloth. The filtrate was collected and left to settle for $2 \mathrm{~h}$, then the supernatant was removed by a siphoning tube. The sediment was suspended in excess $0.2 \%(\mathrm{w} / \mathrm{v}) \mathrm{NaOH}$ and after standing for $12 \mathrm{~h}$ the supernatant was removed. The sedimentation procedure was repeated thrice. The final sediment was suspended in distilled water and passed through a $70 \mu \mathrm{m}$ polypropylene filter cloth under vacuum. The filtrate was 
allowed to settle for $2 \mathrm{~h}$ and the supernatant was removed, again this procedure was repeated three times. Finally, the slurry was neutralized to $\mathrm{pH} 7.0$ by $\mathrm{HCl}$ and passed through a double-layer of Whatman No.4 filter paper, and the filter cake oven dried at $30^{\circ} \mathrm{C}$ for $24 \mathrm{~h}$ in a Fisher Isotemp $615 \mathrm{G}$ forced air oven (Fisher Scientific, Nepean, ON, Canada). The dried starch cake was carefully crushed and sieved $(250 \mu \mathrm{m}$ test sieve, Fisher Scientific Company, USA) to obtain a free flowing powder, which was weighed and the yield was calculated as the percentage of the initial seeds weight.

\subsubsection{Granule morphology}

The granule surface was studied by scanning electron microscopy. Starch samples were mounted on circular aluminum stubs with double sticky tape and then coated with $20 \mathrm{~nm}$ of gold and examined and photographed in a Hitachi scanning electron microscope (S570, Nissei Sangyo, Inc., Rexdale, ON, Canada) at an accelerating potential of $5 \mathrm{kV}$. The size and shape of native starches were examined by a Leica Gallen III microscope. The range of granule size was determined by measuring the length and width of 40 granules from a $1.0 \%$ starch suspension at $10 \times 100$ magnification with an eye-piece micrometer.

\subsubsection{Compositional analyses}

\subsubsection{Moisture content}

Quantitative estimation of moisture was performed according to standard AACC (American Association of Cereal Chemists, 1984) procedures. Pre-weighed (4-5 g) starch samples were dried in a forced air oven (Fisher Isotemp 615G, Fisher Scientific, Nepean, ON, Canada) at $130^{\circ} \mathrm{C}$ for $1 \mathrm{~h}$. The sample was then removed and cooled in a desiccator. The moisture content was calculated as the percentage weight loss of the sample. 


\subsubsection{Ash content}

Pre-weighed $(5 \pm 0.01 \mathrm{~g})$ samples were transferred into a clean, dry porcelain crucible, and ignited over a flame until thoroughly carbonized. Then the sample was placed in a pre-heated $\left(525^{\circ} \mathrm{C}\right)$ muffle furnace (Lab Heat - Blue M model M30A-1C, Blue M Electric Co., Blue Island, IL, USA) and allowed to stand until it became a cotton-like substance and free of carbonaceous matter $(\sim 12 \mathrm{~h})$. The sample was cooled to room temperature in a desiccator and weighed. The ash content was calculated as the percentage weight loss of the sample (AACC, 1984).

\subsubsection{Nitrogen content}

Nitrogen content was determined by the micro-Kjeldahl method. Samples $(0.3 \mathrm{~g}$, db) were weighed on nitrogen free paper and placed in digestion tubes on a Buchi 430 digester (Buchi Laboratorimus-Technik AG, Flawill/Schweiz, Switzerland). The catalyst (two Kjeltab M pellets) and $20 \mathrm{~mL}$ of concentrated sulfuric acid were added to each tube and the sample was digested until a clear yellow solution was obtained. The digested samples were then cooled, diluted with $50 \mathrm{~mL}$ of distilled water, $100 \mathrm{~mL}$ of $40 \%(\mathrm{w} / \mathrm{v}) \mathrm{NaOH}$ was then added, and the released ammonia was steam distilled into $50 \mathrm{~mL}$ of $4 \%(\mathrm{w} / \mathrm{v})$ boric acid $\left(\mathrm{H}_{3} \mathrm{BO}_{3}\right)$ containing 12 drops of end-point indicator $(\mathrm{N}$-point indicator, EM Science, NJ, USA) using a Buchi 321 distillation unit until $150 \mathrm{~mL}$ of distillate was collected. The amount of ammonia in the distillate was determined by titrating against $0.05 \mathrm{~N}$ sulfuric acid (AACC, 1984). Percentage nitrogen was calculated as:

$$
\text { Nitrogen }(\%)=\frac{(\text { Volume of acid }- \text { Blank }) \times \text { Normality of acid } \times 14.0067 \times 100}{\text { Sample weight }(\mathrm{mg})}
$$




\subsubsection{Lipid content}

Different categories of lipid were extracted from starch by the following procedures and the amounts of extracted lipid were expressed as percentages of the initial starch sample weight.

\subsection{Surface lipids}

Surface lipids were extracted at room temperature $\left(25-27^{\circ} \mathrm{C}\right)$ by mixing starch $(5 \mathrm{~g}$, db) with $100 \mathrm{~mL}$ of $2: 1(\mathrm{v} / \mathrm{v})$ chloroform-methanol under vigorous agitation in a wrist action shaker for $1 \mathrm{~h}$. The solution was then filtered (Whatman No.4 filter paper) into a round bottom flask and the residue was washed thoroughly with a small amount of the above chloroform-methanol solution. The solution was then evaporated to dryness using a rotary evaporator (Rotavapor -R110, Buchi Laboratorimus Technik AG, Flawill/Schweiz, Switzerland). The crude lipid extracts were purified by the method of Bligh and Dyer (1959) before quantification. The starch residue was saved for bound lipid extraction.

\subsection{Bligh and Dyer (1959) method of lipid purification}

The crude lipid from the above extract was purified by extraction with chloroform-methanolwater $(1: 2: 0.8, \mathrm{v} / \mathrm{v} / \mathrm{v})$ and by forming a biphasic system (chloroform-methanol-water, 1:1:0.9, v/v/v) by the addition of chloroform and water at room temperature $\left(25-27^{\circ} \mathrm{C}\right)$ in a separation funnel. The chloroform layer was then diluted with benzene and brought to dryness using a rotary evaporator followed by drying at $60^{\circ} \mathrm{C}$ for $1 \mathrm{~h}$ in a forced-air oven. The dried lipid was cooled to room temperature in a desiccator. 


\subsection{Bound lipids}

Bound lipid was extracted using the residue left after surface lipid extraction. The residue was refluxed with $3: 1(\mathrm{v} / \mathrm{v})$ n-propanol-water in a soxhlet apparatus at $85^{\circ} \mathrm{C}$ for $7 \mathrm{~h}$ (Vasanthan and Hoover, 1992). The extracted solution was evaporated using a rotary evaporator. The crude lipid extract was purified by the method of Bligh and Dyer (1959) before quantification.

\subsection{Total lipids}

Total starch lipid was determined by hydrolyzing starch (2 g, db) with $25 \mathrm{~mL}$ of $24 \%$ (v/v) $\mathrm{HCl}$ at $70-80^{\circ} \mathrm{C}$ for $30 \mathrm{~min}$. The hydrolyzate was extracted three times with $\mathrm{n}$-hexane. The extract was evaporated to dryness in a rotary evaporator. The crude lipid extract was purified by the method of Bligh and Dyer (1959) before quantification.

\subsubsection{Amylose content}

Apparent and total amylose content were determined as described by Hoover and Ratnayake (2001).

\subsection{Apparent amylose}

Starch (20 mg, db) was accurately weighed into a round bottom screw cap tube, then $8 \mathrm{~mL}$ of $90 \%$ dimethylsulfoxide (DMSO) was added to the tube. The contents were mixed vigorously for $2 \mathrm{~min}$ using a vortex mixer followed by heating in a water bath (PolyScience, Model 2L-M, PolyScience, Niles, IL, USA) at $85^{\circ} \mathrm{C}$ for 15 min with intermittent shaking. The tube was then allowed to cool to room temperature $(\sim 45 \mathrm{~min})$ and then diluted to $25 \mathrm{~mL}$ in a volumetric flask. $1 \mathrm{~mL}$ of the diluted

solution was mixed with water $(40 \mathrm{~mL}), 5 \mathrm{~mL}$ of $\mathrm{I}_{2} / \mathrm{KI}$ solution $\left(0.0025 \mathrm{M} \mathrm{I}_{2}\right.$ and $0.0065 \mathrm{M} \mathrm{KI}$ mixture) 
was added, and the final volume was adjusted to $50 \mathrm{~mL}$ in a volumetric flask. After $15 \mathrm{~min}$ (for color development), the absorbance was read at $600 \mathrm{~nm}$ using a UV-visible spectrophotometer (LKB Novaspec-4049 spectrophotometer, LKB Biochrom Ltd., Cambridge, England). In order to avoid overestimation of amylose content (due to complex formation between $I_{2}$ and the long outer branch chains

of amylopectin), amylose content was calculated from a standard curve prepared using mixtures of pure potato amylose and amylopectin (over the range 0-100\% amylose and 100-0\% amylopectin) (Fig. A-1 in Appendix).

\subsection{Total amylose}

Starch samples were defatted by extracting in a Soxhlet extractor $\left(85^{\circ} \mathrm{C}\right)$ with $3: 1(\mathrm{v} / \mathrm{v}) \mathrm{n}$ propanol-water for $7 \mathrm{~h}$ prior to the determination of total amylose content by the above procedure.

\subsubsection{Starch damage}

Starch damage was estimated following the AACC (1984) standard procedures. Starch samples $(1 \mathrm{~g}, \mathrm{db})$ were digested with fungal $\alpha$-amylase from Aspergillus oryzae $(0.05 \mathrm{~g})$ having a specific activity of 50-200 units/mg in a water bath (PolyScience waterbath, PolyScience, Niles, IL, USA) at $30^{\circ} \mathrm{C}$ for $15 \mathrm{~min}$. At the end of the incubation, the enzyme action was terminated by adding $3.68 \mathrm{~N}$ sulfuric acid $(3 \mathrm{~mL})$ and $12 \%(\mathrm{w} / \mathrm{v})$ sodium tungstate $\left(\mathrm{Na}_{2} \mathrm{WO}_{4} \cdot 2 \mathrm{H}_{2} \mathrm{O}\right)(2 \mathrm{~mL})$, respectively. The mixture was allowed to stand for $2 \mathrm{~min}$ and then filtered through a Whatman No. 4 filter paper. Aliquots $(2 \mathrm{~mL})$ of the filtrate were mixed with $2 \mathrm{~mL}$ of 3,5 - dinitrosalicylic (DNS) acid and then heated in a boiling water bath for 5 min. The reaction mixture was chilled using an ice bath and diluted with $8 \mathrm{~mL}$ of distilled water. The absorbance was measured at $540 \mathrm{~nm}$ against a blank (Bruner, 1964) (the details of the procedure are outlined in 3.2.4.1). A calibration curve (Fig. A-2 in Appendix) was 
established with maltose (to calculate the maltose equivalents in the digest) and the percentage starch damage was calculated using the following equation:

\author{
Starch damage $(\%)=(\mathrm{M} \times 1.64) /(\mathrm{W} \times 1.05) \times 100$ \\ M: mg maltose equivalents in the digest. \\ W: mg (db) of starch \\ 1.64: the reciprocal of the mean percentage maltose yield from starch (an empirical \\ factor which assumes that under the conditions of the experiment, the maximum \\ degree of hydrolysis is $61 \%$ ). \\ 1.05: molecular weight conversion of starch to maltose
}

\title{
3.2.4.1 Determination of reducing sugar content (Bruner, 1964)
}

Sample solution $(2 \mathrm{~mL})$ was pipetted into a screw cap tube, followed by $2 \mathrm{~mL}$ of 3,5dinitrosalicylic acid (DNS) solution (20 g of DNS dissolved in $700 \mathrm{~mL}$ of $1 \mathrm{~N} \mathrm{NaOH}$ ). The mixture was stirred well to dissolve the DNS and then diluted to $1 \mathrm{~L}$ with distilled water and filtered through a double-layer of Whatman No. 1 filter paper. The mixture was heated in a boiling water bath for $5 \mathrm{~min}$ for color development. The tube was then cooled in an ice bath for $10 \mathrm{~min}$, and then $8 \mathrm{~mL}$ of distilled water was added to make the total volume to $12 \mathrm{~mL}$. The absorbance was read at $540 \mathrm{~nm}$ using a UVvisible spectrophotometer (LKB Novaspec-4049 spectrophotometer, LKB Biochrom Ltd., Cambridge, England) against a reagent blank $\left(25^{\circ} \mathrm{C}\right)$. Standard curves were established by preparing a series of mixtures with known amounts of maltose (Fisher Scientific, Fair Lawn, NJ, USA) (Fig. A-2 in Appendix). 


\subsubsection{Swelling factor (SF)}

The SF of the starches at $80^{\circ} \mathrm{C}$ in excess water was measured according to the method of Tester and Morrison (1990). Starch samples (50 mg, db) were weighed into a screw cap tube, $5 \mathrm{~mL}$ of water was added, and the tube was heated in a shaking water bath at $80^{\circ} \mathrm{C}$ for $30 \mathrm{~min}$. The tube was then cooled to $20^{\circ} \mathrm{C}$ immediately on ice, $0.5 \mathrm{~mL}$ of blue dextran (MW 2,000,000) was added and mixed well. The tube was then centrifuged at 2000 r.p.m for $5 \mathrm{~min}$ and the absorbance of the supernatant was measured at $620 \mathrm{~nm}$ using a UV-visible spectrophotometer against a reference without starch. This method measures only intragranular water and hence is regarded as the true SF at a given temperature.

Calculation of SF was based on starch weight corrected to $10 \%$ moisture, assuming a density of

\section{$1.4 \mathrm{mg} / \mathrm{mL}$.}

Free or interstitial plus supernatant water (FW) is given by:

$$
\mathrm{FW}=5.5\left(\mathrm{~A}_{\mathrm{r}} / \mathrm{A}_{\mathrm{s}}\right)-0.5
$$

Where $A_{r}$ and $A_{S}$ are the absorbances of the reference and sample, respectively.

The initial volume of $\operatorname{starch}\left(\mathrm{V}_{\mathrm{o}}\right)$ of weight $\mathrm{W}$ (in $\mathrm{mg}$ ) is

$$
\mathrm{V}_{\mathrm{o}}=\mathrm{W} / 1,400
$$

And the volume of absorbed intragranular water $\left(V_{1}\right)$ is thus:

$$
\mathrm{V}_{1}=5.0-\mathrm{FW}
$$

Hence the volume of the swollen starch granule $\left(V_{2}\right)$ is:

$$
\mathrm{V}_{2}=\mathrm{V}_{0}+\mathrm{V}_{1}
$$

And $S F=V_{2} / V_{0}$

This can also be expressed by the single equation:

$$
\mathrm{SF}=1+\left\{(7700 / \mathrm{W}) \times\left[\left(\mathrm{A}_{\mathrm{S}}-\mathrm{A}_{\mathrm{r}}\right) / \mathrm{A}_{\mathrm{S}}\right]\right\}
$$

The coefficient of variation of the method was generally less than $1 \%$. 


\subsubsection{Extent of amylose leaching (AML)}

Native starches $(20 \mathrm{mg}, \mathrm{db})$ in water were heated at $80^{\circ} \mathrm{C}$ in volume-calibrated sealed tubes for $30 \mathrm{~min}$. The tubes were then cooled to ambient temperature $\left(25-27^{\circ} \mathrm{C}\right)$ and centrifuged at 2000 r.p.m for $10 \mathrm{~min}$. The supernatant liquid (1 $\mathrm{mL})$ was withdrawn and its amylose content determined as described by Hoover and Ratnayake (2001). Amylose leaching was expressed as percentage of amylose leached per $100 \mathrm{~g}$ of starch.

\subsubsection{Differential scanning calorimetry (DSC)}

Gelatinization parameters of native and enzyme treated residues were measured and recorded on a Seiko DSC 210 (Seiko Instruments Inc., Chiba, Japan) differential scanning calorimeter equipped with a thermal analysis data station and data recording software. Water $(11 \mu \mathrm{L})$ was added with a microsyringe to starch $(3.0 \mathrm{mg})$ in the DSC pans, which were then sealed, weighed, and allowed to stand for $24 \mathrm{~h}$ before DSC analysis. The scanning temperature range and the heating rate were 20 $120^{\circ} \mathrm{C}$ and $10^{\circ} \mathrm{C} / \mathrm{min}$, respectively. In all measurements, the thermogram was recorded with an empty aluminum pan as the reference. The transition temperatures reported are the onset $\left(T_{0}\right)$, peak $\left(T_{p}\right)$, and conclusion $\left(T_{c}\right)$ of the gelatinization endotherm. The enthalpy of the gelatinization $(\Delta \mathrm{H})$ was estimated by integrating the area between the thermogram and a base line connecting the points of onset and conclusion temperature, and was expressed in terms of $\mathrm{mJ} / \mathrm{mg}$ starch (Fig. A-4 in Appendix). All DSC experiments were performed in triplicate.

\subsubsection{X-ray diffraction}

X-ray diffractograms of native and enzyme hydrolyzed starches were obtained with a Rigaku RU 200R X-ray diffractometer (Rigaku-Denki Co., Tokyo, Japan) under the following operating 
conditions as: target voltage $-40 \mathrm{KV}$, current $-100 \mathrm{~mA}$, aging time $-5 \mathrm{~min}$, scanning range $-3-35^{\circ}$, scan speed $-2.000^{\circ} / \mathrm{min}$, step time $-4.5 \mathrm{~s}$, divergence slit width -1.00 , scatter slit width -1.00 and receiving slit width -0.60 .

The moisture contents of all starch samples were adjusted to $19 \%$ by being kept in a desiccator over saturated $\mathrm{BaCl}_{2}$ solution $\left(25^{\circ} \mathrm{C}, \mathrm{a}_{\mathrm{w}}=0.9\right)$ for about 1 week (Barron et al., 2000).

\subsubsection{Determination of relative crystallinity}

The relative crystallinity of samples was quantitatively estimated following the method of Nara and Komiya (1983). A smooth curve which connected peak baselines was computer-plotted on the diffractogram. The area above the smooth curve was considered as the crystalline portion, and the lower area between the smooth curve and a linear baseline which connected the three points of intensity at $2 \theta$ of $4.5^{\circ}, 6.6^{\circ}$ and $35^{\circ}$ was taken as the amorphous portion. The upper diffraction peak area and total diffraction area over the diffraction angle $4.5^{\circ}-35^{\circ} 2 \theta$ were integrated by Origin software (version6.0, Microcal Inc., Northampton, MA, USA). The ratio of the upper area to the total diffraction area was calculated as the relative crystallinity (Fig. A-5 in Appendix).

\subsubsection{Determination of B-polymorphic composition}

B-polymorph content of samples was estimated by the method of Davydova et al.(1995). Different amounts $(0-100 \%)$ of pure potato starch (B type) were thoroughly mixed with proportionate amounts $(100-0 \%)$ of pure waxy corn (A type) starch. Moisture content was adjusted to $\sim 19 \%$ as previously described. The diffractogram of each mixture was obtained (using the same diffractometer settings) and the ratio of peak area at $5.54^{\circ} 2 \theta$ to the total peak area (crystalline portion) was calculated by Origin software (Version 6.0, Microcal. Inc). A standard curve was established by plotting the ratio versus the corresponding percentage of potato starch in the mixture (Fig. A-6 in Appendix). 


\subsubsection{Enzymatic hydrolysis by porcine pancreatic $\alpha$-amylase}

\subsubsection{Hydrolysis pattern}

Enzymatic digestibility studies on native starches were conducted using a crystalline suspension of porcine pancreatic $\alpha$-amylase in $2.9 \mathrm{M}$ saturated sodium chloride containing $3 \mathrm{mM}$ calcium chloride (Sigma Chemical Co., St. Louis, MO, USA), in which the concentration of $\alpha$-amylase was $32 \mathrm{mg} / \mathrm{mL}$ and the specific activity was 1370 units/mg protein. The procedure was essentially that of Knutson et al.(1982), however, a higher concentration of enzyme was used in this study (12 units $/ \mathrm{mg}$ starch). Starch granules $(0.2 \mathrm{~g}$, db) were suspended in distilled water $(11 \mathrm{~mL})$ and then $9 \mathrm{~mL}$ of $0.1 \mathrm{M}$ phosphate buffer ( $\mathrm{pH} 6.9$ ) containing $0.006 \mathrm{M} \mathrm{NaCl}$ were added. The slurry was pre-warmed for $30 \mathrm{~min}$ at $37^{\circ} \mathrm{C}$ and gently stirred before adding $54.7 \mu \mathrm{L} \alpha$-amylase suspension. The reaction mixtures were shaken manually on a daily basis to resuspend the deposited granules. One $\mathrm{mL}$ aliquots were withdrawn at specific time intervals, pipetted into $0.2 \mathrm{~mL}$ of $95 \%$ ethanol, and centrifuged (2000r.p.m.). Aliquots of the supernatant were analyzed for reducing sugar content (Bruner, 1964). The extent of hydrolysis was calculated as the percentage of initial starch converted to maltose. Controls without enzyme but subjected to the above experimental conditions were run concurrently. The experiment was performed in triplicate.

Hydrolysis extent $(\%)=\frac{\text { Released reducing sugar as maltose }(\mathrm{g}) \times 0.95}{100}$ Initial starch weight $(\mathrm{g})$

\subsubsection{Preparation of hydrolyzed residues}

Residues obtained at various time intervals of hydrolysis were washed three times with distilled water, centrifuged (2000 r.p.m.) and freeze-dried. 


\subsubsection{Calculation of initial velocity}

Initial velocity calculations for wrinkled pea and other legume starches were based on the data within the first $20 \mathrm{~min}$ and $4 \mathrm{~h}$ hydrolysis period, respectively. A linear regression line was plotted by the computer and the slope was regarded as the initial velocity (Fig. A-3 in Appendix).

\subsubsection{Statistical analysis}

All determinations were replicated three times, mean values and standard deviations were reported. Analysis of variance (ANOVA) was performed by Turkey's HSD test $(\mathrm{P}<0.05)$ using statistical software SPSS 11.0 for Windows (SPSS, Inc., Chicago, IL, USA). 


\section{Chapter 4 Results and Discussion}

\subsection{Chemical composition of legume starches}

Data on the composition of the legume starches are presented in Table 4-1. The purity of the starches was judged on the basis of composition and microscopic examination. The ash content ranged from 0.01 to $0.04 \%$. This low value indicated that the starches were relatively free of hydrated fine fibers which are derived from the cell wall enclosing the starch granules. The nitrogen content was low in all starches (0.02-0.07\%), indicating the absence of non-starch lipids (lipids associated with endosperm proteins). Therefore, the total lipid (obtained by acid hydrolysis) in the legume starches $(0.35-0.84 \%)$ mainly represent the free and bound lipids. In all starches, the bound lipid content $(0.26-$ $0.81 \%)$ was higher than the surface lipid $(0.01-0.10 \%)$. Significant differences $(\mathrm{P}<0.05)$ in bound lipid content between cultivars was evident only in black bean [Black Jack $(0.43 \%)>C D C$ Nighthawk $(0.26 \%)]$ and pinto bean [Othello $(0.57 \%)>$ Sierra $(0.43 \%)]$ starches. The amounts of bound lipids in wrinkled pea $(0.80 \%)$ and lentil $(0.72-0.81 \%)$ were higher than those in the other legume starches $(0.26-0.48 \%)$. In all starches, there was no significant difference $(\mathrm{P}<0.05)$ between the amount of lipid extracted by acid hydrolysis and that extracted by solvent extraction. Most of the data on the total lipid contents of legume starches reported in the literature have been obtained by the use of solvent systems that have been proven to be ineffective in removing bound lipids. Therefore, a meaningful comparison cannot be made.

The total amylose content of legume starches has generally been reported (Hoover and Sosulski, 1991) to be in the range of $24-65 \%$. The total amylose content of the legume starches in this study (Table 4-1) ranged from 30.5 (lentil, $C D C$ Redwing) to $78.4 \%$ (wrinkled pea). There was no significant difference $(\mathrm{P}<0.05)$ in total amylose content between cultivars of the same species. The 
Table 4-1

Chemical composition $(\%)^{1}$ and some properties of legume starches

\begin{tabular}{|c|c|c|c|c|c|}
\hline \multirow{2}{*}{ Characteristics } & \multicolumn{2}{|c|}{ Black bean } & \multicolumn{2}{|c|}{ Pinto bean } & \multirow{2}{*}{ Wrinkled pea } \\
\hline & CDC Nighthawk & Black Jack & Othello & Sierra & \\
\hline Yield (\% of initial seeds) & $16.37 \pm 0.82^{e}$ & $21.80 \pm 1.06^{c, d}$ & $28.25 \pm 1.25^{b}$ & $25.01 \pm 1.50^{b, c}$ & $21.60 \pm 1.08^{c, d}$ \\
\hline Moisture & $10.99 \pm 0.16^{b, c}$ & $10.82 \pm 0.10^{b, c}$ & $11.38 \pm 0.12^{b}$ & $12.22 \pm 0.20^{a}$ & $11.76 \pm 0.23^{a, b}$ \\
\hline Ash & $0.04 \pm 0.01^{a}$ & $0.03 \pm 0.00^{a, b}$ & $0.03 \pm 0.01^{a, b}$ & $0.02 \pm 0.01^{a, b}$ & $0.01 \pm 0.00^{b}$ \\
\hline Nitrogen & $0.03 \pm 0.01^{b, c}$ & $0.05 \pm 0.01^{a, b, c}$ & $0.07 \pm 0.02^{a, b}$ & $0.08 \pm 0.03^{a}$ & $0.03 \pm 0.01^{b, c}$ \\
\hline \multicolumn{6}{|l|}{ Lipid } \\
\hline Surface lipid ${ }^{2}$ & $0.10 \pm 0.01^{a}$ & $0.08 \pm 0.01^{a, b}$ & $0.06 \pm 0.02^{b, c}$ & $0.04 \pm 0.01^{\mathrm{c}, \mathrm{d}, \mathrm{e}}$ & $0.05 \pm 0.01^{b, c, d}$ \\
\hline Bound lipid ${ }^{3}$ & $0.26 \pm 0.02^{d}$ & $0.43 \pm 0.03^{c}$ & $0.57 \pm 0.03^{b}$ & $0.43 \pm 0.02^{c}$ & $0.80 \pm 0.05^{a}$ \\
\hline Total lipid $^{4}$ & $0.35 \pm 0.02^{\mathrm{e}}$ & $0.52 \pm 0.03^{d}$ & $0.62 \pm 0.04^{c}$ & $0.48 \pm 0.01^{d}$ & $0.84 \pm 0.02^{\mathrm{a}}$ \\
\hline \multicolumn{6}{|l|}{ Amylose content } \\
\hline Apparent amylose ${ }^{5}$ & $35.21 \pm 0.68^{b}$ & $33.07 \pm 1.19^{b, c}$ & $28.36 \pm 1.62^{\mathrm{d}, \mathrm{e}}$ & $27.83 \pm 0.81^{\mathrm{d}, \mathrm{e}}$ & $68.84 \pm 1.71^{a}$ \\
\hline Total amylose $^{6}$ & $39.32 \pm 1.70^{b}$ & $37.17 \pm 0.68^{b, c}$ & $31.93 \pm 2.60^{\mathrm{d}, \mathrm{e}}$ & $31.34 \pm 0.36^{\mathrm{d}, \mathrm{e}}$ & $78.42 \pm 1.52^{\mathrm{a}}$ \\
\hline Lipid-complexed amylose $^{7}$ & $10.37 \pm 2.82^{a}$ & $11.04 \pm 3.14^{\mathrm{a}}$ & $11.18 \pm 1.92^{\mathrm{a}}$ & $11.21 \pm 1.06^{\mathrm{a}}$ & $12.22 \pm 1.96^{\mathrm{a}}$ \\
\hline Starch damage & $0.28 \pm 0.03^{\mathrm{c}, \mathrm{d}}$ & $0.27 \pm 0.04^{\mathrm{c}, \mathrm{d}}$ & $0.22 \pm 0.03^{\mathrm{d}, \mathrm{e}}$ & $0.24 \pm 0.02^{\mathrm{c}, \mathrm{d}}$ & $3.54 \pm 0.02^{\mathrm{a}}$ \\
\hline \multicolumn{6}{|l|}{ Granule size $(\mu \mathrm{m})$} \\
\hline Width & $10.0-32.0$ & $10.0-37.5$ & $10.0-29.0$ & $10.0-32.0$ & $5.0-34.0$ \\
\hline Length & $10.0-40.0$ & $10.0-41.0$ & $10.0-40.0$ & $10.0-42.0$ & $5.0-37.0$ \\
\hline Granule shape & round to oval & round to oval & round to oval & round to oval & $\begin{array}{l}\text { irregular to compound } \\
\text { /rounded rosette }\end{array}$ \\
\hline \multicolumn{6}{|c|}{ 1. Data with the same superscript in the same row are not significantly different $(P<0.05)$ by Tukey's HSD test. All data reported on dry basis and represent the mean \pm SD of three determinations. } \\
\hline \multicolumn{6}{|c|}{ 3. Lipids extracted by hot $n$-propanol-water $3: 1$ ( $/ / v$ ) from the residue left after chloroform-methanol extraction (mainly bound lipids). } \\
\hline \multicolumn{6}{|c|}{ 4. Lipids obtained by acid hydrolysis $(24 \% \mathrm{HCl})$ of the native starch. } \\
\hline \multicolumn{6}{|c|}{ 5. Apparent amylose determined by iodine binding without removal of free and bound lipids. } \\
\hline \multicolumn{6}{|c|}{$\begin{array}{l}\text { 6. Total amylose determined by iodine binding after removal of free and bound lipids. } \\
\text { 7. Total amylose - Apparent amylose }\end{array}$} \\
\hline 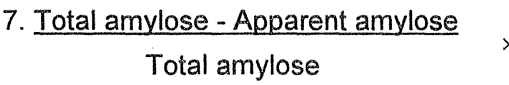 & & & & & \\
\hline
\end{tabular}


Table 4-1

Chemical composition $(\%)^{1}$ and some properties of legume starches(cont'd)

\begin{tabular}{|c|c|c|c|c|}
\hline \multirow{2}{*}{ Characteristics } & \multicolumn{2}{|c|}{ Lentil } & \multicolumn{2}{|c|}{ Smooth pea } \\
\hline & CDC Robin & CDC Redwing & CDC Mozart & CDC Sonata \\
\hline Yield(\% of initial seeds) & $27.44 \pm 1.62^{b}$ & $34.07 \pm 2.04^{\mathrm{a}}$ & $19.40 \pm 1.02^{\mathrm{d}, \mathrm{e}}$ & $28.90 \pm 2.20^{b}$ \\
\hline Moisture & $8.98 \pm 0.32^{\mathrm{e}}$ & $9.87 \pm 0.18^{d}$ & $9.47 \pm 0.15^{\mathrm{d}, \mathrm{e}}$ & $10.47 \pm 0.25^{\mathrm{c}}$ \\
\hline Ash & $0.03 \pm 0.01^{a, b}$ & $0.03 \pm 0.01^{a, b}$ & $0.02 \pm 0.01^{a, b}$ & $0.02 \pm 0.00^{\mathrm{a}, \mathrm{b}}$ \\
\hline Nitrogen & $0.04 \pm 0.02^{a, b, c}$ & $0.05 \pm 0.01^{a, b, c}$ & $0.08 \pm 0.02^{a}$ & $0.02 \pm 0.01^{\mathrm{c}}$ \\
\hline \multicolumn{5}{|l|}{ Lipid } \\
\hline Surface lipid ${ }^{2}$ & $0.01 \pm 0.01^{e}$ & $0.01 \pm 0.01^{e}$ & $0.02 \pm 0.01^{\mathrm{d}, \mathrm{e}}$ & $0.03 \pm 0.01^{\mathrm{c}, \mathrm{d}, \mathrm{e}}$ \\
\hline Bound lipid $^{3}$ & $0.81 \pm 0.03^{\mathrm{a}}$ & $0.72 \pm 0.05^{a}$ & $0.47 \pm 0.04^{b, c}$ & $0.48 \pm 0.03^{b, c}$ \\
\hline Total lipid ${ }^{4}$ & $0.83 \pm 0.02^{\mathrm{a}}$ & $0.71 \pm 0.03^{b}$ & $0.48 \pm 0.03^{d}$ & $0.52 \pm 0.03^{\mathrm{d}}$ \\
\hline \multicolumn{5}{|l|}{ Amylose content } \\
\hline Apparent amylose ${ }^{5}$ & $28.78 \pm 1.29^{\mathrm{d}, \mathrm{e}}$ & $27.35 \pm 1.70^{\mathrm{e}}$ & $31.04 \pm 0.21^{\mathrm{c}, \mathrm{d}}$ & $30.63 \pm 0.31^{\mathrm{c}, \mathrm{d}, \mathrm{e}}$ \\
\hline Total amylose ${ }^{6}$ & $32.29 \pm 1.05^{\mathrm{d}, \mathrm{e}}$ & $30.51 \pm 0.63^{e}$ & $35.09 \pm 0.64^{c, d}$ & $34.73 \pm 1.09^{c, d}$ \\
\hline Lipid-complexed amylose $^{7}$ & $10.88 \pm 0.90^{\mathrm{a}}$ & $10.34 \pm 1.74^{\mathrm{a}}$ & $11.54 \pm 1.29^{\mathrm{a}}$ & $11.83 \pm 1.76^{\mathrm{a}}$ \\
\hline Starch damage & $0.30 \pm 0.01^{c}$ & $0.15 \pm 0.02^{e}$ & $0.40 \pm 0.03^{b}$ & $0.43 \pm 0.03^{b}$ \\
\hline \multicolumn{5}{|l|}{ Granule size $(\mu \mathrm{m})$} \\
\hline Width & $8.0-28.0$ & $6.0-27.0$ & $8.0-32.0$ & $9.0-34.0$ \\
\hline Length & $8.0-36.0$ & $6.0-37.0$ & $8.0-50.0$ & $10.0-50.0$ \\
\hline Shape & $\begin{array}{l}\text { round to oval to } \\
\text { irregular }\end{array}$ & $\begin{array}{l}\text { round to oval to } \\
\text { irregular }\end{array}$ & $\begin{array}{l}\text { round to oval to } \\
\text { irregular }\end{array}$ & oval to irregular \\
\hline
\end{tabular}

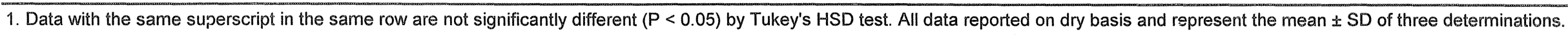

2. Lipids extracted by chloroform-methanol $2: 1(\mathrm{v} / \mathrm{v})$ at $25^{\circ} \mathrm{C}$ (mainly unbound lipids).

3. Lipids extracted by hot $n$-propanol-water $3: 1(\mathrm{v} / \mathrm{v})$ from the residue left after chloroform-methanol extraction (mainly bound lipids).

4. Lipids obtained by acid hydrolysis $(24 \% \mathrm{HCl})$ of the native starch (total lipids)

5. Apparent amylose determined by iodine binding without removal of free and bound lipids

6. Total amylose determined by iodine binding after removal of free and bound lipids.

7. Total amylose - Apparent amylose Total amylose 
extent of granule damage in wrinkled pea starch (3.54\%) was higher than that in the other legume starches $(0.22-0.43 \%)$. Significant differences $(\mathrm{P}<0.05)$ in starch damage between cultivars was observed only for lentil [CDC Robin (0.30)>CDC Redwing (0.15)].

\subsection{X-ray diffraction of native starches}

The X-ray diffraction pattern, relative crystallinity and ' $\mathrm{B}$ ' polymorphic content of the legume starches are presented in Table 4-2 and Fig.4-1 $(a, b)$ [the X-ray spectra of smooth pea, lentil and pinto bean starches (not shown) were similar to that of black bean starch (Fig. 4-1a)]. With the exception of wrinkled pea starch, all other starches showed the characteristic ' $\mathrm{C}$ ' pattern of legume starches (Hoover and Sosulski, 1985a; Gernat et al., 1990; Cheetham and Tao, 1998). The 'C' X-ray pattern was characterized by peaks at diffraction angles $2 \theta$ of $5.6^{\circ}, 15^{\circ}, 17^{\circ}, 20^{\circ}$, and $23^{\circ}$. The X-ray spectrum of wrinkled pea (Fig. 4-1b) starch was of the 'B' type, representative of tuber starches, with prominent peaks at diffraction angles $2 \theta$ of $5.6^{\circ}, 15^{\circ}, 17^{\circ}, 20^{\circ}, 22^{\circ}$, and $23^{\circ}$. The intensity of the peak at $2 \theta=5.6^{\circ}$ (characteristic of the 'B' polymorphic form) in wrinkled pea starch was higher than that in the other legume starches. However, the overall intensity of the peaks in wrinkled pea starch was much lower than that of the other legume starches (Fig. 4-1a). The relative crystallinity (RC) of wrinkled pea starch (17.7\%) was much lower than that of the other legume starches $(29.9-33.4 \%)$ (Table 4-2). There was no significant difference $(\mathrm{P}<0.05)$ in $\mathrm{RC}$ either among or between cultivars of black bean, pinto bean, smooth pea and lentil (Table 4-2). The lower RC of wrinkled pea starch could be attributed to its low amylopectin content (Table 4-1). The 'B' polymorphic content of wrinkled pea starch (92.2\%) was much higher than those of the other legume starches $(27.1-37.5 \%)$ (Table 4-2). There was no significant difference $(\mathrm{P}<0.05)$ in the ' $\mathrm{B}$ ' polymorphic content (Table 4-2) between 
Figure 4-1 X-ray diffraction patterns of native and hydrolyzed black bean (Black Jack) (Fig. 1a) and wrinkled pea starch (Fig. 1b). The X-ray pattern (native and hydrolyzed) of all other starches used in this study were similar to that of Fig. 1a. 

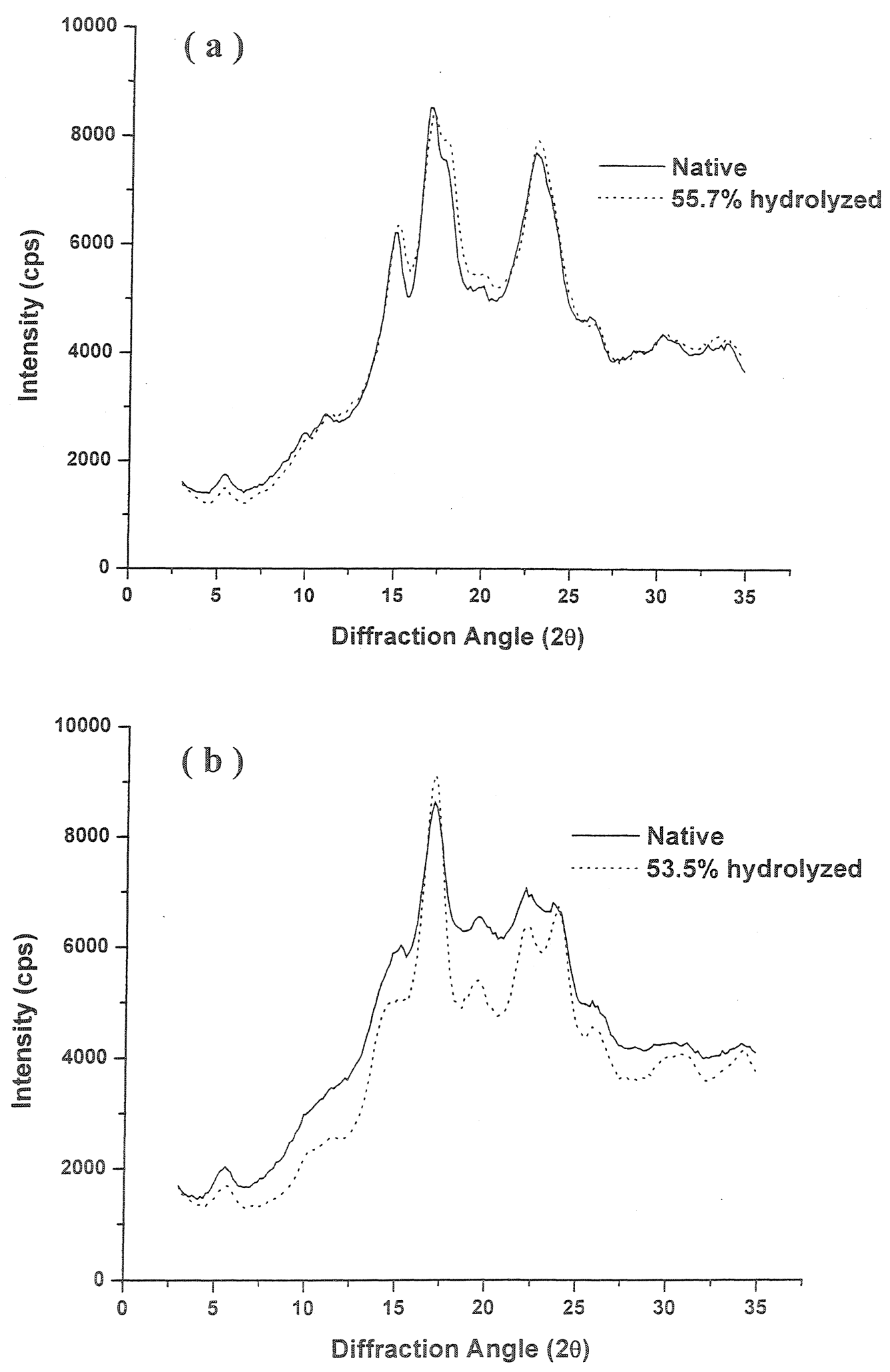
Table 4-2

X-ray diffraction pattern, relative crystallinity and 'B' polymorphic content of legume starches ${ }^{1}$

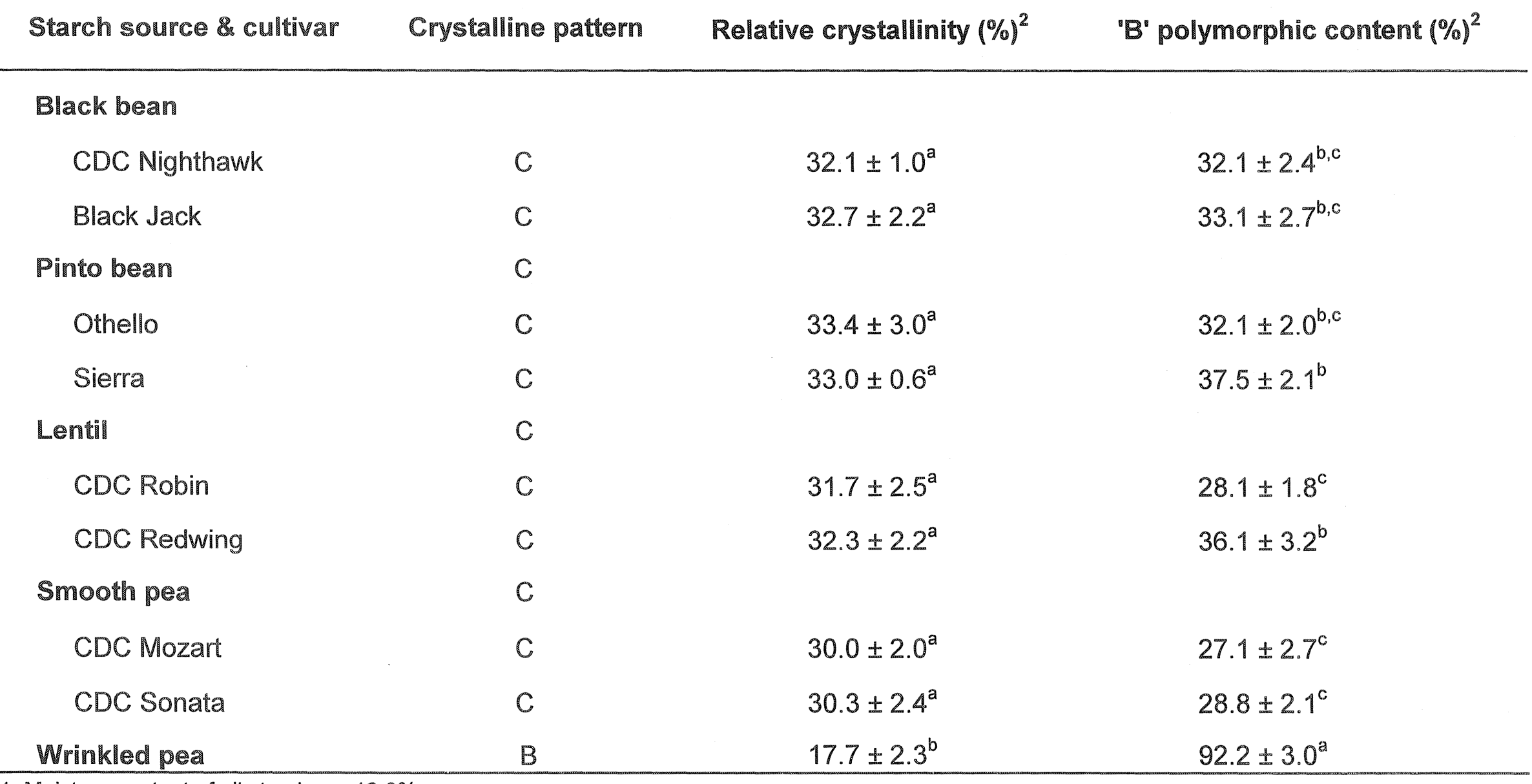

1. Moisture content of all starches $\sim 19.0 \%$.

2. Mean \pm SD of three determinations. Data with the same superscript within the same column are not significantly different $(P<0.05)$. 
cultivars of black bean, pinto bean and smooth pea. However, the 'B' polymorphic content of lentil cultivars differed significantly $(\mathrm{P}<0.05)[C D C$ Redwing $(36.1 \%)>C D C$ Robin $(28.1 \%)]$.

\subsection{Swelling factor (SF) and amylose leaching (AML) at $80^{\circ} \mathrm{C}$}

The SF and AML of native legume starches are presented in Table 4-3. The SF ranged from 3.4 (wrinkled pea) to 18.4 (lentil- CDC Robin). No significant difference $(\mathrm{P}<0.05)$ in SF was observed between cultivars of pinto bean, lentil, and smooth pea. However, cultivars of black bean differed in their SF [Black Jack (17.7) > CDC Nighthawk (8.2)]. The SF of black bean, lentil, pinto bean and smooth pea starches were generally lower than those reported for green pea (21.1), field pea (19.4), and mung bean (31.9), but comparable to those of beach pea (18.4) and grass pea (13.0) (Chavan et al., 1999; Ratnayake et al., 2001). The extent of AML at $80^{\circ} \mathrm{C}$ ranged from 11.0 (pinto bean - Othello) to $17.8 \%$ (smooth pea $-C D C$ Sonata). There was a significant difference $(P<0.05)$ in AML between cultivars of black bean (Black Jack $>C D C$ Nighthawk), pinto bean (Sierra $>$ Othello) and lentil (CDC Robin $>C D C$ Redwing). However, cultivars of smooth pea showed no significant difference $(\mathrm{P}<0.05)$ in AML. The extent of AML exhibited by the legume starches (Table 4-3) was comparable to that reported for beach pea $(9.5 \%)$, grass pea $(15.1 \%)$ and green pea $(14.3 \%)$, but was lower than that reported for mung bean starch (Chavan et al., 1999; Hoover et al., 1997).

SF has been shown to be influenced by: 1) amylose-lipid complexes (Maningat and Juliano, 1980; Tester and Morrison, 1990; Tester et al., 1993); 2) amylose content (Sasaki and Matsuki,, 1998); 3) extent of interaction between starch chains within the amorphous and crystalline domains of the granule (Hoover and Manuel, 1996) and 4) amylopectin molecular structure (Shi and Seib, 1992; Tester et al., 1993; Sasaki and Matsuki, 1998). The differences in SF among legume starches and between cultivars of the same species (Table 4-3) could be attributed to the interplay of factors 2,3, 
Table 4-3

Swelling factor (SF) and amylose leaching (AML) of native legume starches at $80^{\circ} \mathrm{C}$

$\begin{array}{lll}\text { Starch source \& cultivar } \quad \text { SF }^{1} & \text { AML }(\%)^{1}\end{array}$

\section{Black bean}

CDC Nighthawk

Black Jack

Pinto bean

Othello

Sierra

Lentil

CDC Robin

CDC Redwing

CDC Mozart

CDC Sonata
Smooth pea

$$
\begin{array}{r}
8.2 \pm 1.9^{b} \\
17.7 \pm 0.4^{a}
\end{array}
$$

$13.6 \pm 0.5^{b}$

$16.5 \pm 0.6^{a}$

$10.4 \pm 0.9^{b}$

$11.0 \pm 0.4^{b}$

$9.9 \pm 0.8^{b}$

$13.0 \pm 0.6^{b}$

$18.4 \pm 0.9^{a}$

$17.7 \pm 0.9^{a}$

$16.0 \pm 1.0^{a}$

$13.6 \pm 0.3^{b}$

$16.2 \pm 1.3^{\mathrm{a}}$

$17.6 \pm 0.5^{a}$

$16.6 \pm 0.5^{\mathrm{a}}$

$17.8 \pm 0.2^{\mathrm{a}}$

Wrinkled pea

$3.4 \pm 0.5^{\mathrm{c}}$

$11.1 \pm 0.5^{c}$

1. Mean \pm SD of three determinations. Data with the same superscript within the same column are not significantly different $(P<0.05)$. 
and 4 , since there was no significant difference $(\mathrm{P}<0.05)$ in the amount of lipid-complexed amylose chains (Table 4-1). The difference in SF between black bean cultivars (Black Jack $>$ CDC Nighthawk) suggests the presence of longer amylopectin chains in $C D C$ Nighthawk. Association between long amylopectin chains could result in the formation of a large number of double helices, and the helices could then form crystalline clusters which would increase granular stability, thereby reducing the extent of granular swelling. The lower SF (3.4) of wrinkled pea starch (Table 4-3) could be attributed to the interplay of the following factors: 1) lower amylopectin content $(17.1 \%)$ (Table 4-1); 2) longer average amylopectin chain length (CL32- $\overline{45}$ vs. CL24 -27 for the other legume starches) (Colonna et al., 1982; Colonna and Mercier, 1984; Biliaderis et al., 1981; Hoover and Sosulski, 1991; Ratnayake et al., 2002); and 3) closer packing of amylose chains [due to higher amylose (78.4\%) content (Table 41)].

The extent of AML has been shown to be influenced by: 1) the extent of interaction between amylose chains (AM-AM) and/or between amylose and the outer branches of amylopectin (AMAMP), and 2) the amount of lipid-complexed amylose chains (Ratnayake et al., 2001; Hoover and Ratnayake, 2001). In this study, the extent of AML is mainly influenced by starch chain (AM-AM, AM-AMP) interactions within the native granule, since differences in the amount of lipid-complexed amylose chains between and among legume cultivars were not significant (Table 4-1). The results (Table 4-3) indicate that the extent of AM-AM and AM-AMP interactions between cultivars follows the trend: $C D C$ Nighthawk > Black Jack; Othello > Sierra; $C D C$ Redwing > CDC Robin; CDC Mozart $\sim C D C$ Sonata. The results also indicate that the total amylose content per se does not influence AML, since wrinkled pea starch with its much higher amylose content $(78.4 \%)$ exhibited nearly the same degree of AML as did pinto bean starch (32.0\% amylose) (Table 4-1). 


\subsection{Gelatinization parameters}

The gelatinization transition temperatures $\left[T_{0}\right.$ (onset), $T_{p}$ (peak), $T_{c}$ (conclusion) and $\Delta H$ (gelatinization enthalpy)] of native starches are presented in Table 4-4. $T_{0}, T_{p}, T_{c}$ and $T_{c}-T_{0}$ of both cultivars of pinto bean were significantly $(\mathrm{P}<0.05)$ higher than those of the other legume starches. There were significant $(P<0.05)$ differences in $T_{0}, T_{p}$ and $T_{c}$ between cultivars of black bean $(C D C$

Nighthawk > Black Jack), pinto bean (Othello $>$ Sierra) and lentil $(C D C$ Redwing $>$ CDC Robin). Wrinkled pea starch showed no endotherm (Table 4-4). Significant differences in $\Delta H$ were evident only between cultivars of black bean $(C D C$ nighthawk $>$ black jack) and lentil $(C D C$ redwing $>C D C$ robin). Noda et al. (1998) demonstrated that gelatinization temperatures are influenced by the molecular architecture of the crystalline region which corresponds to the distribution of amylopectin short chains (DP6 - 11) and not by the proportion of crystalline region, which corresponds to the amylose/amylopectin ratio. The above authors showed by studies in fifty one cultivars of sweet potato and twenty seven cultivars of buckwheat starches that a low $T_{0}, T_{p}$ and $T_{c}$ reflects the presence of abundant short amylopectin chains. Shi and Seib (1995) have also shown by studies on $a e w x$, ae $d u$ $w x, w x$ and $d u w x$ maize starch, that $a e w x$ starch having the lowest proportion of short chains (DP6 11) exhibited the highest gelatinization temperature and enthalpy. This suggests that the higher $T_{0}, T_{p}$ and $T_{c}$ shown by black bean and pinto bean starches indicate the presence of longer amylopectin chains (Table 4-4). The wider $T_{c}-T_{0}$ exhibited by pinto and black bean starches (Table 4-4) suggests the presence of crystallites of varying stability.

Waigh et al. (2000b) have postulated that two stages are involved during starch gelatinization in excess water. The first stage involves a slow side by side dissociation of helices and the second stage involves a rapid helix $\rightarrow$ coil transition. Cooke and Gidley (1992) have claimed that $\Delta H$ reflects 
Table 4-4

Gelatinization characteristics of native legume starches ${ }^{1}$

\begin{tabular}{|c|c|c|c|c|c|}
\hline Starch source \& cultivar & $\mathrm{TO}^{2}\left({ }^{\circ} \mathrm{C}\right)$ & $\operatorname{Tp}\left({ }^{\circ} \mathrm{C}\right)$ & $\operatorname{Te}\left({ }^{\circ} \mathrm{C}\right)$ & $\left.\mathrm{TC}-\mathrm{To}^{\circ} \mathrm{C}\right)$ & $\Delta \mathrm{H} / \mathrm{AP}^{3}(\mathrm{~mJ} / \mathrm{mg})$ \\
\hline \multicolumn{6}{|l|}{ Black bean } \\
\hline Black Jack & $61.0 \pm 0.2^{d}$ & $70.9 \pm 0.3^{c}$ & $81.2 \pm 0.3^{d}$ & $20.3 \pm 0.5^{b}$ & $17.8 \pm 0.6^{b, c, d}$ \\
\hline CDC Nighthawk & $65.7 \pm 0.3^{a}$ & $74.9 \pm 0.4^{b}$ & $86.7 \pm 0.2^{b}$ & $21.0 \pm 0.1^{b}$ & $20.1 \pm 1.0^{a}$ \\
\hline \multicolumn{6}{|l|}{ Pinto bean } \\
\hline Sierra & $63.3 \pm 0.2^{c}$ & $70.9 \pm 0.2^{c}$ & $85.1 \pm 0.7^{c}$ & $21.8 \pm 0.5^{b}$ & $18.8 \pm 0.1^{a, b}$ \\
\hline \multicolumn{6}{|l|}{ Smooth pea } \\
\hline CDC Sonata & $60.1 \pm 0.2^{e}$ & $66.0 \pm 0.2^{e}$ & $76.4 \pm 0.2^{e}$ & $16.3 \pm 0.4^{c}$ & $15.5 \pm 0.5^{e, f}$ \\
\hline CDC Redwing & $63.9 \pm 0.1^{b, c}$ & $70.6 \pm 0.1^{c}$ & $80.1 \pm 0.9^{d}$ & $16.2 \pm 1.0^{c}$ & $16.3 \pm 0.4^{d, e}$ \\
\hline CDC Robin & $61.1 \pm 0.2^{d}$ & $67.7 \pm 0.1^{d}$ & $77.3 \pm 0.3^{e}$ & $16.2 \pm 0.2^{c}$ & $14.6 \pm 0.1^{8}$ \\
\hline
\end{tabular}

Wrinkled pea

1. Mean $\pm S D$ of three determinations. Data with the same superscript in the same column are not significantly different $(P<0.05)$.

2. $T_{0}, T_{p}, T_{c}$ indicate the onset, peak and conclusion temperature of gelatinization, respectively.

3. Gelatinization enthalpy ( $\mathrm{mJ} / \mathrm{mg}$ ) / Amylopectin content (\%)

4. Gelatinization characteristics were not detected within the temperature range $25^{\circ} \mathrm{C}$ to $145^{\circ} \mathrm{C}$. 
primarily the loss of double helical order rather than loss of crystalline register. The larger $\Delta H$ values for starches of black bean and pinto bean cultivars (Table 4-4) suggest that interactions via hydrogen bonding between double helices that are packed in clusters forming the crystalline region of the above starches are probably more extensive (due to longer chains in amylopectin) than in smooth pea and lentil starches. Consequently, the $\Delta \mathrm{H}$ associated with dissociation and unraveling (hydrogen bonds are broken during both stages of gelatinization) and melting of the double helices would be of a higher order of magnitude in pinto bean and black bean starches.

Jenkins (1994) has postulated that in excess water, gelatinization is primarily a swelling driven process. Water uptake by the amorphous background regions is accompanied by swelling within these regions. Swelling acts to destabilize the amylopectin crystallites within the crystalline lamellae, which are broken, Thus, the DSC endotherm represents solvation assisted melting of amylopectin crystallites. This suggests, that the absence of an endotherm for wrinkled pea starch (within the temperature range $20-145^{\circ} \mathrm{C}$ ) is probably due to its low degree of swelling (Table 4-3) and consequently, a higher thermal input $\left(>145^{\circ} \mathrm{C}\right)$ would be required for crystallite melting.

\subsection{Hydrolysis patterns}

The hydrolysis by porcine pancreatic $\alpha$-amylase in black bean (Fig. 4-2a), lentil (Fig. 4-2d) and wrinkled pea (Fig. 4-2e) starches was biphasic, a relatively rapid rate initially followed by a progressively decreasing rate thereafter (Fig. 4-2a,d,e). However, in pinto bean (Fig. 4-2b) and smooth pea (Fig. 4-2c) starches, the decrease in the rate of hydrolysis, following the initial rapid increase was much less than in the other starches (Fig. 4-2a,d,e). The hydrolysis curves of black bean cultivars (Fig. 4-2a), lentil cultivars (Fig. 4-2d), and wrinkled pea (Fig. 4-2e) showed a plateau at hydrolysis levels of 93 (Fig. 4-2a), 85 (Fig. 4-2d) and 65\% (Fig. 4-2e ), respectively. 
Figure 4-2 Hydrolysis patterns $\left(37^{\circ} \mathrm{C}\right)$ by porcine pancreatic $\alpha$-amylase with legume starches.
a) black bean; b) pinto bean; c) smooth pea; d) lentil; e) wrinkled pea. 

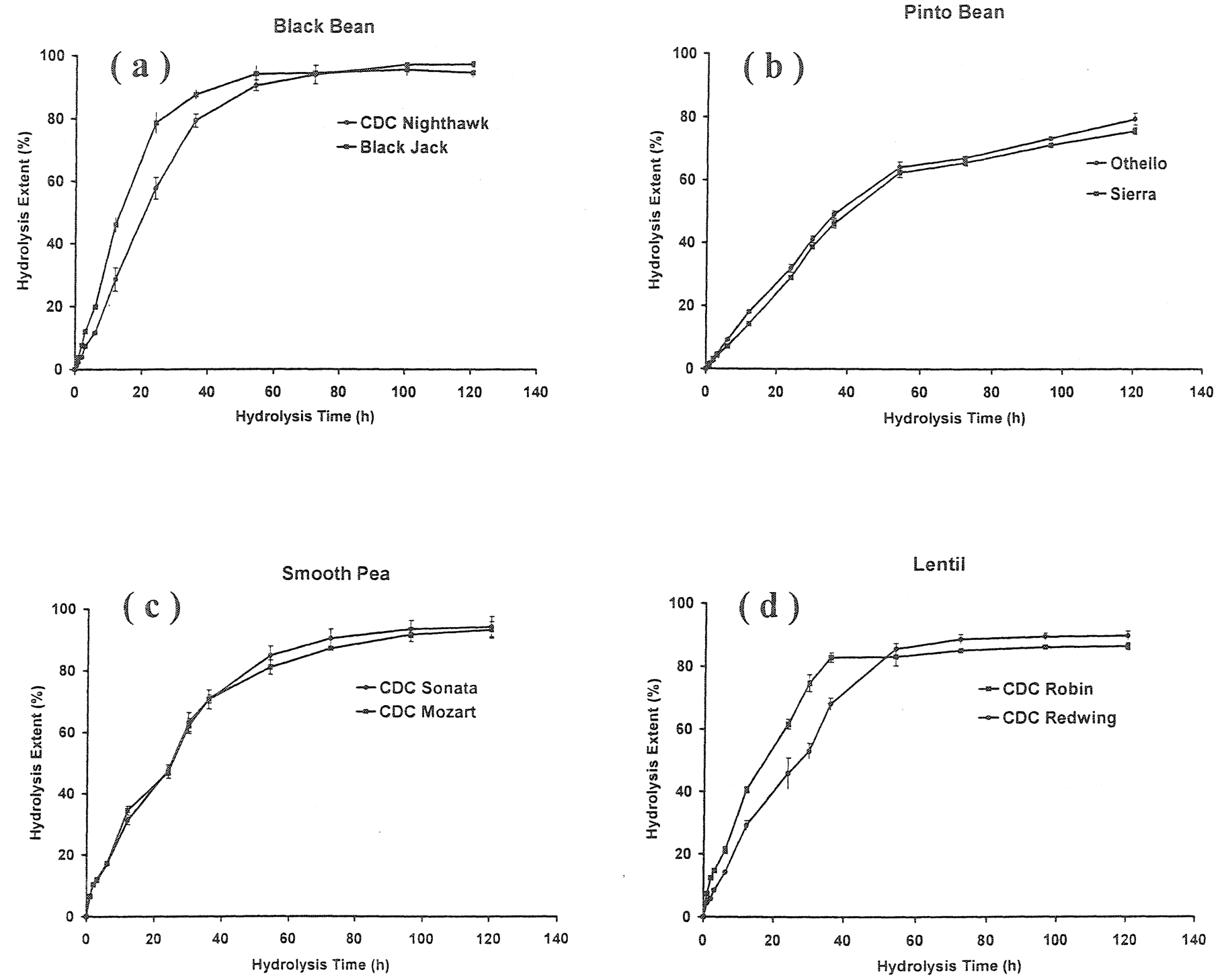

Wrinkled Pea

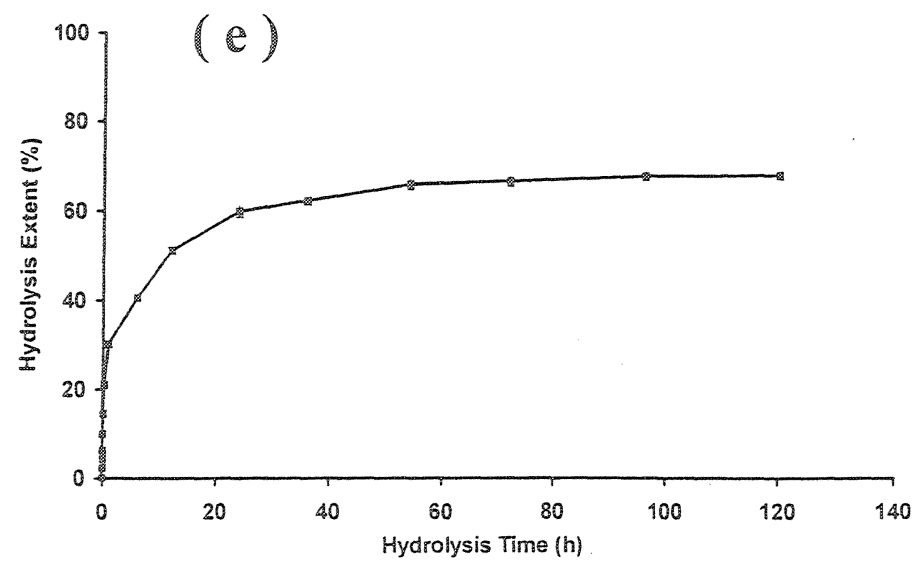


Table 4-5

Initial velocity of a-amylase hydrolysis of legume starches ${ }^{1}$

Starch source \& cultivar

Initial velocity ${ }^{2}$

$(\% / h)$

Black bean

Black Jack

$3.9 \pm 0.3^{c}$

CDC Nighthawk

$2.3 \pm 0.4^{\mathrm{d}, \mathrm{e}}$

Pinto bean

Othello

$1.5 \pm 0.3^{e}$

Sierra

$1.5 \pm 0.2^{e}$

Smooth pea

CDC Sonata

$5.5 \pm 0.4^{b}$

CDC Mozart

$5.4 \pm 0.5^{b}$

Lentil

CDC Robin

$5.4 \pm 0.2^{b}$

CDC Redwing

$2.9 \pm 0.3^{d}$

Wrinkled pea

$241.6 \pm 5.6^{a}$

1. Initial velocity calculation for wrinkled pea and the other legume starches are based on the data within the first $20 \mathrm{~min}$ and $4 \mathrm{~h}$, respectively. Data represent mean $\pm S D$ of three determinations.

2. Data with the same superscript in the column are not significantly different $(P<0.05)$. 
This plateau, appeared at the same time for black bean cultivars $(55 \mathrm{~h})$, but was different for cultivars of lentil [CDC Robin (35h), CDC Redwing (55 h)]. Cultivars of pinto bean (Fig.4-2b) and smooth pea (Fig.4-2c) starches did not exhibit a plateau during the hydrolysis period. Wrinkled pea starch exhibited a higher initial velocity $(241.6 \% / \mathrm{h})$ than the other legume starches $(1.4-5.5 \% / \mathrm{h})($ Table $4-5)$. Difference in initial velocity between cultivars was evident only in black bean [Black Jack $(3.9 \% / \mathrm{h})>$ $\operatorname{CDC}$ Nighthawk $(2.3 \% / \mathrm{h})]$ and lentil $[C D C$ Robin $(5.4 \% / \mathrm{h})>C D C$ Redwing $(2.9 \% / \mathrm{h})]$. During the initial rapid phase of hydrolysis, cultivars of black bean (Fig. 4-2a) and lentil (Fig. 4-2d) were hydrolyzed to different extents. This difference was most marked between the $5^{\text {th }}$ and $40^{\text {th }}$ hour of hydrolysis in both black bean (Black Jack $>C D C$ Nighthawk) and lentil (CDC Robin $>C D C$ Redwing) cultivars. However, during the above time period, there was no significant difference $(\mathrm{P}<0.05)$ in the extent of hydrolysis between cultivars of pinto bean (Fig. 4-2b) and smooth pea (Fig. 4-2c) starches. After 120h, there was no difference in the extent of hydrolysis between cultivars of each legume species (Fig. 4-2). At the end of this time period, the extent of hydrolysis among the legume starches followed the order: black bean $>$ lentil $>$ smooth pea $>$ wrinkled pea $>$ pinto bean (Fig. 4-2).

It is appropriate at this stage to give a brief description of the mechanism of $\alpha$-amylase action, which would then enable a subsequent discussion of the hydrolysis kinetics of the legume starches.

Porcine pancreatic $\alpha$-amylase (PPA) has been shown to have five binding sites with the catalytic site located between subsites 2 and 3, with two subsites to the right and three subsites to the left of the catalytic site (Robyt and French, 1970). These authors have shown that only the chain to the right diffuses away after the initial cleavage and the remaining chain to the left diffuses to fill the open binding subsites to give maltose $(\mathrm{G} 2)$, maltotriose $(\mathrm{G} 3)$ and maltotetraose $(\mathrm{G} 4)$ as products in a multiple attack mechanism. The products of hydrolysis, particularly $\mathrm{G} 2$ and $\mathrm{G} 3$, are known to have an inhibitory effect on the action of $\alpha$-amylase in vitro (Robyt and French, 1970; Elodi et al., 1972; 
Leloup et al., 1991). G2 and G3 have been shown to bind strongly to PPA, thereby impeding their adsorption onto crystalline spherulites of short chain amylose (Leloup et al., 1991).

The appearance of a plateau during hydrolysis of black bean (Fig. 4-2a), smooth pea (Fig. 42c), lentil (Fig. 4-2d) and wrinkled pea (Fig. 4-2e) starches reflects the interplay of the following factors: 1) inhibition of $\alpha$-amylase activity by G2 and G3 (the occupation of the subsites to the left of the catalytic center by G2 and G3 would prevent further hydrolysis of starch chains); 2) formation of crystalline regions during hydrolysis (hydrolyzed amylose chains may retrograde forming crystalline regions which could hinder the accessibility of $\alpha$-amylase to the glucosidic bond), and 3) depletion of substrate. The absence of a plateau in pinto bean starch (Fig. 4-2b), even after 120h of hydrolysis, suggests strong interactions between starch chains within the amorphous and crystalline domains of the native granule. These interactions probably reduce the degree of accessibility of the glucosidic bonds to $\alpha$-amylase, thereby decreasing the rate of release of $\mathrm{G} 2$ and $\mathrm{G} 3$ during hydrolysis. Thus, the time taken for $\alpha$-amylase inhibition by G2 and G3 would be much longer in pinto bean than in other legume starches.

Jenkins and Donald (1995) have postulated that co-crystallization of amylose with amylopectin disrupts amylopectin crystallites. Their postulation was based on the observation that the electron density difference between the crystalline and amorphous lamella decreases with increased amylose content. Cheetham and Tao (1998) have shown by X-ray diffraction studies on native maize starches of varying amylose content $(0-84 \%)$ that crystallinity decreases with increased amylose content in both 'A' and ' $\mathrm{C}$ ' type starches. This suggests that the low RC (17.7\%) of wrinkled pea starch (Table 4-2) is probably due to disrupted amylopectin crystallites. The extent of this disruption is likely to be higher in wrinkled pea starch than in the other legume starches, due to its higher amylose content (78.1\%) (Table 4-1) and the longer average amylopectin chain length [CL $32-45$ vs. $\bar{C} L 24-27]$ in the other legume 
starches (Biliaderis et al., 1981; Colonna et al., 1982; Colonna and Mercier, 1984; Hoover and Sosulski, 1991; Ratnayake et al., 2002) ]. Thus, the higher initial velocity (Table 4-5) exhibited by wrinkled pea starch could be a reflection of a highly disrupted crystalline structure. It is also likely, that the higher initial velocity of wrinkled pea starch could also be a reflection of the higher extent of granule damage incurred during starch isolation (Table 4-1).

Tester and Sommerville (2000) have postulated that granular swelling is controlled by granule order which controls $\alpha$-amylolysis. The difference between black bean cultivars with respect to SF (Black Jack $>C D C$ Nighthawk) and AML (Black Jack $>C D C$ Nighthawk) at $80^{\circ} \mathrm{C}$ (Table 4-3) suggests that starch chain interactions (amylose-amylose, amylopectin-amylopectin, amyloseamylopecin) within native starch granules are of a higher order of magnitude in CDC Nighthawk. Strong interactions between starch chains would not only reduce granular swelling at $37^{\circ} \mathrm{C}$ (assay temperature), but also could hinder the chair $\rightarrow$ half chair conformational transition (the degree of accessibility of the glucosidic oxygen to $\alpha$-amylase is influenced by this transition) of the Dglucopyranosyl unit during hydrolysis [Hoover, 2000]. This would then explain the initial velocity difference between the black bean cultivars (Black Jack $>$ CDC Nighthawk) (Table 4-5). The difference in initial velocity between cultivars of lentil ( $C D C$ Robin $>C D C$ Redwing) can be attributed to a lower degree of interaction between starch chains in $C D C$ Robin [indicated by a higher SF and a higher degree of AML (Table 4-3)]. The marginal difference in SF and AML between cultivars of pinto bean and smooth pea (Table 4-3) may explain their nearly identical initial velocities (Table 4-5).

The above explanation based on SF and AML seems plausible, since differences between cultivars with respect to granule size (Table 4-1), amylose content (Table 4-1), starch damage (Table 41), lipid-complexed amylose chains (Table 4-1), relative crystallinity (Table 4-2) and 'B' polymorph 
content (Table 4-2) are too small to account for the large difference in initial velocity between cultivars of black bean and lentil.

\subsection{Morphology of native starch granules and enzyme hydrolyzed starch residues}

The morphologies of native legume starches and their hydrolyzed residues (at nearly equivalent levels of hydrolysis) are presented in Figs. 4-3 - 4-7. The granules of native black bean (Figs. 4-3a, b),

pinto bean (Figs. 4-4a, b), smooth pea (Figs. 4-5a, b) and lentil (Figs. 4-6a, b) ranged from oval to irregular in shape. The width and length of the granules were within the range $5.0-37.5 \mu \mathrm{m}$ and $5.0-$ $50 \mu \mathrm{m}$, respectively (Table 4-1). Wrinkled pea starch appeared to be a mixture of simple and compound granules (Figs. 4-7a,b,c). Many of the compound granules contained clusters (3-5) of individual granules. Many of the simple granules (mainly small granules) were round in shape; whereas large granules (forming the cluster) were irregular in shape. The width and length of small and large granules ranged from 5.0 to $34.0 \mu \mathrm{m}$ and 5.0 to $37.0 \mu \mathrm{m}$, respectively (Table $4-1$ ). In native wrinkled pea starch, some of the larger granules showed extensive damage, resulting in splitting and exposure of the internal layering (Fig. 4-7b). A similar observation was reported by Bertoft et al (1993). The granule surfaces of native pinto bean (Figs. 4-4a, b), smooth pea (Figs. 4-5a, b) and lentil (Figs. 4-6a, b) starches were smooth and showed no evidence of pores, fissures or indentations. However, in black bean (Figs. 4-3a, b) and wrinkled pea (Figs. 4-7a,b,c) starches, indentations were present on the surface of some granules, whereas others were smooth and free of pores, fissures and indentations. There was no difference in granule morphology between cultivars of the same legume species.

The mode of $\alpha$-amylase attack was examined by SEM during the early stages of hydrolysis $(<$ $20 \%$, and at nearly equivalent levels of hydrolysis. Hydrolyzed (15.4\%) black bean starch (Black 
Figure 4-3 Scanning electron micrographs of native black bean (Black Jack) granules (a \& b) and hydrolyzed (15.4\%) granules (c \& d). 

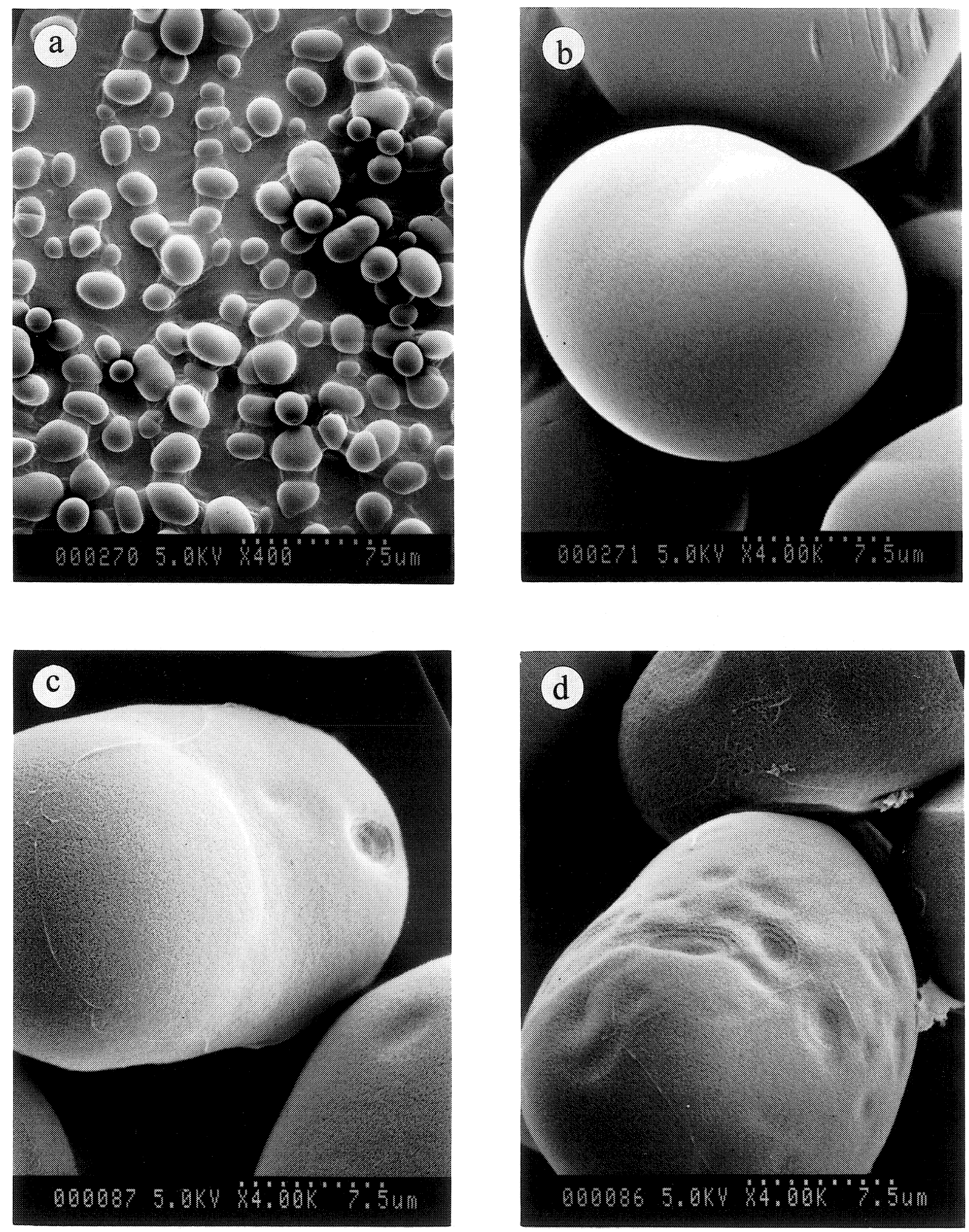
Figure 4-4 Scanning electron micrographs of native pinto bean (Othello) granules (a \& b) and hydrolyzed (18.1\%) granules (c \& d). 

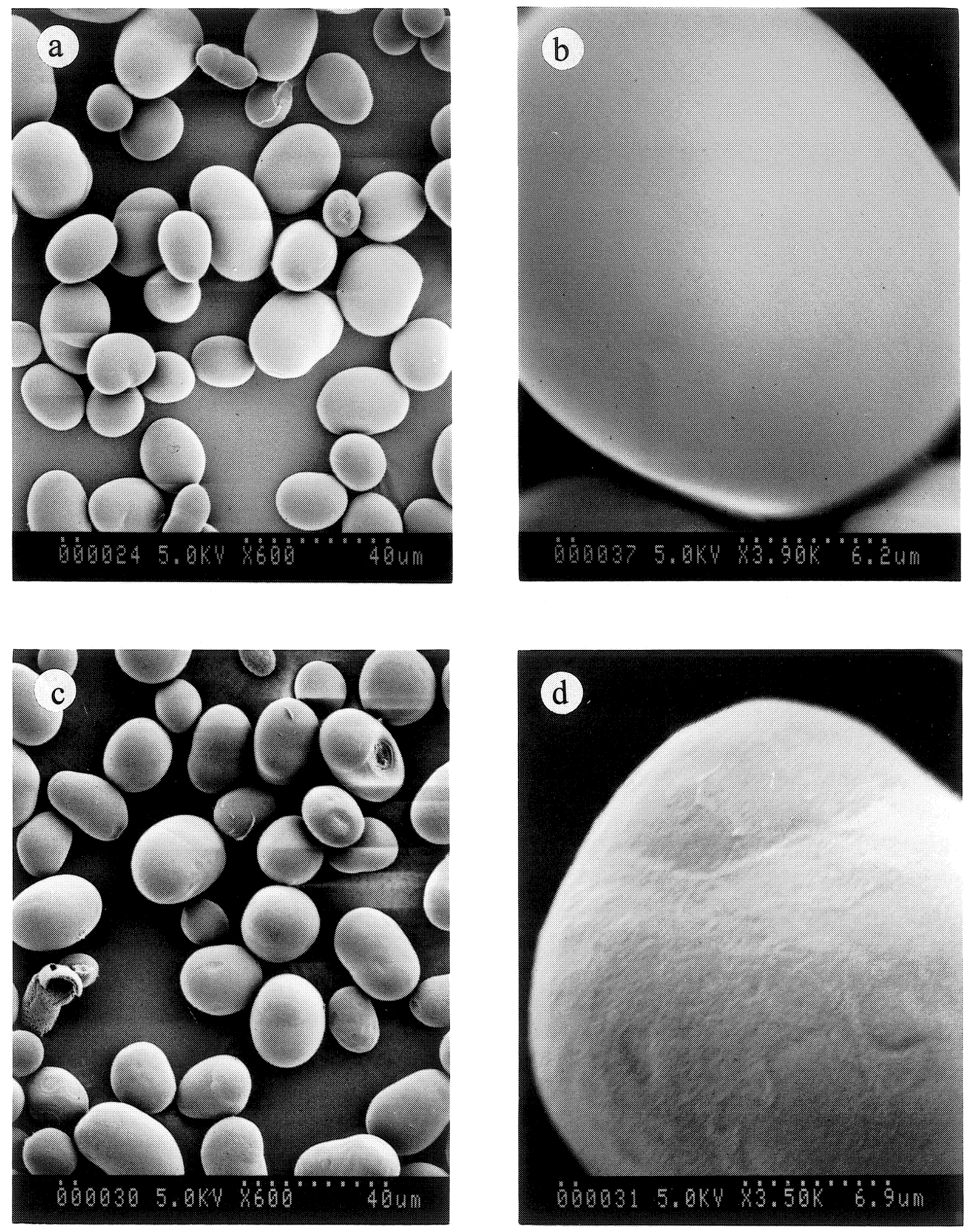
Figure 4-5 Scanning electron micrographs of native smooth pea (CDC Sonata) granules (a \& b) and hydrolyzed (17.0\%) granules (c \& d). 

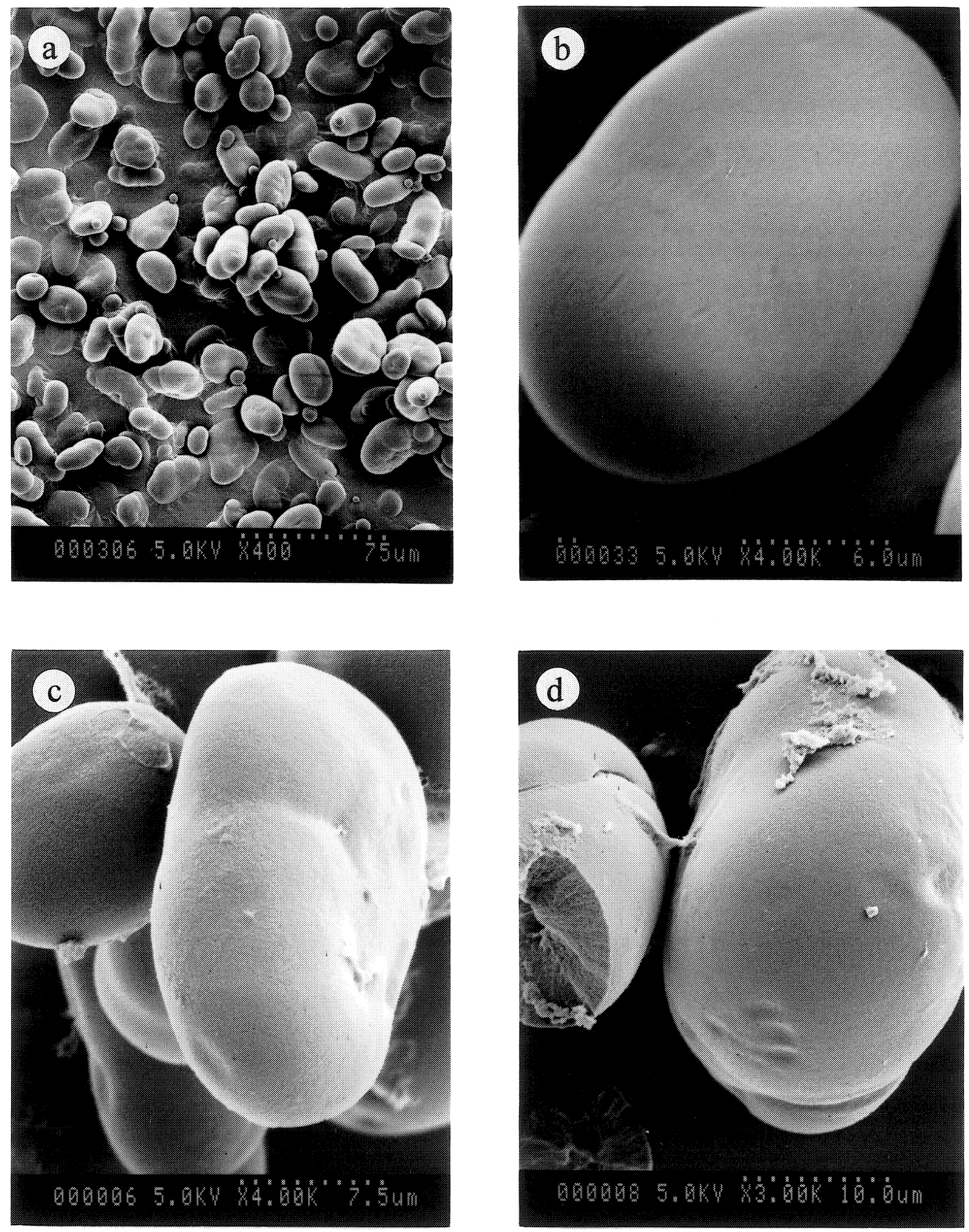
Figure 4-6 Scanning electron micrographs of native lentil (CDC Redwing) granules (a \& b) and hydrolyzed (14.2\%) granules (c \& d). 

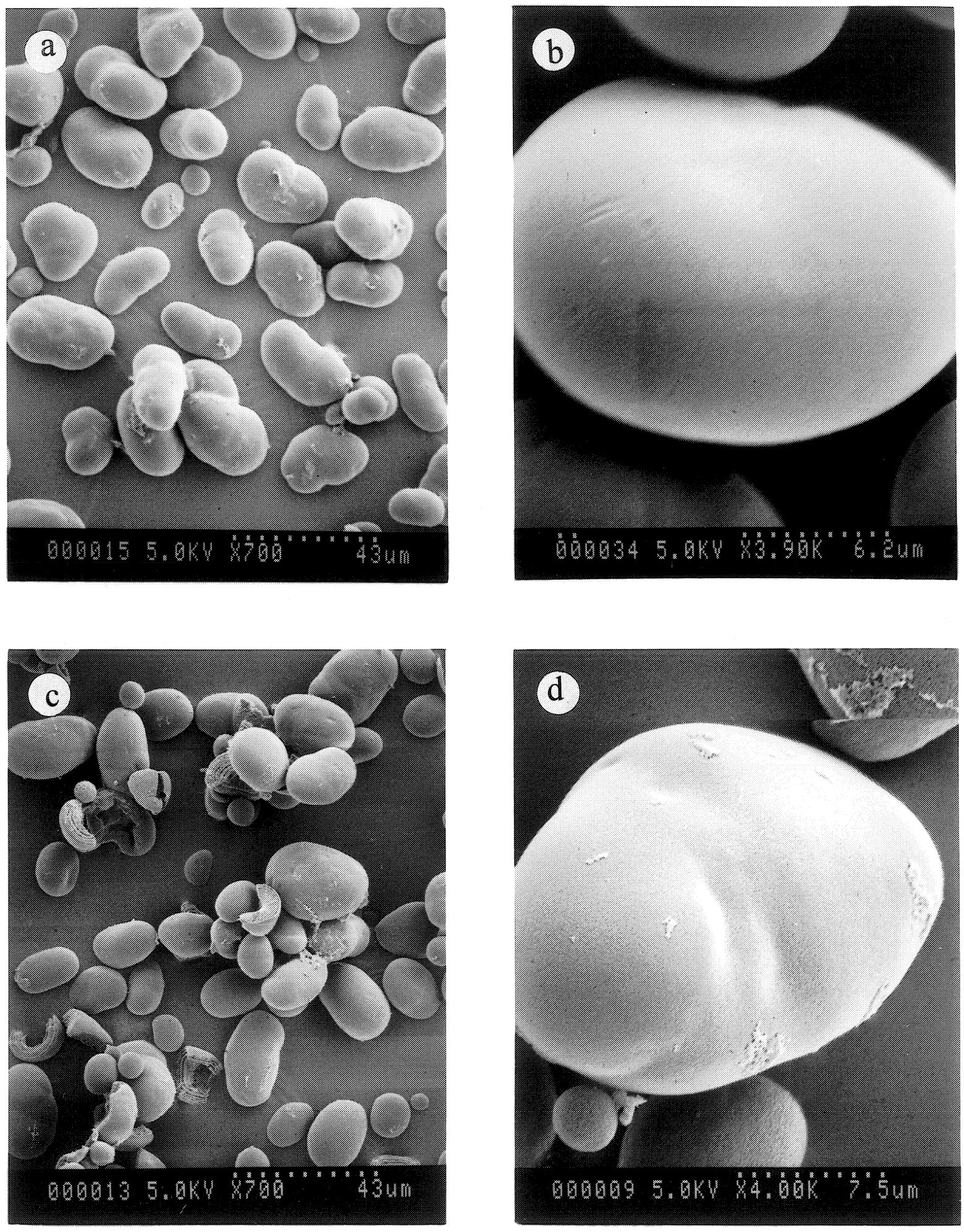
Figure 4-7 Scanning electron micrographs of native $(a, b, c)$ wrinkled pea granules and hydrolyzed (16.2\%) granules (d). 

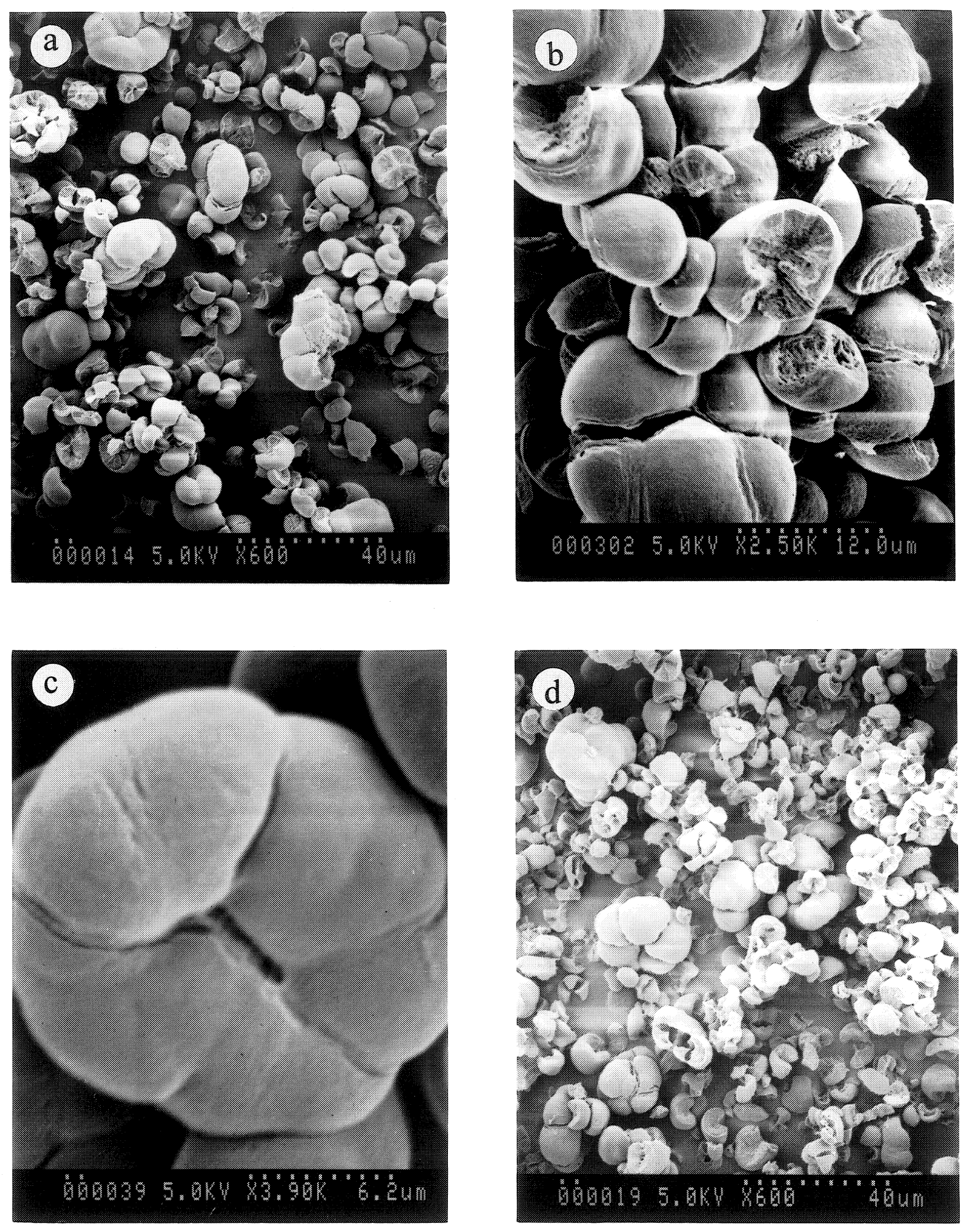
Jack) granules showed slightly roughened surfaces and disc like depressions and the number of depressions varied from granule to granule (Figs. 4-3c, d). Roughened surfaces and disc like depressions were also visible on the surfaces of hydrolyzed (18.1\%) pinto bean (Othello) starch. However, the depth of these depressions (Fig. 4-4d) was much lower than that in black bean (Fig. 43d) starch. In hydrolyzed (17\%) smooth pea starch (CDC Sonata), some granules $(\sim<1 \%$ of the total population) had fragmented so that their interior parts were exposed (Fig. 4-5d), whereas, the major population of the granules was intact and exhibited only roughened surfaces and disc like depressions (Figs. 4-5c,d). Lentil starch (CDC Robin) at 14.2\% hydrolysis behaved similarly to smooth pea starch with respect to roughened surfaces and granule fragmentation $(<1 \%$ of the granule population). However, none of the hydrolyzed granules showed disc like depressions on their surfaces. In hydrolyzed (16.2\%) wrinkled pea starch (Fig. 4-7d), several of the large granules had fragmented, exposing their interior structure. However, some granules were still intact with no evidence of $\alpha$ amylase attack. Furthermore, the extent of fragmentation in wrinkled pea starch was much higher than that in smooth pea and lentil starches. A similar pattern of hydrolysis was observed by Bertoft et al. (1993) on wrinkled pea starch hydrolyzed by Bacillus amyloliquefaciens.

\section{$4.7 \mathrm{X}$-ray analysis of hydrolyzed starch residues}

The X-ray patterns of native and control (treated without $\alpha$-amylase) and the hydrolyzed residues of the legume starches are presented in Figs. 4-1a, $b$ and Table 4-6. There was no significant difference in the X-ray pattern, relative crystallinity or 'B' polymorphic content between native and control starches (Table 4-6). Hydrolysis did not change the X-ray pattern, relative crystallinity or the 'B' polymorphic content of black bean (Black Jack), pinto bean (Othello), smooth pea $(C D C$ Sonata), and lentil (CDC Robin) starches (Table 4-6). This was also true for the other cultivars of the 
Table 4-6

X-ray diffraction parameters of $\alpha$-amylase hydrolyzed legume starch residues

\begin{tabular}{|c|c|c|c|}
\hline Starch source \& cultivar & Crystalline pattern & Relative crystallinity $(\%)^{1}$ & ${ }^{\prime B}$ 'Polymorphic content( $\left.\%\right)^{1}$ \\
\hline \multicolumn{4}{|l|}{ Black bean } \\
\hline \multicolumn{4}{|l|}{ Black Jack } \\
\hline native & C & $32.7 \pm 2.2^{a}$ & $33.1 \pm 2.7^{f}$ \\
\hline control ${ }^{2}$ & C & $32.3 \pm 2.2^{a}$ & $33.8 \pm 2.8^{f}$ \\
\hline hydrolyzed (55.7\%) & C & $28.7 \pm 2.5^{a}$ & $31.7 \pm 2.0^{f}$ \\
\hline \multicolumn{4}{|l|}{ Pinto bean } \\
\hline \multicolumn{4}{|l|}{ Othello } \\
\hline native & C & $33.4 \pm 3.0^{b}$ & $32.1 \pm 2.0^{9}$ \\
\hline control $^{2}$ & C & $32.9 \pm 2.6^{b}$ & $32.4 \pm 1.2^{g}$ \\
\hline hydrolyzed (45.6\%) & C & $29.4 \pm 2.0^{b}$ & $33.4 \pm 1.9^{9}$ \\
\hline \multicolumn{4}{|l|}{ Smooth pea } \\
\hline \multicolumn{4}{|l|}{ CDC Sonata } \\
\hline native & C & $30.3 \pm 2.4^{c}$ & $28.8 \pm 2.1^{h}$ \\
\hline control $^{2}$ & C & $30.0 \pm 1.7^{c}$ & $28.0 \pm 1.7^{h}$ \\
\hline hydrolyzed (41.6\%) & C & $29.0 \pm 1.7^{c}$ & $27.1 \pm 2.6^{h}$ \\
\hline \multicolumn{4}{|l|}{ Lentil } \\
\hline \multicolumn{4}{|l|}{ CDC Robin } \\
\hline native & C & $31.7 \pm 2.5^{d}$ & $28.1 \pm 1.8^{i}$ \\
\hline control $^{2}$ & C & $31.0 \pm 2.0^{d}$ & $28.1 \pm 2.1^{i}$ \\
\hline hydrolyzed $(48.9 \%)$ & C & $28.2 \pm 2.1^{d}$ & $27.8 \pm 2.8^{i}$ \\
\hline \multicolumn{4}{|l|}{ Wrinkled pea } \\
\hline native & $\mathrm{B}$ & $17.7 \pm 2.3^{\mathrm{e}}$ & $92.2 \pm 3.0^{j}$ \\
\hline control $^{2}$ & $\mathrm{~B}$ & $17.8 \pm 1.7^{e}$ & $91.3 \pm 2.3^{j}$ \\
\hline hydrolyzed $(53.5 \%)$ & $\mathrm{B}$ & $33.4 \pm 3.1^{\mathrm{e}}$ & $89.8 \pm 2.2^{j}$ \\
\hline
\end{tabular}

1. Mean $\pm S D$. For each cultivar, data with the same superscript in the same column are not significantly different $(P<0.05)$.

2. Treated without $\alpha$-amylase but subjected to the same experimental conditions. 
above starches (data and figures not shown). The hydrolyzed residues of wrinkled pea starch also showed an unchanged X-ray pattern (Fig. 4-1b) and 'B' polymorphic content (Table 4-6). However, relative crystallinity increased (17.8 to $33.4 \%$ ) substantially on hydrolysis (Table 4-6).

Several researchers have shown that $\alpha$-amylases can simultaneously solubilize both amorphous and crystalline regions of starch granules (Leach and Schoch, 1961; Colonna et al., 1988; Lauro et al., 1999). This was based on the observation that $\alpha$-amylolysis did not produce an increase in crystallline. However, crystallinity and gelatinization enthalpy of barley starches have been shown to decrease during the later stages of $\alpha$-amylolysis (Lauro et al., 1999). This suggests that extensive hydrolysis effectively destroys and solubilizes the crystalline areas of the granule. However, the exact mechanism by which starch crystallites are degraded by $\alpha$-amylase remains controversial. Comparison of our X-ray data with that of Lauro et al., 1999 suggests that crystallites of legume starches are more resistant to $\alpha$-amylolysis than the 'A' type crystallites of barley starch. This is based on the observation that even at $55 \%$ hydrolysis, the relative crystallinity of black bean starch remained unchanged (Table 4-6). The increase in relative crystallinity on hydrolysis of wrinkled pea starch could be attributed to interaction (retrogradation) between partially hydrolyzed amylose chains (dextrins) during the hydrolysis period. This interaction would be of a greater order of magnitude in wrinkled pea starch, due to its higher amylose content (Table 4-1). A high amylose content may have resulted in amylose chains being in close proximity to each other within the amorphous domains of the granule, thus facilitating rapid interaction between hydrolyzed amylose chains. It is highly unlikely that the above interactions are influenced by the temperature of incubation $\left(37^{\circ} \mathrm{C}\right)$, since the relative crystallinity of both native and control wrinkled pea starches were identical (Table 4-6). 


\subsection{Apparent amylose content of hydrolyzed starch residues}

The changes in apparent amylose content (AAC) at different times during hydrolysis are presented in Fig. 4-8. In all starches, AAC decreased with hydrolysis time and the extent of this decrease was most pronounced in wrinkled pea starch. At $60 \%$ hydrolysis, AAC decreased from 68.5 to $28.0 \%$ for wrinkled pea starch. For the other legume starches, the decrease in AAC at $60 \%$ hydrolysis ranged from 9 to $21 \%$ (Fig. 4-8). There was no significant difference $(\mathrm{P}<0.05)$ in the extent of decrease in AAC between cultivars of pinto bean, smooth pea and lentil starches. However, in black bean starches, the decrease in AAC was higher in Black Jack (21\%) than in CDC Nighthawk (12.0\%).

As discussed earlier, disruption of amylopectin crystallites by amylose was most pronounced in wrinkled pea starch. Consequently, the degree of accessibility of $\alpha$-amylase to amylose chains within the amorphous domains of the granule would be of a very high order of magnitude in wrinkled pea starch. This would explain the rapid and large decrease in AAC content upon hydrolysis (Fig. 4-8e). Amylose leaching measurements (Table 4-3) showed that among legume starches, differences in the magnitude of starch chain interactions (AM-AM and/or AM-AMP) were more pronounced between cultivars of black bean $(C D C$ Nighthawk $>$ Black Jack). This suggests that the differences in the extent

of decrease in AAC between black bean cultivars (Fig. 4-8a) reflect differences in the degree of accessibility of $\alpha$-amylase to amylose chains within the amorphous domains of the granule. Biliaderis et al. (1981) showed that on acid hydrolysis, the AAC of wrinkled pea starch (64.0\%) decreased slowly reaching a value of $26.0 \%$ after 20 days whereas the AAC of smooth pea starch $(33.0 \%)$ decreased rapidly reaching a value of $5.0 \%$ after 12 days. This was in marked contrast to changes in AAC during $\alpha$-amylolysis of smooth pea (Fig. 4-8c) and wrinkled pea starch (Fig. 4-8e). This difference can be explained as follows. In acid hydrolysis, amorphous domains are more rapidly hydrolyzed than crystalline domains (Hoover, 2000), 
Figure 4-8 Apparent amylose content of legume starches at different time periods of $\alpha$ amylase hydrolysis. 
Black Bean

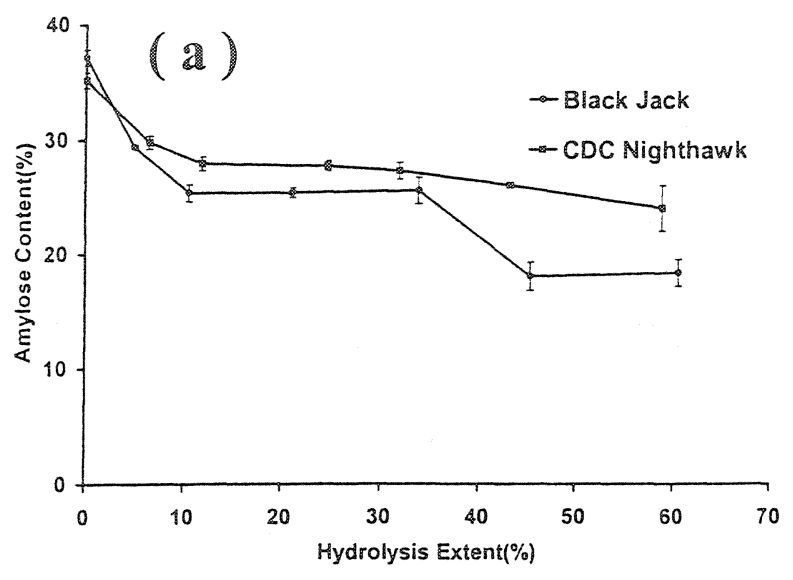

Smooth Pea

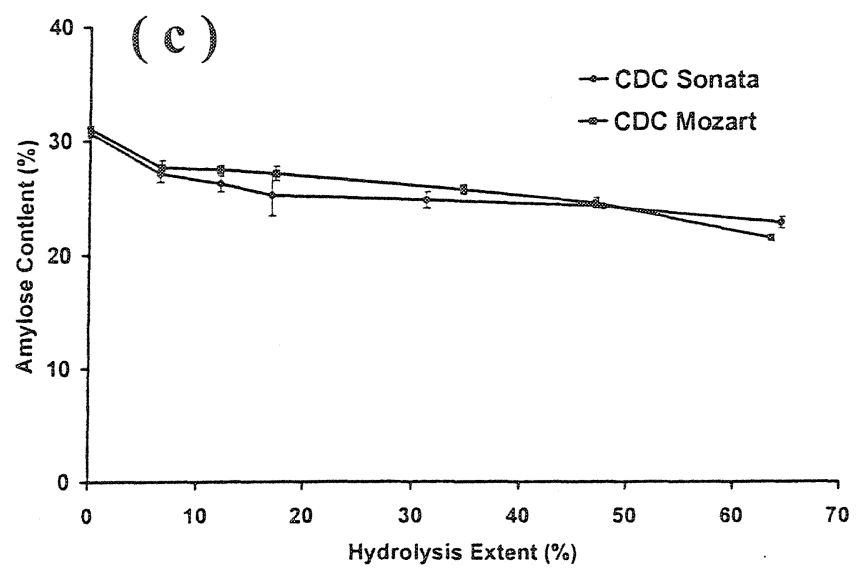

Pinto Bean

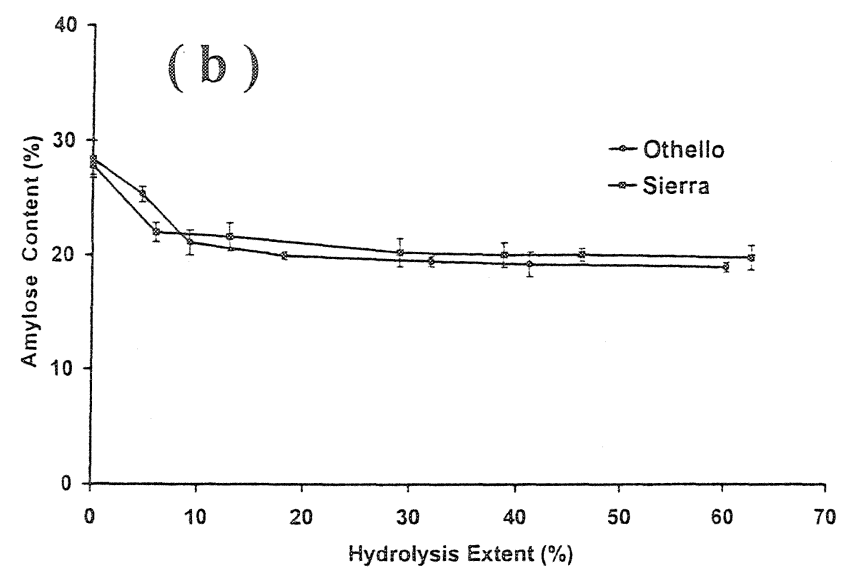

Lentil

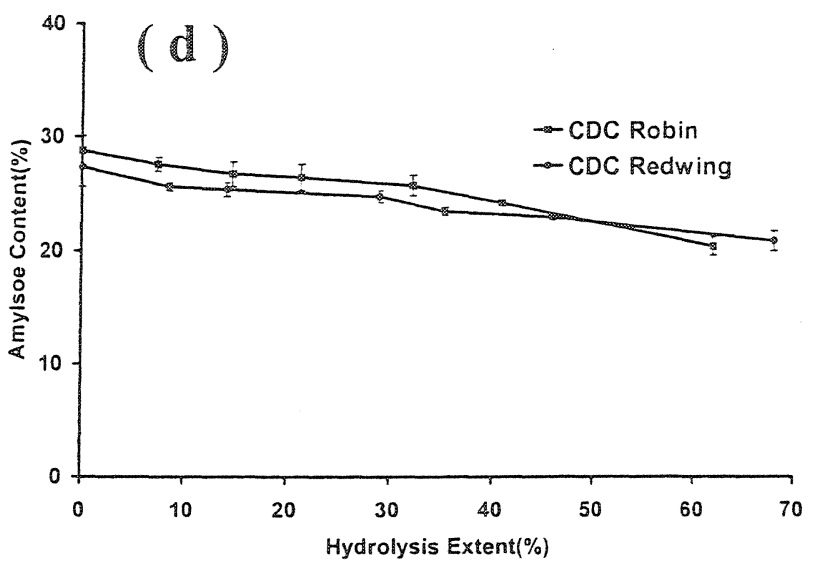

Wrinkle Pea

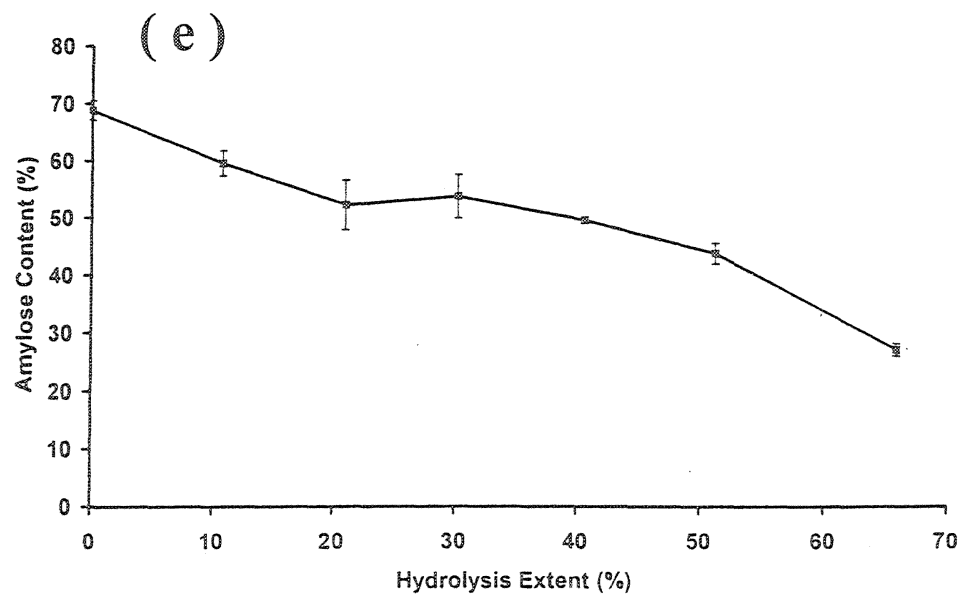


whereas both amorphous and crystalline domains are hydrolyzed simultaneously during $\alpha$-amylase hydrolysis (Lauro et al., 1999). Thus, certain proportions of amylose chains in wrinkled pea starch are closely associated with each other, forming crystalline regions, and/or are co-crystallized with amylopectin. Hence, acid hydrolysis would be much slower than $\alpha$-amylase hydrolysis.

\subsection{Thermal properties of hydrolyzed starch residues}

The gelatinization parameters of native and control starches and hydrolyzed residues are presented in Table 4-7. In general, gelatinization transition temperatures $\left(T_{0}, T_{p}, T_{c}\right)$ increased slightly on hydrolysis. The extent of this increase was nearly of the same order of magnitude in all starches. However, increases in $\mathrm{T}_{\mathrm{o}}, \mathrm{T}_{\mathrm{p}}$ and $\mathrm{T}_{\mathrm{c}}$ were evident only for $C D C$ Mozart and $C D C$ Robin (Table 4-7). Sierra, $C D C$ Redwing and $C D C$ Sonata showed increases only in $T_{0}, T p$ and $T_{p} \& T_{c}$, respectively (Table 4-7). Whereas, Black Back, CDC Nighthawk and Othello showed increases only in $\mathrm{T}_{\mathrm{o}}$ and $\mathrm{T}_{\mathrm{c}}$ (Table 4-7). In all starches, $\Delta \mathrm{H}$ decreased on hydrolysis and the extent of this decrease was nearly the same for all starches (Table 4-7). The decrease in $\Delta \mathrm{H}$ on hydrolysis reflects disorganization of amylopectin chains involved in double helical associations within the crystalline domains of the granule. Since $T_{0}, T_{p}$ and $T_{c}$ reflect crystallite melting, a decrease in $\Delta H$ should have theoretically resulted in a corresponding decrease in $T_{0}, T_{p}$ and $T_{c}$. Thus, the increase in $T_{0}, T_{p}$ and $T_{c}$ on hydrolysis support my earlier postulation that hydrolyzed amylose chains retrograde, forming crystallites. The decrease in $\Delta \mathrm{H}$ on hydrolysis suggests that the crystallites formed due to amylose retrogradation are not involved in double helical associations.

I postulate that the crystallites formed by amylose retrogradation probably differ in number and size among the hydrolyzed legume starches. This would explain why increases in $T_{0}, T_{p}$ and $T_{c}$ on hydrolysis occur only in some starches, whereas in others only one or two of the above 
Table 4-7

DSC parameters ${ }^{1}$ of $\alpha$-amylase hydrolyzed legume starch residues

\begin{tabular}{|c|c|c|c|c|c|c|}
\hline \multicolumn{2}{|c|}{ Starch source \& cultivar } & $\operatorname{To}^{2}\left({ }^{\circ} \mathrm{C}\right)$ & $\operatorname{Tp}\left({ }^{\circ} \mathrm{C}\right)$ & $\operatorname{Tc}\left({ }^{\circ} \mathrm{C}\right)$ & $\left.\mathrm{TC}-\mathrm{TO}^{\circ} \mathrm{C}\right)$ & $\Delta H^{3}(\mathrm{~mJ} / \mathrm{mg})$ \\
\hline \multicolumn{7}{|l|}{ Black bean } \\
\hline \multicolumn{7}{|l|}{ Black Jack } \\
\hline native & & $61.0 \pm 0.2^{b}$ & $70.9 \pm 0.3^{a}$ & $81.2 \pm 0.3^{b}$ & $20.3 \pm 0.5^{a, b}$ & $11.2 \pm 0.1^{a}$ \\
\hline control $^{4}$ & & $60.7 \pm 0.3^{b}$ & $71.3 \pm 0.3^{a}$ & $81.4 \pm 0.4^{b}$ & $20.8 \pm 0.5^{a}$ & $11.4 \pm 0.2^{a}$ \\
\hline \multirow[t]{2}{*}{ hydrolyzed } & $28.3 \%$ & $62.6 \pm 0.2^{\mathrm{a}}$ & $70.8 \pm 0.2^{a, b}$ & $82.5 \pm 0.4^{a}$ & $19.9 \pm 0.4^{\mathrm{a}, \mathrm{b}}$ & $10.2 \pm 0.2^{b}$ \\
\hline & $55.7 \%$ & $63.5 \pm 0.6^{a}$ & $70.2 \pm 0.1^{b}$ & $82.5 \pm 0.3^{a}$ & $19.0 \pm 0.7^{b}$ & $10.0 \pm 0.3^{b}$ \\
\hline \multicolumn{7}{|l|}{ CDC Nighthawk } \\
\hline native & & $65.7 \pm 0.3^{\mathrm{e}}$ & $74.9 \pm 0.4^{\mathrm{e}}$ & $86.7 \pm 0.2^{\mathrm{e}}$ & $21.0 \pm 0.1^{\mathrm{e}}$ & $12.2 \pm 0.6^{\Theta}$ \\
\hline control $^{4}$ & & $65.6 \pm 0.5^{\mathrm{e}}$ & $75.0 \pm 0.3^{\mathrm{e}}$ & $86.3 \pm 0.4^{e}$ & $20.6 \pm 0.4^{\mathrm{e}}$ & $12.1 \pm 0.3^{e}$ \\
\hline \multirow[t]{2}{*}{ hydrolyzed } & $24.6 \%$ & $66.5 \pm 0.4^{\mathrm{e}, \mathrm{f}}$ & $75.6 \pm 0.1^{\mathrm{e}}$ & $86.7 \pm 0.1^{\mathrm{e}}$ & $20.1 \pm 0.5^{\mathrm{e}}$ & $10.3 \pm 0.7^{f}$ \\
\hline & $58.8 \%$ & $67.2 \pm 0.6^{f}$ & $75.4 \pm 0.5^{e}$ & $88.2 \pm 0.4^{f}$ & $21.0 \pm 0.6^{e}$ & $11.0 \pm 0.5^{e, f}$ \\
\hline \multicolumn{7}{|l|}{ Pinto bean } \\
\hline \multicolumn{7}{|l|}{ Othello } \\
\hline native & & $64.5 \pm 0.2^{g}$ & $76.5 \pm 0.6^{9}$ & $88.8 \pm 0.3^{9}$ & $24.3 \pm 0.4^{9}$ & $12.2 \pm 0.2^{g}$ \\
\hline control $^{4}$ & & $64.5 \pm 0.4^{g}$ & $76.5 \pm 0.3^{g}$ & $88.8 \pm 0.4^{9}$ & $24.3 \pm 0.6^{9}$ & $12.4 \pm 0.2^{9}$ \\
\hline \multirow[t]{2}{*}{ hydrolyzed } & $18.1 \%$ & $66.5 \pm 0.3^{\mathrm{h}}$ & $77.1 \pm 0.2^{g}$ & $89.9 \pm 0.2^{h}$ & $23.4 \pm 0.3^{9}$ & $10.7 \pm 0.3^{h}$ \\
\hline & $41.2 \%$ & $66.9 \pm 0.3^{h}$ & $77.0 \pm 0.2^{g}$ & $90.2 \pm 0.2^{h}$ & $23.4 \pm 0.2^{g}$ & $10.2 \pm 0.4^{h}$ \\
\hline \multicolumn{7}{|l|}{ Sierra } \\
\hline native & & $63.3 \pm 0.2^{1}$ & $70.9 \pm 0.2^{1}$ & $85.1 \pm 0.7^{1}$ & $21.8 \pm 0.5^{1}$ & $12.9 \pm 0.1^{\prime}$ \\
\hline control $^{4}$ & & $63.5 \pm 0.4^{\prime}$ & $70.8 \pm 0.4^{\prime}$ & $85.1 \pm 0.2^{1}$ & $21.6 \pm 0.4^{1, \mathrm{~m}}$ & $12.9 \pm 0.1^{\prime}$ \\
\hline \multirow[t]{2}{*}{ hydrolyzed } & $29.0 \%$ & $64.3 \pm 0.2^{m}$ & $70.7 \pm 0.1^{1}$ & $85.7 \pm 0.6^{1}$ & $21.5 \pm 0.8^{1, \mathrm{~m}}$ & $10.6 \pm 0.2^{m}$ \\
\hline & $46.1 \%$ & $65.6 \pm 0.2^{n}$ & $71.1 \pm 0.2^{\prime}$ & $86.0 \pm 0.3^{1}$ & $20.4 \pm 0.3^{m}$ & $10.9 \pm 0.4^{\mathrm{m}}$ \\
\hline
\end{tabular}

1. For each cultivar, data with the same superscript in the same column are not significantly different $(P<0.05)$. The data represent the mean \pm SD of three determinations.

2. To, $\mathrm{Tp}, \mathrm{Tc}$ indicate the onset, peak and conclusion temperature of gelatinization, respectively. Tc - To indicates the temperature range of gelatinization.

3. $\Delta \mathrm{H}$, Gelatinization enthalpy

4. Treated without $\alpha$-amylase but subjected to the same experimental conditions. 
Table 4-7

DSC parameters ${ }^{1}$ of $\alpha$-amylase hydrolyzed legume starch residues(cont'd)

\begin{tabular}{|c|c|c|c|c|c|c|}
\hline \multicolumn{2}{|c|}{ Starch source \& cultivar } & $\mathrm{TO}^{2}\left({ }^{\circ} \mathrm{C}\right)$ & $\mathrm{Tp}\left({ }^{\circ} \mathrm{C}\right)$ & $\operatorname{Tc}\left({ }^{\circ} \mathrm{C}\right)$ & $\mathrm{TC}-\mathrm{To}\left({ }^{\circ} \mathrm{C}\right)$ & $\Delta H^{3}(m J / m g)$ \\
\hline \multicolumn{7}{|l|}{ Smooth pea } \\
\hline \multicolumn{7}{|l|}{ CDC Sonata } \\
\hline native & & $60.1 \pm 0.2^{q}$ & $66.0 \pm 0.2^{q}$ & $76.4 \pm 0.2^{q}$ & $16.3 \pm 0.4^{9}$ & $10.1 \pm 0.3^{q}$ \\
\hline control $^{4}$ & & $60.2 \pm 0.4^{9}$ & $66.0 \pm 0.2^{q}$ & $76.3 \pm 0.3^{q}$ & $16.2 \pm 0.6^{q}$ & $10.1 \pm 0.3^{q}$ \\
\hline \multirow[t]{2}{*}{ hydrolyzed } & $17.0 \%$ & $58.2 \pm 0.4^{r}$ & $65.8 \pm 0.2^{q}$ & $76.7 \pm 0.1^{q}$ & $18.5 \pm 0.4^{r}$ & $8.5 \pm 0.8^{r}$ \\
\hline & $47.8 \%$ & $60.2 \pm 0.5^{q}$ & $67.1 \pm 0.6^{r}$ & $78.4 \pm 0.2^{r}$ & $18.2 \pm 0.6^{r}$ & $8.8 \pm 0.2^{r}$ \\
\hline \multicolumn{7}{|l|}{ CDC Mozart } \\
\hline native & & $60.0 \pm 0.4^{\mathrm{s}}$ & $66.6 \pm 0.1^{\mathrm{s}}$ & $77.5 \pm 0.4^{s}$ & $17.5 \pm 0.7^{\mathrm{s}}$ & $10.8 \pm 0.5^{\mathrm{s}}$ \\
\hline control $^{4}$ & & $60.2 \pm 0.5^{\mathrm{s}}$ & $66.7 \pm 0.2^{s}$ & $77.3 \pm 0.3^{s}$ & $17.2 \pm 0.6^{\mathrm{s}}$ & $11.0 \pm 0.3^{\mathrm{s}}$ \\
\hline \multirow[t]{2}{*}{ hydrolyzed } & $17.3 \%$ & $59.4 \pm 0.3^{s}$ & $67.2 \pm 0.3^{\mathrm{s}}$ & $77.6 \pm 0.3^{s}$ & $18.2 \pm 0.5^{\mathrm{s}}$ & $9.2 \pm 0.3^{t}$ \\
\hline & $47.0 \%$ & $61.2 \pm 0.1^{t}$ & $68.5 \pm 0.3^{t}$ & $80.9 \pm 0.4^{t}$ & $19.7 \pm 0.3^{t}$ & $10.1 \pm 0.4^{\mathrm{s}, \mathrm{t}}$ \\
\hline \multicolumn{7}{|l|}{ Lentil } \\
\hline \multicolumn{7}{|l|}{ CDC Redwing } \\
\hline native & & $63.9 \pm 0.1^{u}$ & $70.6 \pm 0.1^{u}$ & $80.1 \pm 0.9^{u}$ & $16.2 \pm 1.0^{\mathrm{u}}$ & $11.3 \pm 0.3^{\mathrm{u}}$ \\
\hline control $^{4}$ & & $63.9 \pm 0.2^{u}$ & $70.5 \pm 0.3^{u}$ & $80.6 \pm 0.5^{u}$ & $16.7 \pm 0.5^{\mathrm{u}}$ & $11.2 \pm 0.2^{\mathrm{u}}$ \\
\hline \multirow[t]{2}{*}{ hydrolyzed } & $29.0 \%$ & $64.2 \pm 0.4^{u}$ & $71.3 \pm 0.2^{v}$ & $79.8 \pm 0.3^{4}$ & $15.6 \pm 0.1^{\mathrm{u}}$ & $9.6 \pm 0.1^{v}$ \\
\hline & $52.6 \%$ & $64.3 \pm 0.3^{u}$ & $71.8 \pm 0.1^{v}$ & $81.1 \pm 0.3^{\mathrm{u}}$ & $16.9 \pm 0.1^{4}$ & $9.6 \pm 0.5^{v}$ \\
\hline \multicolumn{7}{|l|}{ CDC Robin } \\
\hline native & & $61.1 \pm 0.2^{w, x}$ & $67.7 \pm 0.1^{w}$ & $77.3 \pm 0.3^{w}$ & $16.2 \pm 0.2^{w}$ & $9.9 \pm 0.1^{w}$ \\
\hline control $^{4}$ & & $60.9 \pm 0.4^{w}$ & $67.6 \pm 0.3^{w}$ & $77.1 \pm 0.4^{w}$ & $16.2 \pm 0.5^{\mathrm{w}}$ & $9.9 \pm 0.2^{w}$ \\
\hline \multirow[t]{2}{*}{ hydrolyzed } & $21.4 \%$ & $61.7 \pm 0.3^{x}$ & $68.3 \pm 0.2^{x}$ & $78.0 \pm 0.3^{w}$ & $16.2 \pm 0.2^{w}$ & $9.1 \pm 0.3^{x}$ \\
\hline & $61.9 \%$ & $63.9 \pm 0.2^{y}$ & $70.7 \pm 0.1^{y}$ & $81.1 \pm 0.4^{x}$ & $17.3 \pm 0.5^{x}$ & $8.8 \pm 0.2^{x}$ \\
\hline \multicolumn{7}{|l|}{ Wrinkled pea } \\
\hline native & & - & - & - & - & - \\
\hline control $^{4}$ & & - & - & - & - & - \\
\hline \multirow[t]{2}{*}{ hydrolyzed } & $22.1 \%$ & - & - & - & - & - \\
\hline & $53.5 \%$ & - & - & - & - & - \\
\hline
\end{tabular}

1. For each cultivar, data with the same superscript in the same column are not significantly different $(\mathrm{P}<0.05)$. The data represent the mean $\pm \mathrm{SD}$ of three determinations.

2. To, Tp, Tc indicate the onset, peak and conclusion temperature of gelatinization, respectively. Tc - To indicates the temperature range of gelatinization.

3. $\Delta \mathrm{H}$, Gelatinization enthalpy

4. Treated without $\alpha$-amylase but subjected to the same experimental conditions.

5. Gelatinization characteristics were not detected within the temperature range $25^{\circ} \mathrm{C}$ to $145^{\circ} \mathrm{C}$. 
parameters increase on hydrolysis (Table 4-7). Furthermore, the absence of an endotherm in hydrolyzed wrinkled pea starch (Table 4-7) also suggests a large extent of amylose retrogradation during hydrolysis. This seems plausible, since the swelling factor of $58.5 \%$ for hydrolyzed wrinkled pea starch residue (1.8) was lower than that of its native counterpart (3.4). 


\section{Summary and Conclusions}

1. This study has shown that the granular morphology, relative crystallinity, $\mathrm{X}$-ray pattern $\left({ }^{6} \mathrm{C}^{\prime}\right.$ type), extent of starch damage, 'B' polymorphic content and composition differed only marginally among black bean, pinto bean, smooth pea and lentil starches.

2. Swelling factor, amylose leaching and differential scanning calorimetry measurements showed that the extent of starch chain interactions within the amorphous and crystalline domains of the native granule were more pronounced in pinto bean than in black bean, lentil and smooth pea starches. Wrinkled pea differed from the other legume starches in exhibiting a higher extent of starch damage, a higher content of bound lipids, a different X-ray pattern ('B' type), lower relative crystallinity, different granule shapes and sizes, a highly disrupted crystalline structure and strong interaction between amylose chains.

3. The rate and extent of $\alpha$-amylolysis of black bean, pinto bean, smooth pea and lentil starches were mainly influenced by the interplay of : 1) the magnitude of interaction between starch chains within the amorphous domains of the native granule; and 2) extent to which hydrolyzed amylose chains interact with each other during the time course of hydrolysis. However, in wrinkled pea starch, in addition to the above two factors, a disrupted crystalline structure (influenced by its higher amylose content and longer amylopectin chain length), a higher ' $\mathrm{B}$ ' polymorphic content and a higher extent of starch damage were also causative factors influencing the rate and extent of hydrolysis. Differences in hydrolysis between cultivars were evident only in black bean and lentil starches. 


\section{Directions for Future Research}

1. A study of the fine structures of amylose and amylopectin from the legume starches used in this study would give a deeper insight into how starch chains influence $\alpha$-amylolysis.

2. Application of TEM (Transmission Electron Microscopy) and AFM (Atomic Force Microscopy) may reveal more information on changes in ultrastructure and surface morphology during enzymatic hydrolysis.

3. Since legume starches are generally resistant to $\alpha$-amylase attack and exhibit a low glycermic index in vivo, which is considered beneficial to human health, it is worthwhile to explore their potential as resistant starch (RS) or slowly digestible starch (SDS) related food products.

4. Legume starches have very limited applications in the food industry, partly due to their unattractive properties (e.g. high retrogradation rates). Therefore, further research (i.e. physical and chemical modifications) aimed at to improving their performance would be useful. 


\section{Publications}

1. Zhou, Y. and Hoover, R. (2003) Relationship between $\alpha$-amylase degradation and the structure and physicochemical properties of legume starches (in review).

2. Hoover, R. and $\mathbb{Z}$ hou, $\mathbf{Y}$. (2003) In vitro and in vivo hydrolysis of legume starches by $\alpha$-amylase and resistant starch formation in legumes - a review. Carbohydr. Polym., 54: 401- 417.

3. Hoover, R., Smith, C., Zhou, Y. and Ratnayake, R.M.W.S. (2003) Physicochemical properties of Canadian oat starches. Carbohydr. Polym., 52: 253-261.

\section{Presentations}

1. Poster presentation, $12^{\text {th }}$ IUFoST conference, Chicago, IL. USA, Jul.16 - 20, 2003.

\section{Honors and Awards}

1. Barrowman Biochemistry Graduate Travel Award, Year 2003-2004.

2. Title of "Fellow of the School of Graduate Studies" in recognition of outstanding achievement in graduate program, Year 2002-2003

3. Graduate Fellowship, Graduate School, Memorial University of Newfoundland, St. John's, NL, Canada (from Dec. 2002 to Dec. 2003). 


\section{References:}

AACC (1984) Approved methods of the AACC ( $\left.8^{\text {th }} \mathrm{ed}\right)$. American Association of Cereal Chemists, St.Paul, MN, USA.

Aberle, T., Burchard, W., Vorwerg, W. and Radosta, S. (1994) Conformation contributions of amylose and amylopectin to the structural properties of starches from various sources. Starch/Stärke, 46: 329 - 335.

Agriculture and Agri-Food Canada (2003a) Canada: pulse and special crops outlook. Canada.

URL: http://www.agr.gc.ca/mad-dam/e/sd2e/2003e/sep2003sc e.htm\#download

Agriculture and Agri-Food Canada (2003b) Special crops. Canada

URL: http://www.agr.gc.ca/misb/spcrops/sc-cs e.php?page=pulses-legumineuses

Anderson, J.W. and Major, A.W. (2002) Pulses and lipaemia, short- and long-term effect: Potential in the prevention of cardiovascular disease. Br. J. Nutr., 88 (suppl. 3): S263- 271.

Appelqvist, I.A.M. and Debet, M.R.M. (1997) Starch-biopolymer interaction - a review. Food Rev. Int., 13: $163-224$.

Asaoka, M., Okuno, K., Sugimoto, Y. and Fuwa, H. (1985) Developmental changes in the structure of endosperm starch of rice (Oryza sativa L.). Agric. Biol. Chem., 49: $1973-1978$.

Atichokudomchai, N., Varavinit, S. and Chinachoti, P. (2002) Gelatinization transitions of acid-modified tapioca starches by differential scanning calorimetry (DSC). Starch/Stärke, 54: $296-302$.

Atkin, N.J., Cheng, S.L., Abeysekera, R.M. and Robards, A.W. (1999) Localization of amylose and amylopectin in starch granules using enzyme-gold labeling. Starch/Stärke, 51: $163-172$.

Atwell, W.A., Hood, L.F., Lineback, D.R., Varriano-Marston, E. and Zobel, H.F. (1988) The terminology and methodology associated with basic starch phenomena. Cereal Foods World, 33: 306-311.

Augustin, J. and Klein, B.P. (1989) Nutrient composition of raw, cooked, canned, and sprouted legumes. In Legumes: Chemistry, Technology, and Human Nutrition (Ed. R.H. Matthews). Marcel Dekker, Inc., New York, NY, USA, pp. $187-217$. 
Baldwin, P.M., Adler, J., Davies, M.C. and Melia, C.D. (1994) Holes in starch granules: confocal, SEM and light microscopy studies of starch granule structure. Starch/Stärke, 46: 341 - 346.

Baldwin, P.M., Adler, J., Davies, M.C. and Melia, C.D. (1998) High resolution imaging of starch granules surfaces by atomic force microscopy. J. Cereal Sci., 27: 255 265.

Baldwin, P.M. (2001) Starch granule-associated proteins and polypeptides: a review. Starch/Stärke, 53: 475 - 503.

Ball, S., Guan, H.P., James, M., Myers, A., Keeling, P., Mouille, G., Buléon, A., Colonna, P. and Preiss, J. (1996) From glycogen to amylopectin: a model for the biogenesis of the plant starch granule. Cell, $86: 349-352$.

Banks, W. and Greenwood, C.T. (1971) The conformation of amylose in dilute solution. Starch/Stärke, 23: $300-313$.

Banks, W. and Greenwood, C.T. (1975) Starch and its components. Edinburgh University Press, Edinburgh, UK.

Barron, C., Buleon, A., Colonna, P. and Valle, G.D. (2000) Structural modifications of low hydrated pea starch subjected to high thermomechanical processing. Carbohydr. Polym., 43: 171-181.

Bednar, G.E., Patil, A.R., Murray, S.M., Grieshop, M., Merchen, N.R. and Fahey, G.C. (2001) Starch and fiber fractions in selected food and feed ingredients affect their small intestinal digestibility and fermentability and their large bowel fermentability in vitro in a canine model. J. Nutr., 131:276-286.

Behall, K.M., Scolfield, D.J. and Canary, J. (1988) Effect of starch structure and insulin responses in adults. Am.J. Clin. Nutr., 47: 428- 432.

Bello-Perez, L.A. and Paredes-Lopez, O. (1995) Effect of solutes on retrogradation of stored starches and amylopectins: a calorimetric study. Starch/Stärke, 47: 83-86.

Bertoft, E., Manelius, R. and Quin, Z. (1993) Studies on the structure of pea starches. Part $2 \alpha$-Amylolysis of granular wrinkled pea starch. Starch/Stärke, 45: 258 263.

Biliaderis, C.G., Maurice, T.J. and Vose, J.R. (1980) Starch gelatinization phenomena studied by differential scanning calorimetry. J. Food Sci., 45: 1669 - 1674.

Biliaderis, C.G., Grant, D.R. and Vose, J.R. (1981) Structural characterization of legume starches. I. Studies on amylose, amylopectin, and beta-limit dextrins. Cereal Chem., 58: $496-502$. 
Biliaderis, C.G. (1982a) Characteristics of starch in developing pea seeds. Phytochem., 21: $37-39$.

Biliaderis, C.G. (1982b) Physicochemical studies on legume starches. Diss. Abstr. Int. B, 42: 3177 .

Biliaderis, C.G. (1991) The structure and interactions of starch with food constituents. Can. J. Physiol. Pharmacol., 69: 60 - 78.

Biliaderis, C.G. (1998) Structures and phase transitions of starch polymers. In Polysaccharide association structures in food (Ed. R.H. Walter). Marcel Dekker, Inc., New York, NY, USA, pp. $57-168$.

Björck, I. (1996) Starch: nutritional aspects. In Carbohydrates in food (Ed. A.C. Eliasson). Marcel Dekker, Inc., New York, NY, USA, pp. 505 - 553.

Björck, I., Liljeberg, H. and Östman, E. (2000) Low glycaemic index foods. Br. J. Nutr., 83 (Suppl. 1): S149 - S155.

Björck, I.M., Granfeldt, Y., Liljeberg, H., Tovar, J. and Asp, N.G. (1994) Food properties affecting the digestion and absorption of carbohydrates. Am. J. Clin. Nutr., 59: 699S-705S.

Blanshard, J.M.V. (1986) The significance of structure and function of the starch granule in baked products. In Chemistry and physics of baking (Ed. J.M.V. Blanshard). Royal Society of Chemistry, London, UK, pp. 1-13.

Blanshard, J.M.V. (1987) Starch granule structure and function: a physicochemical approach. In Starch properties and potential; Critical Reports in Applied Chemisty (Ed. T. Galliard). Society for Chemistry and Industry, London, UK, pp. $16-54$.

Bligh, E.G. and Dyer, W.J. (1959) A rapid method of total lipid extraction and purification. Can. J. Biochem. Physiol., 37: $911-917$.

Boel, E., Brady, L., Brzozowski, A. M., Derewanda, Z., Dodson, G. G., Jensen, V. J., Petersen, S. B., Swift, H., Thim, L. and Woldike, H. F. (1990) Calcium binding in $\alpha$-amylases: an X-ray diffraction study at $2.1 \AA$ resolution of two enzymes from Aspergillus. Biochemistry 29: 6244 - 6249.

Bogracheva, T.Ya., Morris, V.J., Ring, S.G. and Hedley, C.L. (1998) The granular structure of C-type pea starch and its role in gelatinization. Biopolymers, 45: 323 -332 .

Bogracheva, T.Ya., Wang, Y.L. and Hedley, C.L. (2001) The effect of water content on the ordered/disordered structures in starches. Biopolymers, 58: $247-259$. 
Bornet, F.R., Fontvieille, A.M., Rizkalla, S., Colonna, P., Blayo, A., Mercier, C. and Slama, G. (1989) Insulin and glycemic responses in healthy humans to native starches processed in different ways: correlation with in vitro alpha-amylase hydrolysis. Am. J. Clin. Nutr., 50: 315 - 323.

Bornet, F.R., Billaux, M.S. and Messing, B. (1997) Glycaemic index concept and metabolic diseases. Int. J. Biol. Macromol., 21:207-219.

Brady, R. L., Brzozowski, A. M., Derewenda, Z. S., Dodson, E. J. and Dodson, G. G. (1991) Solution of the structure of Aspergillus niger acid $\alpha$-amylase by combined molecular replacement and multiple isomorphous replacement methods. Acta Crystallogr., Sect. B: Struct. Sci., 47: 527-535.

Braun, C., Lindhorst, T., Madsen, N. B. and Withers, S. G. (1996) Identitication of Asp549 as the catalytic nucleophile of glycogen-debranching enzyme via trapping of the glycosyl-enzyme intermediate. Biochemistry, 35: 5458 - 5463.

Bravo, L. Siddhuraju, P. and Saura-Calixto, F. (1998) Effect of various processing methods on the in vitro starch digestibility and resistant starch content of Indian pulses. J. Agric., Food Chem., 46: $4667-4674$.

Brayer, G. D., Luo, Y. and Withers, S. G. (1995) The structure of human pancreatic $\alpha$ amylase at $1.8 \AA$ resolution and comparisons with related enzymes. Protein Sci., 4: $1730-1742$.

Broberg, S., Koch, K., Andersson, R. and Kenne, L. (2000) A comparison between MALDI-TOF mass spectrometry and HPAEC-PAD analysis of debranched starch. Carbohydr. Polym., 43: 285 - 289.

Bruner, R.L. (1964) Determination of reducing value. In Methods in carbohydrate chemistry (Ed. R.L. Whistler). Vol. IV- Starch, Academic Press, New York, NY, USA, pp. $67-71$.

Buléon, A., Bizot, H., Delage, M.M. and Multon, J.L. (1982) Evolution of crystallinity and specific gravity of potato starch versus water ad- and desorption. Starch/Stärke, 34: $361-366$.

Buléon, A., Bizot, H., Delage, M.M. and Pontoire, B. (1987) Comparison of X-ray diffraction patterns and sorption properties of the hydrolyzed starches of potato, wrinkled and smooth pea, broad bean and wheat, Carbohydr. Polym., 7: 461 482.

Buléon, A., Colonna, P., Planchot, V. and Ball, S. (1998a) Starch granules: structure and biosynthesis. Int. J. Biol. Macromol., 23: 85-112. 
Buléon, A., Gerard, C., Riekel, C., Vuong, R. and Chanzy, H. (1998b) Details of the crystalline ultrastructure of $\mathrm{C}$-starch granules revealed by synchrotron microfocus mapping. Macromolecules, 31: $6605-6610$.

Carlson, T.L.-G., Larsson, K., Dinh-Nguyen, N. and Krog, N. (1979) A study of the amylose-monoglyceride complex by Raman spectroscopy. Starch/Stärke, 31: 222 -224 .

Chavan, U.D., Shahidi, F., Hoover, R. and Perera, C. (1999) Characterization of beach pea (Lathyrus maritimus, L.) starch. Food Chem., 65: 61 - 70.

Cheetham, N.W.H. and Tao, L. (1998) Variation in crystalline type with amylose content in maize starch granules: an X-ray powder diffraction study. Carbohydr. Polym., 36: $277-284$.

Chen, W.J.L. and Anderson, J.W. (1981) Soluble and insoluble plant fiber in selected cereals and vegetables. Am. J. Clin. Nutr., 34: 1077 - 1082.

Chiotelli, E., Pilosio, G. and Meste, M.Le. (2002) Effect of sodium chloride on the gelatinization of starch: a multimeasurement study. Biopolymers, 63: $41-58$.

Chung, H., Cho, S., Chung, J., Shin, T., Son, H. and Lim, S-T. (1998) Physical and molecular characteristics of cowpea and acorn starches in comparison with corn and potato starches. Food Sci. Biotechnol., 7: 269-275.

Ciacco, C.F. and Fernandes, J.L.A. (1979) Effect of various ions on the kinetics of retrogradation of concentrated wheat starch gels. Starch/Stärke, 31: $51-53$.

Colonna, P., Buléon, A., LeMaguer, M. and Mercier, C. (1982) Pisum sativum and Vicia faba carbohydrates: Part IV - Granular structure of wrinkled pea starch. Carbohydr. Polym., 2: $43-59$.

Colonna, P. and Mercier, C. (1984) Macromolecular structure of wrinkled- and smoothpea starch components. Carbohydr. Res., 126: $233-247$.

Colonna, P., Buléon, A. and Lemane, F. (1988) Action of Bacillus subtilis $\alpha$-amylase on native wheat starch. Biotechnol. Bioeng., 31:895-904.

Colonna, P., Barry, J.-L., Cloarec, D., Bornet, F., Gouilloud, S. and Galmiche, J.-P. (1990) Enzymic susceptibility of starch from pasta. J. Cereal Sci., 11:59-70.

Colonna, P., Leloup, V. and Buléon, A. (1992) Limiting factors of starch hydrolysis. Eur.J. Clin. Nutr., 46(suppl. 2): S17 - S32.

Cooke, D. and Gidley, M.J. (1992) Loss of crystalline and molecular order during starch gelatinization: origin of the enthalpic transition. Carbohydr. Res., 227: 103-112. 
Cui, R. and Oates, C.G. (1999) The effect of amylose-lipid complex formation on enzyme susceptibility of sago starch. Food Chem., 65: $417-425$.

Davydova, N.I., Leont'ev, S.P., Genin, Ya.V., Sasov, A.Yu. and Bogracheva, T.Ya. (1995) Some physico-chemical properties of smooth pea starches. Carbohydr. Polym., 27: $109-115$.

Deshpande, S.S. and Cheryan, M. (1984) Effects of phytic acid, divalent cations and their interactions on $\alpha$-amylase activity. J. Food Sci., 49: 516-519.

Donald, A.M., Waigh, T.A., Jenkins, P.J., Gidley, M.J., Debet, M. and Smith, A. (1997) Internal structure of starch granules revealed by scattering studies. In Starch: structure and functionality (Eds. P.J. Frazier, A.M. Donald and P. Richmond). The Royal Society of Chemistry, Cambridge, UK, pp. $172-179$.

Donald, A.M., Kato, K.L., Perry, P.A. and Waigh, T.A. (2001) Scattering studies of the internal structure of starch granules. Starch/Stärke, 53: $504-512$.

Donovan, J.W. (1979) Phase transitions of starch-water systems. Biopolymers, 18: 263 275.

Dreher, M.L., Dreher, C.J. and Berry, J.W. (1984) Starch digestibility of foods: A nutritional perspective. CRC Crit. Rev.Food Sci. Nutr., 20: 47-71.

Eerlingen, R.C., Crombez, M. and Delcour, J.A. (1993) Enzyme resistant starch. I. Quantitative and qualitative influence of incubation time and temperature of autoclaved starch on resistant starch formation. Cereal Chem., 70: 339-344.

Eliasson, A.C. (1988) Physical and chemical characteristics of legume starches. Atlas Sci.: Animal Plant Sci., 1: 89 - 94.

Eliasson, A.C. and Ljunger, G. (1988) Interaction between amylopectin and lipid additives during retrogradation in a model system. J. Sci. Food Agric., 44: $353-$ 361.

Eliasson, A.C. and Gudmundsson, M. (1996) Starch: physicochemical and functional aspects. In Carbohydrates in Food (Ed. A.C. Eliasson). Marcel Dekker, Inc., New York, NY, pp. $431-503$.

Ellis, R.P., Cochrane, M.P., Dale, M.F.B., Duffus, C.M., Lynn, A., Morrison, I.M., Prentice, R.D.M., Swanston, J.S. and Tiller, S.A. (1998) Starch production and industrial use. J. Sci. Food Agric., 77: $289-311$.

Elmstahl, H.L. (2002) Resistant starch content in a selection of starch foods on the Swedish market. Eur. J. Clin. Nutr., 56: 500-506.

Elodi, P., Mora, S. and Krysteva, M. (1972) Investigation of the active center of porcine pancreatic $\alpha$-amylase. Eur. J. Biochem., 24: $577-585$. 
Emiola, L.O. and Delarosa, L.C. (1981) Physicochemical characteristics of yam starches. J. Food Biochem., 5: 115-130.

Englyst, H.N., Kingman, S.M. and Cummings, J.H. (1992) Classification and measurement of nutritionally important starch fractions. Eur. J. Clin. Nutr., 46 (Suppl. 2): S33-S50.

Englyst, H.N., Englyst, H.N., Hudson, G.J., Cole, T.J. and Cumming, J.H. (1999) Rapidly available glucose in foods: an in vitro measurement that reflects the glycemic responses. Am. J. Clin. Nutr., 69: 448 - 454.

Evans, I.D. and Haisman, D.R. (1982) The effect of solutes on the gelatinization temperature range of potato starch. Starch/Stärke, 34: 224-231.

Fannon, J.E., Hauber, R.J. and BeMiller, J.N. (1992) Surface pores of starch granules. Cereal Chem., 69: $284-288$.

Fannon, J.E., Shull, J.M. and BeMiller, J.N. (1993) Note: interior channels of starch granules. Cereal Chem., 70: $611-613$.

Food and Agriculture Organization (2003) World agricultural information centre. USA. URL: http://www.fao.org/waicent/portal/statistics en.asp

Franco, C.M.L., Wong, K.S., Yoo, S. and Jane, J. (2002) Structure and functional characteristics of selected soft wheat starches (1). Cereal Chem., 79: 243-248.

Fredriksson, H., Silverio, J., Andersson, R., Eliasson, A.-C. and Aman, P. (1998) The influence of amylose and amylopectin characteristics on gelatinization and retrogradation properties of different starches. Carbohydr. Polym., 35: 119- 134.

French, D. (1972) Fine structure of starch and its relationship to the organization of starch granules. J. Jap. Soc. Starch Sci., 19: 8-25.

French, A.D. and Murphy, V.G. (1977) Computer modeling in the study of starch. Cereal Food World, 22: 61 - 70 .

French, D. (1984) Organization of the starch granules. In Starch: chemistry and technology (Eds. R.L. Whistler, J.N. BeMiller and J.F. Paschall). Academic Press, Orlando, FL, USA, pp. $183-247$.

Friedman, M. (1996) Nutritional value of proteins from different food source. A review. J. Agric. Food Chem., 44: 6-29.

Frins, J., Fornal, J., Ring, S.G. and Vidal-Valverde, C. (1998) Effect of germination on physicochemical properties of lentil starch and its components. Lebensm. Wiss. Technol., 31: 228-236. 
Fujimoto, Z., Takase, K., Doui, N., Momma, M., Matsumoto, T., Mizuno, H. (1998) Crystal structure of a catalytic-site mutant $\alpha$-amylase from Bacillus subtilis complexed with maltopentaose. J. Mol. Biol. 277: 393 - 407.

Gallant, D., Mercier, C. and Guilbot, A. (1972) Electron microscopy of starch granules modified by bacterial alpha-amylase. Cereal Chem., 49:354-360.

Gallant, D.J., Bouchet, B., Buléon, A. and Pérez, S. (1992) Physical characteristics of starch granules and susceptibility to enzymatic degradation. Eur. J. Clin. Nutr., 46: S3 - S16.

Gallant, D.J., Bouchet, B. and Baldwin, P.M. (1997) Microscopy of starch: evidence of a new level of granule organization. Carbohydr. Polym., 32: 177- 191.

Galliard, T. and Bowler, P. (1987) Morphology and composition of starch. In Starch: properties and potential (Ed. T. Galliard). John Wiley \& Sons, Chichester, UK, pp. $55-78$.

Garcia-Alonso, A., Goni, I. and Saura-Calixto, F. (1998) Resistant starch and potential glycemic index of raw and cooked legumes (lentils, chickpeas and beans). Zeitschrift Fur Lebensmittel-Untersuchung und-Forschung A, 206: 284 - 287.

Geil, P.B. and Anderson, J.W. (1994) Nutrition and health implications of dry beans: a review. J. Am. Coll. Nutr., 13: 549 - 558.

Gérard, C., Colonna, P., Buléon, A. and Planchot, V. (2001) Amylolysis of maize mutant starches. J. Sci. Food Agric., 81: 1281 - 1287.

Gernat, C., Radosta, S., Damaschun, G. and Schierbaum, F. (1990) Supramolecular structure of legume starches revealed by X-ray scattering. Starch/Stärke, 42: 175 -178 .

Gernat, C., Radosta, S., Anger, H. and Damaschun, G. (1993) Crystalline parts of three different conformations detected in native and enzymatically degraded starches. Starch/Stärke, 45: 309 - 314.

Gidley, M.J. and Bociek, S.M. (1985) Molecular organization in starches: ${ }^{13} \mathrm{C}$ CP/MAS NMR study. J. Am. Chem. Soc., 107: 7040 - 7044.

Gidley, M.J. (1987) Factors affecting the crystalline type (A-C) of native starches and model compounds a rationalisation of observed effects in terms of polymorphic structure. Carbohydr. Res., 161:301-304.

Gidley, M.J. and Bulpin, P.V. (1987) Crystallization of malto-oligosaccharides as models of the crystalline forms of starch minimum chain-length requirement for the formation of double helices. Carbohydr. Res., 161:291-300. 
Gidley, M.J. and Cooke, D. (1991) Aspects of molecular organization and ultrastructure in starch granules. Biochem. Soc. Trans., 19: $551-555$.

Gidley, M.J. (2001) Starch structure/function relationships: achievements and challenges. In Starch advances in structure and function (Eds. T.L. Barsby, A.M. Donald and P.J. Frazier). The Royal Society of Chemistry, Cambridge, UK, pp. $1-7$.

Goddard, M.S., Young, G. and Marcus, R. (1984) The effect of amylose content on insulin and glucose responses to ingested rice. Am. J. Clin. Nutr., 39: $388-392$.

Godet, M.C., Tran, V., Delage, M.M. and Buleon, A. (1993) Molecular modeling of the specific interactions involved in the amylose complexation by fatty acid. Int. $J$. Biol. Macromol., 15: 11 - 16.

Gordon, I. (1999) Starches from differing sources - supply, demand, price and formation. Starch/Stärke, 51: S193 - S196.

Goshima, G., Abe, M., Sato, N., Ohashi, K. and Tsuge, H. (1985) Amylographic reproducibility of defatted potato starch by the reintroduction of lipid. Starch/Stärke, 37: $10-14$.

Granfeldt, Y., Björck, I., Drews, A. and Tovar, J. (1992) An in-vitro procedure based on chewing to predict metabolic response to starch in cereal and legume products. Eur. J. Clin. Nutr., 46: $649-660$.

Granfeldt, Y., Drews, A. and Björck, I. (1995) Arepas made from high-amylose corn produce favourably glucose and insulin low responses in healthy humans. $J$. Nutr., 125: $459-465$.

Greenwood, C.T. and Thomson, J.A. (1959) A comparison of the starches from barley and malted barley. J. Inst. Brew, 65: $346-353$.

Greenwood, C.T. (1979) Observations on the structure of the starch granule. In Polysaccharides in food (Eds. J.M.V. Blanshard and J.R. Mitchell). Butterworths and Co. Ltd., London, UK, pp. $129-138$.

Guilbot, A. and Mercier, C. (1985) Starch. In The Polysaccharides.(Ed. G.O. Aspinall). Academic Press, Orlando, Vol. 3, pp. $209-282$.

Gunaratne, A. and Hoover, R. (2002) Effect of heat-moisture treatment on the structure and physicochemical properties of tuber and root starches. Carbohydr. Polym., 49: $425-437$.

Gupta, Y.P. (1983) Nutritive value of food legumes. In Chemistry and Biochemistry of Legumes (Ed. S.K.Arora). Edward Arnold Publication, London, pp. 287 - 327. 
Guraya, H.S., Kadan, R.S. and Champagne, E.T. (1997) Effect of rice starch lipid complexes on in vitro digestibility complexing index and viscosity. Cereal Chem., 74: $561-565$.

Guraya, H.S., James, C. and Champagne, E.T. (2001) Effect of cooling, and freezing on the digestibility of debranched rice starch and physcial properties of the resulting material. Starch/Stärke, 53: $64-74$.

Guzmán-Maldonado, H. and Paredes-López, O. (1995) Amylolytic enzymes and products derived from starch: a review. Crit. Rev. Food Sci. Nutr., 35: 373 - 403.

Han, X.Z. and Hamaker, B.R. (2002) Association of starch granule properties with starch ghosts and remnants revealed by confocal laser scanning microscopy. Cereal Chem., 79: 892-896.

Hanashiro, I., Abe, J. and Hizukuri, S. (1996) A periodic distribution of the chain length of amylopectin as revealed by high-performance anion-exchange chromatography. Carbohydr. Res., 283: $151-159$.

Hargin, K.D. and Morrison, W.R. (1980) The distribution of acyl lipids in the germ, aleurone, starch and non-starch endosperm of four wheat varieties. J. Sci. Food Agric., 31: $877-888$.

Helbert, W. and Chanzy, H. (1996) The ultrastructure of starch from ultrathin sectioning in melamine resin. Starch/Stärke, 48: 185 - 188.

Hellendoorn, E.W. (1969) Intestinal effects following ingestion of beans. Food Technol. (Champaign), 23(6): 795 - 800.

Hellendoorn, E.W. (1973) Carbohydrate digestibility and flatulence activity of beans. In Nutritional aspects of common beans and other legume seeds as animal and human foods (Ed. W.G. Jaffe). Archivos Latinoamericanos de Nutricion, Caracas, Venezuela, pp. $261-271$.

Hellendoorn, E.W. (1976) Beneficial physiological action of beans. J. Am. Diet. Assoc., 69: $248-253$.

Hellendoorn, E.W. (1978) Fermentation as the principlal cause of the physiological activity of indigestible food residue. In Topics in dietary fiber research (Eds. G.A. Spiller and R.J. Amen). Plenum Press, New York, NY, pp. 127-167.

Hellendoorn, E.W. (1979) Beneficial physiological activity of leguminous seeds. Qual. Plant. - Plant Foods Human Nutr., 29: 227 - 244.

Hibi, Y., Matsumoto, T. and Hagiwara, S. (1993) Effect of high pressure on the crystalline structure of various starch granules. Cereal Chem., 70: 671 -676. 
Hizukuri, S., Kakuto, M. and Nikuni, Z. (1964) X-ray diffractometric studies on starches. Part VII. On the submicroscopic structure of the granule by means of X-ray small angle scattering method. J. Agric. Chem. Soc. Jpn., 38: 520 - 524.

Hizukuri, S., Takeda, Y., Yasuda, M. and Suzuki, A. (1981) Multibranched nature of amylose and the action of debranching enzymes. Carbohydr. Res., 94: $205-213$.

Hizukuri, S., Kaneko, T. and Takeda, Y. (1983) Measurement of the chain length of amylopectin and its relevance to the origin of crystalline polymorphism of starch granules. Biochem. Biophys. Acta, 760: $188-191$.

Hizukuri, S. and Takagi,, T. (1984) Estimation of the molecular weight for amylase by the low angle laser-light-scattering technique combined with high-performance chromatography. Carbohydr. Res., 134:1-10.

Hizukuri, S. (1985) Relationship between the distribution of the chain length of amylopectin and crystalline structure of starch granules. Carbohydr. Res., 141: $295-306$.

Hizukuri, S. (1986) Polymodal distribution of the chain lengths of amylopectins and its significance. Carbohydr. Res., 147: $342-347$.

Hizukuri, S., Takeda, Y., Maruta, N. and Juliano, B.O. (1989) Molecular structures of rice starch. Carbohydr. Res., 189: 227 - 235.

Hizukuri, S. and Maehara, Y. (1990) Fine structure of wheat amylopectin: the mode of A to B chain binding. Carbohydr. Res., 206: $145-159$.

Hizukuri, S. (1996) Starch: analytical aspects. In Carbohydrate in food (Ed. A.C. Eliasson). Marcel Dekker, Inc., New York, NY, USA, pp. 347 - 429.

Holm, J., Björck, I., Ostrowska, S., Eliasson, A.C., Asp, N.G., Larsson, K. and Lundquist, I. (1983) Digestibility of amylose-lipid complexes in vitro and in vivo. Starch/Stärke, 35: 294 - 297.

Holm, J., Björck, I., Asp, N.G., Sjöberg, L.B. and Lundquist, I. (1985) Starch availability in vitro and in vivo after flaking, steam-cooking and popping of wheat. J. Cereal Sci., 3: $193-206$.

Holm, J., Lundquist, I., Björck, I, Eliasson, A.C. and Asp, N.G. (1988) Degree of starch gelatinization, digestion rate of starch in vitro, and metabolic responses in rats. Am. J. Clin. Nutr., 47: $1010-1016$.

Holm, J. and Björck, I. (1988) Effects of thermal processing of wheat on starch: II. Enzymic availability. J. Cereal Sci., 8: $261-268$. 
Holm, J., Hagander, B., Björck, I., Eliasson, A.C. and Lundquist, I. (1989) The effect of various thermal processes on the glycaemic response to whole-grain wheat products in humans and rats. J. Nutr., 119: $1631-1638$.

Hoover, R. and Sosulski, F.W. (1985a) Studies on the functional characteristics and digestibility of starches from Phaseolus vulgaris biotypes. Starch/Stärke, 37: 181 $-191$.

Hoover, R. and Sosulski, F.W. (1985b) A comparative study of the effect of acetylation on starches of Phaseolus vulgaris biotypes. Starch/Stärke, 38: 397-403.

Hoover, R., Cloutier, L., Dalton, S. and Sosulski, F.W. (1988a) Lipid composition of field pea (Pisum sativum cv. Trapper) seed and starch. Starch/Stärke, 40: 336 342.

Hoover, R., Hannouz, D. and Sosulski, F.W. (1988b) Effect of hydroxypropylation on thermal properties, starch digestibility and freeze-thaw stability of field pea (Pisum sativum cv. Trapper) starch. Starch/Stärke, 40: 383 - 387.

Hoover, R. and Sosulski, F.W. (1991) Composition, structure, functionality, and chemical modification of legume starches: a review. Can. J. Physiol. Pharmacol, 69: $79-$ 92.

Hoover, R., Swamidas, G. and Vasanthan, T. (1993) Studies on the physicochemical properties of native, defatted, and heat-moisture treated pigeon pea (Cajanus cajan L) starch. Carbohydr. Res., 246: 185 - 203.

Hoover, R. and Manuel, H. (1995) A comparative study of the physicochemical properties of starches from two lentil cultivars. Food Chem., 53: 275-284.

Hoover, R. and Manuel, H. (1996) The effect of annealing on the physicochemical properties of legume starches. In Agri-Food quality: an interdisciplinary approach (Eds. G.R. Fenwick, C. Hedley, R.L. Richards and S. Khokhar). Cambridge: Royal Society of Chemistry, Cambridge, UK, pp. $157-161$.

Hoover, R., Li, Y.X., Hynes, G. and Senanayake, N. (1997) Physicochemical characterization of mung bean starch. Food Hydrocolloids, 11: $401-408$.

Hoover, R. (2000) Acid-treated starches. Food Rev. Int., 16: 369 - 392.

Hoover, R. and Ratnayake, W. (2001) Determination of total amylose content of starch. In Current protocols in food science analytical chemistry (Eds. R.E. Wrolstad, S.J. Schwartz, T.E. Acree, C.F. Shoemaker, E.A. Decker, D. Smith, M.H. Penner, p. Sporns and D.S. Reid). John Wiley \& Sons, Inc., New York, NY, USA, E2.3.1 $-\mathrm{E} 2.3 .5$. 
Hoover, R. (2001) Composition, molecular structure, and physicochemical properties of tuber and root starches: a review. Carbohydr. Polym., 45: 253 - 267.

Hoover, R. and Ratnayake, W.S. (2002) Starch characteristics of black bean, chick pea, lentil, navy bean and pinto bean cultivars grown in Canada. Food Chem., 78: 489 $-498$.

Hoover, R., Smith, C., Zhou, Y. and Ratnayake, R.M.W.S. (2003) Physicochemical properties of Canadian oat starches. Carbohydr. Polym., 52: 253-261.

Hoover, R. and Zhou, Y. (2003) In-vitro and in-vivo hydrolysis of legume starches by $\alpha$ amylase and resistant starch formation in legumes - A review. Carbohydr. Polym., 54: $401-417$.

Horváthová, V., Janeček, Š., Šturdík, E. (2000) Amylolytic enzymes: their specificities, origins and properties. Biologia, Bratislava 55: 605-615.

Huang, J.J. and White, P.J. (1993) Waxy corn starch: monoglyceride interaction in a model system. Cereal Chem., 70: $42-47$.

I'Anson, K.J., Miles, M.J., Morris, V.J. and Ring, S.G. (1988) A study of amylose gelation using a synchrotron X-ray source. Carbohydr. Polym., 8: 45 - 53.

Imberty, A. and Pérez, S. (1988) A revisit to the three-dimentional structure of B-type starch. Biopolymer, 27: 1205-1221.

Imberty, A., Chanzy, H., Pérez, S., Buléon, A. and Tran, V. (1988) The double-helical nature of the crystalline part of A-starch. J. Mol. Biol., $201: 365-378$.

Imberty, A., Buléon, A., Tran, V. and Pérez, S. (1991) Recent advances in knowledge of starch structure. Starch/Stärke, 43: 375 - 384.

Inouchi, N., Glover, D.V., Sugimoto, Y. and Fuwa, H. (1984) Developmental changes in starch properties of several endosperm mutants of maize. Starch/Stärke, 36: 8 12.

Jacobs, H. and Delcour, J. (1998) Hydrothermal modifications of granular starch, with retention of the granular structure: a review. J. Agric. Food Chem., 46: 2895 2906.

Jacobson, M.R., Obanni, M. and BeMiller, J.N. (1997) Retrogradation of starches from different botanical sources. Cereal Chem., 74: $511-518$.

Jane, J., Xu, A., Radosavljevic, M. and Seib, P.A. (1992) Location of amylose in normal starch granules. I. Susceptibility of amylose and amylopectin to cross-linking reagents. Cereal Chem., 69: 405-409. 
Jane, J.-L. and Chen, J.F. (1992) Effect of amylose molecular size and amylopectin branch chain length on paste properties of starch. Cereal Chem., 69:60-65.

Jane, J.-L. and Shen, J.J. (1993) Internal structure of the potato starch granule revealed by chemical gelatinization. Carbohydr. Res., 247: 279-290.

Jane, J.-L., Wong, K.-S. and McPherson, A.E. (1997) Branch-structure difference in starches of A- and B-type X-ray patterns revealed by their Naegeli dextrins. Carbohydr. Res., 300: 219-227.

Jane, J., Chen, Y.Y., Lee, L.F., McPherson, A.E., Wong, K.S., Radosavljevic, M. and Kasemsuwan, T. (1999) Effects of amylopectin branch chain length and amylose content on the gelatinization and pasting properties of starch. Cereal Chem., 76: $629-637$.

Janeček, Š. (2000) Structural features and evolutionary relationships in the $\alpha$-amylase family. In: Glycoenzymes (Eds. M. Ohnishi, T. Hayashi, S. Ishijima, T. Kuriki), Japan Scientific Societies Press, Tokyo, Japan, pp.19-54

Jankowski, T. and Rha, C.K. (1986) Retrogradation of starch in cooked wheat. Starch/Stärke, 38: 6-9.

Jenkins, D.J., Thorne, M.J., Camelon, K., Jenkins, A.L., Rao, A. V., Taylor, R.H., Thompson, L.U., Kalmusky, J., Reichert, R. and Francis, T. (1982) Effect of processing on digestibility and the blood glucose response: a study of lentils. Am. J. Clin. Nutr., 36: $1093-1101$.

Jenkins, D.J., Thorne, M.J., Wolever, T.M., Jenkins, A.L., Rao, A.V. and Thompson, L.U. (1987a) The effect of starch-protein interactions in wheat on the glycemic response and rate of in vitro digestion. Am. J. Clin. Nutr., 45: 946-951.

Jenkins, D.J., Wolever, T.M., Collier, G.R., Ocana, A., Rao, A.V., Buckley, G., Lam, Y., Mayer, A. and Thompson, L.U. (1987b) Metabolic effect of a low glycemic-index diet. Am. J. Clin. Nutr., 46: $968-975$.

Jenkins, D.J., Wolever, T.M., Buckley, G., Lam, K.Y., Giudici, S., Kalmusky, J., Jenkins. A.L., Pattern, R.L., Bird, J. and Wong, G.S. (1988) Low-glycemic-index starchy foods in the diabetic diet. Am. J. Clin. Nutr., 48: $248-254$.

Jenkins, D.J.A., Jerkins, A.L., Kendall, C.W.C., Augustine, L. and Vuksan, V. (2001) Dietary fiber, carbohydrate metabolism, and chronic disease. In Advanced dietary fiber technology (Eds. B.V. McCleary and L. Prosky). Iowa State University Press, Ames, IA, pp. $162-167$.

Jenkins, P. (1994) X-ray and neutron scattering studies of starch granule structure. Ph.D. Thesis, University of Cambridge, Cambridge, UK. 
Jenkins, P.J., Cameron, R.E. and Donald, A.M. (1993) A universal feature in the structure of starch granules from different botanical sources. Starch/Stärke, 45: 417-420.

Jenkins, P.J. and Donald, A.M. (1995) The influence of amylose on starch granule structure. Int. J. Biol. Macromol., 17:315 - 321.

Jenkins, P.J. and Donald, A.M. (1997) The effect of acid hydrolysis on native starch granule structure. Starch/Stärke, 49: 262 - 267.

Jenkins, P.J. and Donald, A.M. (1998) Gelatinization of starch: a combined SAXS/WAXS/DSC and SANS study. Carbohydr. Res., 308: 133 - 147.

John, M., Schmidt, J. and Kneifel, H. (1983) Iodine-maltosaccharide complexes: relation between chain-length and color. Carbohydr. Res., 119: 254 - 257.

Juliano, B.O. and Goddard, M.S. (1986) Cause of varietal differences in insulin and glucose responses to ingested rice. Plant Foods Hum. Nutr., 36: 35 - 41.

Juliano, B.O. (1999) Comparative nutritive value of various staple foods. Food Rev. Int., 15: $399-434$.

Kadam, S.S., Deshpande, S.S. and Jambhale, N.D. (1989) Seed structure and composition. In CRC handbook of world food legumes: nutritional chemistry, processing technology, and utilization (Eds. D.K. Salunkhe and S.S. Kadam). CRC Press, Inc., Boca Raton, FL, USA., Vol.1, pp. 23-50.

Kadziola, A., Abe, J., Svensson, B. and Haser, R. (1994) Crystal and molecular structure of barley $\alpha$-amylase. J. Mol. Biol. 239: 104 - 121.

Kaneko, H., Kuriki, T., Handa, S., Takada, T., Takata, H., Yanase, M., Okada, S., Umeyama, H. and Shimada, J. (1998) How $\alpha$ - and $\beta$-amylases achieve their perfect stereoselectivity. Res. Commun. Biochem. Cell Molec. Biol., 2: 69 - 89.

Kasemsuwan, T. and Jane, J. (1994) Location of amylose in normal starch granules. II. Location of phosphodiester cross-linking revealed by phosphorus-31 nuclear magnetic resonance. Cereal Chem., 71:282 - 287.

Kasemsuwan, T. and Jane, J. (1996) Quantitative method for the survey of starch phosphate derivatives and starch phospholipids by ${ }^{13} \mathrm{P}$ nuclear magnetic resonance spectroscopy. Cereal Chem., 73: $702-707$.

Katsuya, Y., Mezaki, Y., Kubota, M. and Matsuura, Y. (1998) Three-dimensional structure of Pseudomonas isoamylase at $2.2 \AA$ resolution. J. Mol. Biol. 281: 885 897. 
Kayisu, K. and Hood, L.F. (1979) Effects of dehydration and storage conditions on the pancreatic $\alpha$-amylase susceptibility of various starches. J. Food Sci., 44: $1728-$ 1731.

Kim, H.R. and Eliasson, A.C. (1993) The influence of molar substitution on the thermal transition properties of hydroxypropyl potato starches. Carbohydr. Polym., 22: 31 -35 .

Knutson, C.A., Khoo, U., Cluskey, J.E. and Inglett, G.E. (1982) Variation in enzyme digestibility and gelatinization behavior of corn starch granule fractions. Cereal Chem., 59: $512-515$.

Kohyama, K. and Nishinari, K. (1991) Effect of soluble sugars on gelatinization and retrogradation of sweet potato starch. J. Agric. Food Chem., 39: 1406-1410.

Kong, B-W., Kim, J-I., Kim, M-J. and Kim, J.C. (2003) Porcine pancreatic $\alpha$-amylase hydrolysis of native starch granules as a function of granule surface area. Biotechnol. Prog., 19: $1162-1166$.

Kuipers, A.G.J., Jacobsen, E. and Visser, R.G.F. (1994) Formation and deposition of amylose in the potato tuber starch granule are affected by the reduction of granule-bound starch synthase gene expression. Plant Cell, 6: 43-52.

Kuriki, T., Guan, H. P., Sivak, M. and Preiss, J. (1996) Analysis of the active center of branching enzyme II from maize endosperm. J. Protein Chem., 15: 305 - 313.

Kuriki, T. and Imanaka, T. (1999) The concept of the $\alpha$-amylase family: structural similarity and common catalytic mechanism. J. Biosci. Bioeng., 87: 557-565.

Lajolo, F.M., Finardi-Filho, F. and Menezes, E.W. (1991) Amylase inhibitors in Phaseolus vulgaris beans. Food Technol., 45(9): 119-121.

Landau, L.D. and Lifshitz, E.M. (1958) Statistical physics. Pergamon Press, Oxford.

Larson, S. B., Greenwood, A., Cascio, D., Day, J. and McPherson, A. (1994) Refined molecular structure of pig pancreatic $\alpha$-amylase at $2.1 \AA$ resolution. J. Mol. Biol. 235: $1560-1584$.

Lauro, M., Forssell, P.M.P., Suortti, M.T., Hulleman, S.H.D. and Poutanen, K.S. (1999) $\alpha$-Amylolysis of large barley starch granules. Cereal Chem., 76: $925-930$.

Leach, H.W. and Schoch, T.J. (1961) Structure of the starch granule II. Action of various amylases on granular starches. Cereal Chem., 76: 925 - 930. 
Lehmann, U., Rössler, C., Schmiedl, D. and Jacobasch, G. (2003) Production and physicochemical characterization of resistant starch type III derived from pea starch. Nahrung, 47: $60-63$.

Leloup, V.M., Colonna, P. and Ring, S.G. (1991) $\alpha$-Amylase adsorption on starch crystallites. Biotechnol. Bioeng., 38: $127-134$.

Leterme, P. (2002) Recommendations by health organizations for pulse consumption. Br. J. Nutr., 88(suppl. 3): S239-242.

Lillford, P.J. and Morrison, A. (1997) Structure/function relationship of starches in food. In Starch: structure and functionality (Eds. P.J. Frazier, A.M. Donald and P. Richmond). The Royal Society of Chemistry, Cambridge, U.K., pp. $1-8$.

Lim, S.T., Kasemsuwan, T. and Jane, J. (1994) Characterization of phosphorous in starch by ${ }^{13} \mathrm{P}$ nuclear magnetic resonance spectroscopy. Cereal Chem., 71: $488-493$.

Lineback, D.R. (1984) The starch granule: organization and properties. Baker's Dig., 58: $16-21$.

Lintas, C. and Cappelloni, M. (1992) Effect of processing on legume resistant starch. Eur. J. Clin. Nutr., 16: S103 - S104.

Liu, H. and Lelievre, J. (1993) A model of starch gelatinization linking differential scanning calorimetry and birefringence measurements. Carbohydr. Polym., 20: 1 -5 .

LMC International Ltd. (2002) The structure of the world starch market. URL: http://europa.eu.int/comm/agriculture/eval/reports/amidon/chap1.pdf

Longton, J. and LeGrys, G.A. (1981) Differential scanning calorimetry studies on the gelatinization of aging gels. Starch/Stärke. 33: $410-414$.

LSBU (2003) Starch. London South Bank University. URL: http://www.lsbu.ac.uk/water/hysta.html

MacGregor, A.W. and Morgan, J.E. (1984) Structure of amylopectin isolated from large and small starch granules of normal and waxy barley. Cereal Chem., 61: $222-$ 228.

Machius, M., Wiegand, G. and Huber, R. (1995) Crystal structure of calcium-depleted Bacillus licheniformis $\alpha$-amylase at 2.2Å resolution. J. Mol. Biol., 246: 545 - 559.

Mackenzie, L. F., Davies, G. J., Schulein, M. and Withers, S. G. (1997a) Identification of the catalytic nucleophile of endoglucanase I from Fusarium oxysporum by mass spectrometry. Biochemistry, 36: 5893 - 5901. 
Mackenzie, L. F., Brooke, G. S., Cutfield, J. F., Sullivan, P. A. and Withers, S. G. (1997b) Identification of Glu-330 as the catalytic nucleophile of Candida albicans exo-ß-(1,3)-glucanase. J. Biol. Chem., 272: 3161 - 3167.

Madhusudhan, B. and Tharanathan, R.N. (1996) Structural studies of linear and branched fractions of chickpea and finger millet starches. Carbohydr. Res., 284: $101-109$.

Mahadevamma, S., Prashanth, K.V.H. and Tharanathan, R.N. (2003) Resistant starch derived from processed legumes - purification and structural characterization. Carbohydr. Polym., 54:215-219.

Maningat, C.C. and Juliano, B.J. (1980) Starch lipids and their effect on rice starch properties. Starch/Stärke, 32: 76-82.

Manners, D.J. and Matheson, N.K. (1981) The fine structure of amylopectin. Carbohydr. Res., 90: 99 - 110.

Manners, D..J. (1989) Recent developments in our understanding of amylopectin structure. Carbohydr. Polym., 11:87-112.

Marlett, J.A. and Longacre, M.J. (1996) Comparison of in vitro measures of resistant starch in selected food products. Cereal Chem., 73: $63-68$.

Mathers, J.C. (2002) Pulses and carcinogenesis: potential for the prevention of colon, breast and other cancers. Br. J. Nutr., 88(suppl. 3): S273 - 279.

Matsuura, Y., Kusunoki, M., Harada, W. and Kakudo, M. (1984) Structure and possible catalytic residues of Taka-amylase A. J. Biochem. (Tokyo), 95: 697-702.

McCarter, J. D. and Withers, S. G. (1996) 5-Fluoro glycosides: a new class of mechanism-based inhibitors of both $\alpha$ - and $\beta$-glucosidases. J. Am. Chem. Soc., 118: $241-242$.

McDonald, A.M.L. and Stark, J.R. (1988) A critical examination of procedures for the isolation of barley starch. J. Inst. Brew, 94: 125 - 132.

McDonald, A.M.L., Stark, J.R., Morrison, W.R. and Ellis, R.P. (1991) The composition of starch granules from developing barley genotypes. J Cereal. Sci., 13: $93-112$.

McGregor, E.A. and McGregor, A.W. (1985) A model for the action of cereal alphaamylases on amylose. Carbohydr. Res., 142: 223 - 236.

McPherson, A.E. and Jane, J. (1999) Comparison of waxy potato with other root and tuber starches. Carbohydr. Polym., 40: 57 - 70. 
Miles, M.J., Morris, V.J., Orford, P.D. and Ring, S.G. (1985a) The roles of amylose and amylopectin in the gelation and retrogradation of starch. Carbohydr. Res., 135: $271-281$.

Miles, M.J., Morris, V.J. and Ring, S.G. (1985b) Gelation of amylose. Carbohydr. Res., 135: $257-269$.

Miller, J.B., Pang, E. and Bramall, L. (1992) Rice: a high or low glycemic index food? Am. J. Clin. Nutr., 56: $1034-10.36$.

Mita, T. (1992) Structure of potato starch pastes on the aging process by the measurement of their dynamic moduli. Carbohydr. Polym., 12: 269-276.

Morell, M.K., Samuel, M.S. and O'Shea, M.G. (1998) Analysis of starch structure using fluorophore-assisted carbohydrate electrophoresis. Electrophoresis, 19: 2603 2611.

Morgan, K.R., Fumeaux, R.H. and Larsen, N.G. (1995) Solid-state NMR studies on the structure of starch granules. Carbohydr. Res., 276: 387 - 399.

Morrison, W.R. (1981) Starch lipids: a reappraisal. Starch/Stärke, 33: 408 - 410.

Morrison, W.R. and Milligan, T.P. (1982) Lipids in maize starches. In Maize: recent progress in chemistry and technology (Ed. G. Inglett). Academic press, New York, NY, USA, pp. $1-18$.

Morrison, W.R., Scott, D.C. and Karkalas, J. (1986) Variation in the composition and physical properties of barley starches. Starch/Stärke, 38: $374-379$.

Morrison, W.R. and Gadan, H. (1987) The amylose and lipid contents of starch granules in developing wheat endosperm. J. Cereal Sci., 5: 263-275.

Morrison, W.R. and Karkalas, J. (1990) Starch. In Methods in plant biochemistry. Academic Press, Inc., New York, Vol.2., pp. 323 - 352.

Morrison, W.R., Law, R.V. and Snape, C.E. (1993a) Evidence for inclusion complexes of lipid with V-amylose in maize, rice and oat starches. J. Cereal. Sci., 18: 107 111.

Morrison, W.R., Tester, R.F., Gidley, M.J. and Karkalas, J. (1993b) Resistance to acid hydrolysis of lipid-complexed amylose and lipid-free amylose in lintnerised waxy and non-waxy barley starches. Carbohydr. Res., 245: $289-302$. 
Morrison, W.R., Tester, R.F., Snape, C.E., Law, R. and Gidley, M.J. (1993c) Swelling and gelatinization of cereal starches. IV. Some effects of lipid-complexed amylose and free amylose in waxy and normal barley starches. Cereal Chem., 70: $385-391$.

Morrison, W.R. (1995) Starch lipids and how they relate to starch granule structure and functionality. Cereal Foods World, 40: 437 - 446.

Mosi, R., He, S., Uitdehaag, J., Dijkstra, B.W. and Withers, S. G. (1997) Trapping and characterization of the reaction intermediate in cyclodextrin glycosyltransferase by use of activated substrates and a mutant enzyme. Biochemistry, 36: 9927 9934.

Nakajima, R., Imanaka, T. and Aiba, S. (1986) Comparison of amino acid sequences of eleven different $\alpha$-amylases. Appl. Microbiol. Biotechnol., 23: 355-360.

Nara, Sh., Mori, A. and Komiya, T. (1978) Study on relative crystallinity of moist potato starch. Starch/Stärke, 30: $111-114$.

Nara, S. and Komiya, T. (1983) Studies on the relationship between water-saturated state and crystallinity by the diffraction method for moistened potato starch. Starch/Stärke, 35: $407-410$.

Narayana Moorthy, S. (2002) Physicochemical and functional properties of tropical tuber starches: a review. Starch/Stärke, 54: 559 - 592.

Nebensy, E., Rosicka, J. and Tkaczyk, M. (2002) Effect of enzymatic hydrolysis of wheat starch on amylose-lipid complexes stability. Starch/Stärke, 54: 603 - 608.

Nikuni, Z. (1978) Studies on starch granule. Starch/Stärke, 30: 105 - 111.

Noda, T., Takahata, Y., Sato, T., Ikoma, H. and Mochida, H. (1996) Physicochemical properties of starches from purple and orange fleshed sweet potato roots at two levels of fertilizer. Starch/Stärke, 48: 395 - 399.

Noda, T., Takahata, Y., Sato, T., Suda, I., Morishita, T., Ishiguro, K. and Yamakawa, O. (1998) Relationships between chain length distribution of amylopectin and gelatinization properties within the same botanical origin for sweet potato and buckwheat. Carbohydr. Polym., 37: 153-158.

Oates, C.G. (1997) Towards an understanding of starch granule structue and hydrolysis. Trends Food Sci. Techol., 8: 375 - 380.

Oostergetel, G.T. and Van Bruggen, E.F.J. (1993) The crystalline domains in potato starch granules are arranged in a helical fashion. Carbohydr. Polym., 21: 7-12. 
Orford, P.D., Ring, S.G., Carrol, V., Miles, M.J. and Morris, V.J. (1987) The effect of concentration and botanical source on the gelation and retrogradation of starch. $J$. Sci. Food Agric., 39: $169-177$.

Orford, P.D., Parker, R. and Ring, S.G. (1993) The functional properties of extrusion cooked waxy maize starch. J. Cereal Sci., 18: 277-286.

Osorio-Diaz, P., Bello-Perez, L.A., Agama-Acevedo, E., Vargas-Torres, A., Tovar, J. and Paredes-Lopez, O. (2002) In vitro digestibility and resistant starch content of some industrialized commercial beans (Phaseolus vulgaris L.). Food Chem., 78: $333-337$.

Pagani, M.A., Gallant, D.J., Bouchet, B. and Resmini, P. (1986) Ultrastructure of cooked spaghetti. Food Microstruct., 5: 111 - 129.

Paris, A., Bizot, H., Emery, J., Buzare, J.Y. and Buleon, A. (1999) Crystallinity and structuring role of water in native and recrystallized starches by ${ }^{13} \mathrm{C} C \mathrm{CP}-\mathrm{MAS}$ NMR spectroscopy: 1: Spectral decomposition. Carbohydr. Polym., 39: 327 339.

Periago, M.J., Ros, G. and Casas, J.L. (1997) Non-starch polysaccharides and in vitro starch digestibility of raw and cooked chick peas. J. Food Sci., 62: $93-96$.

Pfannemüeller, B. (1987) Influence of chain length of short monodisperse amylose on the formation of A- and B-type X-ray diffraction patterns. Int. J. Biol. Macromol., 9: $105-108$.

Puls, W. and Keup, U. (1973) Influence of an $\alpha$-amylase inhibitor on blood glucose serum insulin and NEFA in starch loading tests in rats, dogs and man. Diabetologia, 9: $97-101$.

Qian, M., Haser, R. and Payan, F. (1993) Structure and molecular model refinement of pig pancreatic $\alpha$-amylase at $2.1 \AA$ resolution. J. Mol. Biol., 231: 785-799.

Qian, M., Haser, R., Buisson, G., Duee, E. and Payan, F. (1994) The active center of a mammalian $\alpha$-amylase. Structure of the complex of a pancreatic $\alpha$-amylase with a carbohydrate inhibitor refined to $2.2 \AA$ resolution. Biochemistry, 33: 6284 - 6294.

Ramasubbu, N., Paloth, V., Luo, Y., Brayer, G. D. and Levine, M. J. (1996) Structure of human salivary $\alpha$-amylase at $1.6 \AA$ resolution: implications for its role in the oral cavity. Acta Crystallogr., Sect. D: Biol. Crystallogr., 52: 435-446.

Rao, S.P. (1969) Studies on the digestibility of carbohydrates in pulses. Indian J. Med. Res., 57: $2151-2157$. 
Rappenecker, C.R. and Zugenmaier, P. (1981) Detailed refinement of the crystal structure of $\mathrm{V}_{\mathrm{h}}$-amylose. Carbohydr. Res., 89: 11-19.

Ratnayake, W.S., Hoover, R., Shahidi, F., Perera, C. and Jane, J. (2001) Composition, molecular structure, and physicochemical properties of starches from four field pea (Pisum sativum L.) cultivars. Food Chem., 74: 189 - 202.

Ratnayake, W.S., Hoover, R. and Warkentin, T. (2002) Pea starch: composition, structure and properties - A review. Starch/Stärke, 54: $217-234$.

Ring, S.G., Colonna, P., I'Anson, K.J., Kalichevsky, M.T., Miles, M.J., Morris, V.J. and Oxford, P.D. (1987) The gelation and crystallization of amylopectin. Carbohydr. Res., 163: $277-293$.

Ring, S.G., Gee, J.M., Whittam, M.A., Orford, P.D. and Johnson, I.T. (1988) Resistant starch: its chemical form in food stuffs and effects on digestibility in vitro. Food Chem., 28: 97 - 109.

Roberts, S.B. (2000) High-glycemic index foods, hunger and obesity: is there a connection? Nutr. Rev., 58: 163 - 169.

Roberts, K., Dunn, K., Jean, S.K. and Lardinois, C.K. (2000) Syndrome X: medical nutrition therapy. Nutr. Rev., 58: $154-160$.

Robyt, J. F. and French, D. (1967) Multiple attack hypothesis of $\alpha$-amylase action: action of porcine pancreatic, human salivary, and Aspergillus oryzae $\alpha$-amylases. Arch. Biochem. Biophys., 122: 8 -16.

Robyt, J. F. and French, D. (1970) The action pattern of porcine pancreatic $\alpha$-amylase in relationship to the substrate binding site of the enzyme. J. Biol. Chem., 245: 3917 $-3927$.

Robyt, J.F. (1984) Enzymes in the hydrolysis and synthesis of starch. In Starch: chemistry and technology (Eds. R.L. Whistler, J.N. BeMiller and E.R. Paschall). $2^{\text {nd }}$ edition, Chapter IV, Academic Press Inc., Orlando, FL, USA, pp. 87 - 123.

Röper, H. (2002) Renewable raw materials in Europe - industrial utilization of starch and sugar. Starch/Stärke, 54: 89 - 99.

Rosin, P.M., Lajolo, F.M. and Menezes, E.W. (2002) Measurement and characterization of dietary starches. J. Food Comp. Anal., 15:367-377.

Rundle, R.E. and Baldwin, R.J. (1943) The configuration of starch and the starch-iodine complex. I. The dischroism of flow of starch-iodine solutions. J. Am. Chem. Soc., 65: $544-558$. 
Russell, P.L. (1987) Gelatinization of starches of different amylose/amylopectin content. A study by differential scanning calorimetry. J. Cereal Sci., 6: 133-145.

Sahasrabudhe, M.R., Quinn, J.R., Paton, D., Youngs, C.G. and Skura, B.J. (1981) Chemical composition of White Bean (Phaseolus vulgaris L.) and functional characteristics of its air-classified protein and starch fractions. J. Food Sci., 46: $1079-1081$.

Salunkhe, D.K. and Kadam, S.S. (1989) Introduction. In CRC Handbook of World Food Legumes: Nutritional Chemistry, Processing Technology, and Utilization(Ed. D.K. Salunkhe and S.S. Kadam), Vol. 1. CRC Press, Inc., Boca Raton, FL, USA, pp. 1 - 4 .

Sarko, A. and Wu, H.-C.H. (1978) The crystal structures of A-, B- and C-polymorphs of amylose and starch. Starch/Stärke, 30: 73 - 78.

Sarko, A. and Zugenmaier, P. (1980) Crystal structures of amylose and its derivatives: a review. ACS Symp. Ser., 141: 459 - 482.

Sasaki, T. and Matsuki, J. (1998) Effect of wheat starch structure on swelling power. Cereal Chem., 75: $525-529$.

Savage, G.P. and Deo. S. (1989) The nutritional value of peas (Pisum sativum). A literature review. Nutr. Abstr. Rev.(series A), 59:66-88.

Schneider, A.V.C. (2002) Overview of the market and consumption of pulses in Europe. Br. J. Nutr., 88(suppl. 3): S243 - S250.

Schwatz, D. (1982) Amylose distribution in the starch granule of maize endosperm. Maydica, 27: $54-57$.

Seneviratne, H.D. and Biliaderis, C.G. (1991) Action of $\alpha$-amylases on amylose-lipid complex superstructures. J. Cereal Sci., 13: 129-141.

Shi, Y. C. and Seib, P.A. (1992) The structure of four waxy starches related to gelatinization and retrogradation. Carbohydr. Res., 227: 131 - 145.

Shi, Y. C. and Seib, P.A. (1995) Fine structure of maize starches from four wx-containing genotypes of the W64A inbred line in relation to gelatinization and retrogradation. Carbohydr. Polym., 26: 141 - 147.

Shi, Y.C., Capitani, T., Trzasko, P. and Jeffcoat, R. (1998) Molecular structure of a lowamylopectin starch and other high-amylose maize starches. J. Cereal. Sci., 27: $289-299$. 
Shibanuma, K., Takeda, Y., Hizukuri, S. and Shibata, S. (1994) Molecular structures of some wheat starches. Carbohydr. Polym., 25: 111-116.

Siddhuraju, P. and Becker, K. (2001) Effect of various domestic processing methods of antinutrients and in vitro protein and starch digestibility of two indigenous varieties of Indian tribal pulse, Mucana pruriens Var. utilis. J. Agric. Food Chem., 49: $3058-3067$.

Siljeström, M., Björck, I., Eliasson, A.C., Lönner, C., Nyman, M. and Asp, N.G. (1988) Effects on polysaccharides during baking and storage of bread - in vitro and in vivo studies. Cereal Chem., 65:1-8.

Skerritt, J.H., Frend, A.J., Robson, L.G. and Greenwell, P. (1990) Immunological homologies between wheat gluten and starch granule proteins. J. Cereal Sci., 12: $123-136$.

Skrabanja, V., Liljeberg, H.G.M., Hedley, C.L., Kreft, I. and Bjorck, I.M.E. (1999) Influence of genotype and processing on the in vitro rate of starch hydrolysis and resistant starch formation in peas (Pisum sativum L.). J. Agric. Food Chem., 47: $2033-2039$.

Smartt, J. (1990) Introduction: biosystematics of the legumes. In Grain legumes: evolution and genetic resource(Ed. J. Smartt). Cambridge University Press, New York, USA, pp. 1 - 8.

Snow, P. and O'Dea, K. (1981) Factors affecting the rate of hydrolysis of starch in foods. Am. J. Clin. Nutr., 34: 2721 - 2727.

Socorro, M., Levy-Benshimol, A. and Tovar, J. (1989) In vitro digestibility of cereals and legumes (Phaseolus vulgaris) starches by bovine pancreas and human pancreatic $\alpha$-amylase. Starch/Stärke, 41: 69-71.

Song, Y. and Jane, J. (2000) Characterization of barley starches of waxy, normal, and high amylose varieties. Carbohydr. Polym., 41:365-377.

Sosulski, F., Garratt, M.D. and Slinkard, A.E. (1976) Functional properties of ten legume flours. Can. Inst. Food Sci. Technol. J., 9: 66 - 69.

Sosulski, F.W. and Youngs, C.G. (1979) Yield and functional properties of air classified protein and starch fractions from eight legume flours. J. Am. Oil Chem. Soc., 56: $292-295$.

Sosulski, F.W., Yook, C. and Arganosa, G.C. (1997) Functional properties of cationic pea starch. In Starch structure and functionality (Eds. P.J. Frazier, A.M. Donald and P. Richmond). The Royal Society of Chemistry, Cambridge, UK, pp. 36 - 41. 
Sprent, J.I (2001) Introduction to Legumes. In Nodulation in Legumes (Ed. J.I Sprent). Royal Botanic Gardens, the Cromwell Press Ltd., Wiltshire, UK, pp. 1 - 13.

Srisuma, N., Rueng-s, S., Bangkok, Uebersax, M.A. and Lansing, E. (1994) Starch characteristics and canning quality of four selected navy bean (Phaseolus vulgaris) cultivars. Starch/Stärke, 46: $187-193$.

Sumner, A.K., Nielsen, M.A. and Youngs, C.G. (1981) Production and evaluation of pea protein isolate. J. Food Sci., 46: 364 - 366, 372.

Svensson, B. (1994) Protein engineering in the $\alpha$-amylase family: catalytic mechanism, substrate specificity, and stability. Plant Mol. Biol., 25: 141 - 157.

Swift, H. J., Brady, L., Derewenda, Z. S., Dodsen, E. J., Dodsen, G. G., Turkenburg, J. P. and Wilinson, A. J. (1991) Structure and molecular model refinement of Aspergillus oryzae (TAKA) $\alpha$-amylase: an application of the simulated-annealing method. Acta Crystallogr. Sec. B., 47: 535 - 544.

Swinkels, J.J.M. (1985) Composition and properties of commercial native starches. Starch/Stärke, 37: 1 - 5 .

Takahashi, S. and Seib, P.A. (1988) Paste and gel properties of prime corn and wheat starches with and without native lipids. Cereal Chem., 65: 474- 483.

Takata, H., Kuriki, T., Okada, S., Takesada, Y., Iizuka, M., Minamiura, N. and Imanaka, T. (1992) Action of neopullulanase. Neopullulanase catalyzes both hydrolysis and transglycosylation at $\alpha-(1 \rightarrow 4)$ - and $\alpha-(1 \rightarrow 6)$-glucosidic linkages. J. Biol. Chem., 267: $18447-18452$.

Takata, H., Takaha, T., Kuriki, T., Okada, S., Takagi, M. and Imanaka, T. (1994) Properties and active center of the thermostable branching enzyme from Bacillus stearothermophilus. Appl. Environ. Microbiol., 60: 3096 - 3104.

Takeda, Y., Shirasaka, K. and Hizukuri, S. (1984) Examination of the purity and structure of amylose by gel-permeation chromatography. Carbohydr. Res., 132: 83-92.

Takeda, Y., Hizukuri, S. and Juliano, BO (1986) Purification and structure of amylose from rice starch. Carbohydr. Res., 148: 299 - 308.

Takeda, Y., Hizukuri, S., Takeda, C. and Suzuki, A. (1987a) Structures of branched molecules of amyloses of various origins and the molar fractions of branched and unbranched molecules. Carbohydr. Res., 165: 139-145.

Takeda, Y., Hizukuri, S. and Juliano, B.O. (1987b) Structures of rice amylopectin with low and high affinities for iodine. Carbohydr. Res., 168: $79-88$. 
Takeda, Y., Shitaozono, T. and Hizukuri, S. (1988) Molecular structure of corn starch. Starch/Stärke, 40: 51 - 54 .

Tang, H., Ando, H., Watanabe, K., Takeda, Y. and Mitsunaga, T. (2001a) Fine structures of amylose and amylopectin from large, medium, and small waxy barley starch granules. Cereal Chem., 78: $111-115$.

Tang, H., Ando, H., Watanabe, K., Takeda, Y. and Mitsunaga, T. (2001b) Physicochemical properties and structures of large, medium and small granule starches in fractions of normal barley endosperm. Carbohydr. Res., 330: $241-$ 248.

Tao, B. Y., Reilly, P. J. and Robyt, J. F. (1989) Detection of a covalent intermediate in the mechanism of action of porcine pancreatic $\alpha$-amylase by using ${ }^{13} \mathrm{C}$ nuclear magnetic resonance. Biochim. Biophys. Acta, 995: $214-220$.

Tatge, H., Marshall, J., Martin, C., Edwards, E.A. and Smith, A.M. (1999) Evidence that amylose synthesis occurs within the matrix of the starch granule in potato tubers. Plant Cell Envion., 22: 543 - 550.

Teitelbaum, R.C., Ruby, S.L. and Marks, T.J. (1978) On the structure of starch-iodine. J. Am. Chem. Soc., 100: 3215-3217.

Teitelbaum, R.C., Ruby, S.L. and Marks, T.J. (1980) A resonance Raman/iodine Mossbauer investigation of the starch-iodine structure. Aqueous solution and iodine vapor preparations. J. Am. Chem. Soc., 102: $3322-3328$.

Tester, R.F. and Morrison, W.R. (1990) Swelling and gelatinization of cereal starches. I. Effect of amylopectin, amylose and lipids. Cereal Chem., 67: $551-557$.

Tester, R.F., Morrison, W.R. and Schulman, A.H. (1993) Swelling and gelatinization of cereal starches. V. Riso mutants of Bomi and Carlsberg II barley cultivars. $J$. Cereal Sci., 17: 1 - 9 .

Tester, R.F. (1997) Starch: the polysaccharide fractions. In Starch structure and functionality (Eds. P.J. Frazier, A.M. Donald and P. Richmond). The Royal Society of Chemistry, Cambridge, UK, pp. 163-171.

Tester, R.F. and Debon, S.J.J. (2000) Annealing of starch - a review. Int. J. Biol. Macromol., 27: 1- 12 .

Tester, R.F. and Sommerville, M.D. (2000) Swelling and enzymatic hydrolysis of starch in low water systems. J. Cereal Sci., 33: $193-203$. 
Tester, R.F., Debon, S.J.J., Qi, X., Sommerville, M.D., Yousuf, R. and Yusuph, M. (2001) Amylopectin crystallization in starch. In Starch advances in structure and function (Eds. T.L. Barsby, A.M. Donald and P.J. Frazier). The Royal Society of Chemistry, Chambridge, UK, pp. $97-102$.

Thompson, L.U. and Gabon, J.E. (1987) Effects of lectins on salivary and pancreatic amylase activities and the rate of starch digestion. J. Food Sci., 52: 1050-1053.

Tinay, A.H.EL., Hardalou, S.B.EL. and Nour, A.M. (1983) Comparative study of three legume starches. J. Food Technol., 18: 1 - 9.

Tjahjadi, C. and Breene, W.M. (1984) Isolation and characterization of adzuki bean (Vigna angularis cv. Takara) starch. J. Food Sci., 49: 558-562, 565.

Tovar, J., Björck, I.M. and Asp, N.G. (1990) Starch content and $\alpha$-amylolysis rate in precooked legume flours. J. Agric. Food Chem., 38: 1818-1823.

Tovar, J., de Francisco, A., Björck, I. and Asp, N.G. (1991) Relationship between microstructure and in vitro digestibility of starch in precooked leguminous seed flours. Food Structure, 10: $19-26$.

Tovar, J., Björck, I.M. and Asp, N.G. (1992a) Incomplete digestion of legume starches in rats: A study of precooked flours containing retrograded and physically inaccessible starch fractions. J. Nutr., 122: $1500-1507$.

Tovar, J., Granfeldt, Y. and Björck, I.M. (1992b) Effect of processing on blood glucose and insulin responses to starch in legumes. J. Agric. Food Chem., 40: $1846-$ 1851.

Tovar, J. and Melito, C. (1996) Steam-cooking and dry heating produce resistant starch in legumes. J. Agric. Food Chem., 44: 2642 - 2645.

Truswell, A.S. (1992) Glycaemic index of foods. Eur. J. Clin. Nutr., 46: S91 - S101.

Tufvesson, F., Skarabanja, V., Björck, I., Elmstahl, H.L. and Eliasson, A.C. (2001) Digestibility of starch systems containing amylose-glycerol monopalmitin complexes. Lebensm. Wiss. Technol., 34: 131 - 139.

Uitdehaag, J. C. M., Mosi, R., Kalk, K. H., van der Veen, B. A., Dijkhuizen, L., Withers, S. G. and Dijkstra, B. W. (1999) X-ray structures along the reaction pathway of cyclodextrin glycosyltransferase elucidate catalysis in the $\alpha$-amylase family. Nature Struct. Biol., 6: 432 - 436.

van Amelsvoort, J.M. and Weststrate, J.A. (1992) Amylose-amylopectin ratio in a meal affects postprandial variables in male volunteers. Am. J. Clin. Nutr., 55: $712-$ 718. 
van der Maarel, M. J. E. C., van der Veen, B., Uitdehaag, J. C. M., Leemhuis, H. and Dijkhuizen, L. (2002) Properties and applications of starch-converting enzymes of the $\alpha$-amylase family. J. Biotechnol., 94: $137-155$.

Van Soest, J.J.G., Toumois, H., de Wit, D. and Vliegenthart, J.F.G. (1995) Short-range structure in (partially) crystalline potato starch determined with attenuated total reflectance Fourier-transform IR spectroscopy. Carbohydr. Res., 279: $201-214$.

Vasanthan, T. and Hoover, R. (1992) A comparative study of the composition of lipids associated with starch granules from various botanical sources. Food Chem., 43: $19-27$.

Vasanthan, T. and Bhatty, R.S. (1996) Physicochemical properties of small- and largegranule starches of waxy, regular, and high-amylose barleys. Cereal Chem., 73: $199-207$.

Velasco, Z.I., Rascon, A. and Tovar, J. (1997) Enzymic availability of starch in cooked black beans (Phaseolus vulgaris L) and cowpeas (Vigna spp.). J. Agric. Food Chem., 45: $1548-1551$.

Veregin, R.P., Fyfe, C.A., Marchessault, R.H. and Taylor, M.G. (1986) Characterization of the crystalline A and B starch polymorphs and investigation of starch crystallization by high-resolution ${ }^{13} \mathrm{C}$ CP/MAS NMR. Macromolecules, 19: 1030 $-1034$.

Vose, J.R. (1980) Production and functionality of starches and protein isolates from legume seeds (field peas and horsebeans). Cereal Chem., 57: 406-410.

Waigh, T.A., Gidley, M.J., Komanshek, B.U. and Donald, A.M. (2000a) The phase transformations in starch during gelatinization: a liquid crystalline approach. Carbohydr. Res., 328: 165 - 176.

Waigh, T.A., Kato, K.L., Donald, A.M., Gidley, M.J., Clarke, C.J. and Riekel, C. (2000b) Side-chain liquid crystalline model for starch. Starch/Stärke, 52: 450 460.

Waldroup, P.W. and Smith, K.J. (1989) Animal feed uses of legumes. In Legumes: chemistry, technology, and human nutrition (Ed. R.H. Matthews). Marcel Dekker, Inc., New York, NY, USA, pp. 245 - 337.

Wang, J., Jiang, G., Vasanthan, T. and Sporns, P. (2000) MALDI-MS characterization of maltooligo/polysaccharides from debranched starch amylopectin of corn and barley. Starch/Stärke, 51: $243-248$.

Wang, T.L., Bogracheva, T.Ya. and Hedley, C.L. (1998) Starch: as simple as A, B, C? J. Exp. Bot., 49: $481-502$. 
Wang, W.J. and Jane, J. (1994) Correlation between glass transition temperature and starch retrogradation in the presence of sugars and maltodextrins. Cereal Chem., $71: 527-531$.

Wilson, R.H., Goodfellow, B.J. and Belton, P.S. (1991) Comparison of Fourier transform mid infrared spectroscopy and near infrared reflectance spectroscopy with differential scanning calorimetry for the study of the staling of bread. J. Sci. Food Agric., 54: 471 - 483.

Wong, K.S. and Jane, J-L. (1997) Quantitative analysis of debranched amylopectin by HPAEC-PAD with a postcolumn enzyme reactor. J. Liquid Chromatogr. \& Related Technol., 20: 297 - 310.

Wu, H.-C.H. and Sarko, A. (1978a) The double-helical molecular structure of crystalline B-amylose. Carbohydr. Res., 61:7-25.

Wu, H.-C.H. and Sarko, A. (1978b) The double-helical molecular structure of crystalline A-amylose. Carbohydr. Res., 61:27 - 40 .

Wu, J.Y. and Eads, T.M. (1993) Evolution of polymer mobility during aging of gelatinized waxy maize starch: a magnetization transfer ${ }^{1} \mathrm{H}$ NMR study. Carbohydr. Polym., 20: $51-60$.

Wursch, P., Dal Vedovo, S. and Koellreuter, B. (1986) Cell structure and starch nature as key determinants of the digestion rate of starch in legume. Am. J. Clin. Nutr., 43: $25-29$.

Yamaguchi, M., Kainuma, K. and French, D.J. (1979) Electron microscopy observation of waxy maize starch. J. Ultrastr. Res., 69: 249-261.

Yook, C., Pek, U. and Park, K. (1993) Gelatinization and retrogradation characteristics of hydroxypropylated and cross linked rices. J. Food Sci., 58: $405-407$.

Yoshimoto, Y., Tashiro, J., Takenouchi, T. and Takeda, Y. (2000) Molecular structure and some physicochemical properties of high-amylose barley starches. Cereal Chem., 77: $279-285$.

Yoshimoto, Y., Matsuda, M., Hanashiro, I., Takenouchi, T. and Takeda, Y. (2001) Molecular structure and pasting properties of legume starches. J. Appl. Glycosci., $48: 317-324$.

Yoshimoto, Y., Takenouchi, T. and Takeda, Y. (2002) Molecular structure and some physicochemical properties of waxy and low-amylose barley starches. Carbohydr. Polym., 47: $159-167$. 
Yun, S.H. and Matheson, N.K. (1992) Structural changes during development in the amylose and amylopectin fractions (separated by precipitation with concanavalin A) of starches from maize genotypes. Carbohydr. Res., 227: 85-101.

Zeleznak, K.J. and Hoseney, R.C. (1986) The role of water in retrogradation of wheat starch gels and bread crumb. Cereal Chem., 63: 407-411.

Zhang, W. and Jackson, D.S. (1992) Retrogradation behavior of wheat starch gels with differing molecular profiles. J. Food Sci., 57: 1428 - 1432.

Zobel, H.F. (1988a) Molecules to granules: a comprehensive starch review. Starch/Stärke, 40: $44-50$.

Zobel, H.F. (1988b) Starch crystal transformations and their industrial importance. Starch/Stärke, 40: $1-7$.

Zobel, H.F. (1992) Starch granule structure. In Developments in carbohydrate chemistry (Eds. R.J. Alexander and H.F. Zobel). Am. Assoc. Cereal Chem., St. Paul, MN., pp. $1-36$. 
Appendices 
Figure A-1 Standard curve for amylose determination 


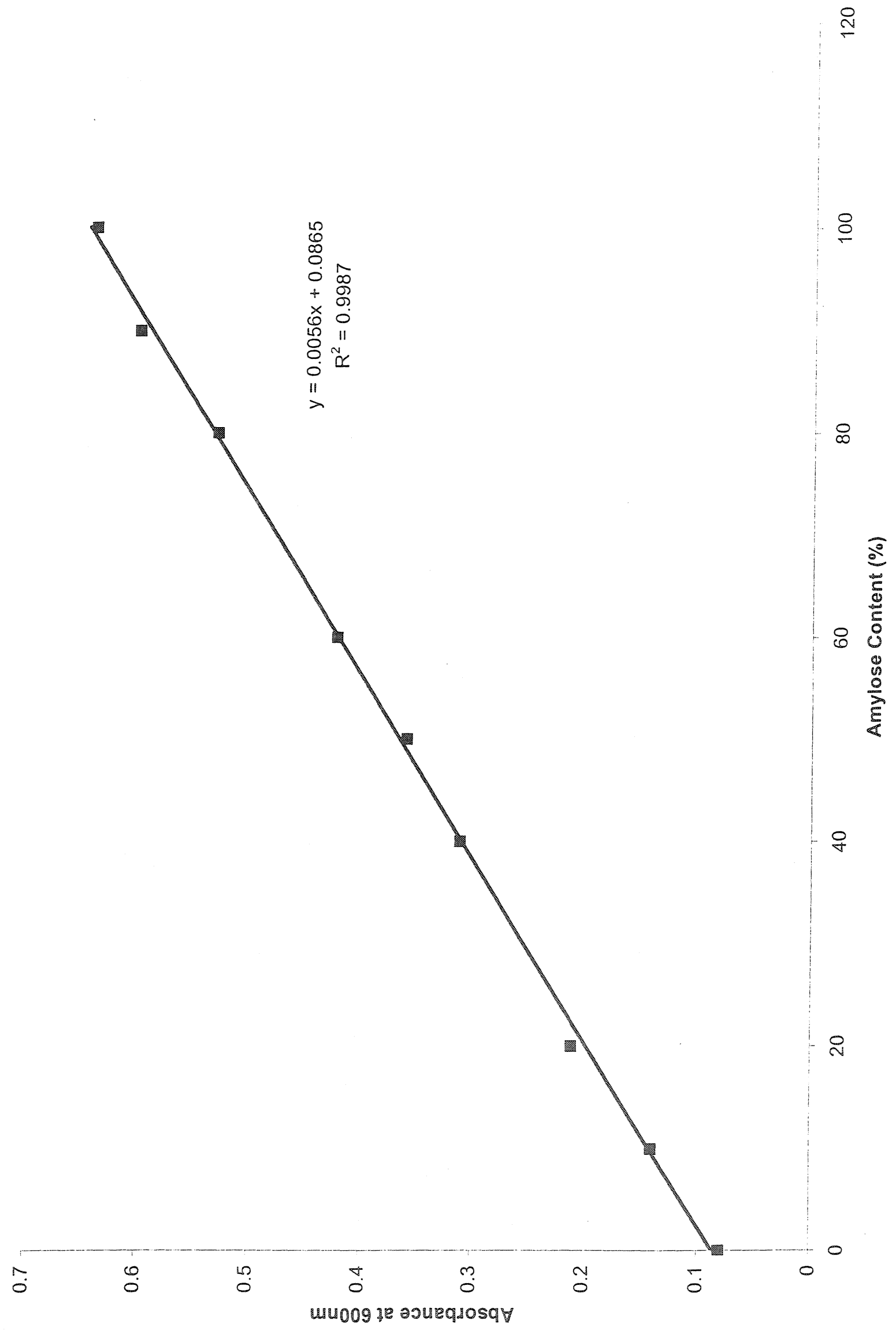


Figure A-2 Standard curve for reducing sugar determination as maltose at $540 \mathrm{~nm}$ 


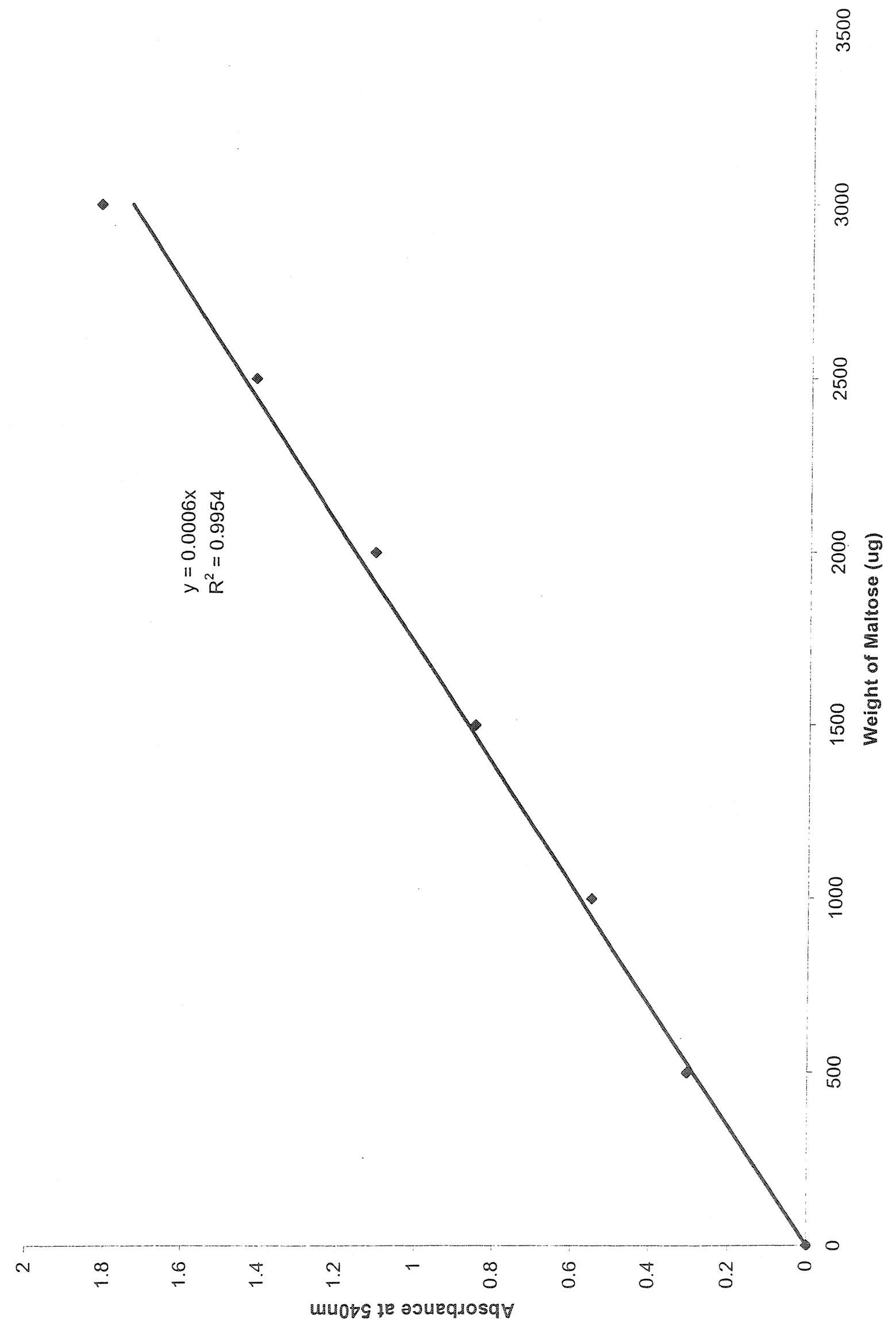


Figure A-3 Schematic illustration for initial velocity determination 


\section{Wrinkled Pea}

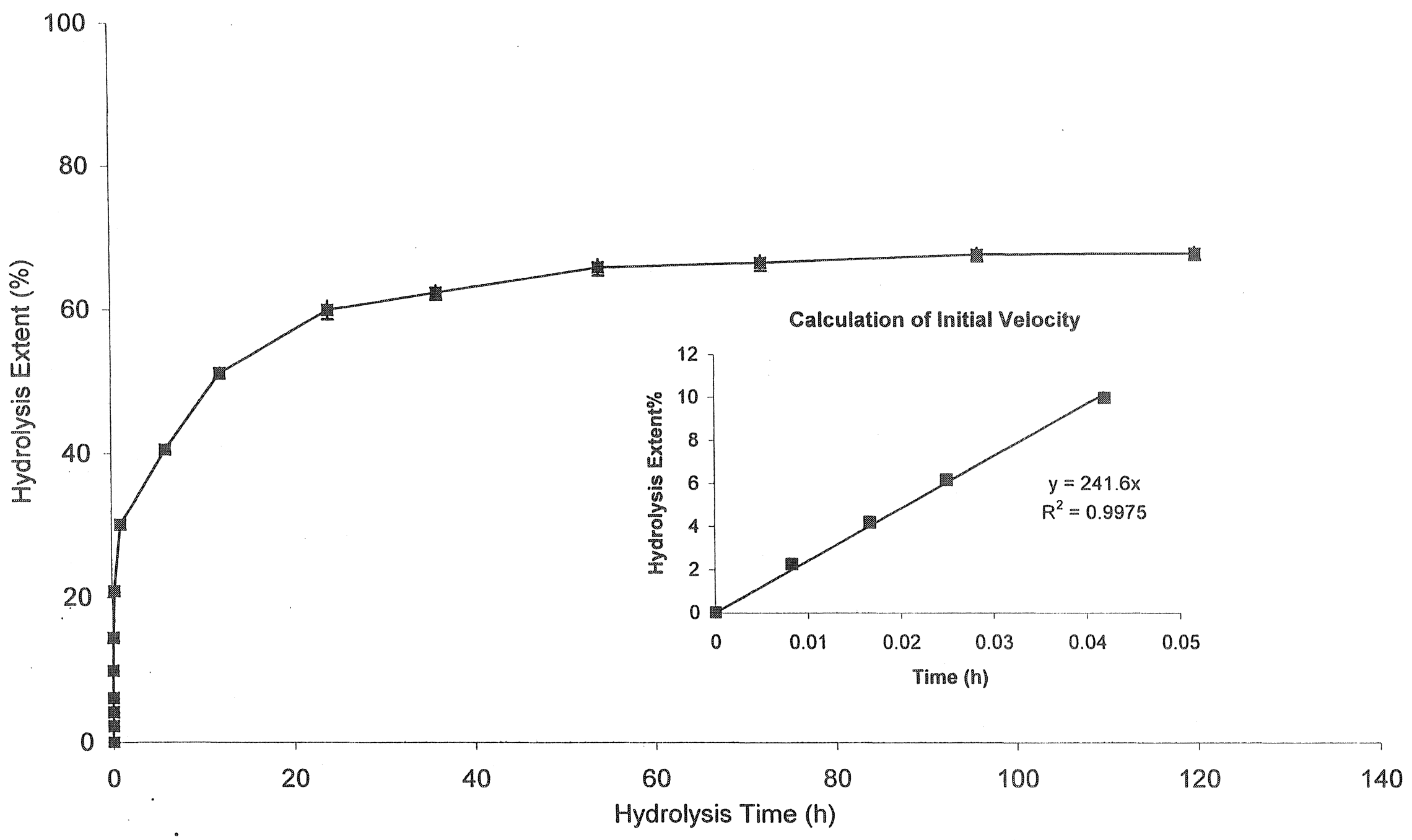




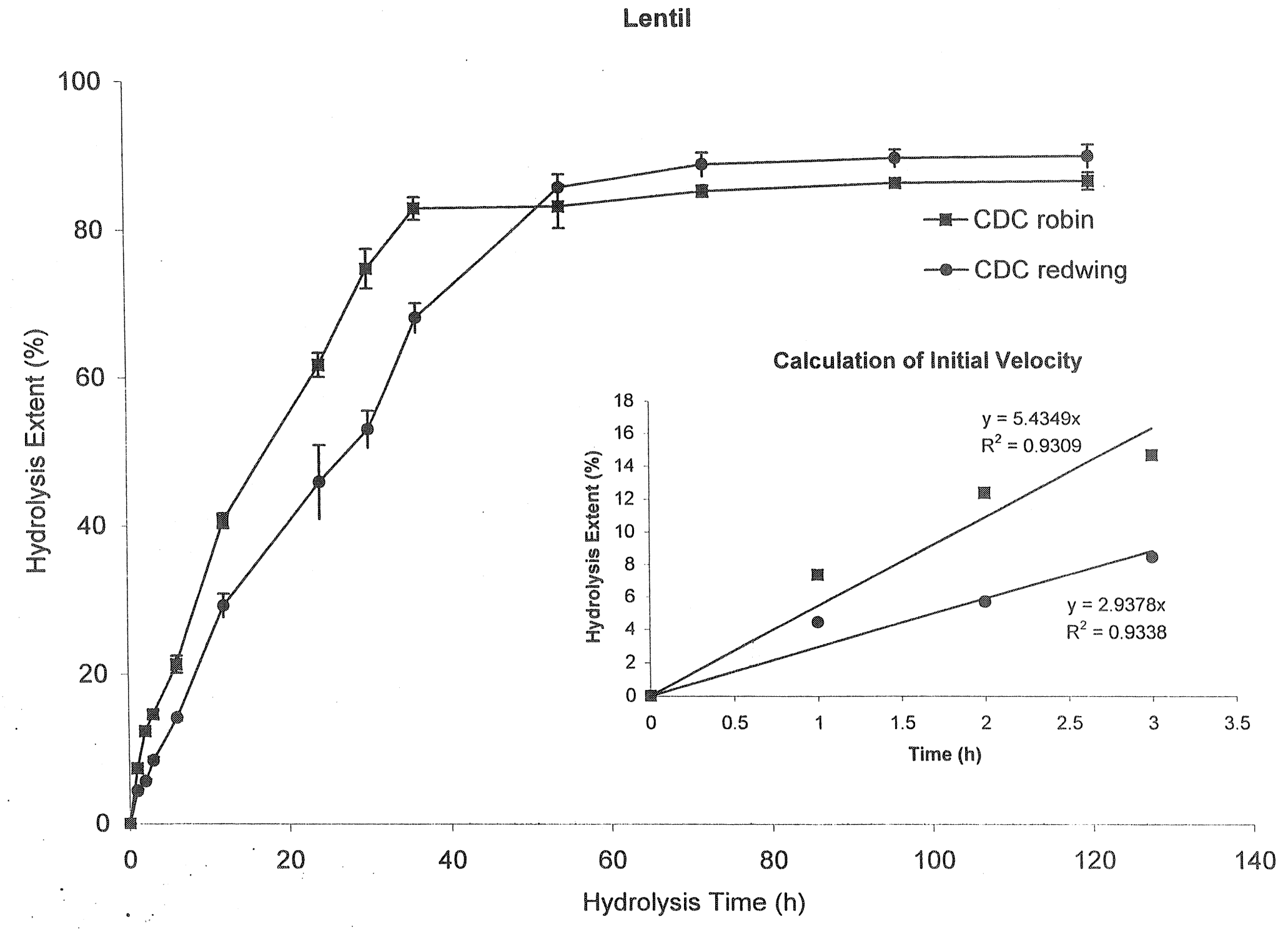


Smooth Pea

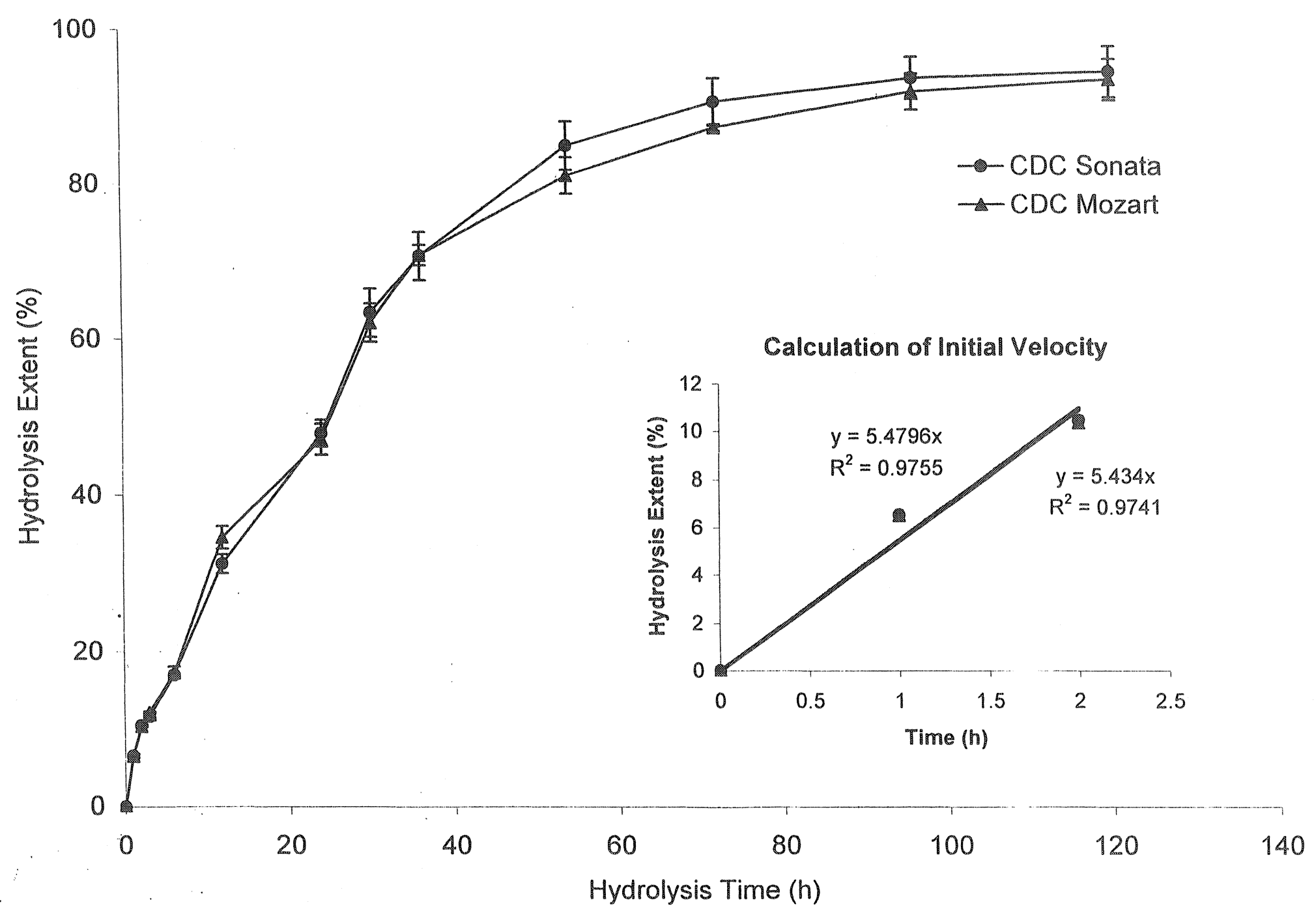




\section{Pinto Bean}

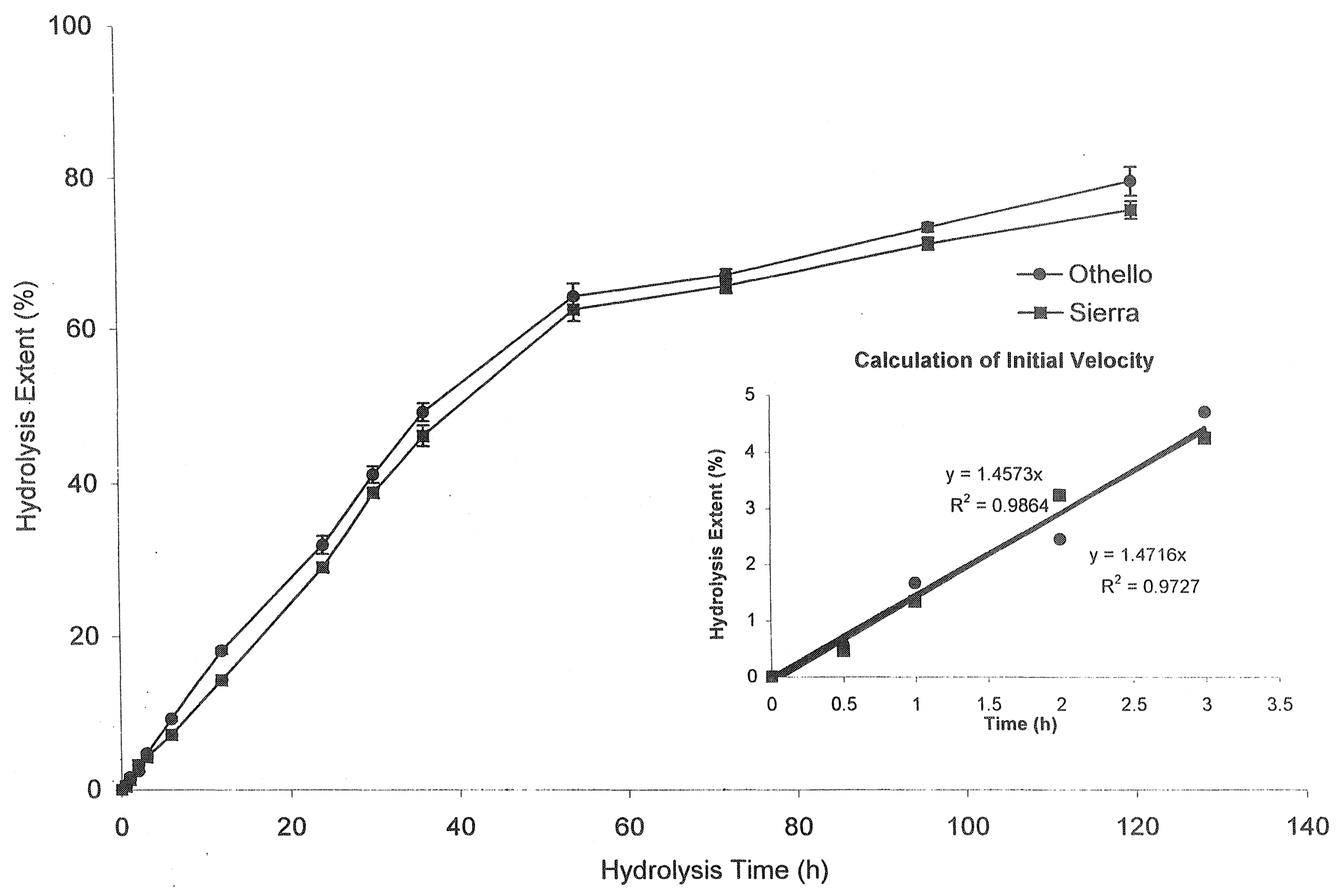




\section{Black Bean}

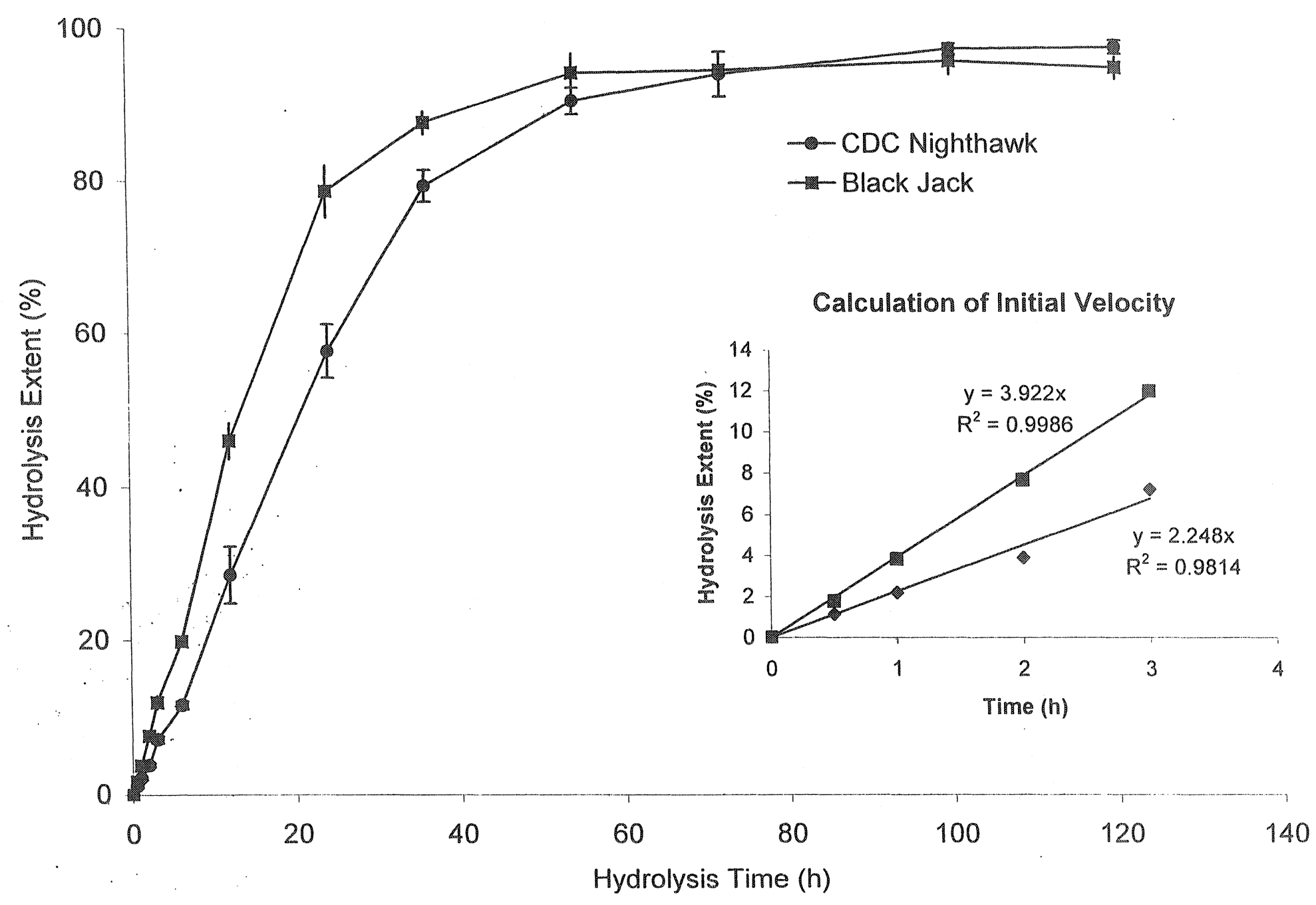


Figure A-4 Schematic illustration for gelatinization parameters determination 


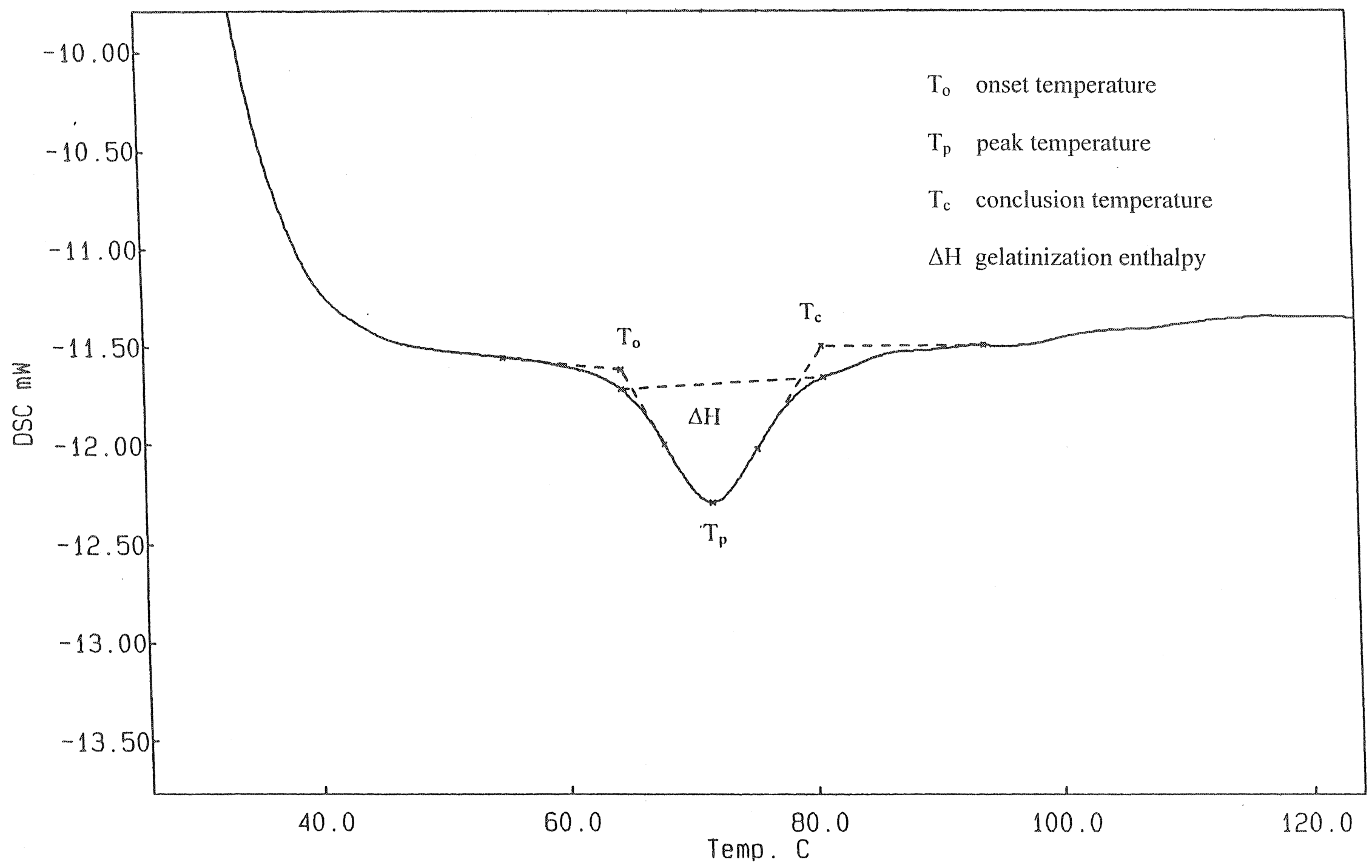


Figure A-5 Schematic illustration for relative crystallinity determination 

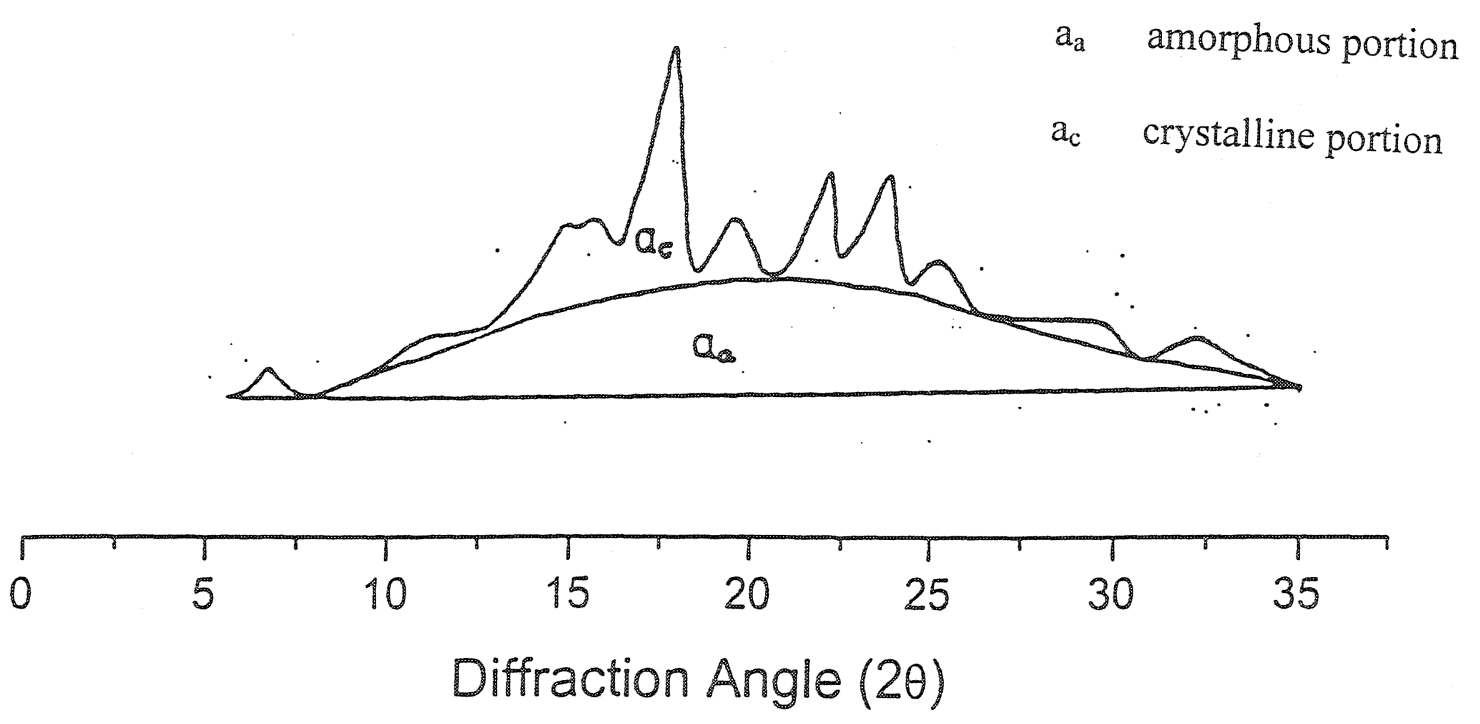
Figure A-6 Standard curve for 'B' polymorphic content determination 


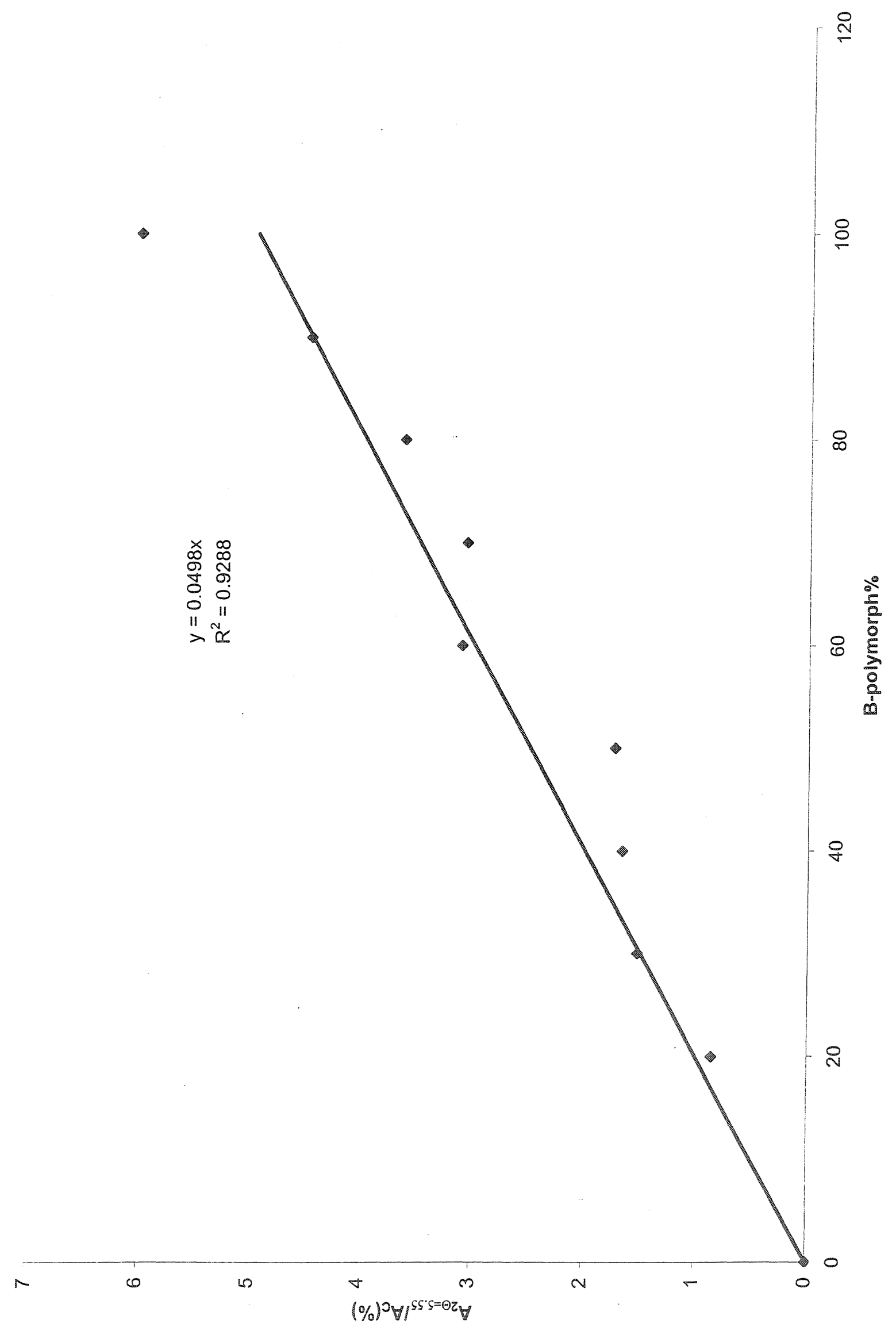





